\title{
Natural hazards and education : the impact of floods on primary school education in Zambia
}

Citation for published version (APA):

Conteh, I. K. (2015). Natural hazards and education : the impact of floods on primary school education in Zambia. [Doctoral Thesis, Maastricht University]. Boekenplan. https://doi.org/10.26481/dis.20150616ic

Document status and date:

Published: 01/01/2015

DOI:

10.26481/dis.20150616ic

Document Version:

Publisher's PDF, also known as Version of record

\section{Please check the document version of this publication:}

- A submitted manuscript is the version of the article upon submission and before peer-review. There can be important differences between the submitted version and the official published version of record.

People interested in the research are advised to contact the author for the final version of the publication, or visit the DOI to the publisher's website.

- The final author version and the galley proof are versions of the publication after peer review.

- The final published version features the final layout of the paper including the volume, issue and page numbers.

Link to publication

\footnotetext{
General rights rights.

- You may freely distribute the URL identifying the publication in the public portal. please follow below link for the End User Agreement:

www.umlib.nl/taverne-license

Take down policy

If you believe that this document breaches copyright please contact us at:

repository@maastrichtuniversity.nl

providing details and we will investigate your claim.
}

Copyright and moral rights for the publications made accessible in the public portal are retained by the authors and/or other copyright owners and it is a condition of accessing publications that users recognise and abide by the legal requirements associated with these

- Users may download and print one copy of any publication from the public portal for the purpose of private study or research.

- You may not further distribute the material or use it for any profit-making activity or commercial gain

If the publication is distributed under the terms of Article $25 \mathrm{fa}$ of the Dutch Copyright Act, indicated by the "Taverne" license above, 
Natural Hazards and Education

\author{
The Impact of Floods on \\ Primary School Education in Zambia
}

By

Ibrahim Khalil Conteh 
ISBN 9789086663248

@ 2015, Ibrahim Khalil Conteh

All rights reserved. No part of this publication may be reproduced, stored in a retrieval system, or transmitted in any form, or by any means, electronic, mechanical, photocopying, recording or otherwise, without the prior permission in writing, from the author.

Publisher: Boekenplan, Maastricht www.boekenplan.nl 


\title{
Natural Hazards and Education
}

\author{
The Impact of Floods on \\ Primary School Education in Zambia
}

\author{
DISSERTATION
}

To obtain the degree of Doctor at Maastricht University, on the authority of the Rector Magnificus, Prof. dr. L.L.G. Soete in accordance with the decision of the Board of Deans, to be defended in public on Tuesday, $16^{\text {th }}$ June, 2015 at 16:00 hrs.

$$
\text { By }
$$

Ibrahim Khalil Conteh 


\section{Promoters}

Professor Dr. Wim Naudé

Professor Dr. Ir. Georg Frerks (Wageningen University)

\section{Degree Committee}

Professor Dr. Hein de Haas - Chair

Professor Dr. Meine Pieter van Dijk (Erasmus University)

Dr. Lutz Krebs

Dr. des. Matthias Garschagen (United Nations University) 


\section{ACKNOWLEDGEMENT}

While I find the outcome of this study inspiring for research practitioners, I hope the thesis will be readily accessible to readers interested in flood hazards and education. Most of the arguments are sufficiently straightforward, not to require for their exposition the rigor and technical apparatus which only academic audiences can be expected to endure, let alone to enjoy.

I am greatly indebted first to Prof. Wim Naudé of Maastricht University, who showed a very keen interest in my research idea and accorded the time to discuss the research concept. Prof. Naudé guided me through the literature and advised to surf in the research library of CRED Data, an Emergency data bank in Leuven, Belgium which has a lot of information on my subject matter. The data bank was very useful in developing my concept to a proposal which has today developed to a PhD thesis. The cordial sessions I had with Prof. Naudé at his office in Maastricht, telephone calls, discussions at seminars and email contacts have provided a very valuable guide to this road map. The ability to complete this study under a very tight time schedule would have been futile without the succinct encouragement, advice, dedication and professional support of Prof. Naudé.

When I started thinking about a PhD on disasters, I remembered my days in Wageningen University where I had come across a Professor on Disaster Studies called Prof. Georg Frerks. As the idea started developing, I contacted Prof. Frerks and shared my thoughts for a PhD. He read through my initial concept and immediately consented that it was an interesting topic and that he would be interested to get involved. I was very pleased to get a positive feedback from Prof. Frerks, understanding that he is a very busy person with a widely divided responsibility and yet he confirmed to me that he was able to make the time. The first meeting I had with Prof. Frerks was in a village between Maastricht and Roermond in Zuid Limburg. We shared a history of Wageningen and shared some drinks. After that meeting, I knew I had garnered a strong support for my study. Interestingly, the two Professors knew each other very well, so getting agreements on directing my research was quite swift. 
As I was developing my research theme, I met Dr. Katrin Kriz of Emmanuel College in Boston. I presented my skeleton proposal and asked for her opinion, first on the subject matter and second on the content. Dr. Kriz immediately thought it was great and the topic has some newness, certainly worth a $\mathrm{PhD}$ research. Those nice words were an added trigger to an already motivated PhD candidate. Over the four years, Dr. Kriz, though not a supervisor, but have been quite generous to provide technical comments to the various pieces of the study.

The PhD programme in Maastricht, by its nature, does not necessarily give one access to supervisors without going through some rigorous "metamorphosis". The successful completion of the course requirements and developing a concrete research idea is what guarantees an entry into the PhD programme. It is not the acceptance letter received after the application. The fulfillment of the PhD programme entry requirements were guided primarily by Dr. Mindel van de Laar. Words are not enough to show my utmost gratitude for the valuable support she provided. Dr. van de Laar has the Governance and Policy Analysis Programme so much at heart that she is always willing to support students, even during private times. She engaged me on Skype, emails, telephone and was ready and able to provide every needed literature. Many thanks, Dr. van de Laar, for your unflinching and remarkable contribution.

During the seminar series in Maastricht, the school offers the services of PhD students who are in advanced stages and PhD graduates to provide coaching and other technical support areas to first and second year students. I benefitted from that gesture and would like to acknowledge the valuable support I received from Dr. Nyasha Tirivayi and Dr. Dorcas Mbuvi. Their inputs have been of immense help in finalizing my proposal and designing the methodology.

My cohort colleagues were an invaluable inspiration to the completion of this study. At the beginning of the programme, we used to deliberate on what life would be after four years. We all believed that four years is a very long time, considering so many other commitments at hand. However, we all noticed that it was always fun to meet in Maastricht and have the nice group lunches and drinks on the last day of a seminar session. Those good moments have always been catalysts of wanting to come back to Maastricht during the next session. We commented on each other's presentation and sometimes we jokingly mocked colleagues who had tough times with some Professors 
such as Prof. Adam (Eddy) Szirmai. Overall, it was a great time and we enjoyed every bit of our time in Maastricht.

I would like to thank my friends at the Ministry of Education in Mongu, Western Province of Zambia, Mr. Muhau Muyanalu and Madam Harriet Wakalala, and another friend Madam Ngula Mubonda of World Wildlife Fund in Shesheke, also in Western Province of Zambia for the great support provided in the data collection. The challenges faced in collecting the data were considerable due to the natural environment, logistics and human resource. These friends took extra time to provide me with most of the information used in this study. Without them, this research would have been extremely difficult.

I owe a great deal of gratitude to my mother and my late father for bringing me into this world and guiding me through life and making me what I am today. To all my friends, brothers, sisters, cousins, uncles and aunts, your courage, inspiration, advises and other areas of support were of immense value to this trajectory. Discussing my research with most of you whenever the opportunity arises and the good words you have always rendered made this dream come true. Thank you so much for your love and friendship.

I have reserved the last paragraph of this acknowledgement to render special thanks to my lovely wife Martha Alice Lahai-Conteh and my dear children, Yamuna, Ibrahim Jr and Fatima. My wife enjoyed reading and commenting on my work. Her suggestions and inputs into the research from the beginning to the end ensured a second opinion on how I could develop certain themes better. She was very instrumental in ensuring that any product of any piece of this research is of an acceptable quality and has challenged me several times on the essence of certain features in the manuscript. In addition to the technical support, my wife and kids have showed a lot of understanding in allowing me to utilize some of the family life time into this work, for which I am most grateful.

Many thanks, to all of you for your diversified contributions.

Ibrahim Khalil Conteh

Maastricht Graduate School of Governance,

Maastricht University, The Netherlands 


\section{ABSTRACT}

In recent years, there has been a growing concern that increasing numbers of the world's population are vulnerable to the adverse impacts of disasters resulting from natural hazards. Disasters, which follow when institutional bulwarks, including social and physical capital are inadequate, or simply overwhelmed, cause destruction to livelihoods, uproot communities and jeopardize development through their impact on human development, including their potential impact on children's schooling outcomes. These concerns are particularly relevant for Sub-Saharan Africa, where a larger proportion of the population is younger than anywhere else, and where the frequency and intensity of natural hazards are expected to increase, among others due to the possible consequences of global climate change.

One of the most frequent disasters in Sub-Saharan Africa is flooding. Flooding occurs when there is an overflow of a large amount of water beyond its normal confines. Large populations live in the coastal areas where they are exposed to flooding (Jongman et al., 2012). Exposure to floods is increasing because human occupation of flood plains and flood prone coastal zones intensifies (Genovese et al., 2007). In the developing world, flood defenses are less developed and the exposed populations are more often subject to flooding with consequent disruption, economic loss, and in the worst cases loss of life (UNEP, 2002).

To understand how flooding affects primary education, this study focuses on the case of primary school education in the Zambezi River Basin of Zambia. In the Zambezi river basin, flooding occurs annually in different magnitudes. Moreover there are fears that the intensity of floods may be increasing. For instance in 2009, Zambia experienced one of the heaviest floods in nearly 40 years. A rapid inter-agency assessment led by the Disaster Management and Mitigation Unit (DMMU) estimated that about 500,000 people were directly affected in various forms. Thousands of people were displaced, crops were submerged, fishing boats lost, and water schemes polluted. Children's education in particular was severely set back not only due to schools being flooded, access roads blocked and homes being destroyed, but also due to flood-associated health problems that subsequently affected children's health. 
More than 30,000 school-going children were displaced and at least 10,000 deprived of education as a result of the 2009 flooding (ZVAC, 2009). Similar patterns of flood induced disruption of children's education have been reported in 2010, 2011 and 2012. Potential climate changes are expected to cause a rise in the frequency as well as the intensity of rainfall, which may lead to more widespread and severe floods in Zambia. Approximately 30 per cent of the three million people who live in the flood plains in Zambia are primary school aged children. The future of these children is at stake, and the long-run development of the entire community is at risk if flooding continues to disrupt their education. Children in Zambia's flood plains face disruptions in education as a result of displacements and damage to school infrastructure, school resources (and records) and a lack of teachers caused by annual floods. To understand better why and how floods disrupt primary education in Zambia, and how the resilience of households and communities in the affected areas can be strengthened, this study was undertaken. Its findings may assist local and national government and community structures in Zambia, as well as development agencies such as UNICEF and others to help households living in the country's flood plains to establish and maintain appropriate bulwarks that will not only protect livelihoods but also meet the education needs of their children.

Data was collected from flood affected areas in Zambia in order to evaluate the impact of floods on the state of primary school education in flood prone areas in Zambia over a 5 years period (2008 to 2012). Next to the in-depth interviews and observations, one of the key elements of this empirical investigation was to assess the state of school infrastructure, enrolment rates, and rates of repeating, dropout rates, and length of stay in school, the quality of teachers and the performance of pupils in national primary school examinations. Ten schools and communities in flood prone areas were compared with ten schools and communities in areas not affected by floods but having similar socio-economic characteristics.

It was found that school enrolment rates for children in the flood plains are much lower compared to regions not affected by floods. The enrolment rates for primary school children in schools not affected by floods were found to be significantly higher than in the flood plains, where the occurrence of floods affects various factors determining the enrolment patterns. Likewise, more pupils repeat classes in flood-affected primary schools than in non-flood affected schools. Unlike the non-flood affected schools where the average annual repeating rate is only 3 per cent, flood affected schools experienced 
a 9 per cent repeating rate annually during the period under scrutiny. Also, dropout rates are higher in flood affected primary schools, where the average annual dropout rate was 3.5 per cent over the period as compared to an average 0.46 per cent dropout rate in non-flood affected schools.

Higher primary school dropout rates in the flood plains were found to be partly due to higher frequencies of child labor, for example when children are expected to work and support the up-keep (or replacement) of the home. Children in Zambia's flood plains generally start schooling later than those in the non-flood plains, often only after the age of 7 , while school starting age in Zambia is on average 6 years.

Floods may also contribute to a deterioration of the quality of primary education in the flood plains; for instance children from schools located in the flood plains perform on average less well than children elsewhere. This study found that over the period 2008 to 2012, only 4 per cent of children in the flood plains who took the national examinations achieved division 1 (highest division) compared to 13 per cent of children in the non-flood area. About 53 per cent of children in the flood plains achieved division 4 (lowest division) as compared to 38 per cent who achieved a division 4 outcome in the non-flood affected schools.

One channel through which perennial flooding may adversely affect the quality of primary school education in Zambia's flood plains is by reducing not only the quality of school infrastructure, but also the availability of adequately qualified and experienced teachers. This study found that teachers in the flood plains are on average much less experienced than those in non-flooded areas and that there are relatively fewer teachers in the flood plains. The pupil: teacher ratio in the flood plains is 45:1 as compared to $28: 1$ in non-flood affected areas.

This study recognizes that flooding has a diverse impact on a range of factors including education. Flooding also affects levels of vulnerability, employment and income, livelihoods, incidence of poverty, investments and capacity to invest in human capital by families as well as government. Through those factors the initial impact on children's education is exacerbated and confounded. One could therefore state that flooding has both direct and indirect impacts on children's education. 
Having documented and analyzed the impact of flooding on primary education, this study also investigated why households and communities in the affected areas remain vulnerable to floods. It was investigated why households continue to live in floodaffected areas. Migrating to other, less affected areas, may seem like a first obvious response to lower a household's exposure.

It was found that households are reluctant to relocate away from the flood plains due to their land ownership rights, traditional livelihood practices and the culture of living in the flood plains. In other words, households' institutional environment limits their mobility and keeps them (and their children) exposed to flooding. Moreover, the communities are poor and cannot afford the standard of life in the upper land and cannot send children to another school due to high costs.

To the extent that households and communities in the flood plains are not mobile enough to reduce their exposure to floods, the challenge they face is to reduce their exposure through various coping strategies, including becoming more resilient to floods. It was found that the difficulties households face in rising to this challenge are due to their relative poverty, neglect in terms of provision of public infrastructure by the government, and weak political structures wherein households affected do not have much of a voice. The poverty of households in the flood plains and their lack of voice are partly due to, and compounded by the fact that most people in the flood plains are not highly educated; that basic social services are not readily accessible; and that early warning systems are not functioning. As a result, many communities in the Zambian flood plains may be caught in a vicious low education-low resilience circle, or poverty trap, necessitating a concerted and coordinated push to escape from.

Despite these constraints, households and communities in the flood plains are not helpless, nor do they sit by passively in the face of the risks of flooding. Hence, the coordinated efforts and assistance that they need, should take into account and build upon their own initiatives, where these are instances of positive coping, to reduce their vulnerability to floods. In this regard, this study explored the various coping strategies that households and communities take in the face of flooding.

Often, coping strategies have adverse consequences for schooling of children. It was found that some communities build their houses on top of mounds to place them out of reach of flood water. They have also learned to effectively use boats during floods. 
Some community members have resorted to the practice of establishing makeshift second homes in higher-lying land for short stays during floods. Social networks within affected communities play an important role including provision of moral and financial support (community-based micro-lending schemes are an example). Inevitably however, households do also resort at times to adverse coping mechanisms, such as reducing meals and sending their children to work. These adverse coping responses are particularly detrimental for primary education.

The intensity of floods, the inadequate household and community bulwarks, and the resorting to adverse coping strategies during floods are the main reasons why households and communities require outside assistance, particularly from the Zambian government, but also humanitarian agencies, the private sector, individual well-wishers, friends and families. In order to understand what more can be done or what can be done differently to make sure that primary education is less affected than it seems to be the case at present, this study also considered the current and past responses such as outside assistance initiatives.

The first action that is usually taken when a flood occurs is for the household to move out of the way of the water, so as to save lives and some assets. Usually, the disaster management unit of the government organizes an inter-stakeholder rapid assessment to determine the level of damage, so that actual needs can be better defined. Once needs are identified, appeals are then made to donors and the government for disaster relief. This includes appeals for temporary shelters, food, medicines, enrolment of displaced children in unaffected schools, or erection of temporary learning centers. Through remittances some households with members abroad or other places in the country receive financial support.

This study established however that external assistance is very short-term, aiming at immediate disaster relief and saving of lives, and not so much on medium to longer term recovery or protection. Support by the government and humanitarian organizations for recovery and rehabilitation to the affected communities, including school children once the flood waters recede is inadequate. This general lack of recovery assistance makes it very difficult for households to get their children back to school and to promote better quality of schooling. 
In order to improve the resilience of households and children's schooling to flooding, and to address the gaps identified in external support in this regard, this study engaged with the community and stakeholders to identify how they envisage the ways and means that primary education could be made resilient in the flood prone areas. Discussions with these stakeholders are documented in this study. It reflects that communities generally prefer to live in the flood plains and reduce their vulnerability to floods through investments in certain key areas.

One of the most direct ways to limit exposure to flooding would be better general water management systems and practices, including investments in infrastructure to facilitate better water management. If dams are constructed in the plains to control water, the incidence of homes been flooded will be considerably reduced; livelihoods and infrastructure and therefore children's education will not be as much affected. This is however, given the many fiscal challenges facing the Zambian government, not a short-term solution. Over the shorter term therefore, improved resilience would require more affordable and immediate actions. In this regard, the stakeholders have raised the provision of improved boats with powered engines as important, as it will facilitate the movement of children from their homes to school even during the flood period (if their homes are not flooded). The availability of 'flood proof' boarding school facilities can also be important, as these may limit the daily (risky) travel of children from schools to their homes, and reduce the risk of drowning. Furthermore, school feeding programmes can motivate parents to send their children to school and children are equally motivated to attend school and get back to learning, particularly in the period after a flood. Stakeholders also pointed out that if teachers could be better paid, perhaps more qualified and experienced teachers could be attracted to the flood plains.

In addition to these specific requirements, the basic development level in the Zambian flood plains is perhaps the most salient and deep-rooted cause of the region's continued vulnerability to floods. This general insight derived from the broader disaster studies literature also applies to the Zambian case. In this regard, general socio-economic development will make the surest longer-term contribution to reduce the impact of flooding on children's schooling. Fostering such socio-economic development will require better provision of basic social services such as roads, hospitals, water schemes, and sanitary facilities. Poverty levels are very high among this community and therefore the financial inability to send children to school or support their schooling is obvious. Microcredit facilities that will enable the 
communities to expand their livelihood activities and engage in business will help generate funds that could enable families to continue supporting children's schooling, even under adverse conditions such as flooding. 


\section{TABLE OF CONTENT}

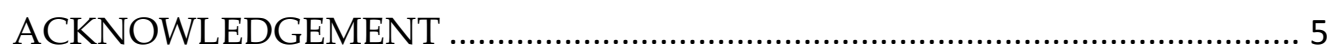

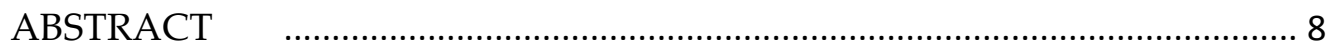

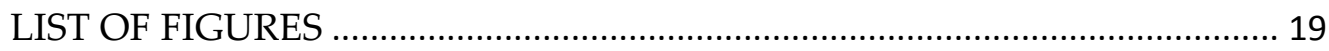

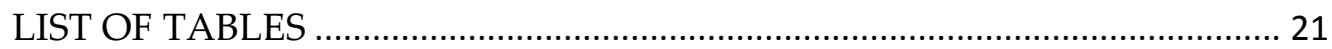

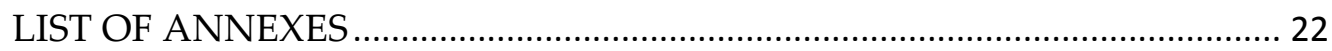

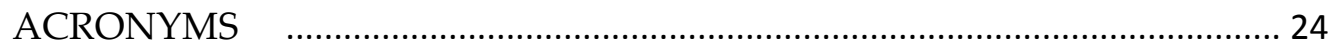

DEFINITIONS OF FREQUENTLY USED WORDS AND PHRASES............... 26

CHAPTER 1 INTRODUCTION ………....................................................... 31

Purpose of this Study ……………......................................... 31

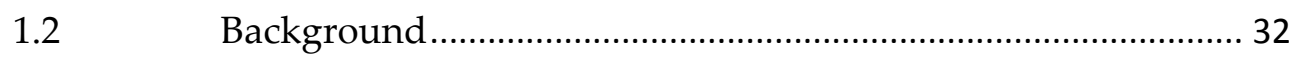

$1.3 \quad$ Other Hazards in Zambia ........................................................ 37

$1.4 \quad$ Problem Statement................................................................. 40

$1.5 \quad$ Research Questions............................................................ 41

1.5.1 Main Research Question ....................................................... 42

1.5.2 Secondary Research Questions ............................................... 42

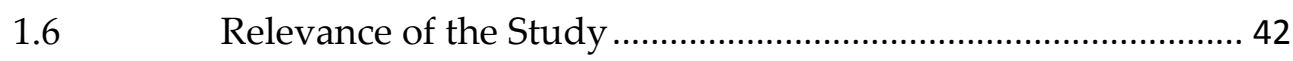

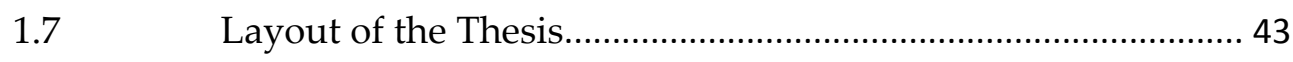

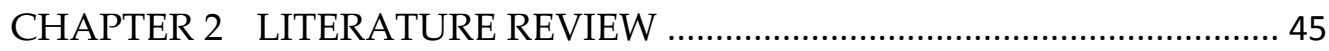

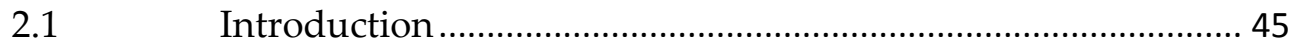

$2.2 \quad$ Education and Development................................................... 46

2.3 General Impacts of Flood Hazards and Disasters ..................... 49

2.4 Impact of Floods on the State of Primary School Education ... 53

2.5 Household Vulnerability to Natural Hazards ........................... 59

2.6 Household Decision Making Frameworks................................. 64 
2.7 Household Coping Mechanisms during and after Disasters... 67

2.8 Mitigating Flood Hazards and Disasters................................... 73

2.9 Community Disaster Resilience - A Capital Approach ............. 76

2.9.1 Disaster resilience ............................................................... 77

2.9.2 Frameworks for analyzing community disaster resilience..... 82

2.9.3 Proposed Capital-based approach............................................ 82

2.10 Summary and Conclusions....................................................... 88

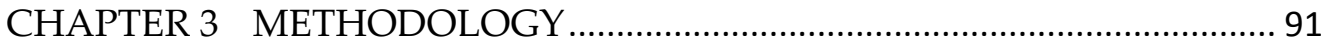

Introduction ......................................................................... 91

3.2 Description of the Study Area .................................................. 92

3.2.1 General overview of the flood plain environment in the study

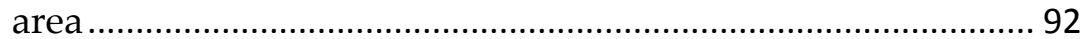

3.2.2 Socio-economic status of the studied community ……............. 94

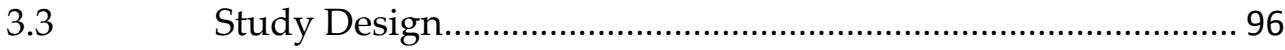

Variables of Interest ............................................................. 97

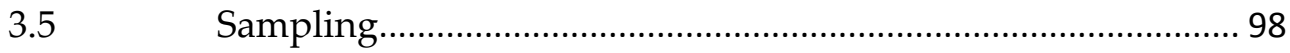

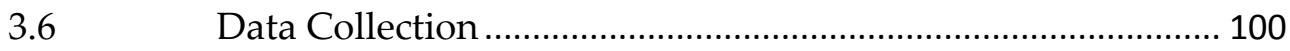

3.6.1 Focus group discussions ...................................................... 102

3.6.2 Key informant interviews ........................................................ 102

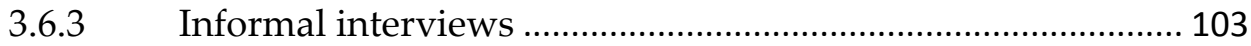

3.6.4 Participant observations........................................................ 104

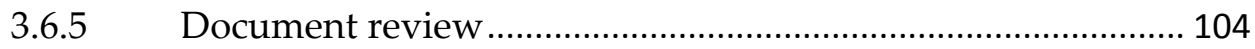

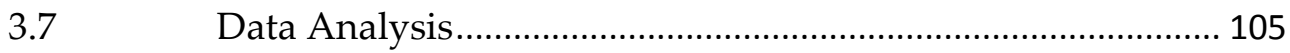

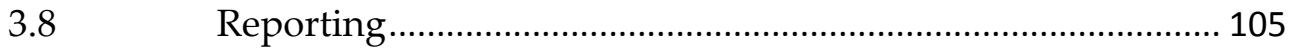

3.9 Constraints during Data Collection........................................ 106

3.10 Summary and Concluding Remarks ........................................ 109 
CHAPTER 4 THE IMPACT OF FLOODS ON PRIMARY EDUCATION IN ZAMBIA

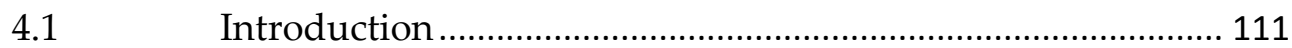

4.2 Results and Discussion........................................................... 111

4.2.1 Effects of floods on the welfare of flood plain communities 111

4.2.2 Effect of floods on primary school education ......................... 113

4.3 Summary and Concluding Remarks...................................... 132

CHAPTER 5 HOUSEHOLD VULNERABILITY AND COPING STRATEGIES IN THE FLOOD PLAINS OF ZAMBIA ............ 134

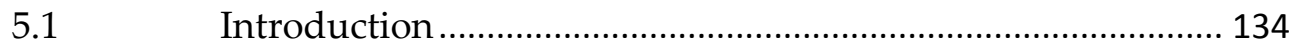

$5.2 \quad$ Results and Discussion......................................................... 135

5.2.1 Household vulnerabilities in the flood plains ........................ 135

5.2.2 Coping mechanisms ……................................................ 143

5.3 Summary and Concluding Remarks....................................... 151

CHAPTER 6 REDUCING THE HAZARDS OF FLOODING FOR PRIMARY SCHOOL OUTCOMES IN ZAMBIA ........................................ 153

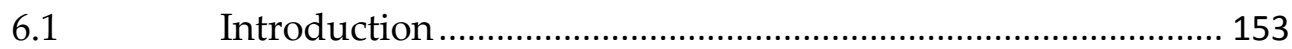

6.2 Results and Discussion.......................................................... 154

6.3 Summary and Concluding Remarks...................................... 164

CHAPTER 7 POLICY RECOMMENDATIONS, LIMITATIONS OF THE RESEARCH AND SUGGESTIONS FOR FURTHER STUDIES.... 166

7.1 Policy Recommendations........................................................ 166

7.2 Limitations of the Research and Suggestions for Further

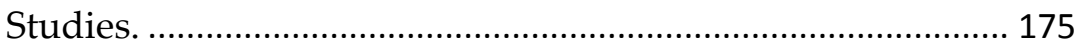

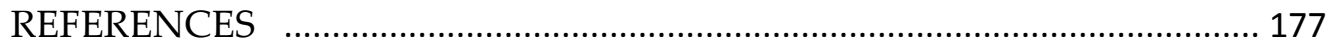

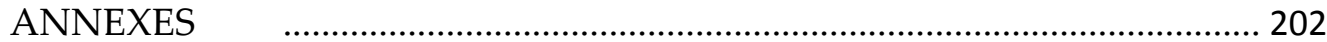




\section{LIST OF FIGURES}

Figure 1.1: Physical causes of floods in relation to other environmental hazards 32

Figure 1.2: Occurrence of disasters in Zambia from 1900 to 2014 (adapted from OFDA/CRED, 2014) .36

Figure 2.1: Hypothetical trajectory of resilient and less resilient community 81

Figure 2.2: Conceptual framework on the relationship between capital domains and community disaster resilience.

Figure 3.1: Map of Zambia highlighting research area

Figure 4. 1: Total enrolment for the 10 flood affected and 10 non-flood affected primary schools

Figure 4.2: Rate of enrolment in flood affected and non-flood affected primary schools

Figure 4.3: Enrolment rate disaggregated by gender for each grade in flood affected and non-flood affected schools

Figure 4.4: Repeating rate per year in 10 flood affected schools and 10 non-flood affected schools

Figure 4.5: Repeating rate by grade for 10 flood affected schools and 10 non-flood affected schools

Figure 4.6: Dropout rate per year for 10 schools in flood affected and 10 schools in non-flood affected areas

Figure 4.7: Dropout rate per grade for 10 schools in flood affected and 10 schools in non-flood affected areas

Figure 4.8: Cumulative dropout rate per grade for 5 years disaggregated by gender in flood affected and non-flood affected areas

Figure 4.9: Average total number of teachers per year for the 10 flood affected and 10 non-flood affected schools

Figure 4.10: Ratio of Teachers to Pupils in floods affected and non-flood affected schools

Figure 4.11: Average performance of pupils in flood affected and non-flood affected schools

Figure 4.12: Performance of pupils in national examination in flood affected and nonflood affected schools 
Figure 5.1: Crossing over of the King from the flood plains to the upper land "Kuomboga". 136

Figure 7:1. A framework for building resilience of primary education......................... 167 


\section{LIST OF TABLES}

Table 1.1: Natural disaster occurrence: comparing 2011 regional figures with 2001 to 2010 averages .35

Table 2.1: Recent impact of floods and other hydro-meteorological disasters on schools .55

Table 2.2: Mechanisms for managing risks/coping strategies .72

Table 3.1: Flood affected and non-flood affected schools in 5 years period (2008 to 2012) .99

Table 3.2: Data collection sample frame 99

Table 3.3: Schematic presentation of data collection techniques and instruments .....101 Table 4.1: Nature of basic infrastructure of flood affected and non-flood affected schools

Table 4.2: Gender proportion of teaching staff in flood affected and non-flood affected schools 128 


\section{LIST OF ANNEXES ${ }^{1}$}

Annex 3.1: Key informant interview guide (Community - Households, Local Authorities, Teachers) in areas affected by floods in the last 5 to 10 years 202

Annex 3.2: Key informant interview guide (Stakeholders - Government, NGOs, UN) in areas affected by floods 205

Annex 3.3: Key informant interview guide (Community - Households, Local Authorities, Teachers) in areas not affected by floods in the last 5 to 10 years 208

Annex 3.4: Key informant interview guide (Stakeholders - Government, NGOs, UN) in areas not affected by floods

Annex 3.5: Key informant interview guide (Children - age 10 to 15 affected by floods).

Annex 3.6: Key informant interview guide (Children - age 10 to 15 not affected by floods).

Annex 3.7: Focus group interview guide (Communities affected by floods in the last 5 to 10 years).

Annex 3.8: Focus group interview guide (Communities not affected by floods in the last 5 to 10 years)......

Annex 4.1: Total school enrolment in flood and non-flood affected primary schools in Zambia 219

Annex 4.2: Proportion (\%) of enrolment according to grade level and gender in flood affected and non-flood affected primary schools in Zambia

Annex 4.3: Proportion (\%) of primary school pupils aged above 7 years at first enrolment in flood affected and non-flood affected areas in Zambia 221

Annex 4.4: Proportion (\%) of pupils aged above 14 years at completion of primary school in flood affected and non-flood affected areas in Zambia..... 221

Annex 4.5: Comparison of the rate of repeating grades among primary school pupils in the study area

${ }^{1}$ Annex numbering is based on chapter numbers. 
Annex 4.6: Average annual rate of repeating among primary school pupils in the study area

Annex 4.7: Comparison of dropout rate by grade level among primary school pupils in the study area. .223

Annex 4.8: Annual dropout rate among primary school pupils in the study area.....223

Annex 4.9: Reasons for primary school dropout in the study areas .224

Annex 4.10: Pupil - Teacher Ratio in the sampled primary schools for 5 years .225

Annex 4.11: Performance of pupils from sampled schools in national primary school examinations. .226

Annex 4.12: Flood intensity data comparing water levels in the flood plains of Zambia over time. .227 


\section{ACRONYMS}

ADPC: $\quad$ Asian Disaster Preparedness Centre

CDM: $\quad$ Clean Development Mechanism

CERF: $\quad$ Central Emergency Response Fund

CLUVA: Climate Change and Urban Vulnerability in Africa

COP: $\quad$ Conference of the Parties

CPD: $\quad$ Continuing Professional Development

CRED: $\quad$ Center for Research on the Epidemiology of Disasters

CSO: $\quad$ Central Statistics Office

DAO: District Administrative Office

DEC: Disasters Emergency Committee

DFID: Department For International Development

DMMU: $\quad$ Disaster Management and Mitigation Unit

DRM: $\quad$ Disaster Risk Management

DRR: Disaster Risk Reduction

EEA: $\quad$ European Environment Agency

EFA: $\quad$ Education For All

EM-DAT: The International Emergency Database

EPRP: $\quad$ Emergency Preparedness and Response Plan

EWS: $\quad$ Early Warning System

FEMCO: $\quad$ Flood Emergency Management Committee

GCMs: Global Circulation Models

GEF: $\quad$ Global Environment Facility

GFDRR: $\quad$ Global Facility for Disaster Risk Reduction

HFA: Hyogo Framework of Action

HIV /AIDs: Human Immunodeficiency Virus/ Acquired Immunodeficiency

Syndrome

IDNDR: $\quad$ UN International Decade for Natural Disaster Reduction

IFRC: $\quad$ International Federation of the Red Cross and Red Crescent Societies

IPCC: $\quad$ Intergovernmental Panel on Climate Change

IRSS: Institut de Recherche Santé et Société (Research Institute of Health and Societies)

MDGs: $\quad$ Millennium Development Goals

MICOA: $\quad$ Ministry of Coordination of Environmental Affairs 
MoE: $\quad$ Ministry of Education

MOPH: $\quad$ Ministry of Public Works and Housing

NDMDs: $\quad$ National Disaster Management Departments

NFNC: $\quad$ National Food and Nutrition Commission

NGO: $\quad$ Non-Governmental Organization

NOAA: National Oceanic and Atmospheric Administration

OFDA: $\quad$ Office of Foreign Disaster Assistance

SADC: $\quad$ Southern Africa Development Community

SCN: $\quad$ Standing Committee on Nutrition

SDGs: $\quad$ Sustainable Development Goals

SEI: Stockholm Environment Institute

TANGO: $\quad$ Technical Assistance to NGOs

UN: United Nations

UNDP: $\quad$ United Nations Development Programme

UNEP: $\quad$ United Nations Environmental Programme

UNESCO: United Nations Educational Scientific and Cultural Organization

UNFCCC: United Nations Framework Convention on Climate Change

UNICEF: $\quad$ United Nations Children's Fund

UNISDR: $\quad$ United Nations International Strategy of Disaster Reduction

UNOCHA: United Nations Office for the Coordination of Humanitarian Affairs

UPE: $\quad$ Universal Primary Education

WCDR: $\quad$ World Conference on Disaster Reduction

WCED: $\quad$ World Commission on Environment and Development

WDR: $\quad$ World Development Report

WFP: World Food Programme

WHO: World Health Organization

ZAMCOM: Zambezi Watercourse Commission

ZDHS: $\quad$ Zambia Demographic and Health Survey

ZMD: $\quad$ Zambia Meteorological Department

ZVAC: Zambia Vulnerability Assessment Committee 


\section{DEFINITIONS OF FREQUENTLY USED \\ WORDS AND PHRASES}

Assets:

Child Labor:

Cholera:

Community:

Coping:

Disaster:

Disaster, natural:
Assets, including social, human, financial, natural, physical, and political capital, are the tangible and intangible resources that enable people to meet their basic needs (Frankenberger $e t$ al., 2013).

Employment of children in any work that deprives them of their normal childhood rights such as deprivation from attending school (ILO, 2014).

An infectious and often fatal bacterial disease of the small intestine, typically contracted from infected water supplies and causing severe vomiting and diarrhea (McElroy and Townsend, 2009).

Climate Change: A change in the state of the climate that can be identified by changes in the mean temperature and/or the variability of its properties, and that persists for an extended period, typically decades or longer (IPCC, 2012).

A group of people living in the same place or having a particular characteristic in common (Author's definition).

Strategies that people use in order to deal with shocks resulting from disasters such as floods (UNISDR, 2009).

Is a sudden and calamitous event that seriously disrupts the functioning of a community or a society and causes widespread human, material, economic or environmental losses and impacts, which exceeds the ability of the affected community or society to cope using its own resources (UNISDR, 2009).

Often used to denote disasters resulting from a natural hazard, such as climatological, seismic, hydrological etc. However, strictly speaking such disasters are the result of the interplay of those natural hazards with human society and even those 
hazards themselves may result from or get worsened by human action, such as environmental mismanagement. Hence, nearly all disasters have an anthropogenic aspect and the term 'natural disaster' is in fact a misnomer. Yet it is frequently encountered in both popular and academic literature (Frerks, Supervisor).

Displacement: Involuntary movement of people inside their country due to events like floods (UNHCR, 2006).

Dropout rate: The proportion of pupils from a cohort enrolled in a given grade at a given school year who are no longer enrolled in the following school year (UNESCO Institute of Statistics, 2009).

Early Warning System:

Educational

Outcomes:

Emergency:

Empirical

Research:

Enrolment:

Evacuation:
The set of capacities needed to generate and disseminate timely and meaningful warning information to enable individuals and communities threatened by a hazard to prepare and to act appropriately and in sufficient time to reduce the possibility of harm or loss (UNSIDR, 2009).

Attributes based on the completion of formal primary education, measured by the performance of school children (Chinapah et al., 2000).

A situation which threatens the lives and well-being of large numbers of a population and in which extraordinary action is required to ensure their survival, care and protection (UNICEF, 2013).

A way of gaining knowledge and searching for ideas by means of direct and indirect observation or experience (Goodwin, 2005).

The process of initiating attendance of children in school to start formal education (UNESCO, 2000).

The immediate and rapid movement of people away from the threat such as floods to a safer place (Author's definition). 
Floods:

Flood plain:

Household:

Hazard:

Humanitarian

Aid:

Learning

Materials:

Livelihoods:

Mitigation:

Policies:

Primary

Education:
An overflow of a large amount of water beyond its normal confines such as a river usually caused by heavy rainfall and submerges land or flood plain (O'Connor et al., 2004).

Areas of low lying land that are subject to inundation by lateral overflow of water from rivers or lakes with which they are associated (Junk and Welcomme, 1990).

Members of the same family unit sharing meals and a common income/expenditure pot (IFRC, 2007).

A dangerous phenomenon or situation that has the potential to cause harm (UNISDR, 2009).

Support provided to address the immediate needs of people affected by disasters. It is provided mainly by nongovernmental and international organizations. These include relief aid such as food, shelter and medical supplies (UNHCR, 2006).

Materials provided to schools for teachers and students to support the teaching and learning processes to meet the expectations for learning as defined by state, provincial or local curricula. These materials include texts books, teaching aids - maps, wall charts, videos, software, pens, pencils, etc., (UNESCO, 2014).

Comprise the capabilities, assets and activities required for generating income and securing a means of living (IFRC, 2011).

The lessening or limitation of the adverse impacts of hazards and related disasters (UNISDR, 2009).

Are principles or protocols that guide decisions and achieve rational outcomes (Anderson, 2005).

The first stage of basic formal education of children usually between 6 and 7 years of age. It marks the beginning of systematic studies e.g. reading, writing and mathematics (UNESCO, 2007). 
Pre-position:

The art of saving relief supplies in warehouses to be used to save lives of people affected by a disaster such as floods (Russell, 2005).

Reconstruction: Developmental interventions which not only seek to build, repair damage or return to the status quo ante, but also address medium and long-term needs and capacities to avert the recurrence of crisis and to reach higher standards of living (UNHCR, 2006).

Recovery:

The restoration and improvement where appropriate, of facilities, livelihoods and living conditions of disaster affected communities, including efforts to reduce disaster risk factors (UNISDR, 2009).

Rehabilitation: Actions which enable the affected population to resume more or less "normal" patterns of life. These can occur simultaneously with relief activities, as well as further recovery and reconstruction activities (UNHCR, 2006).

Relocation: $\quad$ The process of transporting people affected by a disaster to a new settlement either on temporary or permanent basis (Author's definition).

Remittance: $\quad$ This is money sent by friends or family living abroad to people or individuals to assist them in basic living (Ratha, 2013).

Repatriation: The process of returning a person or people to their place of origin after a relocation or evacuation (Brun, 2003).

Resettlement: The transportation of people to a new settlement after being evacuated from a place of origin and do not necessarily have to return to the original place (Brun, 2003).

Resilience:

The capacity of a system, community or society potentially exposed to hazards to adapt, by resisting or changing in order to reach and maintain an acceptable level of functioning and structure (UNISDR, 2009). 
Risk:

Upper Land:

Vulnerability:
The combination of the probability of an event and its negative consequences (UNISDR, 2009).

An area closer to flood plains, but they are usually located above the level of a flood plain and therefore not affected by floods (Author's definition).

The diminished capacity of an individual or group to anticipate, cope with, resist and recover from the impact of a natural or man-made hazard (Wisner et al., 2004). 


\section{CHAPTER 1 INTRODUCTION}

\subsection{Purpose of this Study}

Disasters can have a significantly negative impact on human development. This is in particular a challenge in Africa, where widespread poverty and lack of governments' capacity result in millions of people being exposed to disasters. One of the most frequent disasters in Africa is caused by flooding. Flooding, as a sudden onset event, is often difficult to predict, and is according to many accounts expected to intensify as a result of climate change. One of the potentially most serious effects of flooding at present, and in future, is on the primary education of children. It may therefore be expected that, unless timely action is taken by households, communities, governments and international development agencies in tandem, more and more children's primary education in Africa may be disrupted.

In light of this, this thesis studies the impact of flooding on primary education in Africa and makes recommendations for strengthening household and community level resilience, so that children's education is less vulnerable to flooding. It does so by focusing on the case of Zambia, a country in Sub-Saharan Africa that is regularly subject to severe flooding along the Zambezi River.

The rest of this chapter is structured as follows: Section 1.2 provides the background to the development challenges posed by disasters in general, and floods in particular. Then, in section 1.3, the study presents an overview of other hazards in Zambia that threaten livelihoods and primary education. Section 1.4 outlines the problem and provides a clear understanding of why the study was conducted including a concise description of the issues that justified the research. Section 1.5 is the main thrust of this chapter as it underscores the questions guiding the research under two categories Primary and Secondary research questions. The final section of this chapter (section 1.6) outlines the relevance of the study in terms of the knowledge that will be generated and its potential contributions to policy and actions geared towards addressing the impact of floods on primary education. 


\subsection{Background}

Flood-related fatalities in Africa, as well as associated economic losses, have increased over the past half-century (Di Baldassarre et al., 2010). Floods occur as a result of the overflow of an expanse of water that submerges land (O'Connor et al., 2004). Floods are the result of a mass of water in a river or lake exceeding the capacity of the body. As a result, some of the water flows or sits outside of the normal perimeter of the body, such as a lake or river. Flooding most often happens during and after heavy rainfall, when rivers overflow. It can also happen as a result of heavy ocean waves (as in a tsunami), or when snow melts too fast, or when dams or levees break. Flooding may be only a few inches of water or it may completely immerse buildings and vegetation.

As depicted in the flow chart below (Figure 1.1), there are many causes of floods. These include monsoon rainfalls, hurricanes, undersea earthquakes and/or eruptions of island volcanoes which engenders tidal waves (tsunamis).

Figure 1.1: Physical causes of floods in relation to other environmental hazards

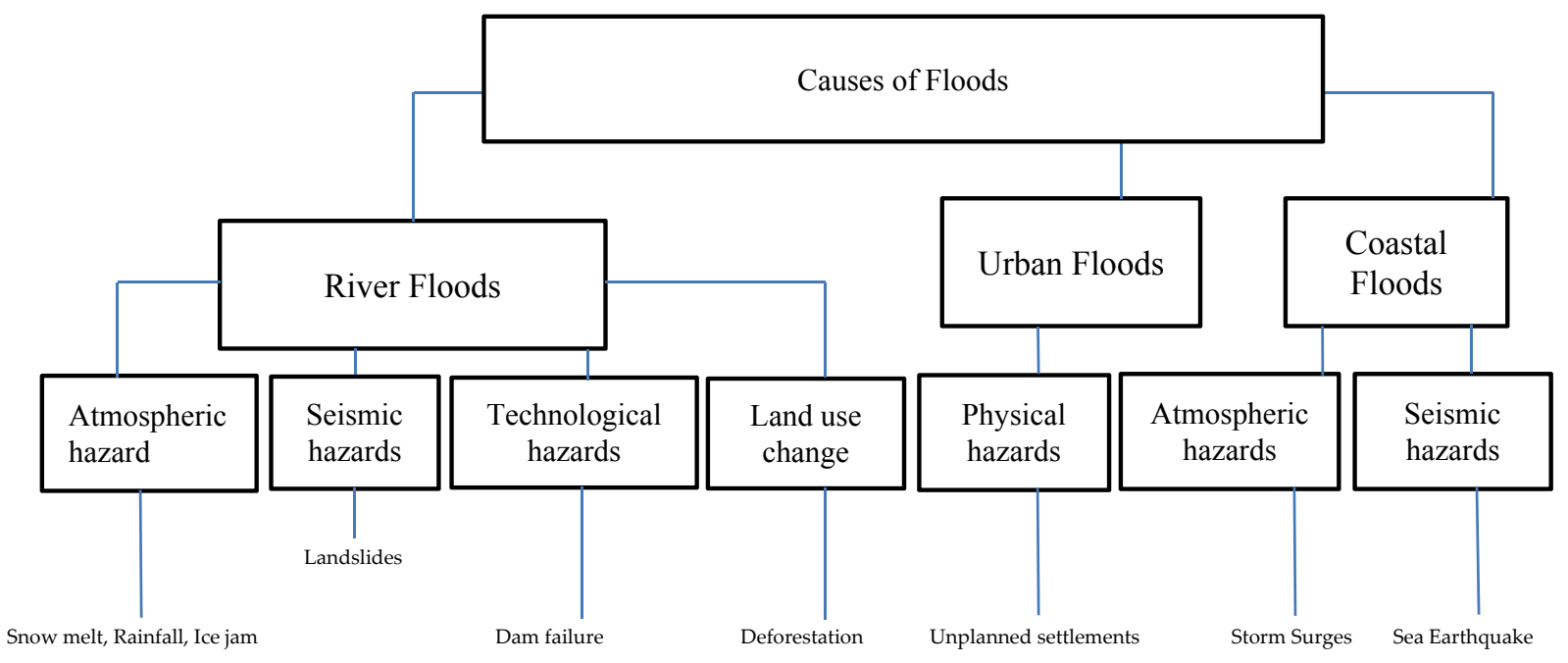

Source: Modified from Smith, 1992, Figure 11.3

Note: Atmospheric hazards resulting from high rainfall are the most important contribution to flood hazard.

Floods are disastrous when they assume unusual proportions, or occur in unexpected places or times. In such cases, affected communities may be caught by surprise, and 
lives and property may be lost. In Western Zambia, floods are events of annual occurrence (Smith, 2009). Where periodic floods occur in a river, it forms what is known as the flood plain. Flood plains are most often very good for agricultural purposes, as the alluvial soil deposited during flooding is highly nutritious (Smith, 2009). It is important to remember that the impact that a flood has is not solely a function of its intensity, but also of societal factors such as human-induced soil degradation and deforestation, urbanization and settlement patterns, and poor urban drainage. Such features increase the risk that floods will cause damage, and will magnify the impacts of flooding such as destruction of infrastructure, displacements and disruption of education for children. On the other hand, the impact of floods can also be mitigated by environmental, agricultural, physical or organizational measures.

Moreover, central to the concept of disaster is the notion that humans interface with the hazard or in this case floods: a flood is not hazardous unless humans are somehow affected. Flood exposure is a measure of the human population, land uses and investment located in flood zones and at risk of flooding, and increasing exposure is a prime contributory cause of flood disasters (Grothmann and Reusswig, 2006). A common method of measuring flood exposure is to count the number of properties of different types that occupy a flood plain or other flood risk area such as coastal flood zone (Grothmann and Reusswig, 2006). Exposure to floods is growing rapidly as human occupation of flood plains and flood prone coastal zones intensifies (Genovese et al., 2007). The possible interaction between human use of the flood plain and the onset of a flood event potentially creates a risk. In fact, a disaster exists once a flood occurs, depending on the amount of property damage, disruption of basic services and livelihoods, and loss of lives (Montz, 2000). For instance, the Centre for Research on the Epidemiology of Disaster (CRED) has as part of its criteria for registering disasters into its database, the aspect of human suffering and human loss - "a natural hazard is considered a disaster when ten or more people are reportedly killed; a hundred or more people are reportedly affected" (Guha-Sapir et al., 2012).

In the developing world, flood defenses are less developed and the exposed populations are more often subject to flooding with consequent disruption, economic loss, and in the worst cases loss of life (UNEP, 2002). Floods sometimes have less tragic outcomes, but by impacting large areas of land and destroying means of livelihoods, they leave many people in a precarious situation, sometimes for long periods. According to Guha-Sapir et al., (2012), the number of people affected by floods and the 
socio-economic losses resulting from flooding on a global basis are on the rise (see literature chapter 2.3 and 2.4 on floods disaster impacts on primary education). Hence, there is the need for decision-makers to adopt appropriate and effective approaches for flood disaster management and come up with lasting solutions.

The CRED/IRSS data on the frequency of disasters resulting from a natural hazard in 2011 (table 1) reveals that floods, as a form of hydrological disaster still lead all other disasters in occurrence, in the number of people affected and in resultant economic losses, with these numbers rising (Guha-Sapir et al., 2012). For instance, 173 of the 332 disasters registered in 2011 were flood disasters, representing a share of 52.1 per cent of total disaster occurrence globally. Floods were responsible for 57.1 per cent (139.8 million) of total disaster victims (244.65 million), 20.4 per cent of the total reported number of people killed and 19.3 per cent of total damages. When compared to the previous decade (2001-2010), the number of flood disaster victims in 2011 increased by 31 per cent.

Like most developing countries, Sub-Sahara Africa seems to be disproportionately hazard-prone. The region's disaster profile is closely linked to the vulnerability of its population and economies and exacerbated by minimal coping capacities. This is due to weak governance structures and institutional capacities, a weak economic foundation based on rain-fed agriculture, limited fiscal space to fund relief and recovery efforts after a major disaster, and a limited knowledge base to forecast and respond to disasters (Sen, 1981; see also GFDRR and The World Bank, 2010:8). As such, (Sub-Sahara) Africa does not have the enabling environment and governance capability to mitigate potential hazards and therefore when natural hazards occur, they cause a lot of damage to life, property, social services and livelihoods.

The distribution of disaster frequency in Africa in 2011 as well as over the last decade resembled the global distribution mentioned above. As depicted in table 1, floods account for 68.8 per cent of all disasters that occurred in Africa in 2011, followed by climatological (drought, forest fires, etc., - 17.2 per cent) and meteorological disasters (storms - 14.1 per cent). According to GFDRR and World Bank (2010), 80 per cent of loss of life and 70 per cent of economic losses linked to natural hazards in Sub-Sahara 
Table 1.1: Disaster occurrence: comparing 2011 regional figures with 2001 to 2010 averages

\begin{tabular}{|c|c|c|c|c|c|c|c|}
\hline \multicolumn{2}{|c|}{ Number of disasters } & \multirow{2}{*}{$\begin{array}{c}\text { Africa } \\
11\end{array}$} & \multirow{2}{*}{$\begin{array}{c}\text { Americas } \\
13\end{array}$} & \multirow{2}{*}{$\begin{array}{c}\text { Asia } \\
11\end{array}$} & \multirow{2}{*}{$\begin{array}{c}\text { Europe } \\
2\end{array}$} & \multirow{2}{*}{$\begin{array}{c}\text { Oceania } \\
2\end{array}$} & \multirow{2}{*}{$\begin{array}{r}\text { Total } \\
39\end{array}$} \\
\hline & 2011 & & & & & & \\
\hline Climatological & $\begin{array}{l}\text { Ave } \\
2001- \\
2010\end{array}$ & 9 & 12 & 11 & 17 & 1 & 50 \\
\hline & 2011 & 0 & 5 & 28 & 1 & 2 & 36 \\
\hline Geophysical & $\begin{array}{l}\text { Ave } \\
2001- \\
2010\end{array}$ & 3 & 7 & 21 & 2 & 2 & 35 \\
\hline & 2011 & 44 & 42 & 76 & 10 & 1 & 173 \\
\hline Hydrological & $\begin{array}{l}\text { Ave } \\
2001- \\
2010\end{array}$ & 44 & 39 & 82 & 24 & 6 & 195 \\
\hline & 2011 & 9 & 33 & 31 & 5 & 6 & 84 \\
\hline Meteorological & $\begin{array}{l}\text { Ave } \\
2001- \\
2010\end{array}$ & 9 & 34 & 40 & 14 & 7 & 104 \\
\hline & 2011 & 64 & 93 & 146 & 18 & 11 & 332 \\
\hline Total & $\begin{array}{l}\text { Ave } \\
2001- \\
2010\end{array}$ & 65 & 92 & 153 & 58 & 16 & 384 \\
\hline
\end{tabular}

Source: CRED, IRSS and UCL (2012): Annual Statistical Disaster Review 2011 - The numbers and trends

Africa are caused by floods and drought. A significant rising trend in the annual frequency of large-scale disaster events like floods has been reported in Sub-Sahara Africa (GFDRR and World Bank, 2010).

In Zambia particularly, floods are the most common hydro-related hazards. Out of a total population of twelve million, around three million people live in flood prone areas. An overview of the disasters profile of Zambia between the 1900 and 2014 (Figure 1.2) depicts floods as the most prominent disaster in the country, after 
epidemics² (EM-DAT: The OFDA/CRED International Disaster Database, 2014). However, it is important to note that although the occurrence of epidemics slightly surpasses that of floods, the predominant epidemic - bacterial infectious diseases like cholera (14 out of the 18 epidemic occurrences recorded), being a water-borne disease is largely triggered by floods. In effect, floods can be portrayed as the predominant disaster in Zambia. In terms of the total number of people affected, floods accounted for seven of the top ten disaster occurrence reported in Zambia between the reviewed periods. Of the 7.5 million people affected by these top ten disasters, about five million people were affected by floods.

Figure 1.2: Occurrence of disasters in Zambia from 1900 to 2014 (adapted from OFDA/CRED, 2014)

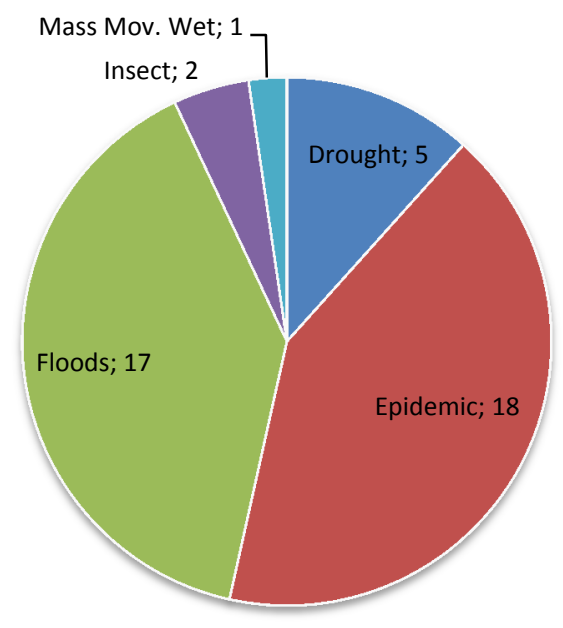

In 2009, Zambia experienced one of the heaviest floods in nearly 40 years in the flood plains. A rapid inter-agency assessment led by the DMMU in December 2009 found that about 500,000 people were directly affected. A large number of these people were displaced, crops were submerged, fishing boats were lost and water schemes polluted. Flood associated health problems affected especially children. In addition, children were also subjected to the disruption of their primary education. In this regard, the 2009 flood assessment found that 67 schools in five districts were severely affected. For instance, school walls collapsed and water caused damages to school furniture and

\footnotetext{
${ }^{2}$ Epidemics include: Viral Infectious Diseases (Yellow fever), Bacterial Infectious Diseases (Cholera, Plague).
} 
school documents and files. It was estimated that of the 30,000 school going children displaced by the 2009 flooding, at least 10,000 were deprived of education (ZVAC, 2009). Beside the loss of infrastructure, the resumption and continuation of children's education was a major challenge. Unfortunately the 2009 flooding was not a singular event; serious flood-induced disruption of education has been reported in 2010, 2011 and 2012.

Schools, because of their necessity for human capital formation, and the importance of human capital formation in turn for economic development, are therefore a particularly unfortunate victim of flooding. Over the years, heavy floods in Zambia have had a negative impact on school children. In many communities, an increase in family poverty (influenced by floods) has led to more children working rather than attending school (UNOCHA, 2003). Gilbert and Kreimer (1999) investigated the net enrolment, attendance and drop-out rate of children living in the flood prone areas in Bangladesh. They found out that the net enrolment is very low, attendance is poor and drop-out rates are very high. This phenomenon has been confirmed for the case of Zambia in this study as shown by the results in chapter 4 .

\subsection{Other Hazards in Zambia}

Apart from flood hazards which are generally restricted within the flood plains and flash floods in unplanned settlements in cities caused by lack of proper drainage systems, there are other hazards (as described in figure 1.2) that may threaten the lives and livelihoods of the people of Zambia. These may also have impact on primary education. These hazards' effects depend on human activities, climate and environment.

Malnutrition: According to the World Food Programme (WFP report, 2013), when a person is not consuming sufficient quantities and quality of food, malnutrition can occur. Even if people get enough to eat, they will become malnourished if the food they eat does not provide the proper amounts of micronutrients - vitamins and minerals - to meet their daily nutritional requirements. Malnutrition at an early age leads to reduced physical and mental development during childhood. The same WFP report indicated that, in developing countries, nearly one-third of children are underweight or stunted (low height for age). Under-nutrition interacts with repeated bouts of infectious disease; causing an estimated 3.5 million preventable maternal and 
child deaths annually and its economic costs in terms of lost national productivity and economic growth are huge (United Nations Standing Committee on Nutrition, 2011).

The Zambia Demographic and Health Survey (ZDHS, 2007), shows that, Zambia is one of 22 African countries with the highest burden of under-nutrition in children under five years of age. Thousands of children and women suffer from one or more forms of malnutrition, including low birth weight, wasting, stunting, underweight, and multiple micronutrient deficiencies such as vitamin A, iron, zinc, and iodine deficiencies. Deficiencies of a single nutrient are uncommon, while multiple nutrient deficiencies usually predominate in the same individuals. Despite its serious effect and occurrence in Zambia, malnutrition is not categorized as a disaster, because it is 'silent' and chronic. This is why it does not appear in the disaster statistics presented in Figure 1.2. Malnutrition is also very closely linked to drought.

According to the Lancet Nutrition Series of 2008 on the effects of nutrition interventions, Zambia is among the 36 countries with more than 20 per cent stunting. The WHO's 2009 landscape analysis on nutrition assessed Zambia's nutrition governance as 'medium' and also noted that the country was making 'insufficient progress' towards the First Millennium Development Goal (MDG 1). Stunting affects health, physical and cognitive development capacity as well as productivity in adulthood. It was estimated that the levels of child stunting of 45 per cent if unchanged in Zambia, may have cost over the last ten years period (2004-2013), US\$775m in productivity (NFNC, 2008).

Drought is -technically speaking- a deficiency in precipitation over an extended period, usually a season or more, resulting in a water shortage (surface or underground water), causing adverse impacts on vegetation, animals, and/or people. It is a temporary aberration from normal climatic conditions, thus it can vary significantly from one region to another (NOAA, 2008). A drought can last for months or years, or may be declared after as few as fifteen days. Although droughts can persist for several years, even a short, intense drought can cause significant damage and harm to the local economy, especially by affecting agriculture, food security and incomes. Droughts are not only to be measured as deviations from normal rainfall patterns or in terms of precipitation, but also have important social, cultural and behavioral connotations, making them more than an issue of rainfall only. Several societies are accustomed to recurrent drought (and flooding) and have devised particular localized forms of 
understanding and perceiving it. They also adjusted themselves to it by developing coping mechanisms and even so called disaster cultures.

Having said that, drought is considered a major threat to Zambia's food security. Although Zambia is land abundant relative to her population, a significant part of arable land is in a semi-arid region that is frequently hit by drought. Only 2.9 per cent of the country's arable land is under irrigation (World Bank, 2009). The remainder depends critically on rain fed subsistence agriculture. Such rain fed agriculture coupled with thin public resource endowments put Zambia in a precarious position to deal with drought impacts. When drought prevails, water, food and other necessities needed by people to live a normal life becomes scarce, a situation that becomes direr for children because it causes deficiencies and affects their health and wellbeing. This situation may affect the educational outcomes of school children, too.

Epidemics: The main epidemic in Zambia is Cholera. According to WHO (2011), the first outbreak of cholera was reported in the country in 1977/1978, and then cases appeared again in 1982/1983. The first major outbreak occurred in 1990 and lasted until 1993. Since then cholera cases were registered every year except in 1994 and 1995. Generally, most cases are recorded in the fishing camps of the rural areas and in the peri-urban areas of Lusaka and the Copper belt provinces. The observed ongoing cholera occurrence in Zambia corresponds to the progressive decline in the economy which started in the late 70s early 80s and still persists. Due to lack of drainage systems, poor hygiene, and sanitation, cholera prevails primarily in the peri-urban settlements, especially during the rainy season, an environment that is conducive for cholera. Access to clean and safe water, and poor sanitation remain the major challenge for effective cholera prevention and control in the country. In Lusaka, this is evident by a concentration of reported cholera death cases mostly in the western parts of the city where access to safe water and good sanitation is poor. Latrine coverage is very low in the cholera-affected areas of the city. The few houses with pit latrines are located very close to the shallow wells with high risk of contamination and people to latrine ratios are high. In 2009 and 2010, averages of 7,000 cholera cases were confirmed nationally with a case fatality rate of 2.2 per cent in each of those years. About 80 per cent of all the cases were from the peri-urban areas in Lusaka (WHO, 2011). 


\subsection{Problem Statement}

In recent years, extreme river flooding has occurred in many parts of Southern Africa including the 2008/2009 floods in Zambia. Floods become a disaster when they have an adverse impact on human lives, settlements and activities. One such adverse impact is on primary education. Primary education is generally seen as the basis for individual and social development. According to the human capital theory, education makes the individual more productive both in the market place and in the household, with higher levels of efficiency in resource utilization. Of the different levels of education, the rates of return are highest in primary education. Unless a population is literate, other (physical) investment projects may fail (Psacharopoulos, 1987). Preventing a hazard such as floods from turning into a disaster with negative impacts on primary education is therefore a priority in countries such as Zambia, where the exposure to flooding is real and is expected to increase in the future.

Potential climate changes are expected to cause a rise in the frequency as well as the intensity of rainfall, which may lead to more widespread and severe floods in many parts of the world. These climatic changes may increase the exposure and vulnerability of communities in the flood plains to flooding, and also, as a consequence, the social and economic damage in case of a catastrophic flood event (Crichton, 2007). It is estimated that in Europe, around three-quarters of economic losses caused by catastrophic events are weather or climate-related, of which flooding is a major component (EEA Signals, 2004). In Sub-Saharan Africa, such climate related disasters (floods and drought) account for 80 per cent loss of life and 70 per cent of economic losses linked to natural hazards (GFDRR and World Bank, 2010). Climate change scenarios generally imply an increase in rainfall variability and, on a global average, an increase in total precipitation, which could lead to more frequent and severe floods (Genovese, 2006). In practice, however, there are spatial variations and fine-grained analyses are needed to specify the impact in particular locations.

Human induced climate change is expected to continue in the coming decades (IPCC, 2001a) with considerable effects on human society and the environment. The magnitude of the impacts strongly depends on the nature and rate of future temperature increase. Consequences of climate change include an increased risk of floods and droughts, losses of biodiversity, threats to human health, and damage to economic sectors such as forestry, agriculture, tourism and the insurance industry (IPCC, 2001b). 
In Zambia, children living in the flood plains experience disruptions in their education due to perennial flooding, which causes displacements, damage to school infrastructure, school documents and the lack of good quality teachers in flood prone areas. Currently, it is estimated that about three million people out of a total of twelve million in the country live in flood prone areas (ZVAC, 2009). Approximately 30 per cent of the three million are primary school going children.

Despite the fact that (primary) education is a major development issue and that children's rights to education need to be protected, not much has been done in Zambia to provide evidence on the impact of floods on primary education. There is a relatively lack of empirical information on the damage floods inflict on the education of children. The relative lack of scholarly attention to the impact of floods on children's education in flood prone areas may have long term consequences for children and the communities, as policy responses and household coping strategies may not be optimal or even lacking in some cases.

In light of this, the goal of this thesis is to evaluate the impact of floods on the state of primary school education in flood prone areas in Zambia. It aims to do so by focusing on enrolment rates, dropout rates, repeating rates, length of stay in school and academic performance. The thesis also investigates levels of vulnerability of the community in the flood plains and household coping mechanisms in the aftermath of floods, including stakeholder interventions and perceptions on how education can be made resilient in the flood plains. As such, this thesis strives to contribute towards policy making and coping by households, as well as towards informing assistance efforts by all stakeholders in order to minimize the impact of floods on primary education. More interestingly, the thesis aims to contribute towards the relatively small academic literature on the effects of floods on primary school education in developing countries.

\subsection{Research Questions}

With the increase in the occurrence of climate related hazards (Guha-Sapir et al., 2012), the communities living in the plains are faced with several challenges induced by floods, one of which is the education of children. The Universal Declaration on Human Rights and the Education For All (EFA) commitment emphasizes education as a basic human right and the need to ensure that by 2015 all children, particularly girls, those in difficult circumstances and those belonging to ethnic minorities, have access to and complete, free and compulsory primary education of good quality. However, in the 
Western Province of Zambia where this research has been conducted, there is clear evidence that most children cannot have quality primary school education because of flood events. This study therefore seeks to investigate the fate of primary school education for children in the flood plains by providing answers to the following questions:

\subsubsection{Main Research Question}

- What is the impact of floods on primary education in Zambia?

\subsubsection{Secondary Research Questions}

- What are the vulnerability factors that expose communities to the risk of flood hazards and what coping mechanisms do households and communities use to deal with the negative impacts of floods?

- How do the interventions of stakeholders address/tackle the effects of floods on the state of primary education in Zambia?

- How can primary education in Zambia be made more resilient against the impact of floods?

\subsection{Relevance of the Study}

Hazards can turn into disasters, and can distress the health and economic situation of school children and their families which may result in lower attendance, lower learning and higher dropout; and this in the long run will negatively influence economic development (Metzler, 2008). Considering the fact that developing countries are geographically more vulnerable to extreme weather events than developed countries, with lower means of protection and insurance against natural hazard events; and that climate change will produce more frequent and severe hazards that may adversely affect educational outcomes and long-term human capital formation in developing countries (CAN 2008), it is of vital importance to provide the evidence regarding floods' impact on education, and hence this research was envisaged.

Communities living in flood prone areas of Zambia have suffered considerable effects of floods over the years and still do so currently. However, not much has been done to mitigate the effects of floods on the education of children in these communities. These flood plain communities depend on the river belt for their livelihoods and therefore find it difficult to vacate the plains. This study therefore aims to identify the impact of floods on primary school education of the children that live in the flood prone areas. Through this, the study hopes to contribute to policy making directed towards 
providing resilience, flood mitigation, disaster risk reduction and interventions implemented by Government and other stakeholders who focus on protecting the rights and welfare of children and their education.

The study seeks to provide more insight on the vulnerability factors which expose the communities to the risk of flood effects; the communities' preparedness, reaction and recovery mechanisms to flood impacts; key actors and how effective their interventions are in making primary education in the flood plains resilient to the impact of floods. Through this, the study is further expected to guide the activities of stakeholders, such as UNICEF, that strive to further the protection of children's rights and welfare in Zambia.

Most importantly, the study hopes to add value and contribute to the academic debate on the impact of floods on human welfare. At the moment there is not much research on the direct effect of floods on primary school education in Africa, particularly in Zambia. It is very difficult to get concrete literature on the impact of floods on primary education. The outcome of this study will provide a foundation for further research on this subject and other flood-related impact studies, as it contributes to the literature of the subject matter.

\subsection{Layout of the Thesis}

Having outlined the purpose of the research, the development challenges posed by disasters caused by natural hazards, particularly floods, the key questions guiding the research and how relevant the study may become to researchers and policy makers interested in the subject; the rest of this thesis will unfold as follows:

In chapter 2 a review of the relevant literature is provided. This lays the theoretical and methodological base for the empirical research undertaken. In chapter 3 a description of the study area, the research design, the various methods, techniques and tools used to collect and analyze the data needed to answer the research questions are set out. Chapter 3 also identifies challenges faced during the empirical research phase and outlines a number of constraints.

The central contribution of the study is contained in chapters 4 to 6 . Chapter 4 illustrates the impact of floods on primary school infrastructure, rates of enrolment, repeating rates, dropout rates, capacity of teachers and academic performance respectively. In Chapter 5, the various factors influencing the level of vulnerability of 
communities to flood impacts are identified. Chapter 5 also discusses the strategies used by the communities to cope with floods. Chapter 6 outlines efforts by stakeholders in reducing the hazards of flooding for better primary school outcomes in Zambia.

The final chapter (Chapter 7) contains a number of policy recommendations and reiterates the limitations the research faced and suggestions for further studies. 


\section{CHAPTER 2 LITERATURE REVIEW}

\subsection{Introduction}

In the previous chapter, the background, problem statement, research questions and relevance of the study were presented, indicating the issues that the research intends to address and the significance of the study. It was pointed out that there is still relatively little scholarly work on the impact of floods on primary education, particularly in Africa. As the thesis will attempt to fill the relatively limited academic work on the subject, this chapter provides an overview of the broader literature that will inspire the approach to be taken. As such, the chapter will focus on the scholarly literature dealing with the concepts of natural hazards and disasters, vulnerability, coping strategies and resilience, as well as analyses of floods, hazards and disasters, and how they have been studied in the Sub-Saharan Africa context. Wherever possible, the concern will be on the case of Zambia.

The chapter is structured as follows: Section 2.2 reviews literature on education from the perspective of development studies and development economics. This section describes the theory of "education and the logic of economic progress" which establishes the fact that education is the key to the development and economic growth of a society and that a more educated society has better potentials of higher economic growth and development than a less educated society. The next section, 2.3 discusses the different impacts of floods against the backdrop of the key concepts of hazards and disasters, taking stock of the global and regional scenarios with focus on Sub-Saharan Africa. Section 2.4 is the core of this chapter and deals with the intersection between floods and primary education. It presents the various ways in which floods impact on primary education. It further provides existing empirical evidence on the direct and indirect effects.

To better understand the factors that exacerbate flood impacts on education, the concepts of vulnerability and coping mechanisms are analyzed in sections 2.5 and 2.6 respectively. In section 2.7 , strategies on how flood hazards can be mitigated are 
presented, while section 2.8 analyzes the concept of resilience. The analysis is based on established models and frameworks, focusing on the local scale - community and household levels. To conclude, section 2.9 summarizes key points of the chapter, outlining the implications for the research questions and methodology.

\subsection{Education and Development}

The idea that education should function to promote development has played a major role in shaping educational policy over the last few decades. So far, however, philosophers of education have shown relatively little interest in analyzing this notion and its implications (Gilead, 2012). Education and development theory critically examines, from a philosophical perspective, the link between education and the currently prevailing understanding of economic progress, which is grounded in human capital theory. A number of familiar philosophical objections to the idea that development is a worthy educational aim are raised, but it is held that many of these objections stem from a partial understanding of economic theory. It is argued that there are inherent tensions between the philosophical foundations of the economist's conception of progress and the very essence of education. Gilead (2012) suggests that in order to resolve these tensions we should consider grounding the economic theory that guides educational policy-making in an inter-subjective or objective conception of welfare.

Today, development is one of the central aims of education. Influential supranational organizations, such as the OECD and the World Bank, view education primarily as a tool for improving economic performance. According to the World Development Report (WDR, 2014), education is one of the most powerful instruments for reducing poverty and inequality and lays a foundation for sustained economic growth. This may lead one to conclude that communities in the flood plains in Zambia are poor because most inhabitants are not well educated, do not have white-collar jobs and do not have a place in the top political and decision making arena (their low educational attainment is to a large degree associated with floods' disruption of educational outcomes of primary school children).

In 2007 the OECD's main webpage on education plainly stated that 'both individuals and countries benefit from education. For individuals, the potential benefits lie in the general quality of life and in the economic returns of sustained, satisfying employment. For countries, the potential benefits lie in economic growth and the development of shared values that underpin social cohesion. In a similar vein, many countries have 
initiated educational reforms that forge a tight link between individual and national economic progress on the one hand, and education on the other (Jones, 2007). Providing the theoretical underpinning for this line of reasoning is human capital theory (Bell and Stevenson, 2006; Resnik, 2006). This theory, grounded in mainstream economic thought, argues that under present conditions education is a worthwhile economic investment and that education increases or improves the economic capabilities of people.

Human capital theory revolutionized the way in which the link between education and development is perceived. Although the notion that a longer and better education can contribute to the wealth of both individuals and the nation dates at least as far back as the 18th century (Gilead, 2011), it was established empirically only with the development of human capital theory. The term 'human capital' generally refers to the education of a population (McDermott, 2012) and was first incorporated into modern economic discourse by Schultz (1961) in an attempt to explain, inter alia, the rapid economic progress that took place after World War II. According to Schultz, the standard growth models of the time failed to predict this phenomenon because they did not take into account one of the major determinants of growth - the individual's productive capacities, which he termed human capital. The incorporation of human capital into economic theory resulted in a fairly simple but powerful link between education and economic progress. By developing the individual's talents and skills and by providing the individual with useful knowledge, education enhances human capital and raises productivity, and this, in turn, leads to greater wealth for both the individual and society. Marshall (2007) also points out that while the types and means of education are diverse, so too are the benefits derived from education. Education makes a perceived contribution to improvements in health and nutrition. In addition, education tends to effect a control on population growth and increases the overall quality of life.

In spite of its potential significance, relatively few studies have attempted to determine the effects of disasters on human capital accumulation at macro level. In general, the long term economic effects of disasters are as yet not well understood (Cavallo and Noy, 2009). One of the few papers that attempt to quantify the long-term consequences of disasters on economic growth is a much cited paper by Toya, Skidmore and Robertson (2010). These authors find a positive correlation between disaster frequency and economic growth, arguing that this could be the result of disasters lowering the 
opportunity cost of investing in human capital relative to investing in physical capital. Disasters frequently result in large-scale loss of life, injury and the spread of illness alongside the displacement of populations, the disruption to everyday life and the welfare costs imposed by the associated destruction of physical assets. These humanitarian effects of disasters are suffered disproportionately by poorer people and poorer countries. Potentially, the disruption of human capital could represent an important channel of transmission from the transient shock of a disaster to long-term economic development.

Several more recent studies have indicated, albeit inconclusively, that by augmenting human capital, education makes a significant contribution to increasing Gross Domestic Product (GDP) per capita, which is still one of the most widely used measures of the economic progress of nations (Gradstein et al., 2005). In a world characterized by intensifying economic competitiveness, the link human capital theory creates between education and wealth has had a profound impact on the development of the former (Burbules and Torres, 2000). It has made education a top priority for economists, policy makers and politicians. It also has led to educational expansion and has driven governments and NGOs all over the world to invest billions in education in the expectation that this will yield ample returns (Resnik, 2006). In contrast, when education for children is limited, such as by flood disruptions, this subsequently limits the economic growth potential of the individuals and the community.

At the same time, however, the aforementioned linkage between education and economic progress has also drawn severe criticism. Some economists have challenged it on methodological grounds, but perhaps the most compelling objections to it are philosophical in nature. One key objection to the aforementioned linkage between education and economic progress is that it reduces education itself to a means of achieving economic ends. Robeyns (2006) provides a clear example of this line of argumentation. She claims that once human capital theory is embraced, the intrinsic worth of education is lost (Robeyns, 2006). Within the framework of human capital, she argues, everything assumes an economic value. Nothing can be sought for its own sake or for the sake of a non-economic good (Robeyns, 2006). This objection, and similar ones, lead many to dispense with human capital theory along with the idea that economic progress should be the ultimate aim of education. 


\subsection{General Impacts of Flood Hazards and Disasters}

A hazard is a situation that poses a potential threat to life, health, property, or environment (UNISDR, 2009). The hazards of concern to this study are hazards of natural origin that arise mainly from hydrological, meteorological, or oceanic sources, sometimes acting in combination, resulting in what is referred to as floods. A hazard could result in a disaster when it hits a community and overwhelms the community's ability to prevent the associated damage or recover.

Disaster as defined by the UNISDR (2009) is a sudden and calamitous event that seriously disrupts the functioning of a community or a society and causes widespread human, material, economic or environmental losses and create negative impacts, which exceeds the ability of the affected community or society to cope using its own resources. According to Wisner et al., (2004), a disaster occurs when a significant number of vulnerable people experience a hazard and suffer severe damage and/or disruption of their livelihood system in such a way that recovery is unlikely without external aid. In the flood plains in Zambia, people suffer tremendous losses in human, capital and livelihoods due to the recurring floods and the displaced have to struggle a lot to make a living if aid is not provided quickly which often is the case. Disasters are often described as a result of the combination of: the exposure to a hazard; the conditions of vulnerability that are present; and insufficient capacity or measures to reduce or cope with the potential negative consequences. As Wisner et al., (2004) pointed out, there cannot be a disaster if there are hazards but vulnerability is (theoretically) nil, or if there is a vulnerable population but no hazard event.

Flooding is considered the most common and widespread of all natural hazards. As indicated in table 1, floods (and other wet mass movement) took the largest share in disaster occurrence in 2011, as it accounted for 52.1 per cent of the total disasters. Based on the global distribution, Asia and Africa are the most flood affected regions, with floods accounting for 52 per cent and 68.8 per cent of all disasters in these regions respectively (Guha-Sapir et al., 2012). Every year, floods cause enormous damage over the world. Floods impact both individuals and communities, and have social, economic, and environmental consequences. As a direct consequence, floods can lead to the loss of human lives, affect human health, and cause damage to physical infrastructure, the environment and properties. Indirectly, floods can cause loss of economic and agricultural production, loss of livelihoods, and decrease of socioeconomic welfare (Jonkman et al., 2009; Mmom and Aifesehi, 2013). 
Floods are the leading cause of disaster deaths worldwide and were responsible for 6.8 million deaths in the 20th century (Doocy et al., 2013). In their systematic review of historical events between 1980 and 2009, Doocy et al., (2013) found an estimated 540,000 deaths and 361,974 injuries attributed to floods. A total of nearly 2.8 billion people were affected by floods during this timeframe with 4.5 million left homeless. Based on the infrequencies with which figures of disaster victims are reported (Doocy et al., 2013), there is the likely gross underestimation of true values of numbers injured and displaced. Flash floods, with little or no warning time, cause more deaths than slowrising riverine floods, although the latter usually affects larger populations and land areas (Jonkman, 2005; Ashley and Ashley, 2008). The lower mortality rates in river floods are mostly attributed to their slower onset allowing for longer time of warning and evacuation. The primary causes and risks of flood-related mortality are drowning and trauma or injury (Jonkman and Kelman, 2005). Over an extended time period, there may also be increased mortality due to infectious disease.

According to Stromberg (2007), flood mortality varies by region, economic development level, and the severity of the event. The majority of flood-related deaths are concentrated in less developed and heavily populated countries, with Southeast Asia and the Western Pacific region experiencing the highest risk of flood-related deaths, followed by Africa (Doocy et al., 2013; Guha-Sapir et al., 2013). Floods in less developed countries kill and affect more people because they affect substantially larger areas with larger populations (Jonkman, 2005); and most importantly because with fewer resources, these countries, are unable to better predict and respond to impending flood events (Stromberg, 2007), while populations are more vulnerable.

Studies reporting the gender breakdown for flood-related deaths, most of which are accounts of flood events in the United States and Europe, consistently show a greater proportion of males as compared with female deaths, with males accounting for about 70 per cent of flood related deaths. While limited to only a few countries, these findings suggest there may be increased mortality risk for males in more developed settings and for females in less developed countries. With regards to age, research has shown that there is an increased risk of death in younger and older populations during floods (Jonkman and Vrijling, 2008; FitzGerald et al., 2010). While the prevailing notion is that women and children are more vulnerable in disasters, there is a paucity of research in less developed countries where the majority of flood deaths occur. 
Another tangible and direct impact of floods is the physical damage to property and infrastructure, which triggers the non-functioning of infrastructure facilities. The functioning of communities and industries depend on infrastructure networks. Daily activities (such as production, supply chain, etc. for industries and commuting for work, business, schooling, etc. for communities) are performed efficiently with the help of the infrastructural network. It is vital for infrastructure to function efficiently at all times. However, during disasters like floods, the functioning or serviceability of infrastructure could be severely affected. This in turn has an impact on the activities and services of communities and industries respectively. These activities and services contribute socially and economically. When their functioning is affected and usually reduced in case of disasters, their social and economic contribution is reduced (Deshmukh et al., 2011). For instance, as communication links and infrastructure such as power plants, roads, bridges, drainages, are damaged and disrupted, and in turn are disrupting the provision of basic social services - supplies of clean water, wastewater treatment, electricity, transport, communication, health care and education, - economic activities come to a standstill, resulting in dislocation and the dysfunction of normal life for a period much beyond the duration of the flooding.

Floods also have significant consequences for the environment. In many natural systems, floods play an important role in maintaining key ecosystem functions and biodiversity. They link the river with the land surrounding it, recharge groundwater systems, fill wetlands, increase the connectivity between aquatic habitats, and move both sediment and nutrients around the landscape, and into the marine environment. For many species, floods trigger breeding events, migration, and dispersal (Apan et al., 2010). The environmental benefits from flooding can also help the economy through increased fish production, recharge of groundwater resources, enrichment of the soil with nutrients and maintenance of recreational environments.

However, with the rapid modification of the natural environments by human activities, floods tend to have more deleterious effects on the environment. Floods tend to further degrade already degraded systems. While cycling of sediments and nutrients is essential to a healthy system, too much sediment and nutrient entering a waterway has negative impacts on downstream water quality. Other negative effects include loss of habitat, dispersal of weed species, the introduction of excess sediment and nutrients and pollutants such as chemicals, heavy metals and debris, which lowers water quality, fish production and contaminate coastal food resources (Apan et al., 2010). 
Apart from fatalities, casualties and infrastructural damages, extreme climate events such as floods disrupt livelihoods and income generating economic activities. In the event of floods, socio-economic life and livelihood of the affected people are distorted. Flooding in key agricultural production areas can lead to widespread damage to crops and loss of livestock. Crop losses through rain damage, waterlogged soils, and delays in harvesting are further intensified by transport problems due to flooded roads and damaged infrastructure. The flow-on effects of reduced agricultural production can often impact well outside the production area as food prices increase due to shortages in supply. In less developed countries, where the (rural) economy largely depends on agriculture, floods severely distort livelihoods as farmlands and livestock which are the major source of the people's livelihood are submerged and agricultural produce are destroyed (Mmom and Aifesehi, 2013). The direct effect on production assets, be it in agriculture or industry, can inhibit regular activities and lead to loss of livelihoods. Furthermore, the huge human displacements caused by floods disrupts livelihood patterns as displaced people leave behind their livelihood tools and maybe unskilled for the livelihood activities in their places of relocation. Loss of livelihoods, reduction in purchasing power and loss of land value in the flood plains can leave communities economically vulnerable. These can have long-term implications for well-being, future human capital accumulation, and economic development (Garbero and Muttarak, 2013).

As Nott (2006) points out, disease outbreak is a common phenomenon during floods especially in less developed countries. The prevalence of infections is greatly worsened by existing environmental health problems such as blockages to drainage channels, poor sanitation systems and the improper disposal of solid waste (Cairncross, 2003). The 2000 floods in Mozambique disrupted water and sanitation systems in the capital, Maputo, causing dysentery and cholera outbreaks (Sanderson, 2000).

According to Nott (2006), some impacts of floods are intangible and are hard to place a monetary figure on. These intangible losses include increased levels of physical, emotional and psychological health problems suffered by flood-affected people. Floods can also traumatize victims and their families for long periods of time. The loss of loved ones has deep impacts, especially on children. Displacement from one's home, loss of property and disruption to business and social affairs can cause continuing stress. For some people the psychological impacts can be long lasting (Nott, 2006). 
There has been limited research on the differential effects of disasters in rural versus urban populations. The few studies that have done so demonstrates disproportionate and longer-term impact of flooding on the rural population and a slower recovery for rural settings after the flood, including greater impact on their income, sanitation and electricity supply and less frequent economic recovery at six months (Kirsch et al., 2012). Although floods have a devastating impact on national economies, it is at the household level where their impact is felt most acutely (Bola et al., 2013). Floods can affect household welfare not only through the destruction of physical stock, but also through the destruction of human capital stock. During a period of crisis, households may be forced to decrease their investments in the human capital of their children through their lowered ability to provide proper nutrition and health care for their children or by reallocating the time children devote in school toward earning income (Skoufias, 2003). Research also reaffirms that the less-educated are more likely to suffer the impacts of a disaster because they have higher vulnerability to income shocks (Skoufias, 2007, Silbert, 2011). Children who are displaced by floods in the Zambezi basin engage in various income generating activities to support the family, which are often detrimental to their learning outcomes.

\subsection{Impact of Floods on the State of Primary School Education}

It has been acknowledged that natural hazards like floods slow down and hinder the progress towards the achievements of EFA goals and the MDGs (UNESCO, 2000). Existing literature has identified the connection between hazards and educational outcomes in developing countries and has generally found negative impacts (Metzler, 2008). Flood disasters impact primary education in numerous ways; through the direct impacts of loss of lives, damages to the physical complementary infrastructure to education (school buildings and material, roads and transport systems); decreased human resource pillars, and the indirect impact of loss of livelihoods, increased opportunity cost of going to school and in turn parents' lack of incentives to send children to school, among others. Floods cause low enrolment of children in school, increased drop-out rates and lower educational attainment (Baez et al., 2010; Metzer, 2008; Petal, 2008; Shah, 2013).

According to Shah (2013), the ultimate exclusion from education caused by floods occurs when students and staff are killed in unsafe schools. Thousands of teachers, educational personnel and students have died or been destabilized by floods (World Bank, 2001). For instance, flooding in the Mekong Delta of Vietnam claimed hundreds 
of lives, the vast majority being young school going children. In the year 2000, 400 school going children died and in 2001, over 300 school going child deaths were recorded. In 2002, 99 children died out of a total death of 106 in the Delta. These death rates affected the number of children who were able to go back to school after the floods. Of the children who survived floods, most did not return to school (Tinh, 2003).

The destruction of education-related infrastructure such as schools and complementary installations and resources is one of the most direct ways in which floods can inhibit educational attainment. Through the impact on infrastructure, natural shocks like floods - in particular serious and aggregate events - have the potential to render critical educational centers and related infrastructure unusable. The damage caused to schools by the 2010 floods in Pakistan left most of the affected schools closed down in Sindh province for a long period of time. In Mozambique, for instance, the World Bank funded the construction of 487 schools over 20 years, but floods in 2000 destroyed more than 500 schools (Baez et al., 2010). An inventory of the physical impacts of floods and other hydro-meteorological related disasters on schools, school-children, and teachers adapted from Petal (2008) as shown in table 2.1 provides compelling evidence on the impact of floods on education.

The damage caused by floods to physical infrastructure hinders school attendance for usually longer periods of time especially in developing countries where reconstruction of the damaged schools usually occurs long after the disaster. Delays in reconstruction of the destroyed schools (that is schools damaged beyond repair) require a level of reinvestment many times higher than the initial small incremental cost of building safely (Petal, 2008). Besides the negative impact on school attendance, floods damage to school infrastructure can have long-term adverse effects on children's educational attainment. When instruction time is lost due to non-functioning of schools, the quality of education may drop. Similarly, when there are no plans for alternative teaching locations and students are denied continuous schooling, many will never be able to catch up and could drop out permanently. Also, when educational records are missing, students may fail to matriculate and go on to further education. With the loss of income and housing associated with floods, delays in matriculation make it challenging for families to support children continuing their education (Petal, 2008). 
Table 2.1: Recent impact of floods and other hydro-meteorological disasters on schools

\begin{tabular}{|c|c|c|}
\hline Year & Location & Effect \\
\hline 2013 & 0 & $\begin{array}{l}\text { At least } 233 \text { schools from } 29 \text { counties reported damage to } \\
\text { infrastructure, teaching and learning material, and school } \\
\text { water and sanitation facilities. }\end{array}$ \\
\hline 2009 & ambia & $\begin{array}{l}67 \text { schools in } 5 \text { districts were severely damaged by floods, } \\
\text { about } 30,000 \text { school going children were displaced, } 10,000 \\
\text { of whom were deprived of education. }\end{array}$ \\
\hline 2008 & Myanmar & $\begin{array}{l}\text { 2,250 schools completely collapsed in Cyclone Nargis. } \\
\text { Another } 750 \text { were severely damaged. }\end{array}$ \\
\hline 2007 & Bangladesh & $\begin{array}{l}\text { Cyclone destroyed } 496 \text { school buildings and damaged 2,110 } \\
\text { more. }\end{array}$ \\
\hline 2006 & Philippines & $\begin{array}{l}\text { Super Typhoon Durian caused } \$ 20 \mathrm{~m} \text { USD damage to } \\
\text { schools including } 90-100 \text { per cent of school buildings in } \\
\text { three cities and 50-60 per cent of school buildings in two } \\
\text { other cities. }\end{array}$ \\
\hline 2006 & $\begin{array}{l}\text { Leyte Island, } \\
\text { Philippines }\end{array}$ & $\begin{array}{l}245 \text { children and their teachers died in a mudslide that } \\
\text { buried the village elementary school after } 5 \text { days of rain had } \\
\text { ceased. }\end{array}$ \\
\hline 2004 & Ban & $\begin{array}{l}\text { 1,259 school buildings were lost to floods and 24,236 were } \\
\text { damaged. }\end{array}$ \\
\hline 2000 & $\mathrm{Car}$ & $\begin{array}{l}\text { Severe floods directly affected between } 500,000 \text { and } 1 \\
\text { million students in } 1,000-2,000 \text { schools in } 8 \text { provinces. }\end{array}$ \\
\hline 2000 & Mozambique & More than 500 schools destroyed \\
\hline 1998 & Bangladesh & $\begin{array}{l}\text { Flooding destroyed } 1,718 \text { school buildings and 12,000 were } \\
\text { damaged. }\end{array}$ \\
\hline 1998 & Nicaragua & $\begin{array}{l}\text { Severe flooding caused by hurricane Mitch destroyed } 340 \\
\text { schools and there were losses of materials and textbooks }\end{array}$ \\
\hline 1998 & Gua & $\begin{array}{l}\text { The severe flooding caused by hurricane Mitch destroyed } \\
27 \text { schools, damaged } 286 \text { others, of which } 175 \text { severely. }\end{array}$ \\
\hline 1998 & Honduras & $\begin{array}{l}\text { Of the total } 20,942 \text { public school classrooms in the country, } \\
4,835 \text { classrooms were destroyed, damaged or affected, }\end{array}$ \\
\hline
\end{tabular}

Source: Adapted from Petal (2008) with contributions from Author's own research 
One of the obvious dangers of floods is when pupils try to make their way to school during and after floods. In his study of the 2010 floods in Pakistan, Shah (2013) described going to school in the flood affected areas as a 'nightmare' as pupils had to either wade through flooded fields or take canoes to row through across inundated fields. In order to avoid drowning, pupils had to forgo meals so as to reduce the number of crossings they made each day. At the time of disaster the cost of travelling daily to school rose sharply as pupils had to pay a higher amount for boat rides in the morning and evening every day. These challenges and difficulties forced the children to discontinue schooling and engage in other activities. In a similar study on the effects of the Budalangi floods in Kenya, Achoka and Maiyo (2008) reported high dropout rates among children affected by floods. These are pupils who dropped out of school completely and never returned, but rather engaged in child labor.

In flood disasters, schools are directly affected because they cannot operate effectively without key human resources. After disasters, the qualified teachers may find it very difficult to resume teaching in the affected areas thus causing perennial shortage of qualified staff. Ultimately, this shortage of qualified staff will affect enrolment, quality of education, overall performance of the students and the schools (Anderson, 1985; see also Shah, 2013:331).

The destruction of education-related infrastructure such as schools and complementary installations and resources is one of the most direct ways in which floods can inhibit educational attainment, but perhaps more important is the drain on household resources that slow and sudden onset floods inflict (Baez et al., 2010; Shah, 2013). Households frequently have to make rational decisions on expending resources for survival and coping with poverty, or on investments (such as education) to alleviate human vulnerability and enhance longer-term development prospects. Unfortunately, for the poorest, there is usually no choice and human vulnerability deepens as resources are targeted towards survival, thus ignoring the call to enroll and retain their children in schools due to the high opportunity cost of education, but rather put their children to work in order to increase household income (Seballos and Tanner, 2011).

Households severely affected by natural shocks such as floods, when left with tighter budgets, resort to 'adverse coping' by reducing their investments in education, health and productive physical capital. A case in point is the decision not to enroll children in school due to other priorities. As a result, enrolment rates declined by approximately 
20 per cent for instance, in regions in Ivory Coast that were hit by extreme weather changes between 1986 and 1987 relative to non-shock regions (Jensen, 2000). Following a similar difference, Jacoby and Skoufias (1997) found that school enrolments in rural areas of India were negatively affected by floods; a ten per cent decline in agricultural income across agricultural seasons is associated with a fall in school attendance of about five days. The consequences of severe floods due to Hurricane Mitch were found to reduce school retention and progression in Nicaragua (Ureta, 2005). In the same way, the 2010 floods in Pakistan led to reduced enrolment and retention in the affected areas (Shah, 2013).

The most evident of the effects of households reducing investment in education is the change in the incidence of child labor in the aftermath of disasters. In response to both anticipated and unanticipated shocks, households send children to work so as to increase household income, thereby decreasing school attendance of children (Jacoby and Skoufias, 1997). Such child labor is pervasive in Africa and also other parts of the developing world. For instance, child labor increased significantly in Nicaragua as a consequence of Hurricane Mitch (Baez et al., 2007). There is also related evidence on this matter in Northern Tanzania, for example, where child labor and chore hours are more prevalent at times when households deal with rainfall shocks (Beegle, Dehejia and Gati, 2003). Furthermore, more research using the same Tanzanian dataset suggests that drawing upon the labor of children following shocks to income including from disasters- in fact comes at a cost in terms of human capital. In the particular case of boys, a 5.7 hours increase in labor reduces their school attainment by one year and increases the likelihood of marrying young by 16 per cent (Beegle et al., 2008). But perhaps more worrisome still is that parental investments in children that appear to be temporary adjustments to difficult times become permanent shifts. Sadoulet et al., (2004) have found that children withdrawn from school during shocks are about 30 per cent less likely to continue studying compared to children who stay in school.

With regards to child labor, research has further indicated important differences between boys and girls in terms of the division of labor. Usually, girls tend to work more than boys (Edmonds 2007), especially in the household. Therefore, domestic work needs to be taken into account when considering the schooling work trade-off, and can be a primary deterrent to school attendance. As boys tend to have a smaller work burden in the household than girls, they face fewer barriers to schooling than 
girls (Assaad et al., 2005). However, the inverse holds when it comes to paid labor, usually outside the household.

There are other indirect pathways through which floods negatively affect child education. A study of floods in Mozambique in 2000 found that in many areas schools which were not damaged by the flood waters were used as evacuation centers to accommodate the displaced people. This interfered with normal learning and contributed to time lost out of school by pupils (Christie and Hanlon, 2001). Similar consequences were reported in Pakistan during the 2010 floods (Shah, 2013) and in Kenya during 2013 floods that were triggered by the long rains of 2013 (Ministry Of Education, Science and Technology, Kenya, 2013). In the former, not only were the schools used as shelter by flood-affected people, but even the furniture was used as fuel for fire and other infrastructure of these schools was completely damaged by the displaced people.

Floods further affect primary education as it exposes people, especially children (being the most vulnerable / most at risk) to infectious diseases, and hence inhibits their school attendance (Zoleta-Nantes, 2000). At the same time, disruption to medical facilities and the increased demand on people's resources can reduce their access to necessary medical treatment (Rashid, 2000). Also important to note are the potential mental health impacts of flooding resulting from stress (Stanke et al., 2012) and the impact of inadequate nutrition following disruption to incomes and food distribution systems (Baez et al., 2010). All these effects have a significant impact on children's education due to low attendance and possible drop out. Some of such effects may not become manifested until long after the flood event.

Even though the vulnerability of school attendance to different forms of shock in developing countries is well established, yet the impact of climate related hazards such as floods on primary education has not been exhaustively analyzed (Metzler, 2008). Indeed, floods can negatively affect educational outcomes via a number of channels on the demand side (lower attendance, lower learning outcomes and higher dropout) and supply side of education (long periods of teaching may be lost due to the destruction of schools and other relevant infrastructure, unavailability of human resource pillars teachers). These channels, especially on the demand side, will be more accentuated in low-income countries (Metzler, 2008). 
The negative impacts of flooding on primary education vary greatly. On the one hand, it is dependent on the extent, depth and duration of flooding, and the velocities of flows in the flooded areas. On the other hand, it is dependent on the vulnerabilities of communities. This latter dimension is discussed in the next section.

\subsection{Household Vulnerability to Natural Hazards}

As a concept, (social) vulnerability has been defined as the diminished capacity of an individual or group to anticipate, cope with, resist and recover from the impact of a natural or man-made hazard or disaster (Wisner et al., 2004). Vulnerability is most often associated with poverty, but it can also arise when people are isolated, insecure and defenseless in the face of risk, shock or stress. People differ in their exposure to risk as a result of their social group, gender, ethnic or other identity, age, special needs population and other factors (Bates and Swan, 2007).

Cutter et al., (2009) and Frankenberger et al., (2013) noted that vulnerability to environmental hazards manifests at several levels (individual, household, community, and higher-level systems e.g., nations, ecosystems) and can therefore be analyzed at different scales, from the personal (through for example loss of livelihoods) to the societal level (through damage to infrastructure systems). However, although floods have a devastating impact on national economies, it is at the household level where their impact is felt most acutely (Bola et al., 2013; Kirsch et al., 2012). Therefore the focus of this research is primarily on the local scale - on households and communities. Research efforts are increasingly shifting in this direction from the former dominance of macro-scale analyses (Norris et al., 2008). The most vulnerable are low-income peoples, less educated, migrants, those living in flimsy houses, those without insurance or financial reserves, the elderly and the physically challenged (Long, 2007; Skoufias 2007; Silbert, 2011).

In developing countries, it might seem that poverty and vulnerability to environmental hazards go hand in hand. Wisner et al., (2004) assert that, though the two are by no means always associated, 'generally the poor suffer more from hazards than the wealthy'. People living in poverty are more vulnerable to hazard impacts than the wealthy (Fothergill and Peek, 2004). According to Cutter et al., (2009), poor people have less money to spend on preventative measures, emergency supplies, and recovery efforts. Although the monetary value of the economic and material losses of the wealthy may be greater, the losses sustained by the poor are far more devastating in relative terms. Poor people are more likely to live in substandard housing, which can 
be a major disadvantage when disasters occur (Long, 2007), and during disasters, they are less likely to have access to critical resources and lifelines, such as communications and transportation. Some research suggests that poor families tend to experience longlasting impacts from disasters (Dash and Morrow, 2007).

One aspect of these connections is directly linked with the geography of exposure - the more traditional concern of hazards assessment. Poor households tend to inhabit the more vulnerable locations such as flood prone environments. While the affluent build large homes in coastal flood plains for the ambiance, the poor are likely to have little alternative, if their livelihoods are tied to tourism, fishing and other coastal enterprises. Brouwer et al., (2007) argue that poverty can drive people toward settling and working in precarious locations such as unstable riverbanks in farming areas. In urban areas, exposure to flood hazard tends to be concentrated in marginal, low-lying sites along rivers, on flood plains and coastal marshes - sites historically avoided by the better-off but often settled by the poorest communities because of their availability and/or proximity to sources of economic livelihood (Brouwer et al., 2007; Wisner et al., 2004 ). It is often poor rural-urban migrants who occupy squatter settlements in urban flood plains and flood prone embankments (CLUVA, 2014). Hardoy et al., (1992) and Main and Williams (1994) noted that squatters tend to find that there is less danger of eviction by city authorities if they locate in areas deemed undesirable for legal private or public development. In turn, the unsustainable settlement of such areas can accentuate flooding levels, causing a cyclical increase in hazard exposure. According to Douglas et al., (2008), as people crowd into African cities, human impacts on urban land surfaces and drainage intensify, causing even moderate storms to produce quite high flows in rivers because of surface runoff from hard surfaces and drains. Urban flooding becomes a problem as soon as it reaches areas with inadequate storm drains, waste management and water supply. In such areas, squatter and other informal settlements with high population density, poor shelter, little or no access to resources such as safe water and public health services, and low adaptive capacity are highly vulnerable (IPCC, 2001b; Smith, 2009).

However, the geography of vulnerability is not the same as the geography of hazard. It is not just that the poor may be more exposed to flooding; crucially they are also more likely than the wealthy to suffer when flooding occurs. Besides the fact that the rich can afford good design and engineering for their homes that minimizes (but does not eliminate) the impact of such events, even if they are living in an area exposed to 
floods hazards; their homes and possessions are usually insured, and they can more easily find alternative shelter and continue with income-earning activities after the hazard impact (Fothergill and Peek, 2004). Wealthier households often also have reserves and access to credit. By contrast, poorer households frequently have their entire stock of capital (home, clothing, tools for artisan handicraft production, etc.) assembled at the site of the disaster, uninsured. Hence, their economic and material losses, while less in absolute terms, can be devastating. Poorer households have fewer resources (cash reserves, less access to credit) upon which to draw to counteract the impacts of flooding - purchasing supplies in anticipation of an event or for buying services and materials in the aftermath of a crisis such as floods (Chan and Parker, 1996; Cutter et al., 2009). Therefore the impact is likely to affect them disproportionately, including higher mortality rates as well as greater housing damage (Blaikie et al., 1994; Wisner et al., 2004).

Typically, poorer households recover more slowly and many never fully regain preimpact levels, increasing their vulnerability to future hazards. Research has it that susceptibility is often cyclical with regard to flood hazards, because disruption to assets and livelihoods by one event often make households yet more vulnerable to future flood hazards (Blaikie et al., 1994; see also Wisner et al., 2004:12). Based on the United States experience, neighborhoods and communities who were poor or declining before a disaster, tend to lose out further during reconstruction (Dash and Marrow, 2007). That downward spiral effect is also highlighted in a report on flood recovery in Vietnam (IFRC, 2001), which confirms how, after each flood, the same families tend to lose their homes, possessions and livelihoods, increasing their vulnerability to the next disaster event.

If poverty itself impacts on vulnerability, then vulnerability to flood hazard now becomes not just a product of physical location but also a social product. This recognition of the social context of vulnerability began to spread its influence in the 1980s, and has been increasingly recognized in hazards literature since the 1990s (Cutter et al., 2009). The work of Blaikie et al., (1994) progressively develops analytical frameworks - a 'pressure and release model' and an 'access to resources model' - to examine political and economic root causes of vulnerability. Cannon (2000) strongly emphasized that it is vital to recognize that vulnerability should be treated as a condition of people that derives from their political-economic position. It is therefore 'dangerous' to use it loosely or as a characteristic of exposure to hazards alone, since 
this allows the key components of power and income distribution to be played down and prominence given to technical fixes.

Wisner (2000) provides an example of this critical social perspective in his discussion of the impact of Hurricane Mitch in Central America in 1998. He argues that the vulnerability of people in the region to flooding and landslides was caused as much by political and economic issues (e.g., land distribution and public expenditure cuts) as by the nature of the storm event itself. Similarly, many scholars refer to Hurricane Katrina as an 'unnatural disaster' (Dyson, 2006; Hartman and Squires 2006; Laska and Morrow, 2006) inferring that the impacts associated with it were more related to the underlying socio-economic inequalities within the affected population rather than the hurricane's intensity. One key insight from this growing body of work is that incomepoverty is certainly not the only non-physical influence on vulnerability, and assumptions that equate the two can lead to blanket solutions without proper analysis of other dimensions (Christoplos et al., 2001). As the preceding arguments suggest, vulnerability to the impacts of hazards has social, political, institutional and cultural dimensions too. Cutter et al., (2009) list vulnerability factors including access to information and knowledge, access to political power and representation, and beliefs and customs. Research shows that the neighborhoods most vulnerable to flooding (particularly in developing countries), tend to be those with low household incomes, poor housing quality and low levels of community organization, thereby seeing the causes of community vulnerability as multi-dimensional (Long, 2007, Wisner et al., 2004).

The effect of a hazard on any particular household results from a complex set of interacting conditions, some having to do with geography and location, some with the dwelling (Long, 2007) and still others with the social and economic characteristics of the people living there (Masozera et al., 2007). According to Cannon (1994), there are no generalized opportunities and risks in nature, but instead there are sets of unequal access to opportunities and unequal exposures to risks which are a consequence of the socioeconomic system. It is more important to discern how human systems themselves place people in relation to each other and to the environment than it is to interpret natural systems.

An important factor in a household's inability to protect itself is the degree to which it lacks autonomous control over its circumstances. Resiliency depends, not only on 
wealth and income, but on a household's relation to community decision-makers (Naudé et al., 2009). Social and political structures are far from objective or impartial and will promote the interests of some, such as business leaders, over those with less power or influence. This is why it serves some 'political interests to maintain the notion that disasters are natural rather than "caused" by political and economic processes' (Cannon, 1994).

Gender also affects social vulnerability. In most societies gender-specific responsibilities, constraints and limited access to resources accentuate the hazard vulnerability of women. Women tend to suffer disproportionately in every stage of disaster response (Enarson, 2007; Morrow, 2008) and their mortality rates have been found to be higher in many disasters (Neumayer and Plümper, 2007; see also UNDP 2010:1) especially in countries where gender discrimination is tolerated. Considering women's heavy care-giving responsibilities within households (Blaikie et al., 1994; see also Cutter, 2009:21), women bear most of the responsibility for meeting the daily needs of family members, particularly dependent children and elders. Their ability to seek safety when disaster looms are restricted by their responsibilities to the very young and the very old, both of whom require help and supervision. Similarly, these domestic responsibilities become more difficult in partially destroyed homes or temporary shelters and expand to include contacts with outside agencies, such as governmentassistance programmes, as well as household reconstruction tasks (Cutter et al., 2009; Morrow, 2008).

The most obvious gender effects of disasters like floods are associated with poverty. Women often suffer the impacts of a disaster disproportionately and are more vulnerable than men to disasters, mainly because women- especially single mothersare more likely to live in poverty (Enarson, 2007). As Marrow (2008) notes, women are more likely than men to hold low-status jobs in the service industry, which often disappear after a disaster occurs. As a result of the economic inequality, single-women and women-headed households are much more likely to be poor and hence more vulnerable to disasters.

The vulnerability of children is self-evident; especially those who lack adequate family support (Phillips and Hewett 2005). According to UNDP (2010), children are fourteen times more likely to die during a disaster than adults. Studies that have examined the psychological effects of disasters (flooding) on children (Stanke et al., 2012), indicate 
that disruptions created by a disaster can have significant psychological and physical impacts on children (Kar, 2009). Stanke et al., (2012) found that children (and older people) suffer post-traumatic stress disorder after flooding and that the prevalence figures are greater than those that are found for adults of working age. Based on the above, children who lack adequate family support are at a major disadvantage for disaster response. It would be useful to have advance knowledge of the number of children likely to require special services in refugee settlements, shelters, temporary housing facilities and disaster-assistance centers.

Household living arrangements also have disaster-related consequences. The resources available to any household are significantly affected by its ratio of healthy, productive adults to dependents. In many industrial economies, it now takes at least two wage earners to provide a middle-class standard of living. Single-parent families, particularly when headed by women, are likely to live on the economic margins. Similarly, the rising cost of raising children has put extra burdens on large families. Families with many dependents - children, elderly or disabled members - are likely to encounter greater obstacles when responding to an emergency (Skoufias, 2003).

Cultural norms regarding family size and household composition vary throughout the world. These norms are influenced by economic conditions, demographic trends and housing availability. There are obvious economic reasons for the preference of large, extended families in agricultural economies and small nuclear ones in industrialized societies. A wide variety of household arrangements, however, have resulted from post-industrial economies combined with current patterns of immigration, fertility and longevity (Skoufias, 2003).

Considering the different ways natural disasters can affect households, households have over the years employed a variety of strategies to mitigate and manage the risks and impacts of disasters. These strategies, usually referred to as coping mechanisms, are being employed by people affected by disasters to reduce their vulnerability and minimize the effect of disasters. The extent to which disasters like floods impact on household welfare is intimately related to their capacity to cope with shocks.

\subsection{Household Decision Making Frameworks}

In crisis situations such as posed by disasters, household decisions are vital to cope with and/or manage shocks. The decisions that households make during flooding periods could have a significant impact on the primary education of children. 
Household decision frameworks can help clarify the impact of those decisions made within households on children's education during times of shock. The theory of family formation and structure by Becker (1993) provides a model for examining these decision making frameworks. He indicated that household decisions in the aftermath of shock could affect children's education if families decide to engage children to work rather than going to school. Families discuss and decide on various aspects of the household, including how to respond to a shock. For instance, decisions can be made on birth control, sending boys to school instead of girls, reducing the number of meals a day, and engaging some children into the labor force.

Many households in the developing world (especially vulnerable communities in rural areas) use child labor as a means of increasing household income (Edmonds, 2007). Theoretical and empirical research shows that household poverty and vulnerability to shocks either prevents investment in education, or forces the practice of child labor (Edmonds, 2005). Regarding poverty, vulnerability to hazards and schooling in South Asia, Maitra (2003) presented evidence on the negative association between poverty, vulnerability and education in rural areas of Bangladesh (the Matlab area), India and Pakistan.

Attanasio and Szekely (2002) studied the dynamics of household decision-making in Latin America. They observed that the size of the family provided an important institution for coping with shocks. This is especially true for extended families and families in rural areas. Fertility control is an important determinant of family size and structure and ultimately of household needs. The research further indicated that many children drop out of school, a decision made by the family to engage those children into the labor force, without necessarily considering the future returns to education across generations and over time. Duryea and Arends-Kuenning (2003) found evidence that the rates of child labor were higher when children received better pay in the urban child labor markets of Brazil and Mexico. In Sub-Sahara Africa, Mwangi (2004) pointed out that in Kenya for example, even with the introduction of free primary education, access to education is still remaining a wide dream to many Kenyan children especially in rural areas because children are required to work to support the family.

Other theoretical and empirical research found that under-investment in education after a disaster and the practice of child labor is a consequence of low parental educational attainment (Dar et al., 2002). There are at least three possible reasons for 
greater parental education resulting in more schooling and less child labor. First, there may be a positive correlation between parental education and children's ability, which reduces the likelihood of a child dropping out of school. Second, educated parents raise the likelihood of a child remaining in school by providing an environment conducive to learning irrespective of a shock (such as directly helping with school work) and being knowledgeable about children's nutritional and health needs. Third, during income shocks (such as due to unemployment and disasters), a household with educated parents is less likely to pull a child out of school, practice child labor, or both because educated families often have safety nets like insurance schemes (Dar et al., 2002). In Zambia and many other developing countries, this is very unlikely because most people living in flood prone areas are often poor and less educated.

Existing research suggests that the direct and indirect costs of schooling affect household decisions. In the developing world, households face direct costs of schooling, such as tuition, fees, donations, books, supplies, uniform, transportation, private tutoring, and miscellaneous costs. According to Baez et al., (2010), direct costs are often a heavy financial burden for households in developing countries, especially during an economic shock or disaster. In response to these high costs, major international education initiatives such as the United Nations' EFA strongly consider reducing or eliminating the direct costs of schooling in order to raise school enrolment and attainment rates in developing countries (UNESCO, 2005). Deininger (2003) presented evidence from Uganda and Pakistan on direct costs discouraging household investment in education. Regarding indirect costs of schooling, Schultz (1960) and Rozenzweig and Evenson (1977) were among the first to discuss the possibility of children's opportunity costs discouraging household schooling decisions.

A household's schooling and child labor decisions have several implications for the household itself and society. By not enrolling children in school or withdrawing children from school, a household prevents itself and its children from benefiting from higher earnings (associated with educational attainment) in the future. For a poor household, this diminishes its chances of escaping the vicious cycle of poverty (Ljungqvist, 1993). From a society's perspective, lower school enrolment or incompletion of primary schooling undermine social cohesion, diminish political participation, encourage crime, and lessen numerous other social benefits associated with having an educated populace (Riddell, 2004). A household's decision to practice in child labor may expose its children to physical injury and other health problems 
(Beegle et al., 2004). Furthermore, health problems harm children's participation in school. Consequently, household decisions to engage children in child labor eventually deprive society of healthy and productive adult citizens.

While knowledge of appropriate mitigation and safety practices is important, it is insufficient to predict appropriate behavior since many other factors, such as money and access, affect household decisions and actions (Varley, 1994). Therefore, the notion of household decision frameworks is vital for this research in understanding the different kinds of decisions made by families during difficult circumstances of a flood and the short and long term implications of those decisions on the individuals, families and the community. In situations of effective humanitarian aid to the affected community, such negative household decisions in flood disasters may not be necessary and hence such disasters may have a more limited impact on children's education.

\subsection{Household Coping Mechanisms during and after Disasters}

Coping is the ability of people (an individual, community or society), organizations and systems, using available skills and resources, to face and manage adverse conditions, emergencies or disasters (UNISDR, 2009). It involves finding ways to manage resources to solve problems, to handle difficult situations or to develop mechanisms that provide solutions to problems, whether temporarily or on a longer term. The mechanisms are based on people's experience, social structures, resources and their capacities to combine them. Coping strategies or mechanisms are remedial actions undertaken by people whose survival and livelihood are compromised or threatened. In response to shocks such as floods, people cope in several ways. Coping mechanisms are often complex; they can include preparation, mitigation, and response or rehabilitation measures. For instance, displaced persons seeking shelter with extended families; merchants providing short-term loans; or parents sending their children to live with relatives in safer and more productive areas (see also Naudé et al., 2009).

Coping mechanisms aim to protect the fundamental means of livelihood for disasteraffected populations. Even in the worst of disasters, decisions made in crisis reflect the awareness of life beyond the emergency. Households affected by disasters employ emergency measures (i.e., coping mechanisms) to reduce their vulnerability and minimize the effect of crisis so as to recover as quickly as possible. Coping mechanisms are employed only as second (or third) best options to the community's preferred way 
of life. Most often, these mechanisms are imperfect and can become more exploitative as crisis intensifies (Skoufias, 2003).

As Skoufias (2003) explains, poorer households are typically less equipped to deal with shocks, and in the absence of an effective public safety net system, these households may use coping strategies that ultimately prevent them from ever escaping from poverty. In order to survive during a time of crisis, for example, poor households may be forced to sell their productive assets, such as draft animals. With limited access to credit and other sources of financing there is a strong possibility that these households may never be able to replenish their stocks of productive assets, thus remaining in poverty permanently or for years after the passing of the crisis. In addition, during a period of crisis, households may be forced to decrease their investments in the human capital of their children through their lowered ability to provide proper nutrition and health care for their children or by reallocating the time children devoted in school toward earning income. One unfortunate consequence of these coping strategies is that they may transmit poverty from one generation to the future generation.

Disasters such as floods affect household welfare through the destruction of physical and human capital stock. However, one must also take into consideration the variety of risk management arrangements and risk management strategies that are available for protection (World Bank, 2001a) of communities affected by disasters. Risk management arrangements include all the informal and formal arrangements that have evolved for the purposes of providing some protection for households in the event of a crisis. Risk management strategies typically cover all the prevention and mitigation strategies that households may implement prior to the crisis event, as well as all the coping arrangements that are available to households after the realization of a crisis (Skoufias, 2003).

A community's capacity to absorb the impact of a hazard event and recover from it is determined by its geographical location, the resistance of its physical structures and infrastructures, its economic capacity expressed in terms of asset levels, reserves and access to loans, its levels of social cohesion and organization, its cultural vision of disasters and many other factors. As underlined by some authors, there is a danger of generalization. Chambers (2006) decries the tendency to view hazard victims as homogenous in terms of vulnerability and generalizable in terms of their needs. Indeed, Maskrey (1999) recognizes the crucial point that communities are not 
necessarily homogenous, and points to variations in vulnerability within communities linked with socio-economic status, gender, age, ethnicity and political or religious affiliation. As such, the coping strategies of those who are poor and deprived vary by region, community, social group, household, and gender; age, season and time in history (Chambers, 2006). Bankoff (2001) goes further to warn of the disempowering effect of creating a discourse of vulnerability for regions that become perceived as disaster-prone. Such discourse undervalues and undermines the potentials and actions of people who face flooding problems. This is one reason for not only considering vulnerabilities but variations in capacities to cope - attention is turning both in development theory and practice to improved understanding of coping strategies.

The capacity to cope is a component of a household's or community's level of vulnerability. Studies have stressed the need to identify the capacities that already exist in societies when designing disaster-related development interventions (Chambers, 2006; van Aalst et al., 2008). People facing flood risk may take action (a) to prevent the spread and penetration of floodwaters through physical means, and (b) to reduce negative effects from floodwaters through actions such as livelihood diversification, relocation of belongings or the community distribution of emergency drug supplies. Blaikie et al., (1994) described how such hazard coping strategies may comprise preventive, impact-minimizing or post-event coping actions.

The relationship between vulnerability and asset-ownership has been highlighted by research: 'the more assets people have, the less vulnerable they are, and the greater the erosion of people's assets, the greater their insecurity' (Wisner et al., 2004). He identifies important assets as labor, housing, social and economic infrastructure, household relations and social capital. Carney (1998) lists five types of 'capital' assets: natural, social, human, physical and financial. A number of commentators note that key among these in fostering coping strategies at various phases of the hazard cycle is social capital (Cutter et al., 2009; Aldrich, 2012; Frankenberger et al., 2013).

Moreover, it has been recognized that people do not simply draw on their assets but possess sophisticated skills in managing them to cope with adversity and take advantage of opportunities. There is a growing recognition that poorer households are strategic managers of complex asset portfolios (Moser, 1998; see also Chambers, 2006:35). A central focus on the assets and strategies of households lies at the heart of the now "influential livelihoods approaches to developmental research and practice". 
In this framework, assets mediate the ability of households to pursue livelihood strategies designed to cope with 'shock' events such as flooding (Carney, 1998; Zhang et al., 2012).

A range of studies have focused on understanding how households and communities perceive and respond to flooding risks, especially in the flood prone countries of Asia (example, Rashid, 2000; Wong and Zhao, 2001, Islam et al., 2012). Household's responses include a variety of coping mechanisms relating to different phases of the flood threat, from flood prediction to recovery after disastrous floods. Typically, they are based on an intimate knowledge of hazard risks and viable coping strategies. As Blaikie et al., (1994) noted, indigenous responses include household's own strategies for dealing with flood risks. These responses have been developed by people in many places, often over hundreds of years, especially where people have had to colonize and cultivate new lands in flood plains. In the northern valleys of Pakistan, Davis and Hall (1999) described a range of traditional risk reduction measures such as tying ropes across fast-flowing rivers with bells attached to warn as the ropes broke when flash floods cascaded down the valleys. Chan and Parker (1996) pointed to the tradition in flood prone regions of Malaysia of raising houses on stilts to minimize flood damage and use the flood plains for 'padi' (wet rice) cultivation and fishing. Other coping mechanisms include the temporary relocation of fairly 'well-to-do' families during flooding periods, while the very poor use 'sampan' transport to prepare for evacuations when flooding occurs. Other communities use crop varieties in the flood plains that are ready for harvest before the actual floods. Among the char community in Bangladesh as identified by Islam et al., (2012) the construction of houses on plinths to raise the platforms above the annual flood levels and placing of barriers around houses in the form of grass, trees to prevent erosion of the soils are examples of coping strategies. Other techniques like having raised platforms inside houses as a temporary shelter (muchan and Pataton), reducing the number of meals and relying on inexpensive food, depending on relief, taking shelter with relatives or neighbors who live on higher lying lands, selling assets, borrowing, selling land and other productive assets, and livelihood diversification (searching for alternative sources of income). With regards to the latter, the study reveals that every flood season, the char dwellers changed their sources of income from farming and farm-based wage labor into non-farm wage labor, rickshaw-van puller, seasonal fishing and boating. The mobilization of communitybased support networks has been further identified as a crucial coping mechanism. This notion was reaffirmed by Chang (2010) whose analysis on community cohesion 
following a disaster shows increased unity among community members after the Carlisle floods of 2005 in the United Kingdom. He indicates that community cohesion is highest particularly at the initial flood stage, as residents recognize the importance of community unity and come together to cope with their losses. Often, it is community-based organizations that provide the first line of relief when floods occur (Nishat et al., 2000; Christie and Hanlon, 2001). It is these grassroots capacities that have been most neglected in flood mitigation interventions in the past, but strengthening them is emerging as a new focus for some agencies (Sanderson, 2000).

Similar coping strategies have been reported in Sub-Sahara Africa where (rural) communities make (mostly short-term) adjustments to their households' livelihood portfolio or drawing on available capital assets to minimize the effects of sudden shocks like floods. For example, diversification of income sources (Paavola, 2008; Brida et al., 2013), agricultural diversification including the use of better suited crop varieties (Deressa et al., 2009), migration, often to provide remittances (Konseiga 2006; Bola et al., 2013), drawing on savings, consuming food stocks amongst other strategies are undertaken depending on the context of both the shock and household (Oyekale and Gedion, 2012; Thornton et al. 2007; Chuku and Okoye, 2009). Brida et al., (2013) also confirmed the relying on help from organizations and others (family, friends, neighbors) and the sale of properties and productive assets (land, livestock) as strategies used in Sub-Sahara Africa to cope with flood disasters.

Table 2.2 adapted from World Bank (2001a) and from Holzmann and Jorgensen (2001) provides a more detailed exposition of the mechanisms for management of risk from crises and disasters. For the purposes of designing safety net programs as well as for quickly implementing public interventions during times of crises, it is critical to know the main coping strategies households rely upon at times of crisis.

Disasters affecting whole villages or even regions may put significant strains on local group-based insurance schemes that in more normal circumstances may be quite effective in providing some insurance. In fact, aggregate shocks may also strain marketbased coping mechanisms such as borrowing from formal financial institutions. Considering that safety net programs are either weak or malfunctioning in many developing countries, it is of particular interest to know the effects of these adverse events on various dimensions of welfare (Skoufias, 2003). 
Table 2.2: Mechanisms for managing risks/coping strategies

\begin{tabular}{|c|c|c|c|c|}
\hline \multirow[t]{3}{*}{ Strategies } & \multicolumn{4}{|c|}{ Mechanisms } \\
\hline & \multicolumn{2}{|c|}{ Informal mechanisms } & \multicolumn{2}{|c|}{ Formal mechanisms } \\
\hline & $\begin{array}{l}\text { Individual and } \\
\text { household based }\end{array}$ & Group based & $\begin{array}{l}\text { Market } \\
\text { based }\end{array}$ & $\begin{array}{l}\text { Publicly } \\
\text { provided }\end{array}$ \\
\hline Reducing risk & $\begin{array}{l}\text {-Migration } \\
\text {-More secure } \\
\text { income sources }\end{array}$ & $\begin{array}{l}\text {-Infrastructure } \\
\text { development } \\
\text { (dikes, terraces } \\
\text {-Common } \\
\text { property } \\
\text { resource } \\
\text { management) }\end{array}$ & & $\begin{array}{l}\text {-Environmental } \\
\text { policy } \\
\text {-Infrastructure } \\
\text { development } \\
\text { (Dams, Roads) }\end{array}$ \\
\hline $\begin{array}{l}\text { Mitigating } \\
\text { risk }\end{array}$ & $\begin{array}{l}\text {-Income source } \\
\text { diversification } \\
\text {-Investment in } \\
\text { physical and } \\
\text { human capital }\end{array}$ & $\begin{array}{l}\text {-Occupational } \\
\text { associations } \\
\text {-Rotating } \\
\text { savings and } \\
\text { credit } \\
\text { associations }\end{array}$ & $\begin{array}{l}\text {-Micro- } \\
\text { finance }\end{array}$ & $\begin{array}{l}\text {-Protection of } \\
\text { property rights }\end{array}$ \\
\hline Insurance & $\begin{array}{l}\text {-Marriage and } \\
\text { extended family } \\
\text {-Buffer stock }\end{array}$ & $\begin{array}{l}\text {-Investment in } \\
\text { social capital } \\
\text { (networks, } \\
\text { associations, } \\
\text { rituals, } \\
\text { reciprocal gift } \\
\text { giving) }\end{array}$ & $\begin{array}{l}\text {-Old age } \\
\text { annuities. } \\
\text {-Accidents, } \\
\text { disability } \\
\text { and other } \\
\text { insurance }\end{array}$ & $\begin{array}{l}\text {-Mandated } \\
\text { insurance for } \\
\text { unemployment, } \\
\text { illness, disability } \\
\text { and other risks }\end{array}$ \\
\hline $\begin{array}{l}\text { Coping with } \\
\text { shocks }\end{array}$ & $\begin{array}{l}\text {-Sale of assets } \\
\text {-Dissaving } \\
\text {-Loans from } \\
\text { money lenders } \\
\text {-Child labor } \\
\text {-Reduced food } \\
\text { consumption } \\
\text {-Seasonal or } \\
\text { temporary } \\
\text { migration }\end{array}$ & $\begin{array}{l}\text {-Transfers } \\
\text { from networks } \\
\text { of mutual } \\
\text { support }\end{array}$ & $\begin{array}{l}\text {-Loans from } \\
\text { financial } \\
\text { institutions }\end{array}$ & $\begin{array}{l}\text {-Social } \\
\text { assistance } \\
\text {-Subsidies } \\
\text {-Relief } \\
\text {-Cash Transfers }\end{array}$ \\
\hline
\end{tabular}

Source: Adapted from World Bank (2001a) 
A distinguishing feature of disasters caused by natural hazards from other types of shocks experienced by households is that they affect many households simultaneously. The aggregate nature of these shocks means that many of the informal mechanisms for mitigating and coping with risk become ineffective. This is particularly the case for the informal mechanisms that are group-based (Morduch, 1999; see also Baez et al., 2010:12) because when aggregate demand and livelihood falls, being a member of an occupational association, can be of little help, when most of the members of the same occupation are also affected negatively by the shock. For instance, being a member of a rural financial institution where deposits are from community members engaged in agricultural activities may be of little help for lending purposes to face any flood or harvest failure because most probably those deposits will be withdrawn all at once during the hardship (Skoufias, 2003).

One of the first studies on coping with shocks by Jacoby and Skoufias (1997) finds that child school attendance decreases as a consequence of the shocks experienced by poor rural households in India. Duryea (1998) for Brazil, and Skoufias and Parker (2002) for urban Mexico, both found similar negative effects on school attainment rather than just attendance, because families withdraw children from school and use them for work to bring income to the home.

Coping mechanisms are also investigated in the paper of McKenzie (2001) who uses the repeated cross-sectional surveys from Mexico. The coping mechanisms examined (in addition to the changes in child schooling mentioned above) include adjustments in household structure, reduction in the number of meals a day, changes in fertility, changes in household labor supply, and inter-household transfers. McKenzie's findings as well as Chambers' (2006) findings from reviews of case studies on vulnerability and coping, confirm that households rely on a portfolio of strategies rather than one single strategy to cope with risks. In the case of Mexico it seems that the primary coping strategies used were declines in fertility (with approximately 1 in 20 households postponing having a child), and inter-household transfers (transfers received from abroad - remittance- increased). Only small changes were detected in household structure and in household labor supply.

\subsection{Mitigating Flood Hazards and Disasters}

Interventions during and after flood hazards and disasters are the various steps taken by governments or other stakeholders to support communities affected by floods. This could be in the form of providing food, medicines, shelter, clothing, for displaced 
communities. It could also be in the form of providing support for schooling such as building temporary learning centers, providing school materials and training of teachers. There are various forms of interventions depending on the type and magnitude of the disaster and the needs identified.

The potential scale of flooding threats suggest that intervention efforts designed to build up the assets of the poor to withstand shocks will be increasingly important in reducing the human burden from flooding (IPCC, 2012). Hazard-related fields have been relatively slow off the mark in engaging with the broader debates on governance, participation and community-based development. However, there is increasing support for greater community involvement in intervention programmes and greater emphasis on strengthening coping capacities at the local level (Jain, 2000). The introduction of flood forecasting systems, the building of population awareness and preparedness, along with the development of local institutional capacities, are effective and socially sustainable actions that should be pursued with priority in the African continent. These actions can appreciably increase the societal capacity to cope with floods and strengthen communities' own resistance and resilience to flood hazard, thereby decreasing their overall impact (Di Baldassarre, et al., 2010). To support these sustainable actions, a great opportunity is offered nowadays by low-cost technologies, already available in many African countries, such as radio links from cellular communication networks, which, in addition to facilitating transmission of point measurements of rainfall and river flow, can be used to monitor path-averaged rainfall (Leijnse et al., 2007), as well as emerging low-cost space-borne data that enable both rainfall measurement (Li et al., 2009) and near real time flood monitoring (Schumann et al., 2010). It has been suggested in Chapter 5 to adopt the use of mobile telephones as an early warning measure that informs people of flood incidences in good time.

Maskrey (1999) notes how a number of development agencies supported a capacitybuilding programme in La Masica, Honduras, part of which was the development of a community-based flood warning system. When Hurricane Mitch struck in 1998, bringing severe floods, the system enabled mitigation efforts to get under way early. 'In contrast to neighboring areas, no life was lost in La Masica' (Maskrey, 1999).

There has been a strong tendency in the past to separate disaster management work from conventional development work by both governments and NGOs, yet risk reduction and development should be seen as part of the same process (Mercer, 2010). 
Chan and Parker (1996) argued that poverty eradication policies can go far toward risk reduction from hazards because they raise people's capacity for recovery. Action to counter vulnerability to flood hazards needs to work hand in hand with action to reduce poverty and promote sustainability.

Approaches to tackling the negative impacts of flooding can comprise actions before, during or after flood events. Parker (1999) made useful distinction between 'structural' and 'nonstructural' approaches in flood interventions. The former generally refers to engineering interventions such as river channel modifications, embankments, reservoirs and barrages designed to control the flow of rivers and abate or control the spread of flooding. Though prominent in the history of flooding intervention, structural measures have achieved mixed success. Many of the structural approaches have proved costly in environmental terms and failure or poor maintenance of some have even exacerbated flood hazards (Jain, 2000; Yin and Li, 2001). The financial cost of structural solutions, however effective they may be, also makes widespread coverage unfeasible (Newman et al., 2008) for many flood prone developing countries (Parker, 1999).

Nonstructural measures have tended to grow in prominence as the limitations of major, engineered solutions have emerged (Newman et al., 2008). They typically refer to measures designed not to prevent floods but to reduce the short- and long-term impacts of the hazard. At a macro-level, they include formal flood warning systems and evacuation programmes, land use controls on flood prone sites, building regulations to prevent incursion of floodwaters and insurance schemes (Parker, 1999). But more recently, and especially in the developing country context, there has been increased attention on nonstructural vulnerability reduction at the micro-scale, to adjustments and actions (both traditional and modern) at the community and household level.

From a community standpoint, the vulnerable poor are likely to require substantial government assistance. They more commonly become the inhabitants of displaced camps, mass shelters and temporary housing and tend to remain there for some time (Peacock et al., 1997). Therefore, mitigation and emergency planning which focuses on the most economically marginal will not only be more humane, but also more cost effective. Public officials must geographically identify and realistically appraise the circumstances of the poorest areas and groups in their communities, thus allowing 
mitigation initiatives and response programmes to target their needs. It is becoming increasingly evident; however, that reducing community vulnerability in any meaningful way must ultimately address the underlying issues of economic stratification and poverty (Bolin and Stanford, 1998).

Environmental hazards in the developing world are essentially unresolved development problems and hazard reduction has become an important dimension of development within sustainable limits. Sustainable development depends upon converging intra and inter-generational equity (World Commission on Environment and Development, 1987). Although the poor may develop hazard adaptations to limit their disaster vulnerability, poverty is generally believed to heighten such vulnerability. Poverty reduction and policies designed to nurture hazard-resistance amongst the poor are therefore important to sustainable development. Unfortunately, loss of indigenous hazard adaptations, and increased vulnerability, are commonly associated with rapid development (Wisner et al., 2004; Hewitt, 2007; Leichenko et al., 2013).

Generally speaking, most interventions in flood disasters in Africa tend to focus a lot on food and medical relief and not so much on education. However, if the interventions also aim at reducing the poverty levels by providing opportunities for increase in income levels of the communities in the flood plains such as cash transfers and not just providing food and medical relief, it will be much easier for these communities to build resilience against the impact of floods on children's education.

\subsection{Community Disaster Resilience - A Capital Approach}

The Indian Ocean Tsunami of 2004, Hurricanes Katrina and Rita in 2005, together with the worldwide evidence of global warming (IPCC, 2012) illustrate that communities and people are increasingly becoming more vulnerable to natural hazards and disasters. It is estimated that the annual average number of disaster victims from 2001 to 2010 amounted to 232 million people with the annual average damages estimated at US $\$ 109$ billion. The numbers were even higher in 2011 as the total number of disaster victims and cost of disaster damages increased to 245 million people and US $\$ 366$ billion respectively (Guha-Sapir et al., 2012). This trend of loss of human lives and property damage suggests that our communities are not resilient enough to deal with disasters in all social sectors including education for children. Over the past decade, many authors have underscored the need to accommodate the concept of resilience in research, policy, and disaster risk reduction arenas. The concept of disaster resilience 
has gained a wide interest and has become more popular especially after the adoption of the Hyogo Framework for Action 2005-2015: Building the resilience of nations and communities to disasters (Manyena, 2006). Since the adoption of the Hyogo Framework, the main goal of hazard planning and disaster risk reduction has slightly shifted to focusing more on resilience rather than only reducing vulnerability.

\subsubsection{Disaster resilience}

According to UNISDR (2007), disaster resilience is the "capacity of a system, community or society potentially exposed to hazards to adapt, by resisting or changing in order to reach and maintain an acceptable level of functioning and structure". This is determined by the degree to which the social system is capable of organizing itself to increase this capacity for learning from past disasters for better future protection and to improve risk reduction measures that enables the community to function and do not excessively disrupt the social fabric in the community's rights to basic social services including education, health services, nutrition, water and sanitation.

The term resilience refers to "bouncing back", reflecting its Latin root "resiliere" which means "to jump back" (Klein et al., 2003; Paton and Johnston, 2006). The concept of resilience gained popularity first in the field of ecology. Holling (1973) is frequently cited as one of the first to use the concept of resilience which he defined as the measure of the ability of an ecosystem to absorb changes and still persist. He also compared the concept of resilience with the notion of stability which he defined as the ability of a system to return to its equilibrium after a temporary disturbance. That is, the more rapidly the system returns to its equilibrium, the more stable it is. He concluded that resilience and stability are two important properties of an ecological system. Therefore, in this context, a system can be very resilient but still fluctuate greatly; that is low stability. Two decades later, Holling revisited his definition, and redefined the concept of resilience as a buffer capacity or the ability of a system to absorb perturbation, or the magnitude of the disturbance that can be absorbed before a system changes its structure by changing the variables (Holling et al., 1995). Since the work of Holling (1973), many ecological definitions of the concept of resilience have emerged.

Generally speaking, ecological definitions place emphasis on the amount of disturbance the system can absorb without a change in its state. It is also clear that they seem to focus more on stability and stress resistance to a disturbance and the speed of return to the equilibrium point. Although there are significant differences in terms of 
behavior and structures between social and ecological systems (Adger, 2000), the ecological theory on resilience concept can be extended to social systems as a way of conceptualizing hazards and their consequences. This means that a resilient social system should be able to absorb shocks and rebuild so that the community remains on the same functioning state. The social system with high resilience should also be able to reconfigure itself without significant decline in the crucial functions in relation to primary productivity and economic prosperity (Foster, 2006; Pendall et al., 2007).

Since the publication of Holling's work in 1973, the concept of resilience has increasingly gained recognition and acceptance and it is now frequently used in many fields, including in the fields dealing with natural hazards and disaster management. The importance of the notion of resilience is especially growing as a concept for understanding and managing complex linked systems of people and nature (Klein $e t$ al., 2003; Walker et al., 2006), especially in studies related to disaster impact analysis on social systems. Timmerman (1981) used the concept of resilience in relation to hazard and disaster and defined resilience as the measure of a system's or part of the system's capacity to absorb and recover from hazardous event (Klein et al., 2003).

Many authors use the term capacity to define the concept of disaster resilience and confine the concept to people, a group of people, a community, or a society (Mayunga, 2007). Hence the notion of disaster resilience could be associated with the capacity/ability of people, a group of people, a community or a society to cope with disasters. Worth noting also is the wide usage of the term recovery in the definitions. Most authors define the concept of disaster resilience in terms of the speed or how quickly people, a group of people, a community or a society can recover from the disaster impacts (Mayunga, 2007).

From the various existing definitions of resilience, the following main conclusions can be drawn:

(1) Some authors base their definitions of resilience on a system perspective. According to Pendall et al., (2007) there are two types of factors of a system (internal and external) that tend to strengthen or stress it. Most of the definitions tend to focus on the internal factors that strengthen the system. Additionally, the authors who adopt the ecological view tend to define the concept of disaster resilience as a process rather than an end or outcome. Generally, the notion of a system perspective is desirable in the sense that once the disaster happens, it facilitates and contributes to the community's recovery 
process (Klein et al., 2003). For instance in the case of the regular flooding in Zambia, communities have different strategies to cope such as building houses on top of mounds, using boats as means of transport, building alternative homes in upland etc. These coping strategies have over the years assisted the communities to build resilience against the impact of floods.

(2) Some definitions tend to take a long term perspective. For example, some authors define disaster resilience as a long-term recovery process after a disaster. As such resilience can be measured in terms of the time it takes to recover (equilibrium). A resilient community in this view would be the one that resumes its previous growth trajectory quickly. As Klein et al., (2003) notes, social systems are in continuous state of change. The notion of resilience as bouncing back to original state (equilibrium) after a disaster may thus be undesirable as it may imply that the system is just as vulnerable as before. In this light, and in light of the discussion in chapter 1 and 2, we may therefore expect that many current approaches to cope with flooding in Zambia is largely adopting a view of resilience as a return to the state existing prior to the flooding impacts.

(3) Some authors refer to the notion of adaptation when defining resilience. When the notion of adaptation is featured in the definition of resilience, especially with respect to a system, it becomes more of a process oriented concept, which has important implications to policies (Manyena, 2006). This means that a social system can reorganize itself to maintain essential structure and process within a coping and/ or adaptation process. For instance, the capacity of a community to send children back to school immediately after a flood disaster is applicable in this situation. The notion of adaptation is desirable because it increases capacity for learning and coping. However, communities in the flood plains of Zambia are yet to attain this notion of adaptation in relation to resilience since the effective resumption of basic services (education, health, etc.) occurs after long periods of time, following a flood disaster.

(4) Some authors link the concept of disaster resilience to the concept of sustainability, which refers to a long term survival at a non-decreasing quality of life. The prominent feature of sustainability is that it highly depends on natural resources (Smith et al., 2001). The notion of suitability is then desirable because it facilitates more sustainable use of community resources. 
(5) In some cases resilience may be understood as the opposite of vulnerability. This means that where social vulnerability is high the level of resilience tends to be low, and vice versa. Communities in flood prone areas in Zambia who are highly vulnerable could present very low resilience. This is due to the fact that these communities are characterized by poverty and have limited capacity to cope with the recurrent floods. As Klein et al., (2003) notes, the problem of defining resilience in this fashion is that it lends itself into the circular reasoning that a community is vulnerable because it is not resilient and it is not resilient because it is vulnerable.

In this thesis the concept of community disaster resilience is referred to as the capacity or ability of a community to anticipate, prepare for, respond to, and recover quickly from impacts of disaster. This means that it is not only the measure of how quickly the community can recover from the disaster impacts, but also the ability to learn, cope with or adapt to hazards. Thus, resilient communities should be organized in such a way that the effects of a disaster are minimal and the recovery process is quick. Figure 2.1, adapted from Zhang (2006) depicts the hypothetical trajectory of two ideal-types of community; (1) a more resilient community (blue-colored arrows), and (2) a less resilient community (red-colored arrows).

These two trajectories represent a sequential change of communities over time through four phases: pre-disaster, disaster, restoration, and long-term recovery. The diagram shows that a more resilient community has better initial status at $(\mathrm{t} 0)$ than a less resilient community. When a disaster strikes at $(\mathrm{t} 1)$, the more resilient community will often experience less impact, while the less resilient community will experience significant impacts at (t2) and hence greater fluctuation. The diagram also shows that the rebuilding and restoration process at ( $\mathrm{t} 3)$ is faster for a more resilient community than a less resilient one. It takes a much shorter time at (t4) for a more resilient community to recover than less resilient community. Communities in flood plains who are more resilient will therefore be able to minimize the impact of floods on the education of their children in a much better way than the non-resilient communities. A less resilient community will take longer to recover. With reference therefore to the above trajectory, one of the questions to be answered in this study is how education can be made more resilient for children in the flood plains. Chapter 7 of this thesis has provided some useful recommendations for governments and policy makers in this regard. 
Figure 2.1: Hypothetical trajectory of resilient and less resilient community

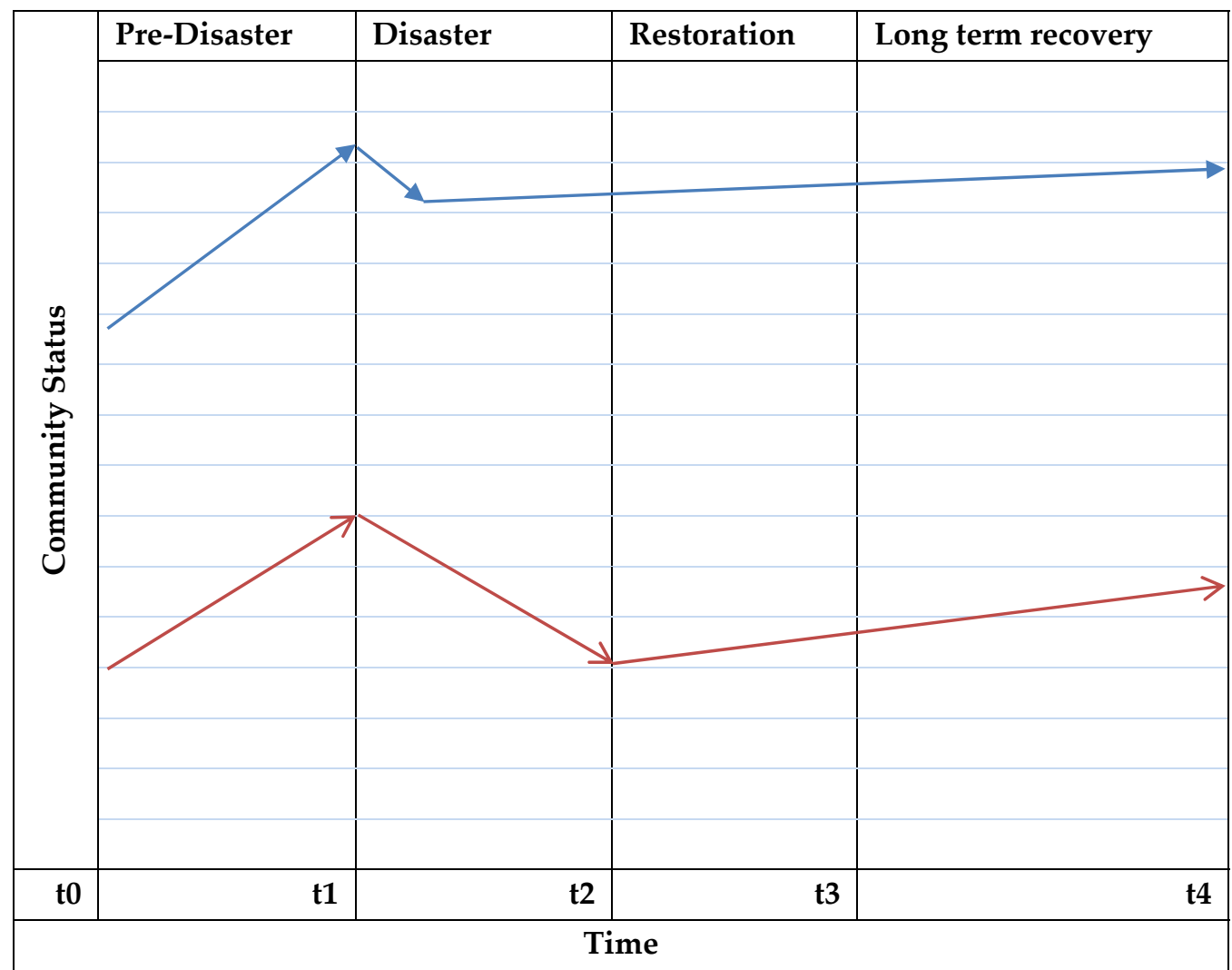

Source: Modified from Zhang (2006)

Where:

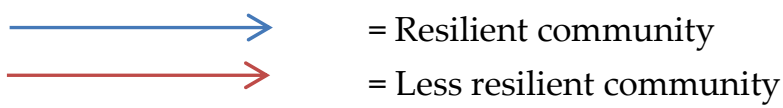




\subsubsection{Frameworks for analyzing community disaster resilience}

Assessing community resilience is a complex process because of the dynamic interactions of people, households, community, societies, and the environment. There are currently many conceptual frameworks proposed to measure this concept (Tierney, 2006). Most of these frameworks conceptualize disaster resilience in the same way in which they all focus on similar factors that could reduce vulnerability and increase community resilience. Such factors include economic resources, assets and skills, information and knowledge, support and supportive networks, access to services, and shared community values. These frameworks seem to focus on what is described as a "community capital". However, the limitation of most of these frameworks is that they tend to only focus on some or one dimension of disaster resilience and do not adequately take the broader view of the concept. If governments and policy makers attempt to strengthen the flood plains community capital, there are very good chances to effectively build community resilience that favor primary school education within these communities. However, this poses a big challenge, because the findings of the study have revealed that these communities are neglected and do not have a voice in the higher ranks of the political and decision making ladder. Since the attainment of its independence in October 1964, Zambia has initiated several decentralization reform programmes that have entailed a mix of decentralization, delegation and devolution. However, the provincial and district level administrations do not have absolute powers to make real changes at local level. They need total backing and support at central level. In the flood plains, that support is limited and hence the challenges.

The next section discusses the proposed framework to assess community disaster resilience.

\subsubsection{Proposed Capital-based approach}

The capital based approach is a framework that assesses community disaster resilience and builds on the foundation that extends the social capital approach already suggested in the literature (Tierney, 2006) to include the five major forms of capital; Social, Economic, Physical, Human, and Natural. As suggested by literature, the notion of capital aligns very well with the concept of sustainability (Smith et al., 2001), which is related to and often linked to the concept of disaster resilience (Frankenberger et al., 2013). The essence of using the capital approach is that, capital consists of those components, which are necessary for development of a sustainable community economy. The conventional wisdom here is that the more economic opportunities the 
community has, the more potential it possesses for reducing disaster impacts; hence the more resilient the community becomes. The capital based approach is not new in the disaster and hazard fields. It has been widely applied in sustainable development and poverty alleviation programs (see for instance DFID, 1999). Figure 2.2 depicts the proposed conceptual framework on how the five major forms of capital can contribute to reducing vulnerability and increasing community disaster resilience. 
Figure 2.2: Conceptual framework on the relationship between capital domains and community disaster resilience

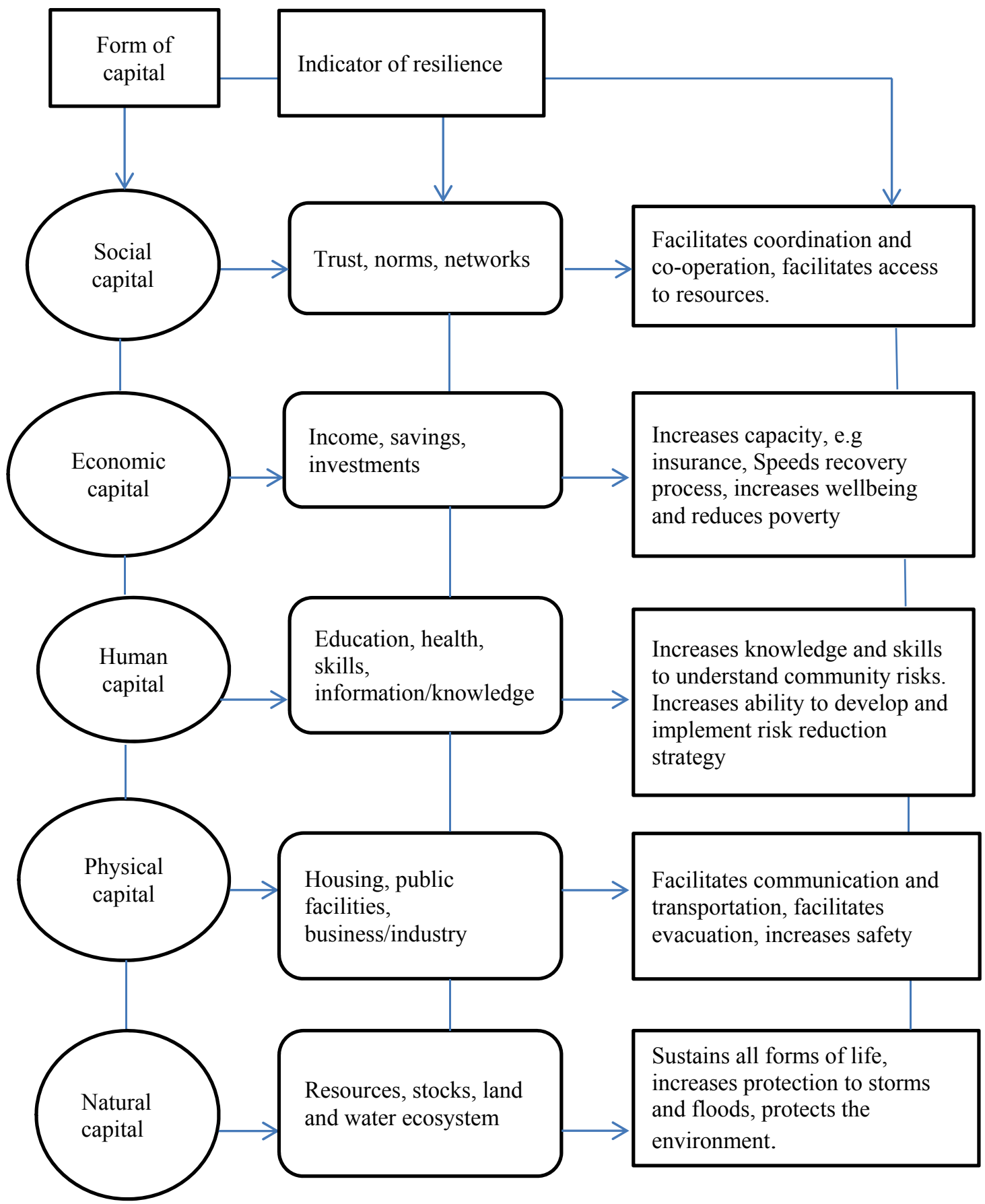

Source: Adapted from Mayunga (2007) 
The major forms of capital particularly social capital have been recognized as important and useful concepts in hazard and disaster fields (Dynes, 2002). Various researches suggest that the community development theory has demonstrated that success and sustainability depend on the ability of a community to appreciate, access, and utilize the major forms of capital (Beeton, 2006). However, capital as a concept has not been acknowledged, and taken as a central focus in understanding and assessing community disaster resilience. The following section defines and discusses the five major forms of capital and how they may reduce vulnerability and increase community resilience (refer also to figure 2.2).

\section{(1) Social capital}

Literature suggests that although social capital has been defined in a variety of ways, there is a common emphasis on the aspect of social structure, trust, norms, and social networks that facilitate collective action (Green and Haines, 2002). TANGO (2006) defines the concept of social capital as features of social organization such as networks, norms, and social trust that facilitate coordination and cooperation for mutual benefit. In the context of community resilience, it reflects the quantity and quality of social cooperation. For instance, community ties and networks are beneficial because they allow individuals to draw on the social resources in their communities and increase the likelihood that such communities will be able to adequately address their collective concerns (Green and Haines, 2002).

Community networks can also provide an external resource that may facilitate the developmental process, especially when social services are being affected such as education for children. The concept of social capital is important because it allows citizens to resolve collective problems more easily. The most resilient communities are those that work together towards a common goal (Davidson, 2006). The idea is that, in circumstances where characteristics of a strong community are missing, members of that community tend to have less capacity to cope with disasters.

Social capital as a source of community cooperation and efficacy can be measured by the number of non-profit organizations, voluntary associations, religious organizations, voter participation and registration, newspaper readership, and sport and recreational clubs operating in the community. Social capital can thus be measured through the activities such as involvement in public affairs, public meetings, informal sociability and trust. Community resilience is determined largely by the capacities 
dependent on social capital (Frankenberger et al., 2013). Research demonstrates that the extent and application of social capital is a crucial element in determining the nature of resilience at the community level (Aldrich, 2012; Wilson, 2012).

\section{(2) Economic capital}

Economic capital denotes the financial resources households and communities use to achieve their economic and social objectives. It includes cash and other liquid resources such as savings, investments, credit, remittances, pensions, etc. (TANGO, 2006). The contribution of economic capital to building community resilience is straightforward in the sense that it increases the ability and capacity of individuals, groups, and communities to absorb disaster impacts and speed up the recovery process. It can be used directly to reduce vulnerability through mechanisms such as the buying of insurance and retrofitting or building protective homes and businesses. This is not the case with communities in the flood plains. They are poor, the sources of livelihood are mainly subsistence and do not have access to formal credit schemes, and therefore do not have the economic capacity to bounce back quickly after a flood disaster. Economic capital is an important determinant of community resilience. For example, the capability of a household to gain access to credit is associated with the level of household preparedness and ability to take protective measures. Communities that have a weak economic capital are mostly unable to send their children back to school after a sudden disaster such as floods. A more stable and growing economy will generally enhance resilience, while an unhealthy or declining economy is an indicator of increasing vulnerability (Oudenhoven et al., 2010). Among other factors, economic capital can thus be measured through household income, property value, employment, petty trade, entitlements and investments (TANGO, 2006).

\section{(3) Physical capital}

Physical capital includes basic infrastructure (e.g., transportation, shelter, energy, communications, and water systems, dams, levees, health facilities, educational facilities, and markets); production equipment; and other material means that enable people to maintain safety and enhance their relative level of well-being (Gill and Ritchie, 2011; Mayunga, 2007). A community's infrastructure systems and other basic services need to operate at a level that provides individuals and groups the means to survive and recover during disasters (Pasteur, 2011). This seems to be lacking for the communities in the flood prone areas in Zambia. Physical capital is one of the most important resources in building capacity of the community to cope with disasters. For 
example, physical infrastructure such as roads, bridges, dams and levees as well as communication and transportation systems are essential for proper functioning of community, especially during evacuation periods. Critical facilities are important to ensure that people have resources and support arrangements during emergencies. In general, lack of physical infrastructure or critical facilities may have direct negative impact on community capacity to cope with disasters. The contribution of physical capital to a community's resilience can thus be measured by the number and quality of infrastructure and whether the available infrastructure supports key services (education, health, safety, economic activity) in the community. Resilience can also be determined based on the accessibility of infrastructure to all members of the community, and community-based mechanisms for maintenance (Frankenberger et al., 2013).

\section{(4) Human capital}

Economists define the concept of human capital as the capabilities both innate and derived or accumulated, embodied in the working-age population that allow it to work productively with other forms of capital to sustain the economic production (Smith et al., 2001). More often, human capital refers to education and includes knowledge and skills that are accumulated through forms of education attainment, training, and experience. Human capital also refers to the health of the working-age population. This means that unless healthy, the population cannot be able to harness other forms of capital (Smith et al., 2001). It also applies to any other advantages people have, including disaster experiences, which gives them the ability to cope with, adapt to, and recover from disasters. For instance, knowledge and skills of individuals on hazards, hazard history, and hazard risk in their community can be an important resource in building community resilience. Human capital is one of the most important determinants of resilience among other forms of capital because it can increase or decrease the efficiency of the other types of capital in resilience-building efforts (Mayunga, 2007; Gill and Ritchie, 2011). Having an adequate, skilled, and trained work force is a prerequisite for economic development and capacity building. This means that the more human capital available in the community, the more the capacity for building resilience. Human capital can thus be measured through education attainment (example, years of schooling), health, population density, population growth, demographic characteristics (e.g., racial and ethnicity), access to transportation services, household characteristics, housing quality, and dependence ratio (Bahadur et al., 2010; Gill and Ritchie, 2011). 


\section{(5) Natural capital}

Natural capital is a community's natural resources: environmental stocks from which resources useful for livelihoods are derived (e.g., land, water, minerals and oil, forest, rangeland, fisheries, wildlife, biodiversity, and environmental services) (TANGO, 2006). Natural capital is essential in sustaining all forms of life including human life. However, human activities are often responsible for the depletion of the stock and quality of natural capital. The quality of water and land may be degraded through the disposal of wastes from factories and consumption by households. Emissions of greenhouse gases from factories and cars can change the composition of the air and contribute to global warming. Therefore, recycling of non-renewable resources such as steel and plastics and renewing resources such as forests and fish stocks are essential for future production and hence community sustainability. In the context of disaster resilience, natural resources such as wetland and vegetation cover play an important role in protecting coastal areas from weather-related hazards such as hurricanes and floods. Several authors have noted that the resilience of a community is directly linked to the condition of the natural environment and the maintenance of productive natural resources (Gill and Ritchie, 2011; Cutter et al., 2008). Resilience at the community level may be affected by an array of factors relating to the quality of natural assets such as water, soil, forest cover, wetlands, pasture, fishery stocks, riverine/coastal habitats and national and local parks.

All the various forms of capital discussed above are important determinants for a community's resilience if acquired and utilized appropriately with all the inherent inter-linkages working together.

\subsection{Summary and Conclusions}

Based on the existing literature on disasters, floods can have an important detrimental effect on the education stock of a country, by affecting complementary infrastructure to education, parents' incentives to send children to get educated and/or increasing the opportunity costs of going to school and disruption in school attendance. These culminate into the temporary or permanent discontinuation of schooling which in turn diminishes educational outcomes. The literature further reveals that the extent to which flood hazards and disasters affect primary education is largely dependent on the vulnerability, coping capacities, and in turn resilience of the affected communities. Vulnerability to the impacts of hazards has social, economic, geographical, political, institutional and cultural dimensions. Income-poverty is said to have a major influence on vulnerability - poor communities are the hardest hit during flood disasters, they 
recover more slowly and most often, never fully regain pre-impact levels, thereby increasing their vulnerability to future hazards. Gender and age are key aspects of the social dimension of vulnerability as women and children tend to suffer disproportionately during disasters.

The extent to which disasters like floods impact on household welfare is intimately related to their capacity to cope with shocks. The scholarly literature reviewed in this chapter explains how decisions made by households before, during and after a flood event do have impacts on the education of the child. While people try to cope in disaster situations, interventions by governments and NGOs are usually still needed to support the affected people especially on issues such as education for school children, which is usually neglected. However, the coping mechanisms employed by households and the complementary interventions by government and NGOs are mostly remedial responses and unsustainable.

Given the positive relationship between vulnerability to shocks such as floods and asset ownership as highlighted by the literature, communities can sustainably manage the effects of floods on primary education by enhancing the communities' assets. These assets (natural, social, human, physical and financial capitals) are essential in building communities' resilience to shocks. Key among these assets in fostering sustainable coping strategies and resilience at various phases of the hazard cycle is social capital. In more resilient communities, the effects of a disaster tend to be less and the recovery process is quicker. The inverse holds in less resilient communities.

Against the backdrop of the above, the following assumptions can be made in line with the research questions:

- Flood disasters will have a negative impact on the state of primary education in the flood prone areas of Zambia as the associated damage to schools infrastructure will disrupt school attendance, encourage dropout rates, drain out resource pillars (qualified teachers) and lower educational attainment, with strong gender disparities in educational outcomes. Apart from those direct impacts, floods also have a significant impact on other socio-economic factors and livelihoods that in turn affect the possibilities of children's primary education 
- In the bid to cope with impacts of floods on household livelihoods and welfare, households in the research area are most likely to use strategies, particularly child labor, that would undermine the education of children.

- To minimize the effects of floods on primary education, the flood prone areas of Zambia need to receive external support from government and NGOs.

In response to the last research question of this study, the concept of resilience and the manner in which people are able to adapt and withstand shocks of disasters based on experiences in other situations will contribute to the debate on how primary school education in Zambia can be made more resilient to floods. Through the insights provided by the reviewed literature, this chapter guided the approaches and helped in shaping the research tools used for collecting field data. 


\section{CHAPTER 3 METHODOLOGY}

\subsection{Introduction}

The previous chapter reviewed the relevant literature on natural hazards and education, and in particular on the general impacts of floods, the intersection between floods and primary education.

The point of departure in the previous chapter was that, a household or community with better educational outcomes has more potential for development and economic growth than a less educated community. This focused further discussion in the direction of the importance of education and what it means when children cannot obtain (quality) education as a result of floods. It was shown that previous research on the general impact of disasters on communities and on education indicates that floods have both direct and indirect negative impacts on children's education due to destruction of school infrastructure, school documents and displacements of children which disrupts their learning and limits their educational outcomes, and through a variety of socio-economic factors. Factors which expose communities to the risk of disasters and how people cope with recurring hazards in other situations/countries was reviewed to support the arguments in the result chapter on household vulnerability and coping mechanisms. A review of literature on interventions by stakeholders and how that helps to mitigate disaster impacts on communities was found useful in the discussion on the effect of interventions on primary school education in Zambia.

This chapter provides a description of the study area and the various approaches, methods and techniques used in collecting the information for the study. Section 3.2 gives a background of the environmental and community characteristics in the area of study. Section 3.3 discusses the layout of the research methods (the design of the study). The research variables and their cause and effect relationships are discussed in section 3.4, while section 3.5 describes the sampling techniques. The specific methods used in the data collection are discussed in section 3.6, and section 3.7 and 3.8 explains how the data was analyzed and reported respectively. Section 3.9 highlights the 
challenges and limitations during the data collection. The last section, 3.10, gives a summary of the methods and some concluding remarks.

\subsection{Description of the Study Area}

The culture, traditional values and livelihoods of the researched communities in the study area is described in this section. The section also provides an overview of the environmental and the ecological characteristics and the overall socio-economic status of the communities. The overview provides insight into the way of life of people in the researched communities, their continued residence in the flood plains and their vulnerabilities; which proved useful in the analysis and discussion of the findings of the study.

\subsubsection{General overview of the flood plain environment in the study area}

The Western Province of Zambia floods every year along the Zambezi River. The river crosses eight countries in Southern/Eastern Africa (Zambia, Angola, Namibia, Botswana, Malawi, Zimbabwe, Tanzania and Mozambique). After rising in NorthWestern Zambia and passing Southwards through Angola, the Zambezi River reenters Zambia in the Western Province and becomes larger and more consolidated, giving rise to a series of flood plains. These include the Barotse flood plain of Western Province (the research area - highlighted in Figure 3.1) and other interconnected areas.

The precise extent of the Barotse flood plain is not easy to determine because annually, flooded areas grade into occasionally inundated parts. Broad estimates put the Barotse flood plain area at approximately 550,000 hectares and the total wetland cover in the region at some 1.2 million hectares (IUCN, 2003). The flood plain is mainly comprised of grasslands with a number of small wooded areas on higher ground, and swamp forests scattered over the area. The Barotse flood plain is flanked by a plateau of Kalahari sand covered in semi-evergreen woodland interspersed with low lying dambos (grass) which are characterized by grassland vegetation. The Liuwa Plain National Park and associated areas to the North West of the flood plain are relatively flat, and are waterlogged during the rainy season while remaining extremely dry during the rest of the year (Timberlake, 1997; Simwinji, 1997). 
Figure 3.1: Map of Zambia highlighting research area

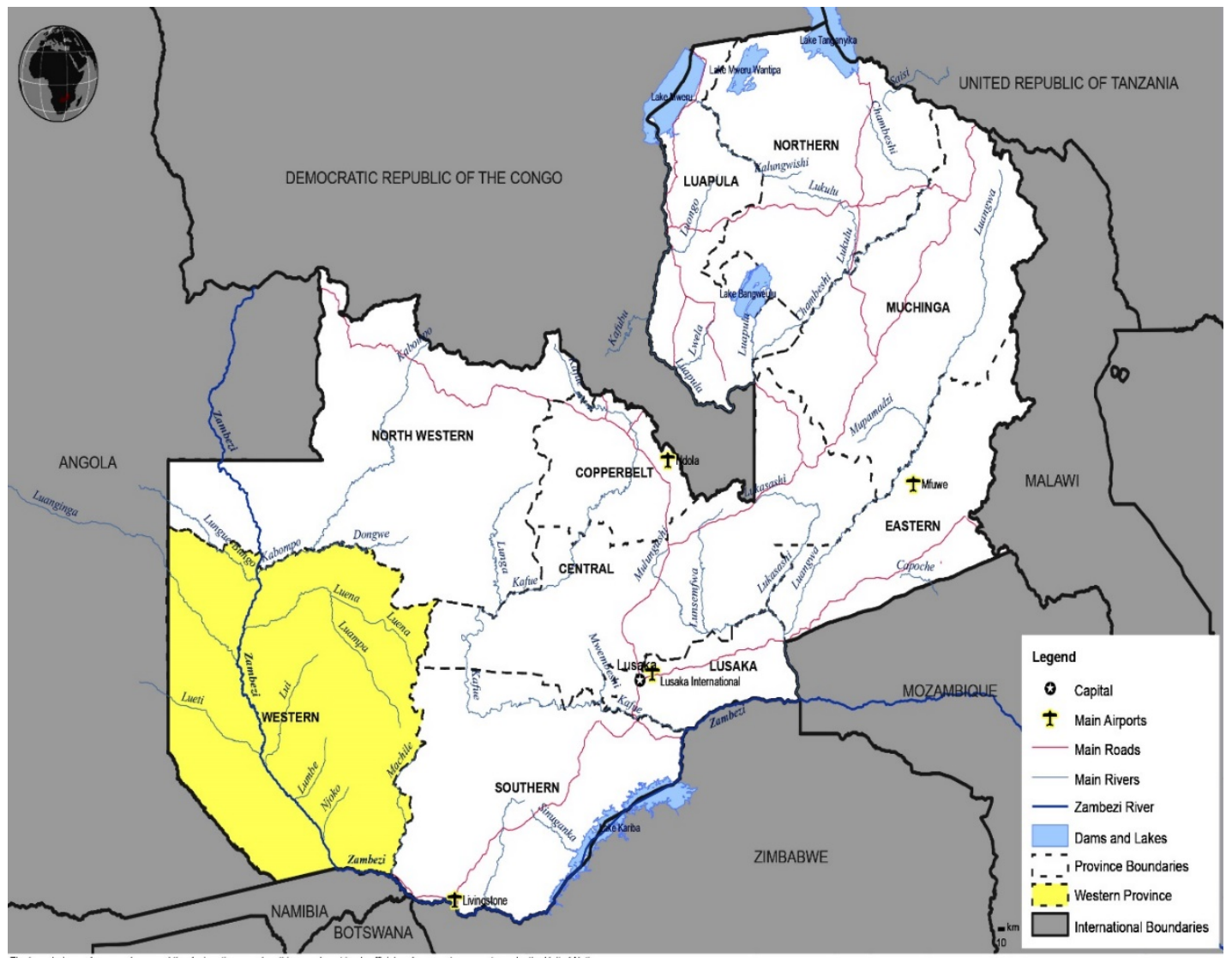

Source: Adapted from UNOCHA Maps, 2013

The ecological characteristics and conditions of the Barotse flood plain, as well as the human production systems it supports, depend largely on the timing and duration of the annual floods. The main wet season runs from November to March, although inundation depends mainly on rainfall in the upper catchment and on seepage from the uplands. The onset of annual flooding varies greatly and may occur anywhere between December and March, although the Northern parts of the flood plain is generally inundated earliest. The highest flood level is attained in April, after which flood waters gradually recede during May, June and July.

In total, the Barotse flood plain is estimated to contain about 1.2 million people. Population density, which is generally low in Western Province with fewer than 5 people per $\mathrm{km}^{2}$, increases sharply around the flood plain. The flood plain area is mainly 
occupied by the Lozi people, and falls under a dual administration - that of the Barotse Royal Establishment under the rule of the King (also known as Litunga) and the government of Zambia through provincial and district line ministries and administrative authorities. The use of flood plain resources was in the past managed according to traditional systems under the customary authority of the Litunga. Today, although formal control over natural resources has been passed over to central and provincial government, the Royal Establishment maintains a great influence on natural resource use patterns and regulations in the region. The Lozi people are also known as the "plains or water people", and local livelihoods and cultural traditions are linked closely with seasonal flooding. During the dry season, the bulk of local production, economic activities and settlement are focused in the flood plain area because it is more habitable and ideal to live, to conduct business and for crop production due to limited water in the plains.

As the plains become inundated, there is mass movement of people from the flood plains to higher grounds during the period of the floods which subsequently affect children's continuation of schooling in the plains. Being a royal community, the King is taken to the upper land in a highly-celebrated traditional ceremony, called the "Kuomboka" meaning "crossing over". This is so because during this period of heavy floods, the environment is not conducive for living. In recent years, the flood situation has become more serious as the water levels and its associated impacts continue to increase compared to previous years. This has become a major concern for communities living in these plains. These communities are highly attached to the area because their forefathers originated from the area and they own the land. This also means that these communities pay less attention to the effects of these movements on the children's education, thereby undermining its importance.

\subsubsection{Socio-economic status of the studied community}

Most of the population in the Barotse flood plain depends on a mixed livelihood strategy, combining crop farming, livestock keeping and fishing. This diversity of livelihood components, many of which depend on wetlands, is an effective strategy for spreading risk since income and subsistence sources vary at different times, especially according to season. The rural economy is for the most part subsistence-based, and is subject to high levels of uncertainty and variability. About 76 per cent of the rural population in Western Province lives in poverty, and lean months are November to 
January/February when incomes are lowest, expenditures highest due to scarcity of food and some non-food items.

Almost all of the flood plain population is involved in crop farming. Of the total area under arable agriculture (280,000 hectares) in Western Province, about 10 per cent is comprised of flood plain farming systems (IUCN, 2003). The main growing season in the flood plain is between November and April, with maize, rice, sweet potatoes, sugar cane, fruits and vegetables being produced as the main crops. Flood plain farming systems are diverse and include raised gardens (Lizulu), rain-fed village gardens (Litongo), seepage gardens (wet Litongo), drained seepage gardens (Sishango), lagoon gardens (Sitapa) and riverbank gardens (Litunda).

Most of the cattle in Western Province are found along the Zambezi flood plain and adjoining plains, and the Barotse flood plain is known to be one of the most productive cattle areas in the country. Over three quarters of cattle in Western Province are pastured in the flood plain, including 265,000 heads that belong to flood plain residents (IUCN, 2003). The bulk of herds are managed under a system of transhumance (the act of moving livestock from one place to another for grazing) and move between the flood plain and adjacent upper lands, usually spending January to July in the flood plain and the remainder of the year in the upper lands. Primarily driven by the seasonal availability of pasture, annual transhumance is also important for the distribution of manure, and in the flood plain there is a strong interaction between herding, cropping and fishing activities.

The fisheries sector is one of the most important sectors in Western Province, and is mainly concentrated in the flood plains of the upper Zambezi, especially the Barotse flood plain. Over half of the flood plain population is engaged in fishing activities. Fish is an important source of protein, and local fish consumption in the study area is five times the national average. Bream make up 80 per cent of the catch, and a number of smaller fish are also caught such as minnows, tilapia, bottle nose and silver barbells. Fishing is a highly seasonal activity. Between December and April, fish move from the main river channels into the wetlands, where they spawn before the height of the flood. As the floodwaters rise, a phenomenon called "red waters" occurs, whereby low oxygen water is pushed forward by the floods. Only barbell can survive in such water. The main fishing season takes place as the floodwaters recede, and gill nets are used in the lagoons created by the floods and in which fish are concentrated. This activity 
intensifies from May until December, when fishing stops in anticipation of the rains. When the flood plain becomes fully inundated, fish is mainly caught using traditional maalelo traps, as well as with normal traps and spears.

The flood plain population also uses a wide range of wetland plants, animals and natural resources for their daily subsistence and income. About 95 per cent of households harvest grass, reeds and papyrus for use in house construction, thatching, mat and basket production, broom making and fishing apparatus construction. Clay is also important, used for house construction and pottery making. Although the loss of many of the flood plain's wild mammal populations has meant that hunting has decreased over time; turtles, birds and birds' eggs form an important supplement to local diets.

\subsection{Study Design}

Since the primary goal of this thesis is to investigate the impact of floods on primary school education in Zambia, a review of the school records data was done and interviews conducted comparing communities with similar socio-economic status (those affected by floods and those not affected by floods) in a 5 years period: 2008 2012 (these two sets of communities live side by side with the occurrence of floods in one community and not in the other being the fundamental difference among them). This, together with the other components of the research questions - investigating communities' vulnerability factors and how they cope with children's education in the flood plains; stakeholder interventions and their effects on children's education during floods; and how primary education in Zambia can be made more resilient to the impact of floods (based on experiences / lessons drawn from the study area) - informed the research design. Hence the flood plains in the Western Province of Zambia have been used as a case study.

A case study design is been used because it is an empirical inquiry that investigates a contemporary phenomenon within its real-life context and allows the use of multiple sources of evidence to collect information (Yin, 2008) to explain the "cause-and-effect" relationship of a situation. Yin (2003) refers to this notion as the "theoretical logic" or "theoretical replication" applied in generalizing results obtained from multiple sources. In this research, various sources of data have been used that provided evidence which has guided the outcome of the study. 
The research was conducted using both qualitative ${ }^{3}$ and quantitative ${ }^{4}$ methods. The basic premise behind using a mixed methods research design is that the combination of both approaches (qualitative and quantitative) provides a more comprehensive and convincing evidence, and in turn a better understanding of a research problem than using only one approach alone (Guest et al., 2013). This integration of methodological approaches strengthens the overall research design, as the strengths of one approach offset the weaknesses of the other. Though the research focused primarily on investigating the impact of floods on the flood plain communities based on perceptions of the respondents and observation, it was found useful to have a control group to substantiate information provided by the respondents on the effect on educational outcomes.

Phenomenology, which is a research method that concentrates on the study of consciousness and the objects of direct experience was the primary qualitative approach applied in this case study design to describe the first hand, "lived" experiences of the study population on how floods impact education of primary school children. The quantitative inquiry was done using a comparative analysis of school records from the sampled primary schools in two communities (those affected by floods and those not affected by floods) and the Ministry of Education (MoE) to determine the state of primary school education in flood prone areas.

\subsection{Variables of Interest}

Based on the problem statement, the state of primary school education, as measured through enrolment rates, repeating rates, dropout rates, and quality of education are the dependent variables. The quality of education is reflected in school infrastructure, access to schools, quality of teachers, access to learning materials and pupils' performance in national examinations.

The main independent variable is the incidence and extent of floods. The various ways in which floods affect the dependent variables was measured. Although other variables/factors such as poverty, household incomes and literacy rates within the community could affect the state of primary school education in flood prone areas in

${ }^{3}$ Qualitative method is an exploratory method of inquiry employed to gather an in-depth understanding of human behavior and the reasons that govern such behavior. It investigates the why and how of decision making, not just what, where, when (Denzin and Lincoln, 2005).

${ }^{4}$ Quantitative method is the systematic empirical investigation of social phenomena via statistical, mathematical or numerical data or computational techniques (Given, 2008). 
some other ways and were therefore given due attention, and are also discussed in the analysis of the results of this study, the focus of this research is the direct and indirect effect of floods on the state of primary school education. In this regard, the study took sample units from the flood plains and upper lands, with the latter, forming the control group of equally low socio-economic indicators as the flood plains but without flood exposure within a five-year period. Unfortunately, hard statistical data on the social indicators for both groups was not available and the selection of and ultimately the inferences on both groups was therefore based on interviews and observations.

\subsection{Sampling}

Since the qualitative component of this research is mainly based on lived and conscious experiences, a purposive sampling technique was adopted to select the study area and "information - rich" participants who have detailed knowledge or direct experiences relevant to the impact of floods on primary school education within the community investigated. The area is prominent for floods effects and there is a presence of several organizations and government officials who could provide relevant information for the study.

The main respondents therefore consisted of selected male and female members of the sampled community (school going children, local authorities and parents), officials in the selected primary schools, key officials from relevant government departments and NGOs who have a direct involvement with the community, especially in the area of primary education, and other individuals who have lived or been educated from the community that were able to provide relevant information for the study. The selection of the respondents was based on a description of the type of respondents needed and in consultations with local authorities, head teachers and some government officials. A total number of ten schools within the sampled community in flood affected areas and ten schools in non-flood affected areas (as presented in table 3.1) were selected and primary school records data from the selected schools were reviewed and analyzed. The ten schools from each community were found sufficient in providing information representing the situation in the flood plain. 
Table 3.1: Flood affected and non-flood affected schools in 5 years period (2008 to 2012)

\begin{tabular}{|l|l|}
\hline Schools affected by floods & Schools not affected by floods \\
\hline Lealui & Mulambwa \\
\hline Malabo & Mabumbu \\
\hline Nakaywe & Limulunga \\
\hline Makuku & Imwiko \\
\hline Ngombala & Tungi \\
\hline Salondo & Mukoko \\
\hline Lyaluo & Mupatu \\
\hline Nangole & Malengwa \\
\hline Ngulumani & Kasima \\
\hline Salunda & Katongo \\
\hline
\end{tabular}

Source: Author

The sampled communities are located along the flood plains or close to the plains (upper lands), with primary schools that have been affected by floods and those that have not been affected during the reviewed period. A total number of 60 households that have had primary school children attending school or have dropped out during the period under review were selected from the sampled community. The first half of the selected communities consisted of households that have been affected by floods and the other half consisted of households that have not been affected by floods during the last five years.

Table 3.2: Data collection sample frame

\begin{tabular}{|c|c|c|}
\hline Sample type & $\begin{array}{l}\text { Sample } \\
\text { size }\end{array}$ & $\begin{array}{l}\text { Sampling } \\
\text { method }\end{array}$ \\
\hline $\begin{array}{l}\text { Households with children in primary schools affected and not affected } \\
\text { by floods ( } 5-10 \text { years) }\end{array}$ & 60 & $\begin{array}{l}\text { Purposive } \\
\text { sampling }\end{array}$ \\
\hline $\begin{array}{l}\text { Local authorities (community leaders) from communities affected and } \\
\text { not affected by floods }\end{array}$ & 10 & $\begin{array}{l}\text { Purposive } \\
\text { sampling }\end{array}$ \\
\hline $\begin{array}{l}\text { Senior government officials at MoE of the District Commissioner, } \\
\text { DMMU, NGOs, Community Based Organizations working in the } \\
\text { sampled area (both affected and not affected by floods) }\end{array}$ & 20 & $\begin{array}{l}\text { Purposive } \\
\text { sampling }\end{array}$ \\
\hline Primary schools in flood affected and non-flood affected areas & 20 & $\begin{array}{l}\text { Random } \\
\text { Sampling }\end{array}$ \\
\hline
\end{tabular}

Source: Author 
Moreover, ten local authorities from the two communities were interviewed to provide relevant information on the state of primary education in their respective communities. Furthermore, officials from government, the United Nations, NGOs and civil society that have been providing support to the sampled communities were selected and interviewed. Similarly, key officials were selected from primary schools that have experienced floods between 2008 and 2012 and those that have not. The described sampled communities, authorities and officials were instrumental in providing answers to the research questions.

\subsection{Data Collection}

In order to provide specific and generalized answers to the research questions, the following data collection methods and techniques were used: focus group discussions, key informant interviews, informal interviews and participant observations, transect walks and school records/documents review. The general principle as described by Wertz (2005) was that of minimum structure and maximum depth, constrained by time and opportunities to strike a balance between keeping a focus on the research issues and avoiding undue influence by the researcher. The establishment of a good level of rapport and empathy was critical in gaining depth of information, particularly when investigating issues where the participant has a strong personal stake.

A key quality in data collection by phenomenologists is concreteness (Wertz, 2005). It was ensured that details of the person's lived situation rather than their abstract views or interpretations were collected in an effort to access the person's lived experience (which goes beyond what they have consciously thought about). The aim was to empathize with the participant's situation and offer further prompts geared to exploring existential dimensions of the situation. Table 3.3 provides a schematic structure of the data collection techniques and instruments that have been used. 
Table 3.3: Schematic presentation of data collection techniques and instruments

\begin{tabular}{|c|c|c|c|c|}
\hline Techniques & Composition & Size & $\begin{array}{l}\text { Number } \\
\text { of } \\
\text { groups }\end{array}$ & Tools \\
\hline $\begin{array}{l}\text { Focus Group } \\
\text { discussion }\end{array}$ & $\begin{array}{l}\text {-Elderly men } \\
\text {-Elderly women }\end{array}$ & 9-10 for each group & $\begin{array}{l}3 \times 2 \\
3 \times 2 \\
\text { Total }=12 \\
\text { groups }\end{array}$ & $\begin{array}{l}\text {-Interview guide (10-15 } \\
\text { open-ended questions, } \\
\text { with detail discussions). } \\
\text {-Prompting/Probing } \\
\text {-Note taking } \\
\text {-Tape recording }\end{array}$ \\
\hline $\begin{array}{l}\text { Key } \\
\text { Informant } \\
\text { interviews }\end{array}$ & $\begin{array}{l}\text { Heads of Households, Local } \\
\text { Authorities, MoE, District } \\
\text { Commissioner's office, } \\
\text { DMMU, NGOs, United } \\
\text { Nations, Community Based } \\
\text { Organizations, Teachers, } \\
\text { Church leaders, school } \\
\text { children }\end{array}$ & $\begin{array}{l}20 \text { individual } \\
\text { interviews, } 1 \text { interview } \\
\text { per person and } 10 \text { for } \\
\text { school children ( } 5 \text { in } \\
\text { each set of community) }\end{array}$ & N/A & $\begin{array}{l}\text {-Interview guide or semi- } \\
\text { structured questionnaire. } \\
\text {-Interactive discussions } \\
\text {-Prompting/Probing } \\
\text {-Note taking } \\
\text {-Tape recording }\end{array}$ \\
\hline $\begin{array}{l}\text { Informal } \\
\text { Interviews }\end{array}$ & $\begin{array}{l}\text { Various people within the } \\
\text { community, officials from } \\
\text { government, NGOs, schools, } \\
\text { fishermen and people in } \\
\text { fishing camps. }\end{array}$ & $\begin{array}{l}\text { A total of } 10 \text { informal } \\
\text { interviews for both } \\
\text { communities on a one to } \\
\text { one basis or in groups } \\
\text { were completed. }\end{array}$ & N/A & $\begin{array}{l}\text {-Spontaneous discussions } \\
\text {-Story telling } \\
\text {-Note taking } \\
\text {-Tape recording when } \\
\text { possible }\end{array}$ \\
\hline $\begin{array}{l}\text { Participant } \\
\text { observations } \\
\text { / Transect } \\
\text { walks }\end{array}$ & $\begin{array}{l}\text { This was done throughout } \\
\text { the research period and } \\
\text { relevant information } \\
\text { recorded }\end{array}$ & N/A & N/A & $\begin{array}{l}\text {-Observations and note } \\
\text { taking }\end{array}$ \\
\hline $\begin{array}{l}\text { Document } \\
\text { review }\end{array}$ & $\begin{array}{l}\text {-Registers, test scores, } \\
\text { records on school } \\
\text { assets/learning material and } \\
\text { other relevant documents } \\
\text { from schools and MoE. }\end{array}$ & $\begin{array}{l}10 \text { schools for each } \\
\text { community (affected } \\
\text { and not affected by } \\
\text { floods for the last } 5-10 \\
\text { years.) }\end{array}$ & N/A & $\begin{array}{l}\text {-Review of class registers } \\
\text { to gather information on } \\
\text { enrolment rates, } \\
\text { completion rates, dropout } \\
\text { spells and length of } \\
\text { attendance. } \\
\text {-Review of test scores } \\
\text {-Review of performance } \\
\text { in national exams. } \\
\text {-Review of quality of } \\
\text { community schools in } \\
\text { affected or not affected } \\
\text { areas }\end{array}$ \\
\hline
\end{tabular}

Source: Author 


\subsubsection{Focus group discussions}

A total number of twelve focus group discussions were held from the selected 60 households. The focus groups were derived from a set of people who share common characteristics relevant to this study. The respondents were clustered into two main groups: households that have experienced floods and have had children that attended flood-affected schools in the 5-years period and those that did not experience floods. For each of these clusters, respondents were further clustered thus: elderly men and elderly women. The respondents selected have good experience about the subject under investigation and were very comfortable to speak freely within their gender groups than when mixed. The selected cluster members have comparable social status which helped to determine the validity of the information and not influenced by differences in status. Each group or cluster had between 9-10 people which formed a very good discussion forum.

The selected focus groups were engaged in in-depth discussions that were guided by the researcher. A discussion guide with about 10 - 15 open ended questions was used, but a whole range of issues were discussed outside the guide. Notes were taken during the discussions, but a tape recorder was also used to ensure that the whole discussion was captured which was very helpful in confirming certain issues or key facts that were not sufficiently captured in the notes during the discussions. The group interaction was very helpful in providing further insights into shared experiences on floods impact, factors that make the communities vulnerable to floods, effects of the coping mechanisms of flood affected families on primary education, interventions by stakeholders and suggestions on how to make education resilient in flood prone areas. The researcher ensured that every member of the group had an opportunity to share their views while guiding the discussions, and permitted free exchange of information and discussions. It was also ensured that the inputs and opinions of every member of the cluster was valued and taken into consideration and the respondents were allowed to interact and exchange views and generate consensus or disagree on certain issues.

\subsubsection{Key informant interviews}

Twenty (20) in-depth interviews with key informants were conducted. Key informants were drawn from heads of households (men, women from the selected 60 households), local authorities, relevant senior government ministries, school authorities and NGOs who have direct involvement with the community as described in the section "sampling". The key informant interviews were done using a discussion guide or a 
semi-structured questionnaire with open-ended questions from a set of topics. Openended questions allowed the informants to answer from their own frame of reference rather than being confined by the structure of pre-arranged questions. This allowed informants to express their thoughts more freely. Prompting and probing was also done to clarify certain concepts, elicit details and extend the narrative discussion. The interviews were kept as interactive as possible to create a rapport, and care was taken to avoid the use of judgmental language. This proved helpful in gathering and recording detailed information to answer the research questions.

An environment that ensured openness and reliability of information was obtained. This was done by creating trust and being friendly to the respondents letting them know that they are not accountable for the outcome of the research and that the outcome will hopefully be a positive move towards improving their lives. The key informant interviews brought out more detailed information and respondents were much more comfortable to open up and discuss issues in depth than when in a group.

\subsubsection{Informal interviews}

In many researches, informal interviews are usually conducted at the early stages of the development of an area of inquiry, where there is little literature describing the setting, experience, culture or issue of interest and can also be used to uncover new topics of interest that may have been overlooked by previous research (Cohen and Crabtree, 2006). In informal interviews, the researcher talks with people in the field informally, without use of structured interview guide of any kind (Cohen and Crabtree, 2006). While in the field as a researcher, informal interviews are often casual conversations one could have with the people that are researched, in which case only jottings or brief notes are recorded and more detailed notes are taken afterwards. The researcher followed the recommendation of Cohen and Crabtree, which was found helpful in gathering a lot of information without the respondent being subjected to a formal data collection process.

It was noted that information obtained from informal interviews seemed to be more reliable and more accurate than information obtained from formal interviews. This was because the respondents were more relaxed and spoke more freely. Informal interviews do not require scheduling time with respondents, so interviews took place everywhere and at any time. The informal interview exercise took the form of "story telling" or a normal conversation and it was very useful in picking out very important 
facts to triangulate certain information collected by other methods, or to complement and provide more details relevant to the study. It was also noted that the nature of collecting information from an informal interview made provision for building a rapport with the respondents and in the process gained their trust as well as their understanding of the subject, situation or setting. It was difficult to tape-record the interviews because they were not planned. Detailed field notes were developed after every informal interview.

\subsubsection{Participant observations}

Participant observations which helped to understand the way of life of the community, the culture and traditions, the level of development in the community, the various activities and interactions with stakeholders, and the way the community cope with children's education during and after flood disasters, was part of the data collection techniques and was carried out throughout the data collection period. Marshall and Rossman (1989) defined participant observation as "the systematic description of events, behaviors, and artifacts in the social setting chosen for the study" (See also Dewalt and Dewalt, 2010:262). The nature of primary schools and the attitudes of teachers, children and parents towards primary education were observed and noted. The information gathered through participant observations was useful in complementing information obtained from the interviews and discussions. With this method, data was collected in a natural environment which engaged a complete natural behavior.

\subsubsection{Document review}

One of the very important techniques used in the data collection that provided quantitative data on school records was document review. Corbin and Straus (2008) defined document review as a systematic procedure for reviewing or evaluating documents - both printed and electronic (computer-based and internet transmitted) material. Like other analytical methods in qualitative and quantitative research, document analysis requires that data be examined and interpreted in order to elicit meaning, gain understanding and develop empirical knowledge (Corbin and Straus, 2008). The document analysis yielded data - that were then organized in a certain form and analyzed.

From the twenty selected primary schools, documents such as class registers were reviewed over a 5 years period to determine the state of primary school education. This 
includes data on enrolment rates, dropout rates, repeating rates and length of stay in primary school. Similarly, a review of other school records such as test scores, grades of national examination and capacity of teachers helped to determine the quality of primary education for children in flood prone areas. Several other documents in the schools and from the MoE that had information relevant to the study were reviewed and analyzed to assist in validating the results of the research.

\subsection{Data Analysis}

Being a research of mixed methods, data collection and analysis was interactive and complementary. Analysis of the data was going on simultaneously with the data collection process. According to Wetz (2005), an early attempt to start analyzing data as it is collected provides avenue for further inquiry to develop additional data. Detailed notes were taken during the data collection period and the information obtained was translated and transcribed on a daily basis to facilitate the analysis. The raw data was summarized and categorized and the categories grouped into umbrella elements. These were then commented on as themes of the interviews. Furthermore, the constant comparative method was also applied, which is a commonly used analytical approach in qualitative research. In this form of analysis, various sources of data were reviewed line by line in detail, provisional themes noted and comparison was made to see if information obtained from the different sources is consistent and also to identify negative cases. This form of analysis helped in enhancing an organized and consistent flow of information that made the analysis and reporting much easier. The school records data were analyzed and a comparison was made between the two situations to determine the variation and effects of floods on the state of primary school education.

\subsection{Reporting}

Assertions developed from the phenomenological findings using the above mentioned data collection techniques and comparative analysis of the flood affected areas and the non-flood affected areas needed to be done diligently to have validity; in particular, the researcher wanted to ensure that the reader is able to work through from the findings to the analysis and reporting, and see how the interpretations and conclusions were arrived at. The findings of this research have been reported for each chapter under 3 main headings; an introduction; results and discussions; and summary and concluding remarks. 


\subsection{Constraints during Data Collection}

The whole process of data collection was not completely free from constraints. Challenges were faced due to several factors. The following paragraphs discuss the key challenges and limitations including strategies that the researcher applied to overcome them;

The period of data collection took much longer than originally planned. Data collection was initially planned for 9 months, but took about 1.2 years to complete. Part of the data collection period occurred during the rainy season when access to the flood plains was difficult due to heavy rains, muddy roads and long distances. About 50 per cent of the schools in the flood plains could not be accessed by vehicles even during the dry season. For these schools, the researcher had to travel on foot from community to community to collect the data. This process took a lot of time and was very tiring. However, several days at each point in time was spent with the communities in the field instead of travelling back and forth from the city to the villages. This was very helpful in engaging the communities even more in the evening hours and was particularly useful for the informal interviews and holding meetings to plan for the following day.

Another challenge faced was the difficulties in organizing focus group discussions. Getting 9-10 targeted people from the community in a focus group discussion was not an easy task. In the process of trying to get the group together to discuss the questionnaire, the people asked a lot of questions about the research. For instance, they were interested to know why they were being interviewed, how will the information they provide change their situation, who has sent the researcher to ask them questions, what would the researcher provide for them? The people in this community are very suspicious of outsiders collecting information from them. Sometimes they view researchers as humanitarian workers who conduct needs assessments that are followed by relief aid. There was a clear tendency for communities to exaggerate the situation being researched, so as to ensure that the situation is seen as dire and to prompt the provision of aid in large quantities. After the first two experiences of focus group discussions which took a very long time to accomplish, the researcher took extra time to sensitize the people on the purpose of the research, pointing out that the recommendations that will be generated could be useful for government policy making that can be beneficial for them and for their children in the long run. The sensitization exercise was initially planned to take place during the group discussion, but that had to change because of the digression and delays experienced. Instead, introductory 
meetings were first held with the local authorities and opinion leaders within each community to inform them about the research and data collection process, and to seek their approval for interviews and discussions with community members. This was instrumental for the community's understanding, acceptance and participation in the research interviews. It was also ensured that each focus group discussion and key informant interviews started with an overview of the research, clearly spelling out its intent and purpose. These preliminaries meant extra time which affected the total period allocated for the data collection.

Some government officials were not very comfortable to discuss certain elements of the questionnaire openly because they see the honest responses as some form of criticism of the government and they could be reprimanded if it is known that they have provided such information. For instance, the ineffectiveness of the government to respond to the floods disasters was an issue raised by many of the respondents but they were very careful with what they said or how they commented on this. The researcher assured respondents (particularly key informants and those involved in the informal interviews) of confidentiality through the use of number codes to identify respondents instead of their names. Confidence was also built when respondents were assured that the information collected is purely for research purposes and no one will be quoted for any information provided. The fact that the outcome of the research might be useful for government planning purposes, policy development and decision making was also reiterated.

The group discussions at the community level needed an interpreter because most people could not speak proper English. An interpreter had to be hired, which was very expensive. Nevertheless, it was felt that the information was not flowing in verbatim. There was a suspicion that the interpreter was not relaying the information as it was given on both sides. Sometimes, some questions had to be repeated twice, but in a different way, just to ensure that the respondents understood what the question was about and that the right information was being communicated. A lot of probing and repetition on some of the questions was necessary to gather the required information in detail. This process also took extra time, but was very useful in ensuring that the responses were of the required detail.

An attempt was made at the initial stages of the data collection to tape-record every conversation during key informant interviews and focus group discussions. At a certain point, it was realized that the respondents were very conscious of the presence 
of a tape recorder. They considered some of the discussions sensitive and did not want their voices to be heard or even quoted by names. Besides, it took a lot more time trying to set up the recorder and the overall management of the tape-recording was cumbersome. In fact, for informal interviews, it was even more unpleasant to use a tape recorder. Since informal interviews occurred "on the fly", that is, it could happen at anytime, anywhere and under whatever situation, it was not appropriate and conducive to tape-record this type of interview. Therefore note taking instead of tape recording became the preferred medium for documenting the interviews, although some interviews were still recorded whenever possible. Data collection was focused on careful listening and note taking. To ensure accuracy in the data recording process, the data collection scripts were transcribed at the end of each day, making detailed notes whilst the information is still fresh in the researcher's mind and conversations / events can be easily remembered. With the daily transcription of the data, it was also possible to go back to the respondents immediately to clarify certain conversations if not very clear from the notes. This helped in ensuring that all the information provided by respondents was captured.

The difficulty in getting reliable data on school records from the schools in the flood plains was another limitation of the study. Due to continuous relocation of people and the schools being affected by the flood waters, most school documents were destroyed and registers were not available in the schools. Though some records were obtained, the data was incomplete at the school level. This had to be complemented by data obtained from the provincial education office, which keeps school records data of all the schools in the province. The researcher then had to get whatever information that was available in the schools and complemented it with information obtained from the ministry.

Information on the total population of school going children in schools within the communities under investigation was not possible to obtain because some children move from one community to attend school in another community for various reasons. If the total population of school going children in each community was known, it would have been possible to determine how many children do not go to school at all. It should have been interesting to find out if floods were the main reason why those children do not enroll in school. The researcher then had to use proportions to determine rates of enrolment, dropout and repeating rates based on the total number of children in the schools over a 5 years period. This worked very well in portraying 
the effects of floods on primary school education comparing schools in the flood plains with schools in the upper land.

Performance data in the national examinations for the ten schools in flood affected areas was not available on a school by school basis because national examinations are taken at selected school centers where children from different schools come together to do the examinations in one school location. This is done primarily to ease work for government officials who conduct the examinations so as to limit the number of staff needed and also to limit the number of places to travel to. Besides, the number of children in a school who take the national examinations in the flood plains is small and therefore it is cost effective and easier to bring them together. All the children in the ten schools in the flood plains took their examinations in three centers. Performance data was therefore analyzed using three school centers in flood prone areas and three school centers in non-flood prone areas.

\subsection{Summary and Concluding Remarks}

The Zambian flood plains have both positive and negative effects on the people because of their livelihood characteristics and the cultural and traditional heritage. The focus of this research was to investigate how the yearly floods impact on the education of primary school children.

The study was designed using the Zambezi River basin of Western Province (study area) as a case study. Both qualitative phenomenological methods and quantitative comparative methods were applied in data collection. Two sets of communities within the same area were selected; those affected by floods and those not affected by floods within a 5 years period (2008 - 2012). Sampling was then done purposively to select "information rich" participants who could provide information needed for the study. The main respondents were selected male and female school going children, teachers, local authorities and parents. Officials from government and NGOs who work with the communities were also selected for providing information. Ten schools from each of the two sets of communities were selected to collect data on the state of primary education.

A number of challenges were encountered during the data collection which delayed the process. However, the researcher developed initiatives to overcome the challenges. For instance, during the rainy season, the roads were muddy and cars cannot reach the villages. The researcher had to work on foot and stayed in the villages for considerable 
periods. Other challenges were the unavailability of proper records at the schools, the language barrier and the difficulty encountered in setting up the focus groups. Also there was a lack of solid quantitative data on the area's socio-economic and wider background variables. Instead, the research had to depend on qualitative data collection methods and observations to gain those insights.

In conclusion, using case study for the research design enhanced a thorough analysis of the impact of floods on primary education while the use of mixed methods in collecting information enhanced complementarity. The perspectives of the people interviewed and the observations made by the researcher were used to validate the results obtained from school records, but also to determine the effects of stakeholder interventions on primary school education and how education can be made resilient in the flood plains. The use of purposive sampling techniques targeted people who have the knowledge and understand the situation under investigation. They were able to provide the required information for the study.

The results of the investigation are reported in the following sequence; Chapter 4 discusses the different parameters on how floods impact primary school education and chapter 5 explains factors that expose the communities to the risk of floods effects and how the communities cope with children's education. Chapter 6 describes the effects of stakeholder interventions on primary education and chapter 7 highlights some policy recommendations on how education can be made resilient in the flood plains based on the views of the respondents interviewed, literature search and the opinions of the researcher. The annexes have been configured based on the chapters they represent. For instance, annex 3 and its subsequent sections represent reference information used in chapter 3 and annex 4 does the same and so on. 


\section{CHAPTER 4 THE IMPACT OF FLOODS ON PRIMARY EDUCATION IN ZAMBIA}

\subsection{Introduction}

The previous chapter described the study area and the various methods and techniques used in collecting the data to answer the research questions. The flood plain of Western Province of Zambia (Barotse Plain) was used for the empirical research. Both qualitative phenomenological and quantitative comparative methods were used for data collection.

This chapter sets out the first findings from this empirical research, starting with the impact of floods on primary school education in the study area. Section 4.2.1 identifies floods effects on the welfare of the communities and the associated impact on the education of school children. The nature of school infrastructure and its effects has been described in Section 4.2.2. This section further discusses flood effects on the rate of school enrolment, the rate at which children repeat classes, dropout rates, the nature and quality of teachers in the flood plains and the performance of pupils in national examinations. The chapter ends with a summary of the findings and some concluding remarks.

\subsection{Results and Discussion}

\subsubsection{Effects of floods on the welfare of flood plain communities}

Floods have both positive and negative effects on communities in the flood plains. On the positive side, flood waters are good for agricultural production due to the high level nutrients that come with the water and due to the fact that irrigation is not necessary during the planting season. The water is also good for grazing animals because the fields are very green with enough fodder for animals.

With regards to the negative effects of floods, when flood levels are higher than $2.5 \mathrm{~m}$ above ground level, they can cause destruction to properties, homes, schools, health facilities, and crops. In the words of a school teacher at the Malabo primary school, "the 
flood waters sometimes come with crocodiles which attack and kill human beings and there are also many cases of snake bites. In total, the Malabo community recorded 12 snake bites with 2 deaths from the snake bites during the 2009 floods". Furthermore, the water sources (mostly hand dug wells) may become polluted due to overflow of flood waters from pit latrines into water wells causing diarrhea, respiratory tract infections, cholera and other water borne diseases which causes high rates of child mortality and high death rates for adolescents and elderly people.

Lives and properties can be lost through boat accidents as communities try to evacuate the flood plains during floods. During this period, animals such as crocodiles may attack people crossing the flood waters. One of the respondents (an elderly woman in Malabo) gave a harrowing account of how a crocodile attacked and killed a 7 years old girl when a boat capsized during evacuation to the upper land in 2010. Apart from the incidents of crocodiles, when a boat overturns, people who cannot swim sometimes get drowned if not rescued quickly.

Another negative effect that may be caused by floods is the destruction of health facilities. When floods destroy health facilities, all medical equipment and medicines are destroyed, making it impossible for people to get any form of treatment and the result is usually death. This situation may be further exacerbated by the difficulty to access the upper land during peak flood periods when the flood waters are high. HIV/AIDS patients as well as pregnant women (especially those with complications) usually do not receive treatment during that period as all health facilities are flooded and therefore not functional; causing deterioration of their health status and in some cases causing their death.

As mentioned by one of the groups, "flooding periods are associated with food insecurity and high rates of malnutrition due to the destruction of crops by the floods, coupled with the lack of access to markets in the upper land after all food reserves have been lost in the floods". Food insecurity may last for months and even a whole year if there is no intervention from the government or humanitarian organizations through the provision of relief aid. Children particularly become malnourished, sick and die.

People who manage to evacuate the flood plains for the upper lands are placed in camps with limited facilities. During their stay, the displaced persons are supported by the government and/or NGOs during that period for their sustenance, although that 
support is mostly not sufficient and the conditions in the camps are not favorable. They usually stay in the camps for three to six months depending on the intensity of the floods. The longer they stay, the more difficult the situation becomes, since immediate relief supplies would have been exhausted and the government or humanitarian agencies do not provide continuous support to the displaced communities. The lack of support in the latter months prompts the displaced people to undertake activities that will enable them generate income. Most often, it is at this stage that parents exploit every available labor in the family, even including that of children, in the bid to support the home. Children are sent out to work or undertake petty trading for the upkeep of the home.

\subsubsection{Effect of floods on primary school education}

\subsubsection{School infrastructure and learning materials}

The effects of floods on primary education in the Western Province of Zambia are described through its destruction of school infrastructure and learning materials. With 30 per cent (shown in table 4.1 ) of the sampled primary schools in the flood plains being

Table 4.1: Nature of basic infrastructure of flood affected and non-flood affected schools

\begin{tabular}{|l|l|c|c|}
\hline \multicolumn{2}{|c|}{ Basic Infrastructure } & $\begin{array}{c}\text { Flood Affected } \\
\text { Schools }\end{array}$ & $\begin{array}{l}\text { Non-Flood Affected } \\
\text { Schools }\end{array}$ \\
\hline \multirow{2}{*}{$\begin{array}{l}\text { Class } \\
\text { Room } \\
\text { Type }\end{array}$} & Temporary & 3 & 0 \\
\cline { 2 - 4 } $\begin{array}{l}\text { Toilet } \\
\text { Facilities }\end{array}$ & Permanent & 7 & 10 \\
\cline { 2 - 4 } & Permanent VIP latrines & & 2 \\
\hline \multirow{2}{*}{$\begin{array}{l}\text { Water } \\
\text { Sources }\end{array}$} & Flushing toilets & 6 & 8 \\
\cline { 2 - 4 } & Unprotected wells & $60 \%$ & 4 \\
\cline { 2 - 4 } & Piped water & $40 \%$ & $0 \%$ \\
\hline Energy & Electricity supply & $0 \%$ & $50 \%$ \\
\hline
\end{tabular}

Source: Author's observations and survey data 
built out of makeshift thatched structures, these schools are easily washed away and completely destroyed when flood waters become high. Although the remaining 70 per cent of the schools sampled are made of concrete, yet parts of the school structures are usually destroyed by heavy floods. During floods, school documents and learning materials get wet and damaged, making them unfit for further use. School records are therefore lost. The time spent in rebuilding the damaged school structures is often long and without the interventions from the government and/or humanitarian organizations, it take months or even a year to rehabilitate since the repair work will have to depend on communities' contributions which is most times meagre. The prolonged reconstruction period disrupts learning and sets the school children backwards.

Due to the fact that schools built in the flood plains are most times destroyed by floods, it is difficult for government to continue spending money on rebuilding or repairing those schools and in some cases the government does not invest in building a school at all. This makes it difficult for the community to ensure that a proper school is available for the children. Most schools in the flood plains lack the basic facilities that schools in the upper lands have. For instance, the sampled primary schools in the flood plains have no electricity, no proper sanitary facilities and no safe water supply. The available furniture is usually not in good condition. The nature and quality of the school affects the children's motivation for schooling and the teachers alike are not motivated to teach in schools with such conditions. This reduces the learning outcomes of the children.

The recurrent floods adversely affect primary education in its role in rendering most if not all of the roads in the flood plains impassable and in turn making the schools inaccessible to most pupils. Some children travel by road from their hamlets to go to school in nearby villages within the flood plains. During the period of floods, roads in the study area become impassable, limiting movement within the community mainly through the use of boats. School going children commute to school by means of boats, which are not always readily available. Although most families own boats, it is worth mentioning that boats are mostly used for fishing and to a small extent in transporting children to school. Therefore, when it floods and the roads are inaccessible, most pupils in the flood plains do not go to school until the road become accessible again. The pupils' absence from school translates into them failing to complete the curriculum per academic year and thereby causing them to perform poorly in the school examinations and repeating one or more classes. The repetition of class (es) frustrates the children 
and lowers their interest in school which sometimes lead to permanent discontinuation of schooling.

The inaccessibility of roads due to floods does not only influence school attendance, but also affects the distribution of teaching and learning materials to schools in the flood plains by the MoE. During the rainy season (flood periods) the supply of these materials gets delayed. Owing to the fact that most of the schools in the flood plains get damaged by floods, the MoE avoids stocking of school materials and supplies in these schools during the dry season as reserve for the rainy season because when the floods are heavy, the reserved school materials get destroyed. The lack of school materials during the rainy season even when schools are in session, affects the learning process. Floods also affect the visits of officials from the MoE who normally visit to monitor progress in the schools and sometimes to conduct examinations. Such monitoring visits become difficult during the floods period as the roads are not easily passable for about four to seven months depending on the intensity of the floods.

\subsubsection{Primary school enrolment}

In addition to the damage to school infrastructure, floods have also been found to affect the total number of students who properly register and attend classes in primary schools. In absolute terms, total enrolment was much lower in flood affected schools compared to non-flood affected schools. As illustrated in Figure 4.1 - a histogram comparing total enrolment of children in ten sampled primary schools in the flood plains and in ten sampled non-flood affected schools-, the number of children that enrolled in the latter was about 75 per cent higher than in the former. In the absence of accurate population data especially for the remote flood plain communities and the fluidity of the school age going population, such that children from one community sometimes attend school in other communities; it was impossible to determine the exact proportion of school going children in each community. However, the tenor of the histogram indicating that relatively more children do enroll for schools in the upper land than in the flood plains, is corroborated by qualitative information. This difference in enrolment between flood affected and non-flood affected schools is attributed, apart from possible disparities in population density, to the financial capability of parents to send children to school, value attached to education by communities, physical access to school by children, teachers and government officials, nature of school infrastructure and the general atmosphere in which the children go to school, all of which are again affected by the floods. As discussed in section 4.2.2.1 (flood effects on primary school 
infrastructure), the conditions in which children go to school are a lot better in the upper land than in the flood plains.

Figure 4. 1: Total enrolment for the 10 flood affected and 10 non-flood affected primary schools

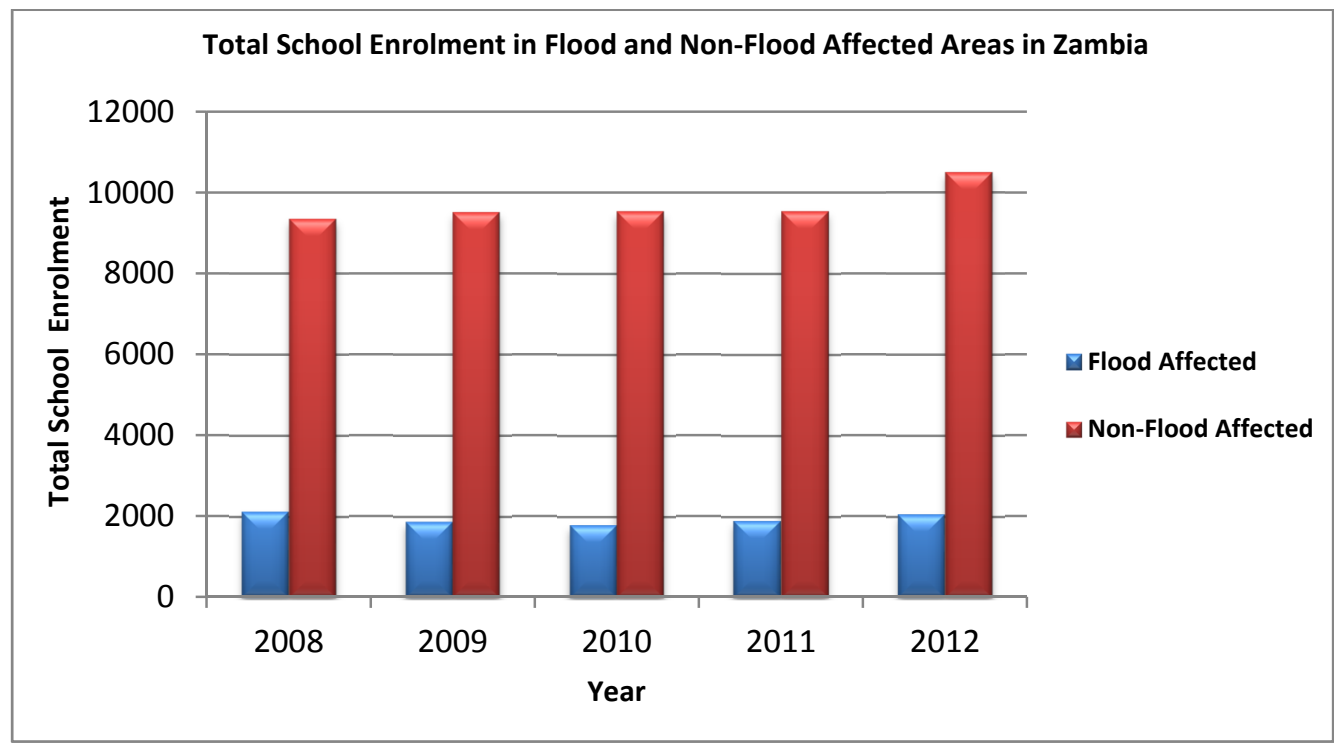

Source: Survey data

The findings further reveal a sharp contrast between flood affected and non-flood affected schools in terms of the rate of enrolment based on the class grade levels. As depicted in figure 4.2, enrolment in flood affected primary schools was highest in the early grade levels of 1 and 2, but decreased with higher grades. For instance, during the period under review (2008 - 2012), grade 1 accounted for 21 per cent of the total enrolment, while grade 7 accounted for only 9 per cent of the total number of pupils that enrolled. However, in the non-flood affected areas, total school enrolment during the last 5 years showed very little variation irrespective of the grade levels. The rate of enrolment was almost constant for all seven grade levels in the different schools, with 15 per cent enrolment in grade 1 and 14 per cent enrolment in grade 7.

The observed enrolment pattern in flood affected schools is due to the fact that the financial commitment to education is usually minimal during the early stages of schooling; encouraging almost every parent to send their children to school. Furthermore, the children in these lower grades are usually tender in age and are therefore not expected to contribute towards the upkeep of the household in terms of 
labor and income, hence their being enrolled in school. However, as the children grow older and move to higher grades, the cost of books, uniforms, clothes and other school necessities increase, making it difficult for parents to cope. This, coupled with the fact that at higher grades (between grades 4 and 7), most children become more engaged in income generating activities to contribute towards sustaining their families, explains the lower enrolment rate in higher grade levels in flood affected schools.

Figure 4.2: Rate of enrolment in flood affected and non-flood affected primary schools

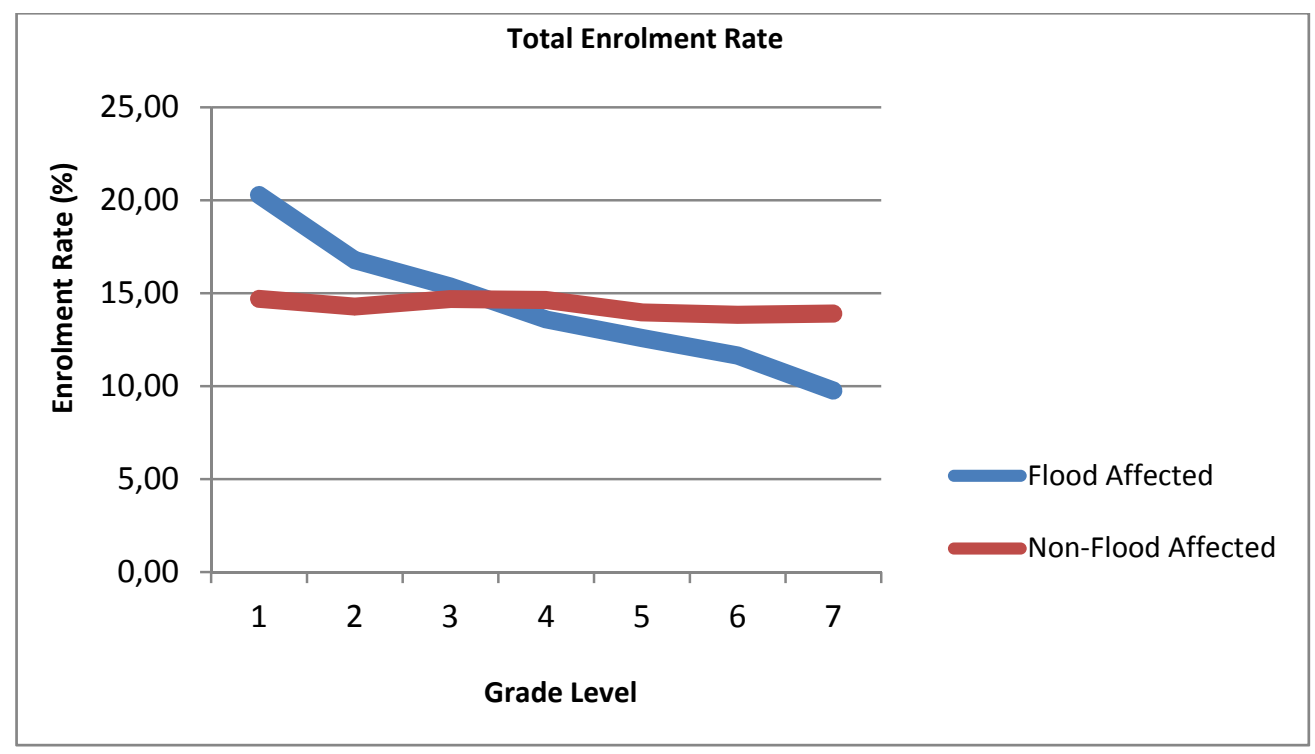

Source: Survey data

Within the framework of enrolment, the effects of floods on the age of children at first enrolment, the length of stay and the age of children at completion of basic education was further determined. The research data reveals that 50 per cent of children in flood affected areas are first enrolled in school when they are above 7 years old, and in turn completing basic education (grade 7) when they are over 14 years. This contrasts with what was obtained in non-flood affected areas where the bulk (about 80 per cent) of the total number of children enrolling in primary schools for the first time are younger than 7 years. Similarly, about 84 per cent of these non-flood affected school children complete basic education before their $14^{\text {th }}$ birthday (Annexes $4.3,4.4$ ).

With regards to gender, the research findings as depicted in figure 4.3 confirm that floods have no significant effect on what gender enrols the most in primary schools. In flood affected areas, the pattern of enrolment for the female child was found to be the 
same as that of the male child, whereby the higher the school grade, the lower the enrolment of both genders. Similarly, enrolment of male and female school children in the sampled non-flood affected schools shows no significant difference in all seven classes.

Figure 4.3: Enrolment rate disaggregated by gender for each grade in flood affected and non-flood affected schools

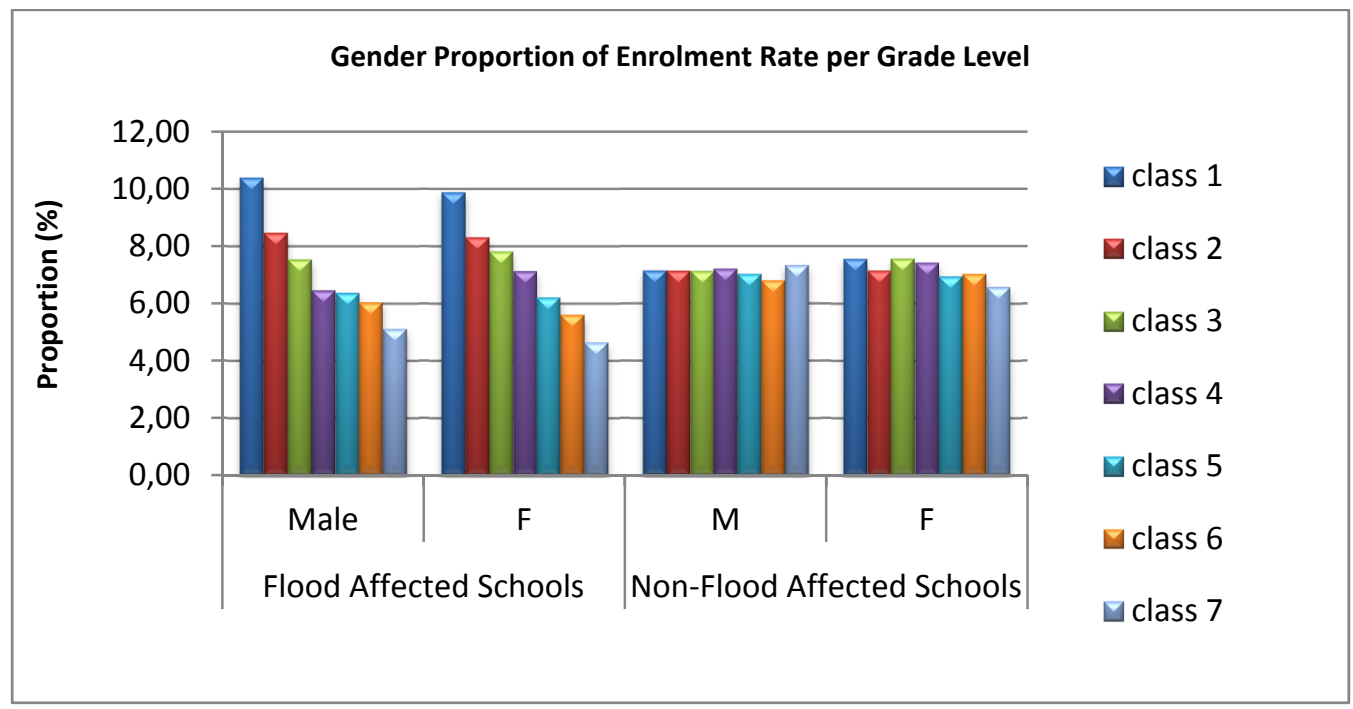

Source: Survey data

\subsubsection{Rate of repeating in primary schools}

Another effect of floods on primary education is manifested in the rate at which children repeat grades due to the disruption of learning caused by floods effects and other associated problems. To determine how floods influence class repetition, the research data collected on class enrolment and class promotion was analysed to deduce the number of repeaters per class, per school and per year. Figure 4.4 is a graph that shows the average annual rate at which children repeat classes, comparing aggregated data for grades $1-7$ in floods affected schools with those for non-flood affected schools over the 5 years period. The graph indicates a strong correlation between floods and the annual rate of repeating in primary schools as more pupils repeated classes in flood affected schools than in non-flood affected schools during the period under review.

Unlike the non-flood affected schools where the average annual repeating rate was only 3 per cent, flood affected schools experienced a 9 per cent rate of repeating 
annually. In other words, the rate of repeating classes in primary schools was 3 times higher in flood affected areas than in non-flood affected areas. Figure 4.4 further reveals that the annual repeating rate in flood affected schools was at its peak in 2009, and then gradually decreased in subsequent years. Superimposing this trend of repeating against the flood data for Zambia showed that the year in which repeating was highest in the flood plains coincided with the heavy and high intensity floods of 2009 (Annex 4.12). Qualitative data obtained from key informants confirmed that the heavy flood of 2009 was one of the worst floods experienced in Zambia in over 40 years. It took long for the flood waters to recede thereby causing most children not to attend school for a very long period during that year (6 months: from December to May). The pupils' long absence from school translates into them failing to complete the curriculum per academic year and thereby causing them to perform poorly in the school examinations and repeating one or more classes.

Figure 4.4: Repeating rate per year in 10 flood affected schools and 10 non-flood affected schools

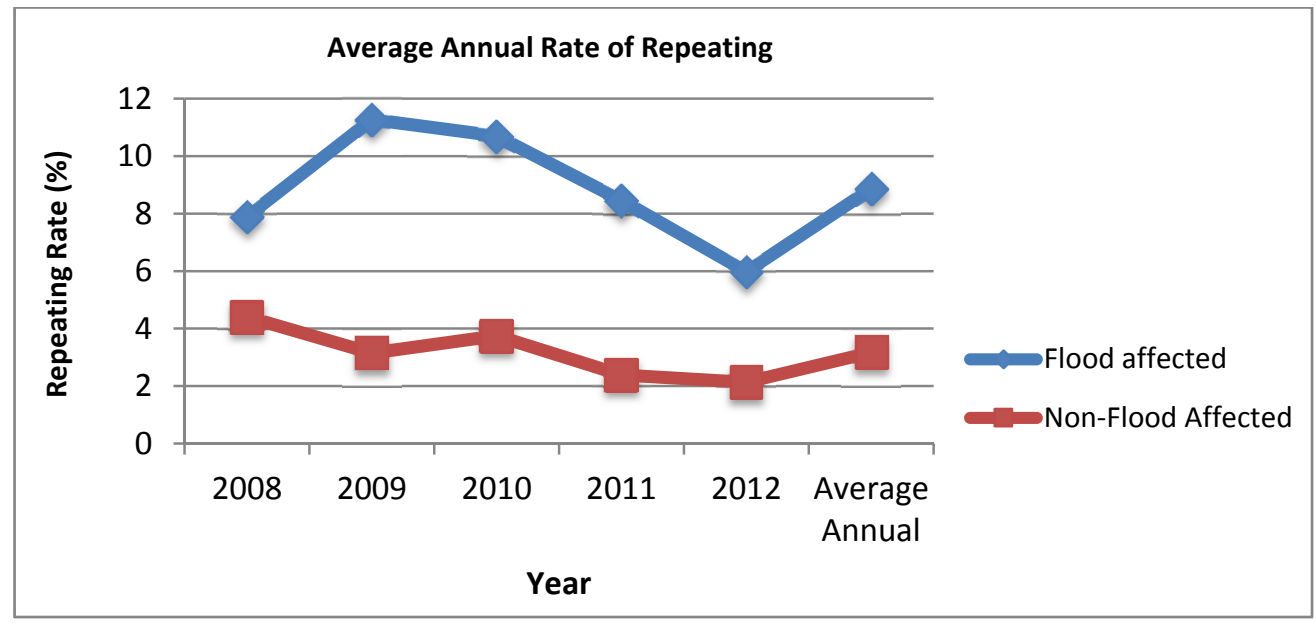

Source: Survey data

After a severe flood in 2009, it took the flood affected schools about 3 years to bring the average annual repeating rate below the rate experienced before the floods in 2008 . The slow drop in the annual rate of repeating after floods is attributed to the fact that it took the flood affected families several years to completely recover from the effects of the 2009 floods. This implies that (high intensity/magnitude) floods have a long lasting negative effect on the rate of repeating classes in primary schools and in turn, education. Although 2010 also had a relatively high floods intensity, the shock of 
communities experiencing such a high flood magnitude in 2009 after so many years meant they were less prepared for such a shock and therefore the effect in 2009 was more severe than 2010 .

Further investigations and analyses of the annual repeating rate demonstrated that the high rate of repeating in flood affected schools was triggered by the corresponding higher rates of repeating in especially the lower class grades of 1 and 2. As illustrated in figure 4.5, almost half of all the pupils who repeated between 2008 and 2012 in flood affected schools (that is 4.6 per cent of the annual repeating rate of 9 per cent) were found to be pupils from grades 1 and 2 . The repeating rate dropped between grades 3 and 6 , but sharply increased in grade 7 . The stark contrast in the rate of repeating between the flood affected and the non-flood affected schools in Zambia is also confirmed by this figure. Qualitative data from key informant interviews and focus group discussions with parents, teachers and the children highlighted the major flood related effects that are responsible for high repeating rate in flood affected schools. These include inaccessible roads leading to schools, the height and coldness of the flood waters which is usually at knee height for adults and chest level for children, the fear of drowning and / or being attacked by crocodiles and snakes; which discourages parents from sending especially their younger children (in lower class grades) to school. Most parents only send these children back to school when the situation completely normalises. In some instances, parents keep the younger children home for the rest of the year on the pretext that the children are still very young, having more time to catch up in school and therefore could afford to skip a school year. This is associated with lower grade school children in the flood plains to repeat at a much higher rate. 
Figure 4.5: Repeating rate by grade for 10 flood affected schools and 10 non-flood affected schools

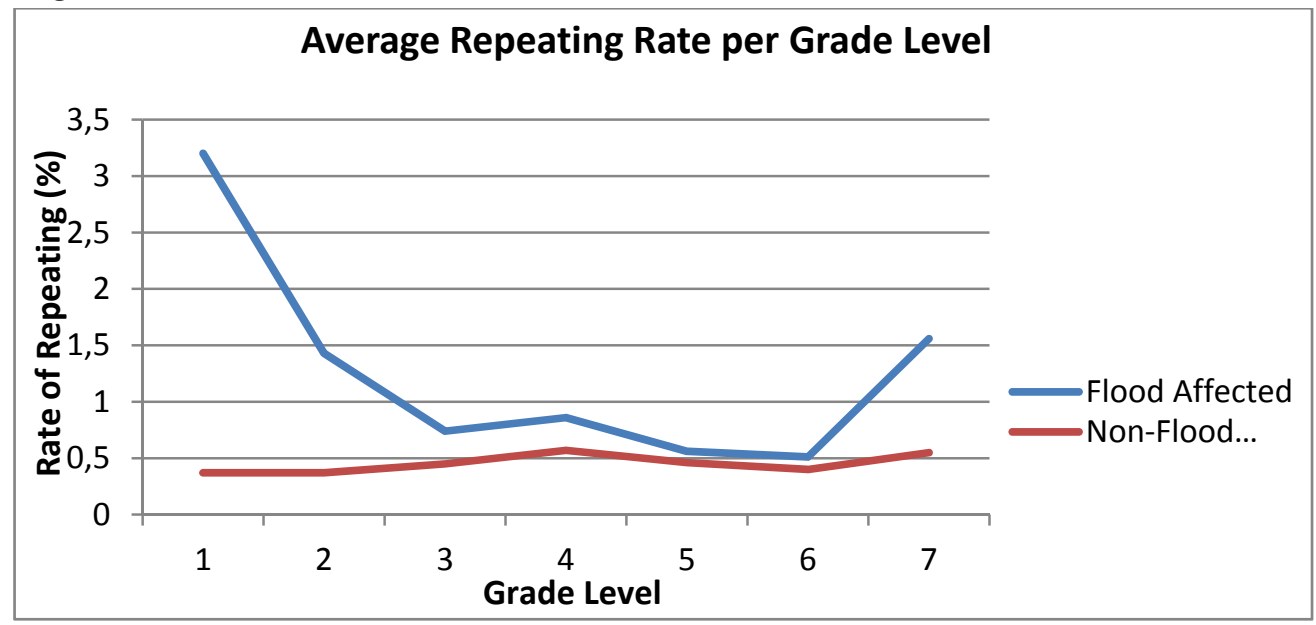

Source: Survey data

The increased repeating rate observed in class 7 in the flood plains is mainly associated with the fact that most pupils in the flood plains are over 14 years by the time they reach grade 7 , and are considered old enough to contribute to the upkeep of their families, they become more engaged in income generating activities. It is at this stage also that the girls become more engaged in emotional relationships which often distract their attention in schooling.

Contrary to the above, the axis for the repeating rate in the non-flood prone areas is almost flat with slight variations between classes (Figure 4.5). The repeating rate was much lower for all grades in the non-flood prone areas, ranging from 0.37 per cent to 0.57 per cent. The situation in the upper land is more stable, children have ample time to study and parents do make effort to provide extra support to children at home such as helping them with homework. With no floods to affect children's education in the upper land, the few children who repeat classes are either weak in terms of intelligence or have other limitations that are not flood related.

Due to the frequent disruption of schooling caused by flood incidences, repeating rates are generally much higher in the sampled flood affected schools than the non-flood affected schools. The more children repeat grades, the more they become de-motivated and lose interest in schooling. This in turn increases the chances of them dropping out of school. 


\subsubsection{Dropout}

Dropout refers to the permanent discontinuation of schooling by pupils. Dropout in primary schools is one of the most tangible and glaring manifestations of flood effects on education. To examine the contemporary patterns of dropout in relation to floods, the researcher examined quantitative data on school enrolment, attendance and discontinuation. Based on the fact that the flood plain population is a fluid one - in that children displaced by floods from one community can temporarily or permanently relocate to another school in a different community-, permanent discontinuation of schooling was analysed through the following.

First, the researcher used national school enrolment registers from the MoE at the district level. These registers contain enrolment data per class, year and by gender for all communities within the district, making it easier to track school transfers, temporary and permanent dropout levels. This process was followed by an analysis of enrolment and attendance registers from the respective sampled schools in the study area (flood plains and the upper land). Information obtained from key informant interviews within the sampled school (head teachers and parents) was then used to triangulate the data obtained on dropout rates from the above mentioned sources. The analysed data provided a profile of the average annual rate of dropout among primary school children in flood and non-flood affected schools, the classes where children dropout the most and the gender disparities as shown in figures 4.6, 4.7 and 4.8 respectively. 
Figure 4.6: Dropout rate per year for 10 schools in flood affected and 10 schools in non-flood affected areas

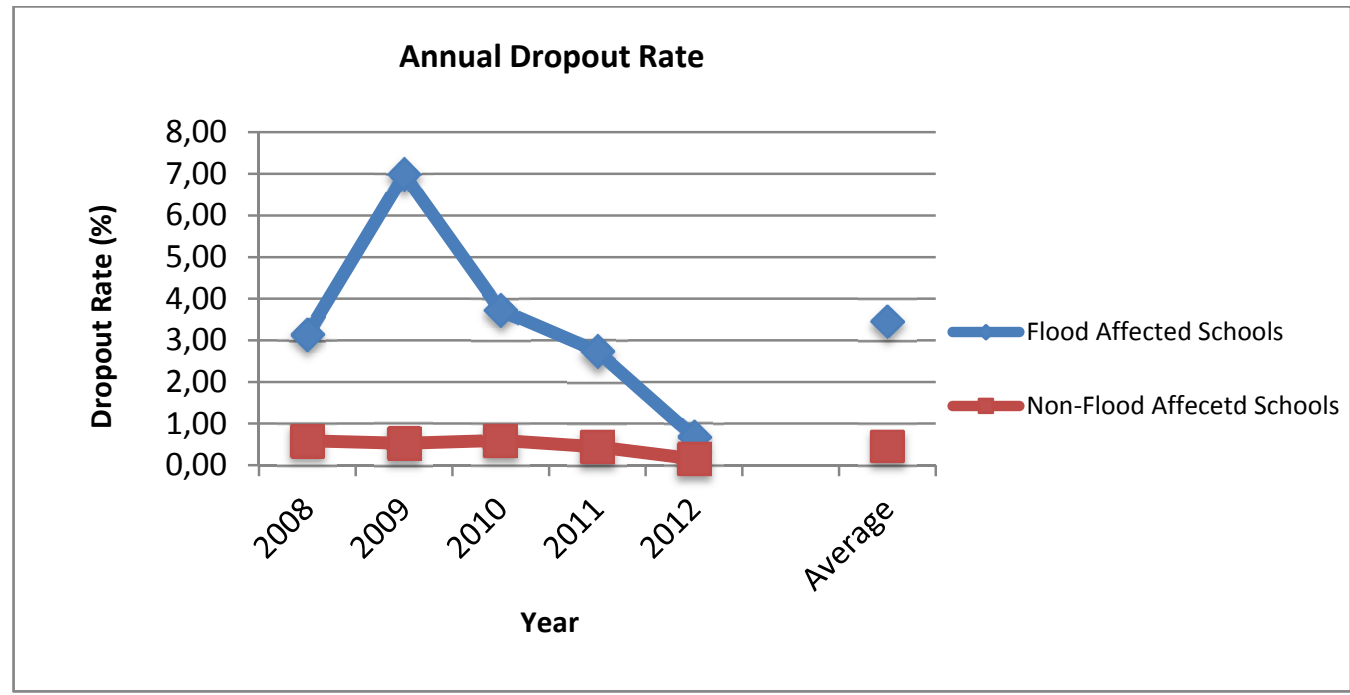

Source: Survey data

As shown in figure 4.6, dropout is more pronounced in flood affected primary schools than in the non-flood affected primary schools, as the former experienced an average dropout rate of 3.5 per cent annually compared to 0.46 per cent dropout rate recorded in the latter. Similar to repeating rates (described in section 4.2.2.3), the average annual rate of dropout between 2008 and 2012 was 3 times higher in flood affected schools. Moreover, during this period, the highest rate of dropout in the flood plains was experienced in 2009, whereby dropout sharply increased from 3 per cent in 2008 to 7 per cent in 2009 and then gradually declined in subsequent years. The massive floods in 2009 after several years of a lesser intensity disrupted education so badly, that many children in the flood plains dropped out of school that year. In the upper land however, the rate of dropout was negligible, ranging from 0.6 per cent to 0.15 per cent between 2008 and 2012. The sharp contrast in dropout rates between flood affected and nonflood affected schools; together with the pronounced increase in dropout rates in 2009 when the flood plains experienced one of its strongest flood incidences over the last 40 years, confirms a strong correlation between floods and the rate of dropout among primary school children.

The damage to school infrastructure and learning materials; inaccessibility of roads and schools; prolonged disruption of schooling; increased rate of repeating classes and 
in turn prolonged length of stay in schools in the flood plains; coupled with increased food insecurity and other socio-economic effects of floods that drain household resources; translates into the high rate of dropout observed among primary school children in flood affected areas in Zambia. These research findings are consistent with Achoka and Maiyo (2008) who investigated the effects of the Budalangi floods on education in Kenya. They associated the high dropout rate among children affected by floods with the challenges and difficulties faced by pupils in accessing schools, forcing them to discontinue schooling and engage in income generating activities among others.

Having established the pattern of annual primary school dropout rates in flooded and non-flooded communities, the research further assessed the rate of dropout at each grade level in order to determine the stages where dropout is highest in primary schools. As depicted in figure 4.7, the highest rate of dropout among flood affected primary school pupils occurred in the seventh grade, accounting for more than half (1.78 per cent) of the average dropout rates of 3.46 per cent observed each year. Also prominent is the high dropout rates among grade 1 pupils in flood affected schools.

Figure 4.7: Dropout rate per grade for 10 schools in flood affected and 10 schools in non-flood affected areas

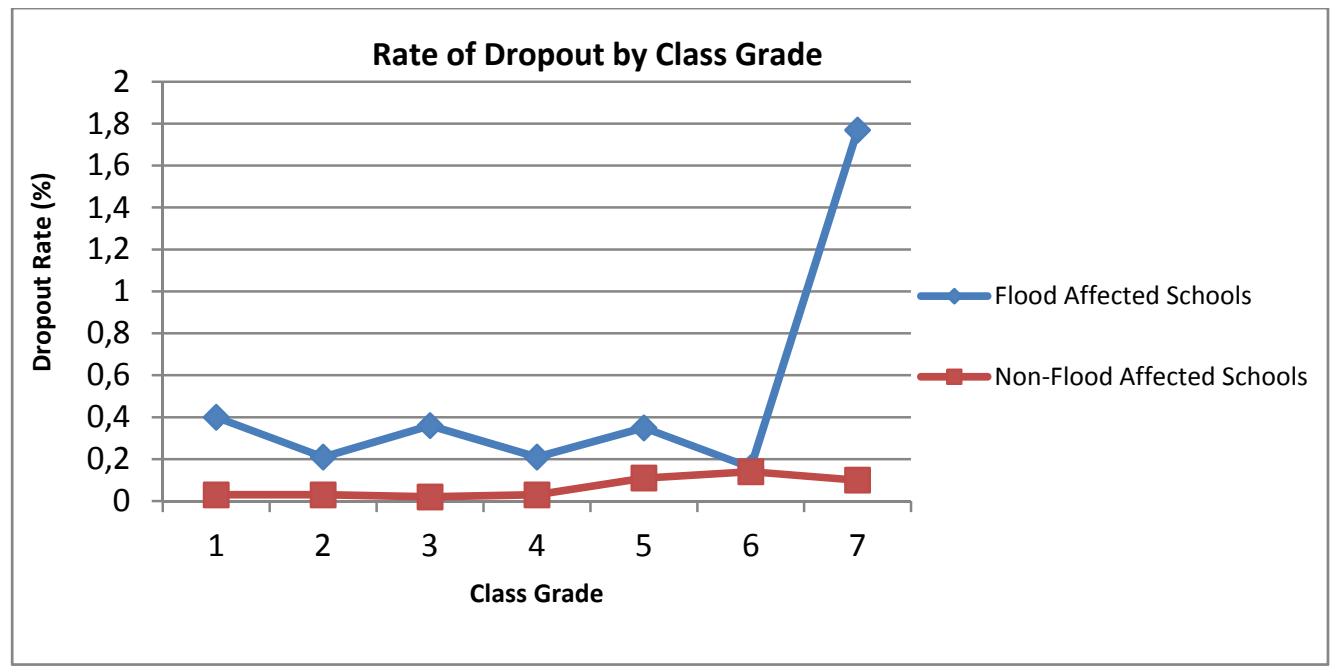

Source: Survey data 
The fluctuation observed between grades 2 to 6 in flood affected schools is associated with the incidence of floods. Higher dropouts are envisaged during years of heavy floods and lower dropouts during years of less or no floods. Compared to flooded communities, dropout in the non-flooded communities was almost negligible for the first four grades, but increased slightly between grades 5 and 7 . The increased dropout rate observed in class 7 in the flood plains is mainly associated with the absence of secondary schools in these areas. This, coupled with the fact that most parents lack the financial capability to sponsor their children's higher education in the upper lands (non-flood affected areas) reduces the child's interest in school as she/he approaches the end of basic education in grade 7. Furthermore, since most pupils in the flood plains are over 14 years by the time they reach grade 7 , and are considered old enough to contribute to the sustenance of their families, they become more engaged in income generating activities. It is at this stage also that the girls become more engaged in emotional relationship which often distracts their attention from schooling.

The research further disaggregated the data on primary school dropout by gender so as to ascertain the gender that is mostly affected by floods in terms of dropout. The data as shown in figure 4.8, highlights that dropout in flood affected areas is most prominent among female pupils especially in grade 7 . Unlike dropout rates among grade 7 male pupils which ranged around 6 per cent, dropout rate was as high as 21 per cent among the females. The non-flood affected areas however revealed less gender disparity in relation to proportion of dropout. The pattern of dropout among male pupils is similar to the dropout patterns among their female counterparts.

According to qualitative data obtained from interviews and focus group discussions, high incidences of pregnancy and marriage were the two main factors responsible for the high level of dropout recorded among girls in the flood plains. The high rate of dropout among girls in the flood plains was also attributed to girls being more challenged by the effect of floods. For instance, girls find it more difficult or impossible to paddle canoes to school. Similarly, poor sanitary facilities like flooded toilets, poses a serious constraint to girls; making it hard for them to adequately take care of themselves especially during their monthly menstrual flow. This causes girls to be more absent from school. In the words of a key informant (head teacher of a 
Figure 4.8: Cumulative dropout rate per grade for 5 years disaggregated by gender in flood affected and non-flood affected areas

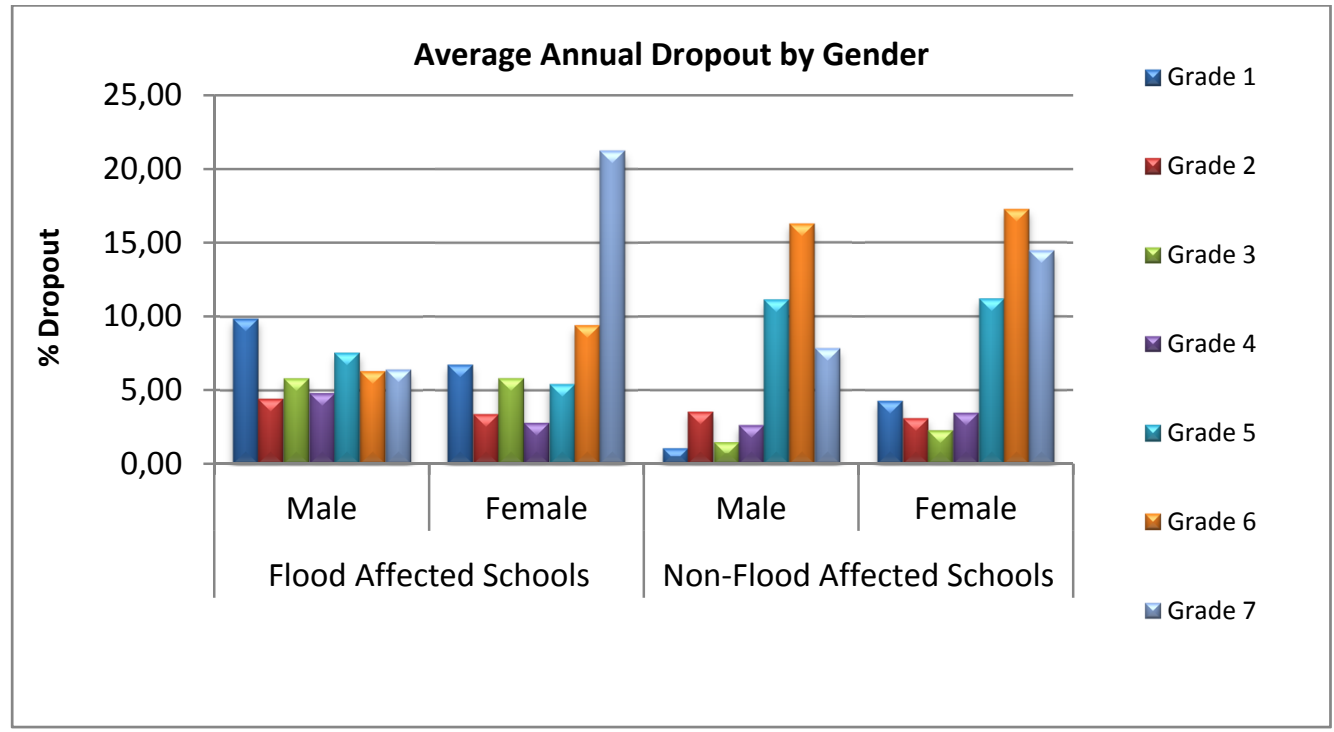

Source: Survey data

flood affected school), "more girls drop out of school than boys because when schools close down or pupils are forced to be absent from schools because of flood effects, girls easily revert to other activities, leading to teenage pregnancy and in turn permanent discontinuation of schooling-dropout". Boys on the other hand mainly dropped out of school for economic reasons as they become more involved in income generating activities to support their families.

In the non-flood affected areas, economic reasons, being orphaned and illness were among the most prominent factors responsible for dropout among primary school children. The extent to which teenage pregnancy and marriage influenced dropout rates during the period under review was minimal in non-flooded areas compared to flooded areas. For instance, in the former, only 14 per cent of girls dropped out of school due to pregnancy and 0.44 per cent due to marriage. The corresponding proportions in the flooded communities were 42.3 per cent dropout due to pregnancy and 5.7 per cent due to marriage (Annex 4.9). 


\subsubsection{Nature and quality of teachers and their impact on primary education}

Based on the premise that teachers are key human resource pillars that influence the effective functioning of schools in terms of the quality of education, the research examined flood effects on primary education by comparing capacity of teachers in flood affected schools with those in non-flood affected schools between 2008 and 2012. Teacher capacity was examined within the context of number of teachers, academic qualification and the years of professional experience. The results as presented in figure 4.9 indicates a marked difference between flood affected and non-flood affected schools in their average total number of teachers. Compared to an average total number of 34 teaching staff per sampled school in non-flood affected areas, flood affected areas only had 4 teachers in each of the 10 sampled schools annually during the reviewed period. As shown in the graph (figure 4.9), the total number of teachers per school in both situations varied from year to year, which, according to key informants, depended on the severity of floods. For instance, the data shows that in 2009 which recorded the most severe floods, flood affected schools had the lowest number of teachers of about 3 per school. This decrease was triggered by the temporary

Figure 4.9: Average total number of teachers per year for the 10 flood affected and 10 non-flood affected schools

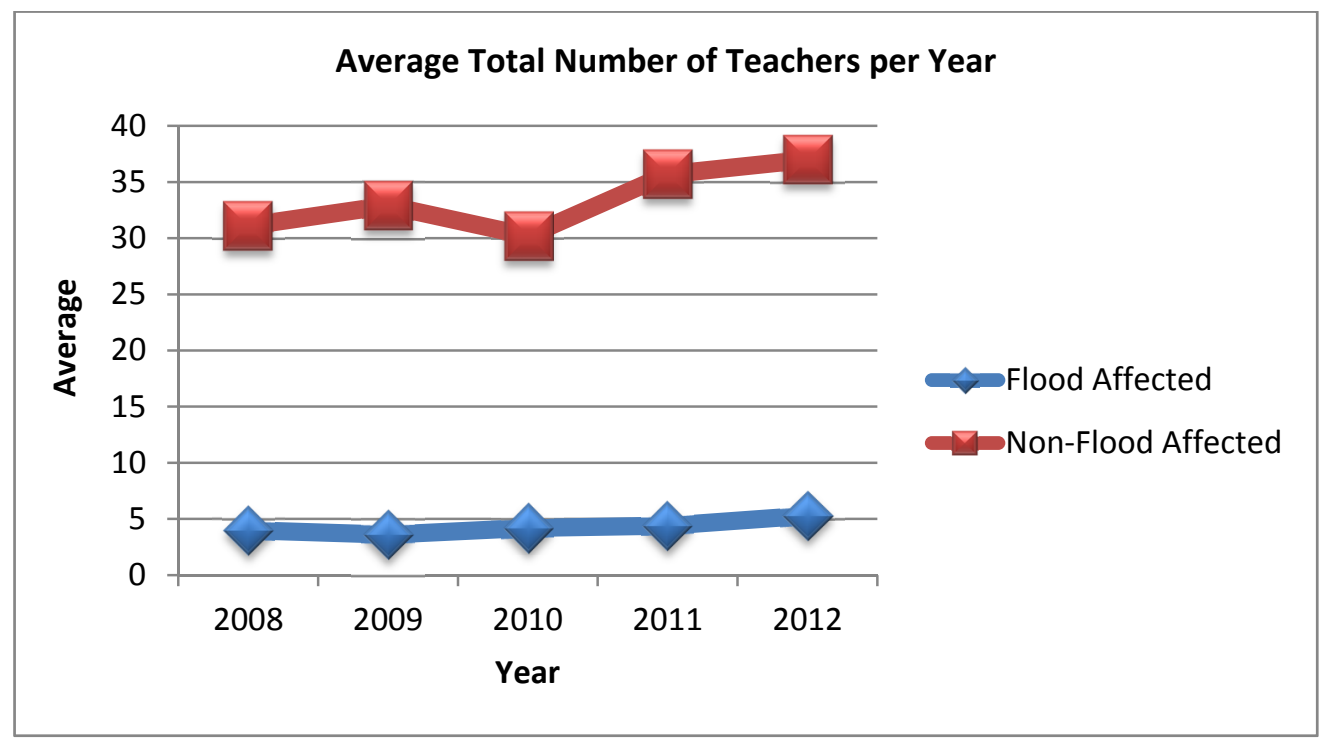

Source: Survey data 
relocation of teachers from the flood plains to schools in the upper land, which explains the slight increase in the average total number of teachers in the non-flood affected schools. However with less severe floods in subsequent years, flood affected schools experienced a small, but gradual increase in the number of teachers.

When disaggregated by gender, the data in table 4.2 reveals that unlike the non-flood affected schools, there were more male teachers in the sampled flood affected schools than females. The gender disparity was particularly strong during the severe floods of 2009, whereby 68 per cent of the teaching staff were males. The harsh teaching and living conditions caused by floods (inaccessible roads and schools, poor sanitation, animal attacks, damage to personal properties, among others) explains this bias. In the Zambian / African cultural context, having more male than female teachers in disaster prone environment like the flood plains could further exacerbate the vulnerability of female pupils because female teachers are the culturally accepted resource persons to counsel female pupils on sexual maturation issues related to girls. This also explains the high dropout rate of female pupils in flood affected schools when in higher classes. This is the period that these pupils need support as they are more mature.

Table 4.2: Gender proportion of teaching staff in flood affected and non-flood affected schools

\begin{tabular}{|c|c|c|c|c|c|c|c|}
\hline & Teachers & $\mathbf{2 0 0 8}$ & $\mathbf{2 0 0 9}$ & $\mathbf{2 0 1 0}$ & $\mathbf{2 0 1 1}$ & $\mathbf{2 0 1 2}$ & $\begin{array}{c}\text { Annual } \\
\text { Average }\end{array}$ \\
\cline { 2 - 8 } $\begin{array}{c}\text { Flood } \\
\text { Affected } \\
\text { Schools }\end{array}$ & $\%$ Male & 61 & 68 & 57 & 50 & 55 & $\mathbf{5 8 . 2}$ \\
\cline { 2 - 9 } & $\%$ Female & 39 & 32 & 43 & 50 & 45 & $\mathbf{4 1 . 8}$ \\
\hline $\begin{array}{c}\text { Non- } \\
\text { Flood } \\
\begin{array}{c}\text { Affected } \\
\text { Schools }\end{array}\end{array}$ & $\%$ Females & 83 & 18 & 17 & 78 & 85 & $\mathbf{4 3}$ \\
\cline { 2 - 9 }
\end{tabular}

Source: Survey data

Floods were found to further influence the capacity of teachers as the research discovered that although teachers in both the flood and non-flood affected schools were academically qualified, most of whom had completed tertiary education, the disparity became evident in the number of years of teaching experience. Based on the 
research's categorization of teacher qualification ${ }^{5}$, non-flood affected schools were characterized by highly qualified teachers as over 80 per cent of teachers had completed tertiary education with over 7 years of teaching experience. The qualification of teachers in the flood affected schools however, ranged from moderate to less qualified, as most of the teachers had completed either secondary or tertiary education, but had less than 5 years of teaching experience.

Due to the remote nature of the environment in the flood plains with less facilities and limited basic social services, it is very difficult to attract highly qualified teachers, especially those who hail from other parts of the country or even those in the same districts but live in the upper land. Most qualified teachers prefer to stay in big cities or places that are not afflicted with recurrent disasters such as floods. This, coupled with the fact that the government do not usually provide good incentives to attract qualified teachers to work in the flood plains, contributes to the limited number of qualified and experienced teachers in primary schools in the flood plains. Often times, the teachers who offer to teach in the flood plains either come from the area, or have just obtained a teaching certificate and wish to gain work experience, or could not easily get teaching jobs in other parts of the country. Although the assignment of teachers to the various districts and communities in Zambia is coordinated by the government through the MoE teachers transfer scheme, yet most of those transferred to the flood plains stay to perform their duties not by choice, but because of the lack of options. These less motivated teachers lack commitment to the work. They spend more time looking for other opportunities elsewhere. This overall situation becomes a problem and seriously affects the learning outcomes of the children.

To better explain the impact of floods on the capacity of teachers in primary schools, the absolute number of teachers per school was assessed alongside the total student population of each school to provide a profile of the teacher-pupil ratio from 2008 to 2012. In all the 5 years, the ratio of pupils to teachers was higher in the flood plains than in the upper lands. In other words, there were generally less teachers to a higher number of pupils in the flood affected schools than in the non-flood affected schools. The fewer number of teachers in the flood affected schools translates into a higher

\footnotetext{
${ }^{5}$ Highly qualified teachers: complete tertiary education plus over 7 years of teaching experience; Moderately qualified teachers: complete tertiary or secondary education plus 5-7 years' experience; Less qualified teachers: complete primary or incomplete secondary education plus less than 5 years' experience
} 
number of pupils per teacher. As shown in figure 4.10, the average annual ratio of teachers to pupils in the former was 1:45, compared to that of 1:28 in the latter.

Figure 4.10: Ratio of Teachers to Pupils in floods affected and non-flood affected schools

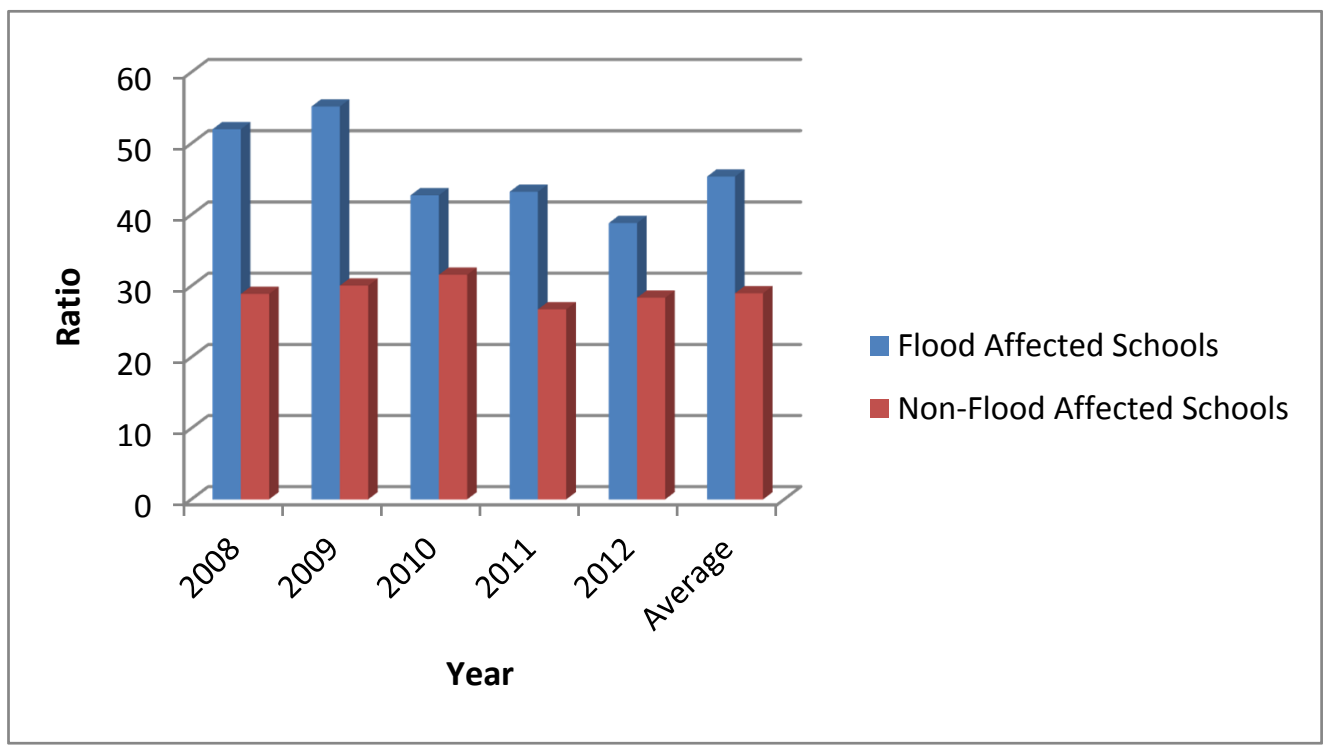

Source: Survey data

The high reduction in the number of teachers to a pupil in the flood affected schools particularly in 2008/2009 is associated with the severe floods of that year, which forced the relocation of teachers to the upper land. After such relocation, it sometimes takes longer for teachers to return to their original schools in the flood plains after an evacuation or displacement. In other cases, those teachers who are evacuated try to look for other jobs during the evacuation period and do not return back to the flood plains. A major consequence of such ratio of a higher number of pupils to a teacher as seen in the flood plains is the amount of time and attention teachers' accord to pupils. This in turn affects the performance and learning outcomes of primary school pupils in the flood plains.

\subsubsection{Performance in national examinations}

Like dropout rates, the academic performance of pupils in the final national primary school examinations is a strong indicator of flood's impact on primary education. It does not only portray the academic attainment of pupils, but to a large extent, influences the child's future academic and career path. Within the Zambian context, 
performance in national primary examinations dictates the secondary schools that later absorbs the primary school graduates. The better a child's performance, the higher are his/her chances of being accepted in "good secondary school". The same holds in other parts of Africa and the world. In the Zambian educational system, performance is categorised in four key Divisions. Division 1 is the highest level of attainment hence regarded as the best level of performance, followed by Division 2, 3 and lastly Division 4 which categorizes pupils that score the least grades in the examinations, thereby considered the lowest level of performance.

To assess floods impact on performance in the national primary school examination in Zambia, the research collated and compared performance data from sampled schools in the flood plains and those from upper lands. The findings as illustrated in figure 4.11 reveal that during the reviewed period (2008 to 2012), performance was much better in the non-flood affected schools in the upper land than in the flood plains.

Figure 4.11: Average performance of pupils in flood affected and non-flood affected schools

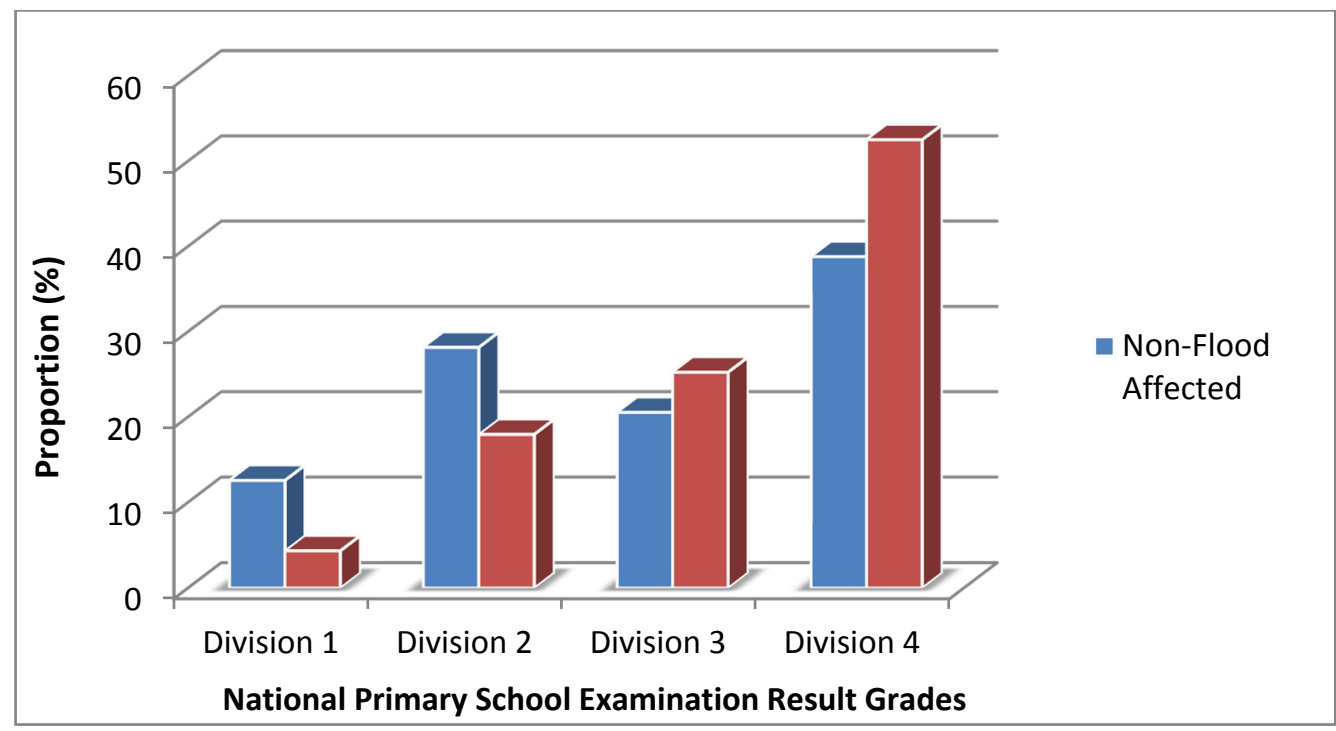

Source: Survey data

The proportion of pupils in division 1 and 2 was far much higher in the non-flood affected schools than in the flood affected schools for all the 5 years. The most striking variance between these areas is seen in the proportion of pupils that scored division 1 and division 4 respectively; 13 per cent of the pupils in non-flood affected schools 
compared to only 4 per cent in flood affected schools; 39 per cent and 53 per cent respectively in the division 4 category. In each of the 5 years, the bulk of the pupils (78 per cent) who sat for the national primary examinations in the flood plains ranked between division 3 and 4 .

To ascertain the effects of floods on the trend in performance, the data was looked at in conjunction with the floods incidence data. The results revealed that the performance trend in the flood plains as described above (poor performance in flood plains as opposed to the upper land) was at its worst in 2009 when the most severe floods in all five years were experienced in the area. From figure 4.12, it is evident that in 2009, only 1.3 per cent of flood affected school pupils attained the highest performance category of division 1 , while about 70 per cent got division 4 , the lowest performance category. These proportions, both for division 1 and 4 in 2009 in the flood affected schools are seen to be the highest in all the 5 years. The proportion of division 1 and 4 only got back to the pre-2009 levels in 2011 and 2012 respectively. This confirms the negative effect of floods on the performance of school children and how long it takes for the effects of floods to be reversed.

Figure 4.12: Performance of pupils in national examination in flood affected and non-flood affected schools

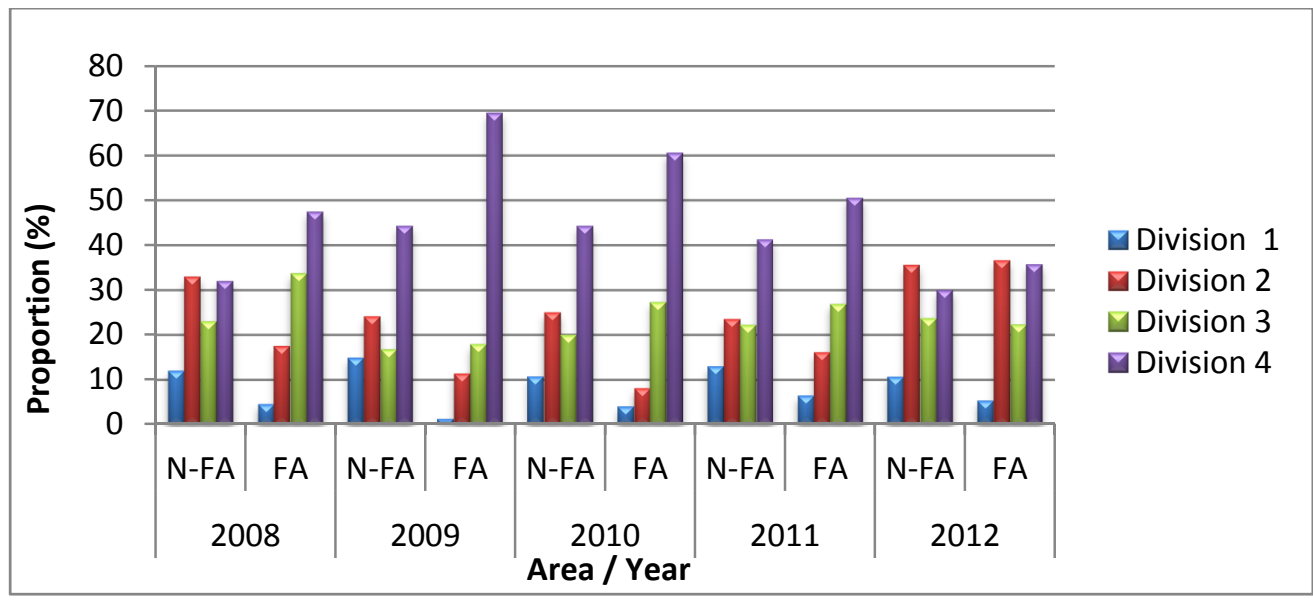

Source: Survey data

\subsection{Summary and Concluding Remarks}

When floods occur, there is destruction of lives, livelihoods and property. Homes are destroyed, schools damaged including school materials. Farmlands, fishing gear and 
animals are lost. The meager public services available collapses and there are mass displacements of people, a situation that sometimes causes death through illnesses, snake bits, drowning or hunger and malnutrition. Under these conditions, it is very difficult for school children to obtain quality education.

Based on the review and analysis of school records data for both floods affected and non-floods affected schools, children in the flood affected schools have a lower net enrolment rate, higher repeating rate, higher dropout rate and lower performance in national examination due to several underlying factors described in section 4.2.2. This undermines the learning achievement of primary school children in the flood plains.

It was found here that 30 per cent of schools in the flood prone areas of Zambia are made of makeshift structures built out of local materials and with limited facilities. The sanitary conditions are not good with most schools having pit latrines instead of flush toilets, no electricity or pipe borne water supply. This makes the school environment not conducive for the children and diminishes their motivation to go to school.

The average annual ratio of teachers to pupils in flood affected schools is 1:45, while in non-flood affected schools it is 1:28. Apart from the limited number of teachers in the flood affected schools, the quality of most of teachers is low. A good number of teachers in the flood plains are not experienced. They are also not motivated due to the limited facilities, low standard of living in the plains and the challenges inflicted by floods.

Based on the findings set out in this chapter, it can be concluded that the flood plains in the Western Province of Zambia are not a conducive environment for children's education. The floods have an impact on several contributory elements pertaining to children's educational outcomes. The area is remote with limited public services and perpetual displacements of people, a situation that disrupts children's schooling. Much needs to be done by all stakeholders to strengthen community resilience against the impact of floods on primary school education.

The next chapter will discuss the various environmental and community characteristics that exposes people in the flood plains to the effects of floods. It also discusses the mechanisms applied by the communities to deal with the situation and how those mechanisms affect children's learning outcomes. 


\section{CHAPTER 5 HOUSEHOLD VULNERABILITY AND COPING STRATEGIES IN THE FLOOD PLAINS OF ZAMBIA}

\subsection{Introduction}

The previous chapter detailed the impact of floods on primary education in Zambia. Most parents either do not have the financial capacity to continuously support children's schooling, or they do not perceive education for children as a priority, but rather focus on fishing, farming and animal rearing for their livelihood. The school infrastructure does not motivate the children and when floods occur, schools are damaged and learning materials destroyed. Highly qualified and experienced teachers are not attracted to teach in schools in the flood plains. Due to the aforementioned factors, enrolment rates are low; most children either drop out of school or repeat classes several times. The general performance in national examination of school children is low and the overall quality of education is at its minimum.

This chapter discusses the reasons why primary school children are most vulnerable to the impact of floods. This is contained in the first part of the chapter, section 5.2.1, which underscores livelihoods, culture, traditions, poverty, and weak administrations at community level, low tertiary education of the communities, limited social services and non-functioning early warning systems, as factors that expose communities to the risk of being affected by floods.

In the second part of this chapter, section 5.2.2, a description of how the researched communities cope with the impact of floods has been provided. Building houses on top of mounds, constructing makeshift houses in the upper land to migrate to during floods period, using boats as means of transport, borrowing money for survival, selling assets, reduction in number of meals taken a day are some of the strategies used by the communities to cope with floods impacts. The section further discusses the effects of these coping mechanisms on primary education. A summary of key points and concluding remarks are then presented in the last part of this chapter, section 5.3. 


\subsection{Results and Discussion}

\subsubsection{Household vulnerabilities in the flood plains}

A discussion of disasters and their consequences should start with an assessment of vulnerability: the well-being of individuals, households, and communities in the face of a changing environment (Coetzee, 2002).

Communities in the flood plains in Western Province of Zambia are exposed to various risks of being affected by floods and the resultant effect on the education of primary school children. Interviews held with the communities in the flood prone areas, government officials, teachers and humanitarian workers including observations made have indicated the following vulnerabilities:

\subsubsection{Land, livelihoods, culture and traditions}

Communities living in the flood plains are the traditional owners of the land they occupy and they want to have full control of their land by living there constantly. One of the elders in Makuku village mentioned, "Even though we suffer in this plain because of the floods, we also derive a lot of benefits from fishing. Besides, the land is ours and therefore could do anything here that we want and we have abundant land to cultivate crops. We do not intend to go anywhere; we will rather stay here no matter what happens". Land is being used for agriculture and grazing of animals. The vast agricultural land in the flood plains is used primarily for rice cultivation and the rice produced is the best in the country with a unique flavor that is liked by many people. Due to the high water table and the richness of the soil, which is exacerbated by the drift of alluvial soil into the plains by the rain, the soil becomes good for agricultural purposes.

Apart from rice, communities in the flood plains also cultivate other cereals (such as maize, sorghum) and vegetables. Not every part of the plain is cultivated and the rest of the land which is mainly grassland is being used for grazing animals. When the rains are not of high magnitude, flooding becomes less and some parts of the plains are not flooded at all. This implies that the destruction of crops, animals and infrastructure is much less, sometimes not at all. However, when there are heavy rains, flooding becomes intense and the damage to crops becomes high. Sometimes all the crops are submerged by flood waters and everything is lost. With climate change, it is now very difficult for the communities to predict the level of floods. One old man in Salondo village said, "About 40 years ago, our parents were able to predict whether high or low level 
floods are expected in a particular year due to some indicators on the weather conditions. Now it is not possible anymore. This is because the climate has changed so much". Apparently, the best period to cultivate is during the rainy season to ensure that there is sufficient water for the crops. Lately, the communities will only hope in each year that floods are not of high magnitude so that they can realize good harvest.

Fishing is another major livelihood support activity that sustains communities in the flood plain. Fishing is going on for most of the year except between December and March when the government restricts fishing to allow the fish to re-generate and reproduce. During the flooding period, fishing still happens, but on a very low scale. This is because the communities are now more concerned about their assets and saving their lives than fishing. The level of fishing that is done depends on the magnitude of the floods.

Generally, the livelihood support mechanism of the communities through fishing, crop production and animal rearing is usually done on a smaller scale. It is mainly for subsistence and about $30-40$ per cent of the produce is sold to buy other basic needs by the community or used for building makeshift houses and support children's schooling or for medical support. This is a key reason why the communities are so vulnerable when there are heavy floods, because they do not have much reserve in terms of financial savings and the little food reserve is often destroyed by the floods.

Communities in the flood plains have a unique culture. For instance, during the flood periods, when water levels are high, the King is ferried on a big boat with traditional henchmen to the upper land on a grand occasion called the "kuombonga".

Figure 5.1: Crossing over of the King from the flood plains to the upper land "Kuomboga"

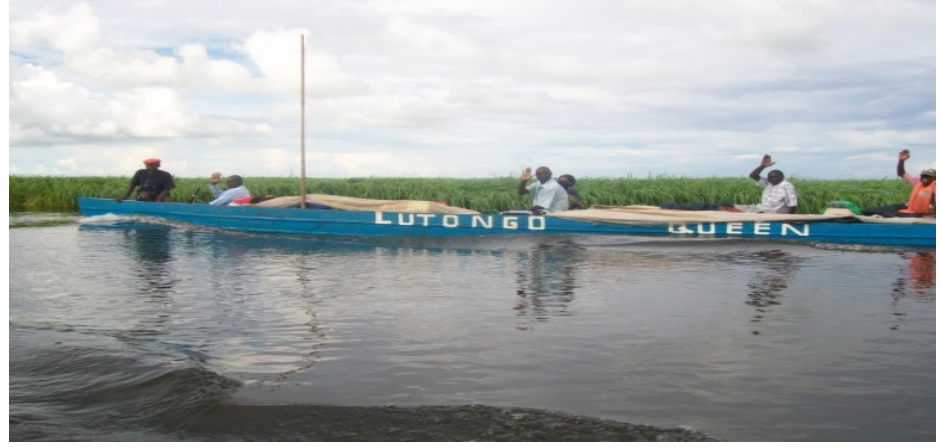

Source: Photo shoot by the Author in Mongu on $8^{\text {th }}$ March 2011 
During this time, the Lozi people (the main tribe that inhabits the flood plains) have a ceremony on the shores of the flood plains with music, dancing, eating, drinking and various celebrations. People from all over the country including foreigners often come to witness this ceremony. This tradition is so liked by the people that they believe they need to stay in the flood plain to maintain the tradition, even though floods do affect them negatively. The Lozi people believe that as they have been born and bred in the flood plains, just like their fathers and forefathers, they have to continue living in the plains. It is very difficult to convince them to leave the flood plains. An old woman in Ngombala village mentioned that, "my best time in the whole year is during the kuomboga. My father used to be very excited during the Kuomboga period because he used to have a special task of catching and drying fish for the guests who come to witness the ceremony. My father would buy me anything to support him in preparing the fish. During this time, everything is so plenty at home and we used to have a lot of fun. Since then I have always liked being in the plain to see the ceremony every year". Communities in the flood plains are so attached to the plains that irrespective of the recurring effects posed by yearly floods, they prefer to be in the plains and carry on with life.

\subsubsection{Poverty and neglect}

Communities in the flood plains are poor. As mentioned in the previous section 5.2.1.1, their livelihood support is mainly subsistence. They cannot afford good homes or expensive amenities such as a refrigerator, improved bed etc. The little savings earned from either fishing, animal rearing, or crop production is used to take care of the home or buy consumer goods such as food stuff, soap and other household items. Any extra pressure will make life difficult. This makes these communities vulnerable to the event of floods.

About 90 per cent of the people interviewed in both focus groups and key informant interviews were of the opinion that they have been neglected by the government. They feel that their region is one of the least developed in the country and the government is not doing enough to get them out of the circle of poverty. The discussion may have had some political connotation but it seems that the community expects much more from the government than what the government is currently doing to develop the flood plains and improve the lives of the people. For instance, an old lady who was a key informant in Nakaywe village informed the researcher that "the land is very fertile for agricultural purposes and if the government could invest in mechanized agriculture or provide loan schemes, it would greatly help them to produce more rice for commercial purposes". Another lady in a focus group discussion pointed out that "the government could even 
build dams to control the water, so that the floods do not spread in the whole plain". However, there is a mix of feelings among community members on what the government could or could not do. In the opinion of a male respondent of an informal discussion, "they (flood plain communities) are not so much keen on what the government is providing because it could be a form of control of their land and resources if they allow too much interference by the government on their land issues". Generally, the communities believe they are not getting adequate and genuine support from the government, so they had better manage the situation and continue to live the way they live now.

\subsubsection{Weak political structures}

Like in many other rural settings in Zambia, communities in the flood plains have weak political structures. Simply put, they do not have a strong voice to ear out their issues for government to address them. According to the local authorities interviewed, their subjects in the flood plains look so much up to them to address all the community problems when they occur or ask them to request government to support in developing the flood plains, but the government does not listen or rather ignore the issues. The local authorities are trying very hard to have an administration that supports their communities, but most of the effort is coming only from them and not so much from government. One of the local authorities interviewed indicated that, "everyone in the flood plain is poor including themselves (the local authorities) in one way or the other. We as local authorities cannot do much for our people. We depend on the bigger government system, such as the provincial administration which also depends on the central government. We are the least in the line of authority. We do not have highly placed people in the government and therefore there is no one to fight for the development of our people in the flood plains. This makes it difficult to present a strong case that would be addressed by government". The local authority acknowledged that their administration is very weak and people cannot depend on it for the development of the flood plain. The fact that the local authorities are voiceless and cannot stand-in as part of a government system to support the people they administer, neither represent them strongly at the provincial and central government bodies for issues that relate to their development and the development of their children such as provision of basic social services or education for children, makes the communities highly vulnerable to the impact of floods. Though Zambia has a decentralized system of government, the decision making responsibilities are still at federal level. 


\subsubsection{Lack of higher level education}

It was established from the discussions with teachers during the interviews that in the flood plains an estimated 85 per cent of the parents, including their forefathers (based on experience from previous surveys) have not had the chance to have secondary or tertiary education because of the inherent challenges linked to the floods and the associated socio-economic problems. While many of the people interviewed valued education, the environment is not conducive and the capacity to attain higher level education is limited, considering the cost, commitment and other sacrifices that parents need to make to send their children to school. A few children who manage to gain higher level education often do not come back home to help develop the area. The limited education levels of most people in the community limits their capacity to think strategically and come up with ideas on how to develop the area. The lack of higher education and the absence of highly educated people placed in high positions in the government make it difficult or impossible for the community to make their voices heard and therefore unable to advocate and push government to pay attention in the development process of the flood plain. This situation makes the community vulnerable to the effect of floods.

\subsubsection{Limited access to the plains and to basic social services}

Access to the flood plains is difficult even during the dry periods when it is not flooding. There are no proper road networks and vehicles cannot access some places in the plains. Most often, people have to walk long distances to access the villages. The main means of transport in the flood plains is by use of boats, but boats cannot reach everywhere in the dry season. This makes life very difficult for the people. Government staff who need to visit the communities to either monitor the performance in schools or pay official visits to the local authorities find it difficult to travel to the areas. This also holds for the transportation of school materials, food, medical supplies and other commodities needed by the community. Although there are public transport facilities that travel to some of the areas, they however cannot reach everywhere. If something needs to be transported to a village where the vehicle cannot reach, the goods are dropped at the closest accessible village and then transported further either by carrying on the heads, wheelbarrows, bicycles or sometimes boats if there is water connecting the two areas.

Compared to communities in the upper land, communities in the flood plains generally have very limited basic social services. For instance, health facilities in the plains are 
not in very good condition and the staff capacity is very limited. In times of crises, health facilities are not able to support people who are sick and who may have been bitten by snakes. The health facilities themselves are normally affected by floods which could destroy the structures, the medicines and even the records. Schools are not in a good condition. There are no good markets to buy basic needs for home use or for children. No electricity supply, no good water supply and no good sanitary facilities. The water supply is mainly from the river. Some communities have hand dug wells which are overflown during heavy rains. The incidence of diarrheal diseases is a big threat to the health situation of the communities. A teacher in Malabo reported of 125 cases of diarrheal disease in 2010 including 3 deaths, and 90 per cent of the cases were children. The compounded limited basic social services subject these communities to high level vulnerability and when it floods, it becomes a problem for the people to support themselves.

\subsubsection{Absence or non-adherence to early warning systems}

An early warning system (EWS) is a set of capacities needed to generate and disseminate timely and meaningful hazard warning information to enable individuals, communities and organizations to prepare and act appropriately, and in sufficient time to reduce harm or loss (UNISDR, 2009). EWS information provides actors with a decision framework to help choose Disaster Risk Reduction (DRR) measures and act upon them as quickly as possible. Zambia has a meteorological department and other government offices responsible for hydrological data management. However, the weather stations in most parts of the country are not perfectly functional due to nonrepair of gauging stations and insufficient financial and human resources to sustain full scale functionality. These insufficiencies limit the amount of data available, leading to short lead time and inaccuracy of forecasts (Banda and Ng'ambi, 2007). If forecasted conditions do not occur, the consequent loss of confidence in forecasts can lead to avoidable human deaths (Madamombe, 2004). Yet, meteorological forecasts are crucial in Disaster Risk Management (DRM). In 2007 in Mozambique, the national EWS played a vital role in reducing the impact of floods and cyclones. It contributed to one of the most important achievements of the preparedness and response operation: 'the relatively low impact on human life, compared to the devastating floods in 2000 and 2001 which killed 700 people' (IFRC, 2009b). The enhanced collaboration between the National Institute of Meteorology and the National Disaster Management Institute during the Mozambican floods of 2000 also reduced subsequent damage (Euroconsult Matt 
MacDonald, 2008). Thus, good practice in DRM that is worth emulating exists across the basin.

Although the weather stations in Zambia are not perfectly functional, the government, private sector and even local communities in the upper lands provide information to warn people of the incidence of floods. These early warning systems are either ignored or not followed properly. For instance, the meteorological department though not fully functional, does make an effort to provide information on the rainfall situation and incidence and time of floods including the magnitude in newspapers, through the radio and sometimes through messages sent to communities to be delivered by the local authorities. The information is mostly inaccurate but some people do take the messages seriously and make necessary preparations, but others neglect the warnings either because they believe they do not have anywhere to go to live a peaceful life; or because of the fear of leaving their homes, crops, assets and other forms of livelihoods behind; or they do not trust the information. Besides, most of the people do not have homes in the upper land and therefore are not motivated to leave the flood plain. This makes the people highly vulnerable and affected by the floods when they happen. One pregnant woman informed the researcher that she had to be ferried on a boat at night when water suddenly entered their house after so much effort to build a mound around the house with soil. Her life was saved but she lost all her belongings including food reserves in the house. She was taken to a temporary displaced camp where life was equally difficult and scramble for relief food and no medication. For this lady, life outside the flood plain is more challenging and if not because of her life, she will never leave the plain. Another woman explained that she kept on moving from place to place with her boat. As the water took over where she currently lives, she jumped on the boat and moved somewhere else where she could find dry land and make a temporary settlement. This is how she survived. This woman is single without a family, so for her, she is alone and do not need to worry about children so she could "paddle her life".

The communities generally do not have much trust in whatever early warning systems that exist because they have not been reliable. This is a problem for communities in the flood plains who experience the flood hazards in various magnitudes almost on a yearly basis, and do not have very accurate information on the degree of flooding. Today, the use of mobile phones have become prominent to warn people, but due to the cost involve, people in the flood plains are not readily using the phones. 


\subsubsection{Climate Change}

Since the 1960s, Zambia has been experiencing climate change. The Zambia Meteorological Department (ZMD) analyzed climate variability in the last four decades and established that, there has been an increase in frequency of extreme events such as floods and droughts, and increases in temperature both cool and warm (Funder et al., 2013). With climate change, the region is likely to experience potential increases in rainfall between the periods January to March. However, the frequency and spatial distribution of heavy rainfall remains uncertain. Climate change will affect disaster risk in two ways (UNISDR, 2008): Firstly, the likely increase in climatic hazards will increase the number or scale of weather-related disasters. Secondly, climate change exacerbates currently precarious livelihood conditions, thereby increasing the vulnerability of communities to natural hazards. In recognition of the importance of DRR for adaptation and development, the Hyogo Framework for Action (HFA) and the United Nations Framework Convention on Climate Change (UNFCCC) aim to reduce risks and increase the resilience of communities to hazards (UNISDR, 2005). However, disaster impacts are increasing in Africa rather than decreasing (Guha-Sapir et al., 2012), most probably because the principles of HFA and UNFCCC are not adopted or resources are not available to adopt them.

Most of the communities interviewed in the flood prone areas indicated that the weather and climatic situation is changing. "Forty years ago, the pattern of rainfall was predictable in terms of when the rain starts and when it ends", said one respondent. They were also able to predict the intensity of the rainfall through certain indicators that are shown before the onset of the rains. For instance, if temperatures are very high two months prior to the rains, it is an indication that the rains will be heavy. One of the participants in a focus group discussion mentioned that "prior to the rains the sun has become hotter now than forty years ago, but that doesn't necessarily mean higher rainfalls anymore". The floods used to last for four months maximum, but nowadays flood waters sometimes stay for almost six months. That is a serious problem because it means people are not very settled for the most part of the year and children's schooling is affected. He mentioned that when children stay too long out of school, they lose interest, get involved in all kinds of activities such as fishing, prostitution or child labor. Once they get used to the money, they become reluctant to go back to school and that is a problem. Many years ago, people were able to adapt and plan well for the rainy season when they had an idea of the intensity of the rainfall, but these days you can never tell if the rains are going to be heavy or light. The change in weather and climatic 
conditions further exacerbates a high level of vulnerability for the communities who are already vulnerable in so many other ways.

\subsubsection{Coping mechanisms}

Communities in the flood plains in Western province have over the years implored several coping mechanisms to deal with the floods. The respondents who were interviewed have mentioned the following coping mechanisms:

\subsubsection{Building houses on mounds}

Sixty per cent of the communities interviewed who live in the deepest part of the flood plains have makeshift houses. About thirty per cent of the people who live in the makeshift houses erect an artificial heaped pile of earth, gravel, sand or debris called a mound and the house is built on top of the mound. This is done to protect the houses and other household assets from water entering the house and lessen the extent of danger of the house. However, this protective mechanism is feasible when the magnitude of the floods is low and therefore the height of the water is also low. As the height of the flood water increases, the force of the water increases as well, this damages the mound and causes water to enter the house. At this point, it becomes extremely challenging for the people to save their homes, their assets, their lives and the lives of their children. The use of a mound as a coping mechanism is temporary and not reliable especially when local materials are used. They do not use cement to keep the soil or sand intact and therefore this is easily washed away by water. However, if the mound is high enough and it is repaired every dry season, houses on mounds can last for over five years. This is not usually the case as people do not have enough resources to repair their houses and the little they have is rather spent on livelihood support activities.

\subsubsection{Use of boats as means of transport}

The respondents interviewed and the observations made indicate that about 75 per cent of all families in the flood plains have at least one boat made of local wood material ridden with a paddle or long sticks. The boats are used throughout the year for fishing and for transporting goods and people from one location to another. The same boats are used for transporting children to and from school. Children who are older than twelve years of age do paddle themselves in turns with their colleagues to go to school. During the flooding periods, the boat can even go to more places as long as there is deep water. Boats are very instrumental in ferrying people who have been displaced by floods or whose homes have been affected. However, as the sizes of these boats are 
small and driven manually by people, they are not very reliable in terms of sudden onset of floods, especially when floods are of high magnitude and with heavy force. It takes a lot of time to move from one place to another and sometimes the boat capsizes, causing a lot of harm to people such as school going children or even elderly people who cannot swim and loss of property.

Nevertheless, boats have been known to provide life-saving transport means during a flood crisis and have saved a lot of lives and property when well prepared and well utilized. "This is the way people have been living hundreds of years, says one young man in Malabo village who provided an explanation on the usefulness of boats during floods emergency. For them, a boat is one of the most important ways to cope with the floods, because it helps them in their fishing activities, it helps them to transport goods and people and it helps them to save property and lives during a floods crisis. This is the main reason why it is very crucial for each family to have a boat or more", as described by the young man. Boats are even used for movement within homes when they are badly flooded.

\subsubsection{Saving food for difficult times}

All respondents in the flood plains have the tact of saving food for "red tape days" as was clearly put by a local authority in Lealui village. He said food reservation is a means to cope during the flood period because when floods occur beyond certain limits, certain crops that are cultivated just before the rainy season such as rice and maize are affected. Other crops such as vegetables are also affected, but are not considered very important and are easy to re-cultivate anytime of the year, as long as they are being irrigated. Rice and maize are seasonal crops and form the main food basket for the community. If and when affected by floods to a level that they are completely lost, the community suffers for the rest of the year. As the floods do not necessarily affect all the crops every year, during years of good production, food is being reserved to cover a considerable period when crops are destroyed. This food never serves them for the rest of the year, but can serve for a couple of months. As it begins to flood, some families who have places to store food in the upper lands transport the reserves immediately. Those who do not have homes in the upper lands only hope, that the floods will not destroy their homes in the flood plains which have been built on mounds. However, when the mounds are affected and water enters the house, it is very likely that the food reserves are destroyed as well. Generally, saving food as a coping mechanism during times of floods has always been very helpful for the communities who are able to manage it without it being destroyed. It helps them 
for a short period before aid is provided or before they start engaging in other income generating activities such as fishing, which happens after they are settled either in the displaced areas or back to the flood plains when the water has receded.

\subsubsection{Owning homes in higher lying areas}

Among the sampled communities in the flood plains, only about 30 per cent of the respondents either have second homes in the upper lands or have relatives they can stay with when things go really bad in the plains during the flood period. Movement to the upper land has been recommended even by the government for the communities in the flood prone areas, at least during the rainy season. Since these people need the plains, more so in the rainy reason for their crops and fishing, they are reluctant to move to the upper lands. Those who have homes there or have families they could stay with tend to move as soon as flood waters start rising. Those who do not have places to stay wait until things get serious before they start moving. These are the people who suffer considerable loss and they are usually in high numbers.

These people initially look for dry areas within the plains, except when the whole plain is taken by water, then they move to the upper land and this is when most times government takes over and put them in temporary camps. One of the respondents in a focus group discussion mentioned that, the loss for people who do not have homes in the upper land has been very high and today many households in the flood plains are considering to have something in the upper lands, even if it is not good enough, but will act as a safe haven. A lot of people are now securing places in the upper lands and have structures with locally made materials. Those families who have animals are often relatively better off and most of them have homes in higher lying areas. When floods occur, they take their animals away immediately. However, the sooner the flood waters recede; they return to the flood plains and continue their routine livelihoods. "Having homes to stay in the upper land during the flood period has been known to be a very good coping mechanism" said a respondent in Makauku. Some families leave a part of the family in the upper land home and provide some means of livelihood either to do some petty trading or work in low paid jobs. School children are usually not left in those homes except if there is proper care arrangement from elderly members of the family to support the children. Most people who have homes in the upper lands are less affected by floods because they do not invest much in the homes that are based in the plains. All valuable assets are stored in the upper land homes and as the rains start and water level starts rising, they are usually the first to leave the plains. 


\subsubsection{Community social networks}

Communities in the flood plains have a culture of supporting each other in times of difficulties, but also in times of happiness. There is a culture of sharing happiness and sorrow within the communities. One household interviewed in Lyaluo testified..." In the year 2011, the floods entered our house at a time when my husband was away. I was helpless having three children, the household assets and food. What assisted me was the good relationship I had with the neighbors and I was rescued by a neighbor who had four strong men. The children and most of the assets were loaded in boats and carried to a dry place close to the upper lands". According to the respondents interviewed, in most cases, families whose food reserves are not destroyed by the floods do help others who have lost everything. They share food, clothes and other basic necessities. Apart from this support provided within the communities during flood period, the people also have the culture of contributing money and sometimes food for a family that either has a bereavement or any misfortune or during times of joy, for instance when a family member is getting married. This is a form of social security. During times of floods, those families that are better off or not seriously affected do cater and support those that are seriously affected. This helps the communities to sustain themselves for a short period before any external support comes through.

\subsubsection{Borrowing money}

Borrowing money from fish mongers (people who buy and sell fish caught from the river) and people who are relatively richer within the community or outside of the flood plain area is one of the ways flood plain communities cope with flood disasters. One respondent mentioned that "during the floods of 2011/2012, he lost his fishing gear including the boat and did not have money to replace them. He had to contact a 'fish business woman' (who most times buys fish from him) to loan him money to replace the fishing gear. Though it was easy to get the loan, the interest rate was high. He was happy though because during those times, it was difficult to acquire a loan from other people". There have been instances where people borrow money and could not pay back in good time because it takes long for people to recover and paying back debts is often the last thing that they wish to do. People who are in desperate situation borrow money or sometimes even food from any available source they are able to get it from and most times under any condition as long as they are able to sustain the family during that acute period. The loan they obtain is certainly used only for the upkeep of the home and not to send children to school, among other things. Another respondent mentioned that "people who have the capacity to lend money to the needy are sometimes very reluctant to do so because 
some borrowers do not pay back or pay very late and sometimes less than the agreed amount". Borrowing money is a common coping strategy, especially for communities whose primary livelihood is fishing. When floods occur and fishing comes to a halt, there is nothing that these people can fall back on, and if there is no other source of support, borrowing then becomes inevitable.

\subsubsection{Sale or mortgage of assets}

During times of difficulties such as a flood disaster when family resources are overstretched and may have lost all that they have during the floods, life becomes very difficult and in the absence of a rapid relief response to the crisis, it is difficult for the communities to cope with sustenance. For members of the community who manage to escape with some assets (household items, livestock etc.), but do not have any other means of livelihood or sustenance, they resort to selling some of their assets including animals to make a living. This is normally the last resort as communities in the plain are not very fond of selling their own properties. Under these desperate situations, their assets are sold at very low prices, usually less than the actual value. The assets are either sold to other fellows in the same situation, but who are better-off, or to petty traders in the upper land who buy the assets to sell and make some profit. As mentioned above, the sale of property or animals during times of floods is not a very common practice, but happens when the people are extremely desperate. The income generated from these sales is primarily used for food for the home. This helps the family to carry on for a while before external relief interventions from the government and NGO's comes in.

\subsubsection{Humanitarian support}

The government body responsible for disaster management is DMMU. With support from the district commission and humanitarian organizations such as WFP, UNICEF, OXFAM, World Vision and a few others, the flood displaced communities are provided with temporary shelter, food and medicines for a short period of about three months or a bit longer depending on the situation and availability of resources by the government or humanitarian organizations. In the focus group discussions with elderly men, respondents indicated that it normally takes long for the government to react to flood victims and when they do, the support is insufficient. The food they get is not enough and they have to struggle to get it. This is also true for other basic services such as water, sanitation, medical supplies etc. In the camp environment, they organize themselves as a group, with a camp leader who appeals on their behalf to the 
government and humanitarian organizations, and sometimes to the private sector for support. The appeal most times yields some fruits and more support is provided, which even if not overly sufficient, can serve them for a much longer period.

Whilst in the camp, the people also try to engage in other activities such as working in low paid jobs to complement whatever is provided to make a living. "It is a difficult life, said one of the respondents, but better than nothing. He said, when they are in the flood plains, no matter how difficult circumstances are, when they go with their boats to the river, they are able to catch some fish which they can either use for food or sell to buy some food. They are very uncomfortable staying in camps, when they could do so much in the plains". Though humanitarian support do make a difference in providing some basic needs for the affected people, in most cases, the support is not sufficient enough to provide for children's schooling. There are certain times when emergency education support provided by UNICEF, WFP and World Vision do ensure that children go to school. Under this support, school feeding is provided for a certain period in the schools where displaced children are enrolled. Basic school materials such as school-in-a-box kits and blackboards are provided. This extra support encourages children to go to school and parents to send their children to school.

\subsubsection{Reduction of meals / Food rationing}

Communities in the flood plains usually have three meals a day (a light breakfast, a heavy lunch with 'Nshima' made of maize meal with vegetables and fish, and a normal meal in the evening, either with Nshima, fish, meat and vegetables; or rice, vegetables and fish. The heavy afternoon meal is to retain much needed energy for the hard work during the day - working in the field, fishing in the river or caring for the animals. In all the focus group discussions, the communities in the flood plains mentioned that during times of floods, people are occupied with taking care of their animals and assets and transporting them to safer places. Agricultural and fishing activities are both neglected during this period. This of course reduces their daily income and hence their ability to provide sufficient food on a daily basis is reduced. Under these circumstances, households tend to not only reduce the number of meals they take in a day, but also the quantity of food intake per meal. This is a way of coping with the little food available. Such food rationing continues even when support comes from government or NGOs because most often the food relief supply is not sufficient, forcing people to reduce the number of meals a day. This reduction of meals can sustain the community for a considerable period until life returns to normal. However, children 
most often do not have sufficient food intake to have a proper stamina to go to school. When children are not well fed, they are not motivated to walk long distances to go to school. With children not having balanced diets, there are eminent health problems that emerge, which further disrupts schooling for the children.

\subsubsection{Reducing expenditure}

Most of the communities interviewed mentioned that during times of good harvests and continuous fishing, when there are no floods that affect their livelihoods, there is plenty and therefore people can be extravagant in their expenditures by spending money on things that they may need but can do without. For instance, buying a new bicycle or new shoes, making unnecessary trips to the upper lands and paying for entertainment. During times of floods when things are hard, the communities cannot afford doing extra-ordinary things apart from providing food for the home. This reduces the burden on the meager resources they have as they focus on the most important needs such as food and medical care. "One of the respondents mentioned that for him, even when times are good and there are no floods, all the extra money he makes from harvests and fishing is invested in preparing a home in the upper lands. He does not buy expensive goods to bring to the flood plains because he knows that sooner or later, it will flood again and he will possibly lose all his assets". Another respondent mentioned that "he doesn't have a home in the upper land. His life is settled in the flood plains and he rather spends money on things he needs, use them to feel good and if and when they are lost, he will try again to replace them". The discussion provided conflicting positions by the respondents, but generally, communities in the flood plains do not spend lots of money on buying expensive goods because of fear of them being destroyed by the floods. They would rather save the little money they have for "red tape days". Most of the money the communities make is used for subsistence. Not much is saved for higher investments, only for contingency.

\subsubsection{Diversifying livelihoods}

The links between climate shocks and diversification of livelihoods are well established both in Mozambique (Osbahr et al., 2008) and more widely in rural Africa (Assan, Caminade, and Obeng, 2009). As part of a coping mechanism in the flood plains, the communities do not 'put all their eggs in one basket' by having only one source of livelihood or income. About 30 per cent of the households engage in fishing, crop production, livestock rearing and craftsmanship. About 70 per cent of the households produce crops and at the same time do fishing. 
When crop fields are destroyed by floods and fishing is impossible due to floods, those who own livestock are often less affected if they had taken their animals out of the plains. For the communities who may have had a good harvest in the previous year and had reserved food, which is not destroyed by the floods, they have little to serve them for a while (during and/or after floods). Other livelihood activities undertaken by some community members include mat and basket weaving. Those who only depend on fishing are at a higher risk during floods when fishing is impossible. The situation worsens if these people do not manage to save their assets. These are the people that need considerable support from the government or the humanitarian community. Diversifying livelihoods is a common phenomenon among communities in the flood plain. It presents a form of security that enables people to have something to fall back on when other livelihood activities are affected. Therefore households with more than one livelihood support system, usually cope a lot better than those with only one livelihood.

\subsubsection{Migration in search of petty jobs and use of child labor}

As mentioned in chapter 4 of this study, one of the reasons for dropout of children from school is the use of children by parents to work for the livelihood of the household (child labor). Over 80 per cent of the research respondents mentioned that when children drop out of school either because of the disruption caused by floods or due to lack of school fees by the parents or sometimes lack of motivation by either the parents or the children themselves in school, they engage in work. The boys very often join their parents in fishing, work in the fields or take care of animals. The girls do the household chores and help out in the field as well. During floods period when the communities are displaced and they temporarily relocate to the upper land, life is sometimes difficult and children are sent to town to undertake low paid jobs, such as house cleaning or work in shops as casual laborers. Some children do petty trading by selling small items. In extreme cases, some of the girls unfortunately engage in unethical practices such as prostitution. The above mentioned are some of the ways children help to bring income home to help the parents in taking care of the household. In very few cases, these livelihood activities are temporary, basically just during difficult periods and when the household return to the flood plains, life becomes normal again and the children whose families could cater to send them back to school, do so. However, very often, the children get used to earning money and therefore continue with their income earning activities. Some of the girls become pregnant in the 
process and abandon school. Some children become infected with HIV/AIDS. This coping mechanism negatively affects children. It violates the child rights international charter and contributes immensely in getting children out of school which affects the state of primary school education in the flood prone areas.

\subsection{Summary and Concluding Remarks}

From all indications, communities in the flood plains are not prepared to leave the plains in spite of the prevailing circumstances. The researcher discovered that on numerous occasions, the government had planned for the relocation of flood plain communities to the upper lands; but those ventures have been repeatedly rejected by the communities because better livelihood alternatives have not been provided. Apart from the issue of livelihoods, flood plain communities are very attached to the culture and do not want to give up their land ownership entitlements. Therefore any development plan for these communities has to be carried out in the plains.

Poverty is endemic in the flood plains and when floods occur, the effect is immediate because most families do not have the upper hand to prepare ahead of the floods. It takes a long period of time for people to recover after being affected by floods. Under such circumstances, any resources available are mainly used for food and other basic services and not for the education of school children. Besides, not much support is coming from government. The local authorities do not have a strong voice to air out the issues affecting the community to the central government which makes life even more difficult.

Early warning systems which are supposed to inform people as early as necessary on the period and intensity of the floods, so that people can prepare well and in good time are not functioning well. Other basic social services, such as hospitals and safe drinking water are limited. This puts people at high risk when floods occur.

The communities adopt several coping mechanisms to deal with the situation of floods such as building houses on top of mounds to protect the houses from being damaged by flood waters. Some well-to-do families have alternative homes in the upper land where they temporarily stay during the floods period. Social insurance schemes do help people affected by floods to carry on for a while before help comes from government or humanitarian organizations. The practice of selling assets to make some money is common among flood affected people. In most cases children are subjected to work and bring money home to support the house upkeep. 
Generally, the communities in the flood plains are exposed to the risk of being affected by floods due to their livelihood characteristics and the environment in which they live. They do implore several coping mechanisms to survive. However, some of the coping mechanisms have a negative impact on the education of primary school children. Interventions are needed from government and NGOs to change the situation without which the education of primary school children in the flood plains will be at stake.

The next chapter reports on various interventions implemented at different levels to support people affected by floods, some of which, have a positive impact on the educational achievement of primary school children in the flood plains. 


\section{CHAPTER 6 REDUCING THE HAZARDS OF FLOODING FOR PRIMARY SCHOOL OUTCOMES IN ZAMBIA}

\subsection{Introduction}

In the previous chapter, household vulnerability of communities including school children in the flood plains was discussed. Poverty, neglect, weak political structures among communities, limited tertiary education of people in the flood plain, limited basic social services, absence of improved early warning systems in the face of a changing climate were highlighted as some of the factors that exposes communities to the risk of flood hazards and disasters. The previous chapter also discussed several coping mechanisms implored by the communities over time to deal with the flood situation. These include livelihood diversification, building houses on top of mounds, owning homes in the upper land for habitation during floods period, community social networks and sale of assets, among others. Most of the coping mechanisms were found to have a negative impact on children's education because they focus more on protecting the welfare and livelihoods of people and not on ensuring support to children's schooling. Any development intervention that does not address the challenges of primary school education for children is insufficient, understanding the fact that development cannot prevail without education.

One of the research questions is to investigate whether interventions by stakeholders in flood plains do have a positive effect on children's education. This chapter argues, based on empirical evidence, that interventions to some extent do have a positive effect on children's education. The various sections (6.2.1 to 6.2.9) of this chapter report on the interventions undertaken by government, NGOs and other stakeholders to lessen the impact of floods disasters on the researched communities. These interventions provide an opportunity for children to continue schooling, though in an abnormal situation. The last section (6.3) provides a synopsis of the chapter and conclusion on the general effect of interventions on primary education. 


\subsection{Results and Discussion}

\subsubsection{Flood preparedness}

The DMMU in Zambia have a decentralized disaster management framework which has a component of an Emergency Preparedness and Response Plan (EPRP). The decentralized framework starts from a central plan, to a provincial plan, to a district plan and sometimes community level plan. In the Western province, a major emergency profile is that of floods. Every year, DMMU with technical support from government line ministries and humanitarian workers on the ground under the auspices of the District Administrative Office (DAO) prepare a provincial EPRP and a district level EPRP. The plan indicates the various locations within the district or province that will potentially be affected if there is a flood disaster. It indicates the number of people that will potentially be affected, the various sectors that will be affected and the modalities of support to save their lives and properties, the cost of the emergency operation, and the type and amount of supplies that would be needed. Furthermore, the type of agency, organization or government department that will provide what type of support is specified in the plan. The education sector is usually well covered in the plan. For instance, provision of temporary learning centers, education emergency supplies and training of teachers.

Once the plan is prepared, it is then supposed to be operationalized by ensuring that all the elements in the plan are addressed and all logistics and operational support are in place. That means all emergency supplies estimated for a potential emergency are supposed to be prepositioned, contracts with transporters to move supplies are being drafted, organizations responsible to provide support are being alerted. However, despite the good intentions of flood preparedness as an intervention, it yields very little in terms of impact, owing to the fact that this process hardly goes beyond the preliminary phase of 'planning'. Generally, these plans are prepared and 'kept on the shelf' with very little action taken to operationalize them. The plans are mostly only referred to when disaster (floods) strikes, as that is when the government starts looking for support in terms of logistics, human and finance to respond to the crisis. In the process, more lives are lost, people suffer a lot and the overall response becomes ineffective. Operationalizing a preparedness plan at the onset of the disaster is too late for immediate actions to be taken. "One teacher in Lealui School mentioned that he has been invited on several occasions to take part in the development of the floods emergency plan, but whenever it floods, he doesn't see any of the promises made in the plan. Actions are always very late and the support is not sufficient, not even measurable to what is stipulated in the plan. As 
a result, flood victims experience difficult living conditions in the displaced camps and many school children do not go to school".

The delay in operationalizing the flood preparedness plan translates into delayed and inadequate responses allocated for the disaster. For instance, delayed relocation of flood victims to the upper land implies a break in the educational system of primary school children as they await relocation to the upper land. Shelving the preparedness plan for the last minute also results in fewer flood affected children being enrolled in upper land schools as only fewer families get relocated through government or other external interventions. One government official indicated that sufficient budget is not set aside for disasters. The funds allocated to DMMU are primarily for operational costs. Funds for the emergency response are usually only secured when the crisis is already there and that poses a risk of a higher impact when the disaster strikes.

\subsubsection{Relocation and resettlement}

When floods occur in high magnitudes, the whole flood plain is completely covered by water without any pockets of dry land. During this period, everyone in the flood plain needs to relocate to higher grounds. Those families that have the means to move to the upper land either by use of their own boats or support from neighbors, friends or wellwishers do relocate in good time. However, there are some families that do not have the means, either because they do not have (strong) boats to withstand the velocity of the water or do not have family members, friends or neighbors that can support their relocation. So there are always people who are caught up in the plains during heavy floods and these are the people that need support from either the government or humanitarian organizations for relocation. The DMMU unit of the government has an office in Mongu, the Provincial Headquarter town of Western Province. This agency works closely with the DAO to support people who are affected by floods. DMMU organizes rescue programmes supported by other government offices to rescue people who are in trouble during floods. "In 2008/2009, the caseload of the affected people was so high that DMMU could not handle it, so humanitarian organizations in Western province, such as OXFAM had to intervene", said an official from Red Cross Society. During that year, about five deaths were recorded of people who got drowned and the rest were relocated. About 500,000 people were displaced by the flood plains and were relocated to the upper land in temporary camps. Many school structures were damaged and schools closed for about 6 months, said a teacher in Lealui School. 
"The government of Zambia have been advocating for a permanent relocation and resettlement arrangement for people in the flood plains who are affected by floods yearly to relieve them from the dangers caused by floods, said a staff of the DAO office, but the people are reluctant to leave the flood plains because of their livelihoods, landownership and their cultural attachment to the plains. They prefer to go through the rigors and challenges posed by floods than to abandon their motherland for a different location".

Relocation and resettlement, it is argued, is a key component of vulnerability reduction in areas at risk of flooding and brings resettlers closer to international development programmes and government services (UNOCHA, 2001). However, little is known about the long-term effects of such programmes on livelihoods, and their success or otherwise in helping to resolve the problems posed by flooding (Wiles, Selvester and Fidalgo, 2005). Most reports have been relatively anecdotal in nature, and the debate rarely has extended beyond the development agencies working with resettled populations in the country (Bobb, 2007). This is at a time when there are calls to improve understanding of different approaches to enhancing local development by conducting comparative analyses of displacement and resettlement in developing countries (Koenig, 2005).

The Asian Disaster Preparedness Centre (ADPC) has reported that 'relocation and 'resettlement' can be favorable in certain conditions where financial instruments and resources are available. Yet, in most parts of Asia, this mitigation measure has proven to be less successful, costly; and economically, politically and socially sensitive' (ADPC, 2005). Of particular concern is the possibility that powerful actors can use the excuse of reducing community exposure to environmental hazards to conduct forced migration for political or economic gain (Barnett and Webber, 2009). Overall, relocation has resulted in major socio-economic challenges for affected populations. In Africa, there is particular concern about the government of Ethiopia's resettlement and 'villagisation' programmes, which, in the past few decades, have moved millions of people from drought-prone highland areas in the west of the country to more fertile regions in the south, and led to considerable hardship among those relocated (Hammond, 2008). The drivers of Ethiopia's schemes are complex, and rooted in concerns about overpopulation and agricultural stagnation (Devereux, Teshome, and Sabates-Wheeler, 2005). 
"In Zambia, whenever people are relocated to the upper land, the sooner the water recedes, they are in a hurry to go back", said the DAO Officer. This is a major challenge for the government considering the amount of resources used to relocate the people almost every year. Badri et al., (2006) mentioned that involuntary resettlement - defined as the planned, physical displacement of people to a new, permanent relocation - has been a preferred approach to post-disaster reconstruction in developing countries in recent years. Recent high-profile disasters, such as the floods in Pakistan in 2010, combined with increasing concern about climate change, have raised the profile of resettlement as a potential response to climate-related disasters among governments and the international development community (Bogardi and Warner, 2008). Communities in the flood plains in Zambia argued that the government has not provided better alternatives that will motivate them to leave the flood plains. The education of their children has been seriously affected for several years. A lot of children drop out of school or spend longer time to complete primary school because of the disruption caused by floods. The lack of good education for people in the flood plains has affected the development of the flood plains communities. As their livelihoods depend on the plains for agriculture, fishing and livestock rearing, they need a guarantee to secure sustainable livelihood if they are to relocate and resettle permanently in the upper lands. The United Kingdom's Disasters Emergency Committee (DEC, 2001) reflected these concerns in its 2001 review of the floods in Mozambique, reporting that farmers opting to live outside of resettlement areas indicated by government were unfairly denied livelihoods support.

Similar concerns were reflected in the Zambian context. In the words of a young female respondent, "it is very difficult for us to leave the flood plains to resettle in the upper land as indicated by the government. The government has not supported us while in the plains. There are no development programmes, our children's education is affected and we feel neglected. How then can the government expect us to leave our livelihood environment and go to a completely new place to start a new life without any guarantee that we will get ample support from government to start a new life? We will rather stay back in the plains and continue to hope that in the near future, our plight will be understood and a conscious effort will be made by stakeholders to provide sustainable support". She added that "if the government wants to assist communities in the plains, it should be committed to develop the flood plain by controlling the water through dams, pave roads, provide electricity, build good schools and improve education of our children. All of these are lacking, therefore we do not have any motivation to leave the flood plains. We would rather relocate temporarily during the floods and return home when 
floods are over". The communities in the flood plains in Zambia do not completely resist moving to the upper land, but they need a guarantee from government that their lives will be better outside the plains. This has however not been provided, hence the struggle in the plains continues.

\subsubsection{Rapid assessments}

In the aftermath of floods, governments and humanitarian agencies usually carry out rapid assessments to determine the extent of the damage and the needs of the affected people, so that support could be provided in areas of immediate need to save lives. Coordination at this early stage between the organizations involved determines the effectiveness of the humanitarian interventions (IFRC, 2009b). The government of Zambia through DMMU leads the overall response mechanism, from assessment to delivery of services, working closely with line ministries and in many occasions with the humanitarian community. Zambia has a decentralized Disaster Management Framework with the main body in Lusaka (the capital of Zambia) and provincial and district level coordination systems. In Western province, there is a DMMU provincial coordinator who works with the various DAOs including the district level line ministries and any existing NGOs and UN bodies at district level to organize an interagency assessment of the flood disaster. This usually happens less than a week after it floods. The framework has various sectors including health, education, nutrition, water and sanitation, food security, livelihoods and child protection. Recommendations from the rapid assessment usually indicate the approximate number of people that are affected, the level of effect, the exact needs and the cost for the interventions. These recommendations are shared with federal level DMMU, which then presents it to relevant bodies including the various government line ministries, bilateral bodies, donors, embassies and the UN to solicit an emergency response support. In the meantime, whatever resources are available at the district level in terms of prepositioned supplies by either the government or humanitarian organization are sent immediately to the affected people while waiting for extra support. Human resources are also deployed by humanitarian organizations to provide technical and logistics support. During the 2008/2009 floods which affected nearly half a million people in Zambia, the needs were enormous and the UN had to establish an appeal process to seek external support through the Central Emergency Response Fund (CERF), managed by UNOCHA. Education for children was one of the main areas affected and the requested support had a big component of emergency education to enhance enrolment of displaced primary school children in the upper land schools. 


\subsubsection{Relief aid}

When floods occur, like any other disaster, the government and the humanitarian community provide relief aid to support the affected people. In the flood prone areas in Zambia, the government pre-position food stocks in the districts of the plains in order to reduce the time it takes for emergency supplies to arrive in the affected areas. This enables faster, more cost-effective and focused relief delivery. However, resources are often inadequate, causing humanitarian agencies to appeal for more funds. Even then, donors are reluctant to support a flood disaster in Zambia because the floods are predictable and they expect stronger actions by the government to protect people from the impact of floods. Thus, a lack of funds limits the extent to which humanitarian agencies support the government in addressing the adverse impacts on the population. Hence subsequent floods can hit an already vulnerable population that has hardly recovered from previous flood impacts, and so the continuous need for external assistance.

The communities interviewed mentioned that the support they receive from government is short-lived and often not sufficient to cater for their welfare in terms of food, medication, shelter, children's education and nutrition needs of the children. "The government of Zambia through DMMU provide tents which are erected in isolated places to host the displaced people and also provide food rations for a couple of months including water, medical supplies, mosquito nets and non-food items such as cooking utensils, blankets and other basic needs", said an official from DMMU. "The government sometimes also provides school tents and school materials if there is a need to establish a temporary learning center". As the caseload is often high, the government very often solicits assistance from UN and NGOs to provide extra support to the communities, although this is usually limited.

In previous years, the floods lasted for only three to four months, but in recent times, the plains can be flooded for up to six months. This makes it very difficult for the government to continue supporting the communities for a very long time. If support from the humanitarian agencies is equally not sufficient, it results in human suffering, forcing the affected people to look for other means of sustenance. This is one of the factors that make it difficult for parents to enroll their children in schools in the upper land during times of displacement. Children are often sent out to work or do petty trading to earn some money for the home upkeep, because the relief aid from the government or humanitarian community is insufficient. "Sometimes, girls get into prostitution and the dangers of HIVIAIDs infections or unwanted pregnancies are eminent. 
This is a major factor that gets the children completely out of school", a parent remarked. However, if the support from government is reasonable and floods take a fairly short time, then the displaced people are able to cope with whatever little that comes from government till it's time to go back to the plains.

For those communities who have homes in the upper land or are able to stay with family members or friends, the situation is a little different. They may not need to go through the troubles that those in the displaced camp go through, although staying with friends and family members for a long period of time does pose a burden, too. Sometimes if the situation in the flood plains does not change after a couple of months of displacement, some family members expect the relocated victims to contribute towards the upkeep of the home hosting them. This then forces these people to look for jobs or find other means of making money. Under these circumstances, children of the displaced families usually form part of the family work force, which potentially takes them out from school and very often dropout.

In essence, relief aid from government or the humanitarian community does help, but what is supplied is often not sufficient to provide a complete relief. The affected communities usually need to do a lot more extra things to cope with the situation and in the process children assume adult roles as they join the family to generate income for sustenance.

\subsubsection{Remittances}

Remittance is the process of sending money or goods from a working country to a home country to meet certain obligations. Remittances are one of the most obvious interventions in disasters such as floods that provide immediate support to the affected communities if received in good time. Some people in the flood plains have relatives, friends or well-wishers who live outside the country. "When there is a flood disaster and that information reaches the family members or friends of the affected people who live abroad, money or goods are often sent by the family members or friends to the victims, in most cases relatively quickly", said a respondent beneficiary. Even though the amount of money sent may not be much, it makes a huge difference, at least for a couple of weeks before support comes from government or the humanitarian community. These remittances complement the relief aid received to cover certain areas of welfare that are not covered by relief aid from government or the humanitarian community. According to one of the respondents interviewed, 'his brother who lives abroad sent money during times of displacement in 2008/2009 floods and the brother insisted that the money should be spent for 
the schooling of the children. He was able support the children to enroll in an upper land school because of the remittance'. Sometimes, remittances help support not only the targeted recipients, but neighbors as well. It has been noted from the respondents interviewed that only about 15 per cent of the communities living in the flood plains do receive remittances. This is not a large proportion of the community, but the effect of the money sent to the people who actually benefit from it is quite huge, this includes the actual recipients of the remittances and the neighbors they share with. "People who receive remittances often have something extra and can most times afford to send their children to upper land schools during the relocation period", said a respondent.

\subsubsection{Enrolment of children in upper land schools}

One of the key roles played by the government through the Ministry of Education is to ensure that children who are displaced and willing to go to school are registered and enrolled in upper land schools. The government ensures that support is provided to the school to help cater for the extra burden of having children from the plains. Sometimes extra class rooms are constructed or tents erected as emergency classrooms and extra teachers are provided to ensure that there is sufficient capacity for the extra caseload. The government and humanitarian community also provide school supplies such as school in a box kits, teachers' kits, blackboards, tents and other materials to cater for the extra caseload. Children are enrolled in schools which are closer to where they live (displaced camps or homes of relatives/friends), so as to ensure that distances to schools are relatively shorter.

While this is a very good intervention to ensure that children continue their schooling and do not stay out of school for long periods of time, this venture is more beneficial to 'better-off' families who have enough resources for the home upkeep and could afford the extra cost (clothing, shoes, transport fare, lunches etc.) of sending the children to upper land schools. For families who find it difficult to make a living, it is difficult to afford the extra cost and sometimes require the children to assist in the home upkeep. Furthermore, as children in the flood plains have a different method of teaching due to the environment in which they go to school, they struggle to catch up with the new environment. Besides, the learning outcomes of children from the flood plains are lower than those in the upper land. It is usually a big challenge for the displaced children to cope with the standards in the upper land schools if enrolled in the same grade levels that they have attained in the plains. The relatively high standards in the upper land are due to better quality of teachers, better quality school 
infrastructure, no disruptions as a result of floods and a better general school environment.

\subsubsection{Support for people with special needs}

In the flood plains in Western province of Zambia, just like in many other rural settings in Africa, there are a good number of people who are disabled or have other health related problems that do not make them completely fit for any physical or mental activity and this includes all ages. During times of floods, these people are extremely vulnerable and are usually given due attention first, just like the very young children. The initial response from government or the humanitarian community or other rescue groups are geared towards these people if their locations are known. Family members of this group of people try to ensure that care is taken of them as early as possible since they are helpless. However, sometimes when floods are sudden, it becomes difficult to accord people with special needs the required attention as everyone fights to save their own lives. When these helpless people are relocated to the upper land and placed in camps, the government provides reasonable basic support services, especially for school going children. The government tries to ensure that wheelchairs are provided to people who cannot work, HIV/AIDs treatment is provided to people with the disease, antenatal care is provided to pregnant women and therapeutic milk including other support for breast feeding mothers. Children, who are traumatized by the effect of the floods and become disturbed, are offered trauma counseling services provided either by government or NGOs to stabilize them. However, the support to people with special needs is not always forthcoming and sometimes when it does come, it is at a later stage. This happens often in emergencies. Even though the support is not always readily available, it makes a difference once it is there, especially for the children who need the services to continue schooling in the upper lands.

\subsubsection{Repatriation to the flood plains}

After floods induced displacements and the associated challenges and problems, the affected persons would immediately want to go back to their original places as soon as the flood water recedes. Some people try to return to the plains even before the flood water completely recedes because they are tired of the "difficult life" in the upper land, especially after missing their livelihood support mechanisms for a considerable period. However, going back to the plains after floods poses many challenges. Crops have been destroyed, fishing gear and boats damaged, houses damaged, food reserves and other assets lost and many other challenges. It is difficult for the affected people to go back and start life having lost so much and not knowing where to start. It is then common 
practice that these people are supported with some basics to go back and start life. However, understanding that it is difficult for the government to do much due to the high cost involved, very little support is given. This includes food stock for about a month, clothing, cooking utensils and sometimes a little amount of money for transport fare. Some people get support from relatives or friends to repatriate back with a very good package to help them start life. "Going back to the plains is always a big challenge", said a young woman from Lyaluo. "Whilst life is very difficult in the upper land in the displaced camp, starting is also not easy in the flood plains. If the boats are damaged, we need new ones; if houses are damaged, we need to re-construct them; we cannot just start fishing, we need time to prepare the fishing equipment. The floods are really a problem to us and the government needs to do something otherwise our future and the future of our children is at stake. Most of our children discontinue school because the schools are not good, we don't get good teachers. This is all because of the floods", lamented the young woman. Going back to the flood plains is an immediate desire of the affected communities, but what they bring with them to re-start life is a challenge and this makes it difficult to settle very quickly.

\subsubsection{Recovery, rehabilitation and reconstruction activities}

Humanitarian organizations do provide some support such as seeds for planting and other micro level support to get the people back on their feet. The government on the other hand, mostly feels responsible for the rehabilitation of public infrastructure owned and run by government such as schools and health facilities, but not private homes or assets owned by individuals. The manner in which government takes action to spend resources for a recovery programme is very slow due to its bureaucratic systems. In effect, the reconstruction and rehabilitation of schools among others is delayed, implying that even when flood displaced children (together with their families) are repatriated to the plains, attendance is delayed as they wait for the flood damaged schools to be repaired or rebuilt. One school teacher in Nangole mentioned that his school was destroyed by the floods since 2011 and the government has made no efforts to repair the damage as at the time of the data collection for this research in June, 2012. Such delays in making flood damaged schools functional means disruption in school attendance, which in turn affects the motivation of children for schooling. A farmer in the same village mentioned that in 2010, he lost his whole field of crops which was meant to sustain his family for the whole year and no one came to his aid, not the government, nor the humanitarian agencies, relatives or friends. It was very difficult for him and his children. What helped him was his strong fishing ability in order to provide food for the family. This means that the little money he gets cannot be used for any extra-ordinary activities other than food, not even to send children to school. 
Nevertheless, it is important to mention that the government and humanitarian agencies do assist in the recovery process for these communities and also provide support in rebuilding, reconstructing and rehabilitating government infrastructure, despite the fact that the support is usually delayed and insufficient.

\subsection{Summary and Concluding Remarks}

As discussed in this chapter, several interventions are being undertaken by the government, NGOs, and other stakeholders to mitigate the negative impacts of floods on the affected communities. These interventions include flood preparedness, relocation, relief aid, remittances, enrolment of children in upper land schools during displacements, support for children with special needs after evacuation, repatriation, and rehabilitation of public services in the plains. The interventions do, to some extent, directly or indirectly minimize the negative impact of floods on primary school education by providing opportunities for children to continue schooling, though in an abnormal situation. Interventions such as the enrolment of flood displaced children in upper land schools, remittances and rehabilitation of flood damaged public services like schools in the plains were found to be crucial in ensuring the continuation of children's primary education during and after displacement.

However, most of the interventions undertaken to mitigate floods impact (on education) are not seen as having the desired effect because most of them are reactive and late instead of proactive. In other words, action is taken or concern is shown only during the floods disaster and immediately after, not before or long after. For instance, even though flood preparedness is a key intervention that could considerably minimize the impact of floods, it hardly gets past the planning stage. It is only operationalized (see section 6.3.1) when the disaster occurs. This makes external response (government, NGOs, etc.) to floods disasters in the flood plains late and in turn less effective. Similarly, interventions on the rehabilitation of flood damaged schools, which would ensure the immediate return to schools once displaced persons are repatriated to the flood plains, only takes place long after repatriation. Most often, the reconstruction and rehabilitation of schools and other public services (an intervention mainly undertaken by the government) is delayed, thereby leading to the disruption of schooling even when the pupils have resettled back in the flood plains.

An intriguing finding of this research was that even when these interventions do provide the enabling environment for children to continue schooling whilst in the upper lands (displaced from the plains), it usually benefits families that are financially 
"better off" because they can afford the extra cost of sending the children to upper land schools. Poor families on the other hand find it difficult to afford the extra cost and sometimes require the children to assist in the home upkeep.

Most of the interventions discussed above provide relief to the affected people and some of the assistance, particularly that of enrolment of flood affected children in upper land schools -supporting the establishment of temporary classrooms, schools, providing school supplies etc.,- does help the communities to continue supporting the education of school children. Generally, in most disasters, especially in Africa, it is difficult for the government to single-handedly provide a complete support package to victims of disasters, which is why the support from humanitarian organizations comes in handy, even then, the needs are always enormous and humanitarian assistance is not enough. However, whatever support that is provided makes a difference and the government should always engage with the humanitarian organizations to ensure that adequate support is available and in good time.

The following chapter discusses in detail some policy recommendations on how to make primary education resilient to the impact of floods, and also outlines the limitations of the research undertaken leading to some recommendations for further studies on the subject matter. 


\section{CHAPTER 7 POLICY RECOMMENDATIONS, LIMITATIONS OF THE RESEARCH AND SUGGESTIONS FOR FURTHER STUDIES}

\subsection{Policy Recommendations}

A number of recommendations can now be forwarded for improving the resilience of primary education in the case of flooding in the Zambezi River belt in Zambia. Whilst it is easy to draw up a washing-list of measures based on interviews with various stakeholders, practical and effective policy making in the light of scarce public resources requires prioritization. This is what the remainder of this section attempts to illustrate.

The measures to prioritize are justified using the following proposed diagrammatic framework (figure 7.1 adapted from Naudé et al., 2009), which makes a resilient primary education sector the key focus area, and relates the various findings of the thesis to this. The framework illustrates the inter-linkages between communities' vulnerabilities, coping mechanisms and the various measures to be undertaken and actors involved in building resilience for primary education in the flood plains.

As shown in the below figure (figure 7.1), there are several factors that expose communities to the risk of being affected by floods. These risk factors can be categorized into idiosyncratic (risk specific to individual or house hold assets) and covariate (risk to the entire community such as the flood plain context itself and all the associated risks of being in the plains). Irrespective of the underlying risk factors within the community, they have been striving to cope. Some of the coping mechanisms are harsh and negative to children's educational outcomes such as child labor, reduction in number of meals a day. Moreover, some coping mechanisms are Ex ante such as building houses on top of mounds and others Ex post such as using boats as means of transport during floods. 
Figure 7:1. A framework for building resilience of primary education

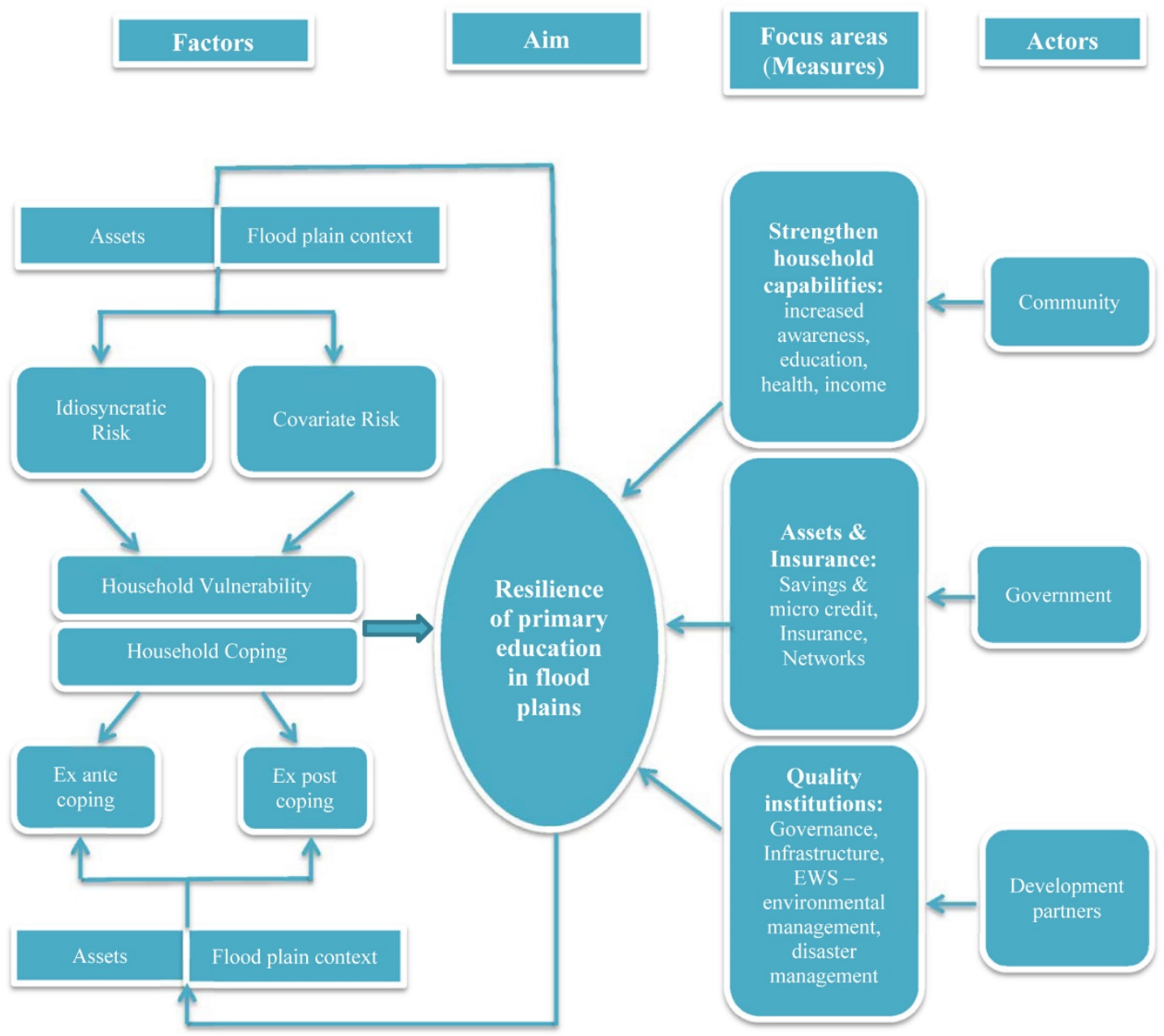

Source: Adapted from Naudé et al., 2009 
Whilst the factors that put the communities at risk of being affected by floods and the associated impact on the education of primary school children are perfectly known, communities coping mechanisms enable them survive to a certain extent, often at the risk of compromising the educational achievement of children. To ensure resilience to primary education in the flood plains, a concerted effort is required by various actors; community, government and development/humanitarian organizations using various measures such as strengthening household capacities, asset generation and providing quality institutions. In this research, the various measures and the actors working in tandem to provide the appropriate enabling environment for primary school education in the flood plains are described in the below paragraphs;

- Increased awareness and knowledge about the current and projected nature of flood disasters and the roles and responsibilities of the actors involved can trigger self-reflection (a vital first step if mind-sets are to be changed). This thesis identified several factors that limit the education achievement of children within the flood plain communities such as poverty, neglect, low value attached to education, culture, livelihood, and weak political structures. In order to ensure greater interest in education by the communities and ensure parents send their children to school, a high level advocacy needs to be applied. The elite group (educated and well-to-do indigenes) that hail from the community need to take extra steps and work through national education systems to institute education awareness campaign programmes that will enlighten communities on the essence of education and the long term benefits for the children and the society. The elite group should take a lead in providing opportunities for the children to engage in educational programmes outside the flood plains that will educate them on the value of education and what it means for them when they are educated. Carefully planned radio programmes and jingles as well as civic education in schools can be used to achieve this goal. Such campaigns can be supported by external stakeholders such as UNICEF and other organizations working on children's education.

- Discussions with technical engineers in the study area and literature reviewed indicated that powered engine boats will make a huge difference in supporting the movement of children to and from school during the floods period. These boats are safer, faster, with large carrying capacity to transport as many children as necessary to the various school locations. Though the boats can be 
expensive, community contributions over a period of time, with good management of the contributions can help in acquiring the boats on a periodic basis. The availability of these powered engine 'school boats' will reduce the dropout rate, repeating rate and improve the learning outcomes and hence quality of education in the flood plains. For sustainability of this initiative, a management committee of school boats within the community need to be instituted that will handle community contributions, procurement, operations and overall management.

- It is recommended to find a way of keeping the children in school in the flood plains even during the flooding period. UNICEF Zambia did a feasibility study on the possibility of constructing a school on top of a mound that will be created from soil and coated with concrete to reduce the effect of water from destroying the mound. The school will have a boarding home with catering services and quarters for teachers using local materials. The children will then be required to go home only during weekends if necessary and feasible. An effective means of transport such as a powered engine boat would therefore be necessary only during weekends. Such initiatives are cost effective and can easily be handled by the community if committed to do so. It minimizes travelling by children and maintains them in school throughout the flooding period. This will ensure a continuation of learning for the children all year round.

- One of the factors that demotivate school children in the flood plains, especially when they are at higher grades (6 to 7) is the feeling of not being able to continue on to high school after primary school. The results of this study showed very high dropout rates for both boys and girls at grades 6 and 7; and the major reason is the lack of secondary schools in the plain. The likelihood of them continuing outside the plain is very limited due to the associated high costs. Many parents cannot afford the cost of sending their children to upper land schools to have secondary education. Therefore the establishment of secondary schools in the flood plains through communities' efforts and advocacy through the MoE to subsidize the education system in order to reduce the financial burden of children's education on parents will make a remarkable difference in primary educational attainment in the plains. The possibility for parents to send their children to secondary schools will be much 
higher if there are secondary schools in the flood plains. It would be more cost effective for the parents, easily accessible and the children will be more motivated and enthusiastic to continue while in the final grades of primary school because they are aware of the fact that a good performance in the final primary school examinations automatically guarantees their enrolment into secondary school.

- The elites from the flood plain communities and the community leaders should advocate through district, provincial and national government and the donor community to put in place mechanisms that will enhance better education coverage in remote areas like the flood plains by ensuring that highly qualified and experienced teachers are recruited and motivated to work and live in the flood plains. For instance, the provision of free housing facilities for teachers, extra allowances through community contributions as incentives can increase the capacity of teachers and reduce teacher absenteeism in the flood plains, which will inevitable increase the quality of education and improves the learning achievement of school children.

- Communities in the flood plains need to consider advocating for a school curriculum and system which ensures that children do not go to school during the peak period of floods. That means, the school calendar and curriculum for schools in the flood plains need to be adapted based on the flood situation. As the period of flooding is known by the people, schools should be closed during periods when water levels are expected to be high (January to March). This will limit travel by children to school during the peak periods and reduce the risk of the education of children being affected by floods.

- Poverty and neglect are major challenges among households in the flood plains. While fishing and subsistence agriculture are the major livelihood activities, more can be done and a lot of resources from these livelihood activities can be obtained if people have a strong base to start. Micro credit facilities can help people to buy better fishing gear that will enhance fishing activities, which translates into increased income and in turn increased support for the education of their school children. As at the time of this research, households in the researched communities could only afford low quality fishing gears and some agricultural inputs, which allows low scale fishing and 
crop production activities despite the high population of fish and fertile soils. Humanitarian and development organizations interested in improving the lives of the flood plain communities could consider supporting the people by establishing improved and effective micro credit facilities that would engage them into better income generation and subsequently enable them to support children's education. Another possibility is for the flood plains community leaders to put the plains into better use by encouraging investors to establish massive agricultural production which will provide jobs for the community and will encourage development within the community. Communities will have the upper hand to support their children to go to school and the plains would be a lot developed.

- National savings and insurance schemes if effective, will guarantee compensation to families who are badly hit by floods and have lost their key livelihood assets to enable them restart life after a severe flood disaster. While humanitarian support from government or humanitarian organizations is important to provide relief to the affected people, this support is usually not on time and not sufficient. The availability of an immediate support to the affected people through a national insurance scheme will ensure that parents are not overstretched to a level that they can risk not sending children to school because there is nothing at home or engage the children into labor to support the upkeep of the home.

- Child labor is commonly practiced in the flood plains. Children are subjected to work and support the home upkeep instead of going to school. Organizations working on children's rights such as UNICEF should work through community leaders, district, provincial and state government to strengthen policies on child labor and put in place control mechanisms to ensure that parents do not exploit children and subject them to a responsible life whilst they are yet kids. If child labor is discouraged and emphasis is placed on education for every child initiatives, primary education in the flood plains will improve tremendously.

- The flood plains in Zambia are characterized by low infrastructure and very meagre basic social services. One of the major challenges for children in the flood plains is their inability to access good medical services, lack of safe 
drinking water, lack of electricity, and poor road conditions, which endangers their lives and limit the chances of acquiring good education. Most childrelated illnesses cannot be cured in the flood plains and most parents do not have the means to send their sick children to better hospitals in the upper land. This causes a lot of deaths among children in the flood plains. Provision of adequate basic social services through community development programmes supported by donor communities would keep children safe, healthy and in a better frame of mind to focus on education.

- EWSs in Zambia instituted by government are not functioning well, therefore people cannot rely on them for flood warning. Communities can develop their own alert systems based on their own indigenous knowledge and experience on flood incidences to inform people to be better prepared well ahead of the floods. For instance, the use of town criers to pass on messages of a potential devastating flood will alert people to take appropriate actions and ensure that the incidence of the floods do not have a major effect on the education of school children. Moreover, many African countries now use low-cost technologies, such as radio links from cellular communication networks, which, in addition to facilitating transmission of point measurements of rainfall and river flow, can be used to monitor path-averaged rainfall (Leijnse et al., 2007), as well as emerging low-cost space-borne data that enable both rainfall measurement ( $\mathrm{Li}$ et al., 2009) and near real time flood monitoring (Schumann et al., 2010). These kinds of technologies can be applied in the Zambia situation.

- Owing to the flooding patterns and size of the Zambezi basin of which the research area is part of, flooding in the basin is not an issue that any country can single-handedly manage effectively, especially where heavy rains in one country influence flooding in the territory of a neighboring country. While national-level coordination seems to be improving in all affected countries, coordination between basin countries is still limited. In this respect, the SADC Zambezi Watercourse Commission (ZAMCOM) seems to be promising for trans-boundary flood management. However, coordination of flood issues is not mentioned explicitly as one of ZAMCOM's functions, although the commission is to 'collect, evaluate and disseminate all data and information on the Zambezi Watercourse as may be necessary for the implementation' of the ZAMCOM Agreement. In the SADC Declaration on Agriculture and Food 
Security (SADC, 2004b), the region aims to develop programmes to improve flood and drought mitigation, to develop water harvesting technologies, flood control and strategic water storage infrastructures, and to develop water management and irrigation plans. However, it is not yet established how SADC/ZAMCOM will improve flood preparedness and flood response mechanisms to reduce humanitarian crises. The SADC countries affected by the recurring floods will need to strengthen the trans-boundary flood mitigation initiatives involving the communities concerned to generate knowledge on how to reduce the level of impact caused by the floods to the communities themselves, but most importantly how to reduce the impact on the education of school children.

- Several attempts have been made by the humanitarian community and government to encourage people to relocate to higher grounds since the yearly floods have so many negative effects. However, communities in the flood plains are very reluctant to leave the plains. It is home to them, their generations past and most importantly, their livelihoods are attached to the floods (fishing, farming and livestock rearing). Therefore they cannot easily survive in the upper lands if they are to leave the flood plains. If people are reluctant to vacate flood prone areas, then the question is what alternatives have they got if they stay? Communities must devise ways of living with the floods. After the flood disaster response operations, the various stakeholders need to analyze the lessons learned from the interventions to inform future flood related activities and interventions. However, events often overtake 'lessons learned'. As situations normalizes, the strength of stakeholders to change management habits, allocate more funds and resources to flood management, enforce laws and build the resilience of the local population tends to wither until the next disaster strikes. To counteract this, stakeholders should mainstream flood management into all relevant activities geared towards supporting flood plain communities. For instance, there should be education in disaster programmes mainstreamed into partners' work plans that ensures that children's education is protected during disasters such as floods. Moreover, integrating climate forecasts into all dimensions of disaster management will also ensure that stakeholders are prepared for floods that occur in the midst of recovery interventions. In this way, the hazard effects on the education of school children will be minimized. 
- The inadequate development interventions and the magnitude of flood disasters necessitate humanitarian interventions in the first place. The dominance of humanitarian interventions as a response to floods highlights development gaps such as poverty and inadequate services, infrastructures and capacities. The humanitarian and development communities need to address these gaps in a more sustainable manner. In the context of climate change, if floods become more intense and if all interventions by key actors fail to build the resilience of the population, then more flood-triggered humanitarian emergencies should be expected in the Zambezi basin in the future. Admittedly, development and humanitarian interventions have made progress, but the continued loss of livelihoods and human life and the perpetual disruption of the education of children means that there should be more focus on improving development interventions. Various options that are not resource intensive exist for DRR. However, the issue of inadequate resources still needs to be addressed, for instance through sourcing for adaptation funding and increasing the effectiveness of development interventions. Ensuring a sustainable development path will address most of the flood challenges and positively influence adaptation to climate change. Humanitarian interventions are short term, lasting 3-6 months, and thus cannot adequately address the factors that make people vulnerable under nondisaster conditions. Development interventions on the other hand are long term. It is not realistic to expect humanitarian organizations to implement long-term development interventions within such a short period. Most donor agencies however, are now emphasizing on linking relief and development and DRR, but these approaches are not yet seemingly mainstreamed in development plans, but should actually do. The donor community will also need to address chronic problems of poverty and unequal access to resources, as well as human development that would increase the resilience of local populations. The many community based initiatives for natural resource management in Zambia can also act as vehicles for a participative DRR, as they form an integral part of many conservation or development interventions. 


\subsection{Limitations of the Research and Suggestions for Further Studies.}

There has been relatively limited research done on the direct impact of floods on primary education, especially in Africa. The availability of sufficient literature on the subject could have assisted in concretely confirming the results obtained. This thesis will provide a base for further academic research in this field in Sub Saharan Africa.

This study focused on the impact of floods on primary school education in the flood prone areas of Zambia over a 5 years period, based on stakeholders' perspectives and review of school records. There was no investigation on the long term implications of the impact on the development of the community and the nation. A broader research on this subject could look at the economic loss on human capital as a result of the impact on children's education and what it means for the development of the community and the nation in economic terms.

It could have been interesting to do a statistical analysis of socio-economic indicators for both the flood affected and the non-flooded affected communities to further determine the comparability of the two communities in socio-economic terms and hence provide further information to substantiate that the low education outcomes in the flood affected communities are due to floods. This analysis was not possible because data was not available. Inference on the comparability of the two communities was therefore based on interviews and observations which was found sufficient. However, future studies could look at this aspect more closely.

Some of the policy recommendations discussed in Section 7.1 demands the attention of top level decision makers in government and the donor community to come up with policies that will strengthen community resilience to floods on primary school education. The top decision makers and donor officials are seating in Lusaka, the capital city. The study did not make provision to capture the views and perspectives of these decision makers. Further research on the subject should engage these people to have a clear understanding on why things remain the way they are and what stakeholders are thinking to avert the situation.

Supporting communities to develop effective and sustainable social insurance schemes should be a focus in further research on the subject matter. Social insurance schemes such as community driven money saving ventures developed and owned by the communities themselves will help people live with floods and ensure immediate relief 
and education support to the children. The management of such schemes will need technical support that can come from either within the communities themselves or from stakeholders supporting the flood plain communities.

The Baroste flood plain in the Western Province of Zambia was researched as case study and inferences were made based on the data collected in the study area. The Zambezi River from which the Baroste plain emerges passes through 8 basin countries in Africa. Further research should compare the situation in all the 8 basin countries to provide a more accurate conclusion. Broader research on the subject should consider not only the comparison of the Zambezi river basin countries but also look the situation in a different continent such as Asia to determine the impact variations and similarities and how people deal with the situation. 


\section{REFERENCES}

Achoka J.S. K and Maiyo, J (2008). Horrifying disasters in western Kenya: Impact on education and national development. Academic Journals, Educational Research Reviews, 3(3):154-161.

Adger, W.C (2000). Social and ecological resilience are they related? Progress in Human Geography, 24(3): 347-364.

ADPC (2005). Integrated Flood Risk Management in Asia: A Primer. ADPC, Bangkok.

Aldrich, D. P (2012). Building resilience: Social capital in post-disaster recovery. Chicago: University of Chicago Press.

Anderson, C (2005). What's the Difference Between Policies and Procedures?, Bizmanualz. April 4, 2005.

Anderson, M (1985). A reconceptualization of the linkages between disasters and development. Disasters: The international journal of disaster studies and practice. (Havard supplement).

Apan, A; Keogh, D.U; King, D; Thomas, M; Mushtaq, S and Baddiley, P (2010). The 2008 floods in Queensland: A case study of vulnerability, resilience and adaptive capacity. Report for the National Climate Change Adaptation Research Facility, Gold Coast.

Ashley, S.T and Ashley, W.A (2008). Flood Fatalities in the United States. Journal of Applied Meteorology and Climatology, 47:805-818.

Assaad, R; Levison, D and Zibani, N (2005). The Effect of Child Work on Schooling: Evidence from Egypt. Unpublished manuscript.

Assan, J.K; Caminade, C and Obeng, F (2009). 'Environmental variability and vulnerable livelihoods: minimizing risks and optimizing opportunities for poverty alleviation'. Journal of International Development. 21(3): 403-418.

Attanasio, O and Szekely, M (2002). A Dynamic Analysis of Household DecisionMaking in Latin America: Changes in Household Structure, Female Labor Force Participation, Human Capital and its Returns. Research Network Working papers. 
Badri, S.A; Asgary, A; Eftekhari, A.R and Levy, J (2006). 'Post-disaster resettlement, development and change: a case study of the 1990 Manjil earthquake in Iran'. Disasters. 30(4): 451-468.

Baez, J and Santos, I (2007). Children's Vulnerability to Weather Shocks: A Natural Disaster as a Natural Experiment, Working Paper.

Baez, J; Fuente, A and Santos, I (2010). Do Natural Disasters Affect Human Capital? An Assessment Based on Existing Empirical Evidence. The Institute for the Study of Labor (IZA) Discussion Paper No. 5164.

Bahadur, A.V; Ibrahim, M and Tanner, T (2010). The resilience renaissance? Unpacking of resilience for tackling climate change disasters. Strengthening Climate Resilience Discussion Paper 1.

Banda, G. Z and Ng'ambi, M (2007). Climate change and rural livelihoods: Impact and adaptation of small-scale farmers in Malawi. Africa Can Feed Itself, A. Nærstad (eds.), 79-92. www.agropub.no/asset/2636/1/2636_1.pdf. (Accessed on 5 August 2009).

Bankoff, G (2001). Rendering the world unsafe: 'vulnerability' as western discourse. Disasters 25(1): 19-35.

Barnett, J and Webber, M (2009). Accommodating Migration to Promote Adaptation to Climate Change. Commission on Climate Change and Development, Stockholm.

Bates, K. A and Swan, R. S (eds.) (2007). Through the Eye of Katrina: Social Justice in the United States. Durham, NC: Carolina Academic Press.

Becker, G (1993). Human capital: A Theoretical and empirical analysis, with special reference to education (3rd ed.). Chicago: University of Chicago Press.

Becker, G (1993). A Treatise on the Family. Cambridge, United States: Harvard University Press.

Beegle K; Dehejia, R; Gatti, R and Krutikova, S (2008). The Consequences of Child Labor: Evidence from Longitudinal Data in Rural Tanzania. Policy Research Working Paper 467. http://elibrary.worldbank.org/doi/pdf/10.1596/1813-94504677. (The World Bank Development Research Group, Macroeconomics and Growth Team). 
Beegle K; Dehejia, R and Gatti, R (2004). Why should we care about child labor? The education, labor market, and health consequences of child labor. Working paper 19980, National Bureau of Economic Research.

Beegle, K; Dehejia, R and Gatti, R (2003). Child Labor, Income Shocks, and Access to Credit. World Bank Policy Research Working Paper No. 3075.

Beeton, R.J.S (2006). Society's forms of capital: A framework for renewing our thinking. Paper presented at the 2006 Australian State of the Environment Committee, Department of the Environment and Heritage, Canberra, http://www.deh.gov.au/soe/2006/emerging/capital/index.html.

Bell, L and Stevenson, H (2006). Education Policy - Process. Themes and Impact. London: Routledge.

Berman, R; Quinn, C and Paavola, J (2013). Identifying drivers of household coping strategies to multiple climatic hazards in Western Uganda: implications for adapting to future climate change. Sustainability Research Institute (SRI), Paper No. 51. School of Earth and Environment, The University of Leeds, Leeds, LS2 9JT, United Kingdom.

Blaikie, P; Cannon, T; Davis, I and Wisner, B (1994). At Risk: Natural Hazards, People's Vulnerability and Disasters. London: Routledge.

Bobb, S (2007). 'Mozambican floods prompt debate over permanent resettlement of displaced'. 15 March. http://reliefweb.int/report/mozambique/mozambicanfloods-prompt-debate-over-permanentresettlement-displaced. (Accessed on 28 January 2013).

Bogardi, J and Warner, K (2008). 'Here comes the flood'. Nature Reports Climate Change. 138.

http://www.nature.com/climate/2009/0901/full/climate.2008.138.html. (Accessed on 28 January 2013).

Bola, G; Mabiza, C; Goldin, J; Kujinga, K; Nhapi, I; Makurira, H and Mashauri, D (2013).Coping with droughts and floods: A Case study of Kanyemba, Mbire District, Zimbabwe. J. Phys. Chem. Earth

(2013). http://dx.doi.org/10.1016/j.pce.2013.09.019.

Bolin, R and Stanford, L (1998). The Northridge Earthquake: Community-based Approaches to Unmet Recovery Needs. Disasters 22(1): 21-38. 
Brida, A; Owiyo, T and Sokona, Y (2013). Loss and damage from the double blow of flood and drought in Mozambique. Int. J. Global Warming, 5(4): 514 - 531.

Brouwer, R; Akter, S; Brander, L and Haque, E (2007). Socio-economic Vulnerability and Adaptation to Environmental Risk: A case study of Climate Change and Flooding in Bangladesh. Risk Analysis, 27 (2): 313.

Brun, C (2003). Local Citizens or Internally Displaced Persons? Dilemmas of Long Term Displacement in Sri Lanka. Journal of refugee studies. Oxford University Press.

Burbules, N. C and Torres, C. A (2000). Globalization and Education: An Introduction, in: N. C. Burbules and C. A. Torres, (eds.) Globalization and Education: Critical Perspective. New York: Routledge.

Cairncross, S (2003). Editorial: Water Supply and Sanitation: Some Misconceptions. Tropical Medicine and International Health, 8(3): 193-195.

CAN (2008). El Cambio Climático no tiene fronteras. Impacto del Cambio Climático en la Comunidad Andina. Lima: La Comunidad Andina.

Cannon, T (2000). Vulnerability analysis and disasters. In Parker, D.J., (ed.), Floods. London: Routledge, 45-55.

Cannon, T (1994). Vulnerability Analysis and the Explanation of Natural Disasters. In A. Varley (ed.) Disasters, Development and Environment. New York: Wiley.

Carney, D (ed.) (1998). Sustainable rural livelihoods: what contribution can we make? London: Department for International Development.

Cavallo, E.A and Noy, I (2009). The Economics of Natural Disasters: A Survey. RES Working papers 4649. Inter-American development Bank, Research Department.

Chambers, R (2006). Vulnerability, Coping and Policy. IDS Bulletin 37(4): 33-40.

Chan, N.W. and Parker, D.J (1996). Response to dynamic flood hazard factors in peninsular Malaysia. The Geographical Journal, 162(3), 313-25.

Chang, K (2010). Community cohesion after a natural disaster: insights from a Carlisle flood. Disasters 34(2):289-302 
http://www.ncbi.nlm.nih.gov/pubmed/19863571.

Chinapah, V (2000). With Africa for Africa, Quality Education for All. South Africa/Paris: Human Science Research Council. UNESCO/South Africa.

Christoplos, I; Farrington, J and Kidd, A.D (2001). Extension, Poverty and Vulnerability: Inception Report of a Study for the Neuchâtel Initiative. ODI Working Paper No. 144. London: Overseas Development Institute.

Chuku, C. A. and Okoye, C (2009). Increasing resilience and reducing vulnerability in Sub-Saharan African agriculture: Strategies for risk coping and management. African Journal of Agricultural Research, 4(13):1524-1535.

CLUVA (Climate change and Urban Vulnerability in Africa) (2014). Climate change and vulnerability of African cities. Research briefs. AMRA s.c.ar.l., Naples, Italy.

Christie, F and Hanlon, J (2001). Mozambique and the Great Flood of 2000. Oxford: James Currey.

Coetzee, E (2002). 'Urban vulnerability: a conceptual framework'. In C. Nomdo (ed.) Urban Vulnerability: Perspectives from Southern Africa. Cape Town: Periperi Publications, pp. 2-39.

Cohen, D and Crabtree B. (2006). Qualitative Research Guidelines Project. http://wwwqualres.org/HomeInfo-3631.html.

Corbin, J and Strauss, A (2008). Basics of qualitative research (3rd ed.). Los Angeles, CA: Sage.

CRED (2012). Annual Statistics Review. Université Catholique de Louvain Brussels - Belgium.

Crichton, D (2007). “Increasing vulnerability to climate change and international developments in flood risk management". Proceedings of a seminar "UK Flood: Recent Lessons; future prospects." In association with the under 35s Reinsurance Group, organized by the Benfield UCL Hazard Research Centre, 9th November, 3 Minster Court, Mincing Lane, London.

Cutter, S.L; Emrich, C. T; Webb, J.J and Morath, D (2009). Social Vulnerability to Climate Variability Hazards: A Review of the Literature. Hazards and 
Vulnerability Research Institute, Department of Geography, University of South Carolina, Columbia. SC 29208.

Cutter, S. L; Barnes, L; Berry, M; Burton, C; Evans, E and Tate, E (2008). A placebased model for understanding community resilience to natural disasters. Global Environmental Change, 18: 598-606.

Dahlberg, K; Dahlberg, H and Nystrom, M (2001). Reflective life world research (2nd ed.). Lund, Sweden: Studentlitteratur.

Dar, A; Blunch, N.H; Kim, B and Sasaki, M (2002). Participation of children in schooling and labor activities: A review of empirical studies. Social Protection discussion paper 0221, Washington: World Bank.

Dash, N and Morrow, B.H (2007). "Lasting effects of Hurricane Andrew on a working-class community." Natural Hazards Review 8(1): 13-21.

Davidson, M.A (2006). Designing for disasters. Massachusetts coastal hazards commission, NOAA coastal services center.

Davis, I and Hall, N (1999). Ways to measure community vulnerability. In Ingleton, J., (eds.), Natural disaster management. Leicester: Tudor Rose, 87-89.

DEC (2001). Independent Evaluation of Expenditure of DEC Mozambique Floods Appeal Funds March to December 2000. DEC, London.

Deininger (2003). Does cost of schooling affect enrolment by the poor? Universal primary education in Uganda. Economics of Education Review, 22 (3): 291-305.

De Janvry, A; Finan, F; Sadoulet, E and Vakis, R (2006). “Can conditional cash transfer programs serve as safety nets in keeping children at school and from working when exposed to shocks?" Journal of Development Economics, 79(2): 349373.

Denzin, N. K and Lincoln, Y. S (eds.) (2005). The Sage Handbook of Qualitative Research (3rd ed.). Thousand Oaks, CA: Sage. ISBN 0-7619-2757-3. 
Deressa, T. T; Hassan, R.M; Ringler, C; Alemu, T and Yesuf, M (2009). Determinants of farmers' choice of adaptation methods to climate change in the Nile Basin of Ethiopia. Global Environmental Change, 19 (2): 248-255.

Deshmukh, A; Ho Oh, E and Hastak, M (2011) "Impact of flood damaged critical infrastructure on communities and industries", Built Environment Project and Asset Management, 1(2): 156 - 175.

http://www.emeraldinsight.com/journals.htm

Devereux, S; Teshome, A and Sabates-Wheeler, R (2005). 'Too much inequality or too little? Inequality and stagnation in Ethiopian agriculture'. IDS Bulletin. 36(2): 121-126.

DeWalt K.M and DeWalt, B.R (2010). Participant Observation: A guide for field workers (2nd ed).

DFID (1999). Department for international development. Sustainable livelihoods guide sheets. London, DFID.

Di Baldassarre, G; Montanari, A; Lins, H; Koutsoyiannis, D; Brandimarte, L and Blöschl, G (2010). Flood fatalities in Africa: From diagnosis to mitigation. Geophysical Research Letters, 37(22): 1-5; L22402, doi:10.1029/2010GL045467.

Doocy, S; Daniels, A; Murray, S and Kirsch, T. D (2013). The Human Impact of Floods: a Historical Review of Events 1980-2009 and Systematic Literature Review. PLOS Currents Disasters (Edition 1).

Douglas, I; Alam, K; Maghenda, M; Mcdonnell, Y; Mclean, I and Campbell, J (2008). "Unjust waters: climate change, flooding and the urban poor in Africa". Environment \& Urbanization, 20(1): 187-205. Doi: 10.1177/0956247808089156.

Duryea, S and Arends-Kuenning, M.P (2003). School attendance, child labor and local labor market fluctuations in urban Brazil, World Development 31(7): 11651178.

Duryea, S (1998). Children's advancement through school in Brazil: the role oftransitory shocks to household income. Inter-American Development Bank, Office of the Chief Economist, Working Paper No. 376, July. 
Dyson, M. E (2006). Come Hell or High Water: Hurricane Katrina and the Color of Disaster. New York: Basic Civitas Books.

Dynes, R.R (2002). The importance of social capital in disaster response. Preliminary Paper no.327. University of Delaware, Disaster research center.

Enarson, E. (2007). "Chapter 13: Identifying and addressing social vulnerabilities." In W. L. Waugh and K. Tierney (eds.), Emergency Management: Principles and Practices for Local Government (2nd ed.). Washington D.C.: ICMA Press, pp 257-278.

Edmonds, E.V (2007). Child labor. In: J. Strauss and T.P. Schultz, Editors. The Handbook of Development Economics Vol. 4, North Holland, Amsterdam (2007).

Edmonds, E.V (2005). Does child labor decline with improving economic status? Journal of Human Resources 40(1): 77-99.

EEA (2004). Signals 2004, “A European Environment Agency update on selected issues", Office for Official Publications of the European Communities, Luxembourg.

EM-DAT (2014). The OFDA/CRED International Disaster Database www.emdat.be - Université Catholique de Louvain - Brussels - Belgium.

Euroconsult Mott MacDonald (2008). SADC-WD/Zambezi River Authority/

SIDA /DANIDA, Norwegian Embassy Lusaka 2008: Integrated water resources management strategy and Implementation plan for the Zambezi River Basin. www.zamwis.com/Disk/PDF/Final_Strategy_Apr08_ZAMWIS.pdf. (Accessed on 24 April 2008).

FitzGerald, G; Du, W; Jamal, A; Clark, M; Hou, X.Y (2010). Flood fatalities in contemporary Australia (1997-2008). Emergency Medicine Australasia, 22(2):80186.

Foster, K. A (2006). A case study approach to understanding regional resilience. A working paper for building resilience network. Institute of urban regional development. University of California.

Fothergill, A and Peek, L (2004). "Poverty and disasters in the United States: A review of recent sociological findings." Natural Hazards, 32(1): 89-110. 
Frankenberger, T. R and Nelson, S (2013a). Background paper for the expert consultation on resilience measurement for food security. Paper presented at the Expert Consultation on Resilience Measurement Related to Food Security. Rome, Italy: Food and Agricultural Organization and World Food Programme. Retrieved from:

http://www.fsnnetwork.org/sites/default/files/resilience_measurement_backgro und_paper_2.12.2013.docx

Frankenberger, T; Mueller, M; Spangler, T and Alexander, S (2013). Community Resilience: Conceptual Framework and Measurement Feed the Future Learning Agenda. Rockville, MD: Westat.

Funder, M; Mweemba, C.E and Nyambe, I (2013). The climate change agenda in Zambia National interests and the role of development cooperation. DIIS working paper.

Garbero, A and Muttarak, R (2013). Impacts of the 2010 droughts and floods on community welfare in rural Thailand: differential effects of village educational attainment. Ecology and Society 18(4): 27. http:// dx.doi.org/10.5751/ES-05871180427.

Genovese, E; Lugeri, N; Lavalle, C; Barredo, J. I; Bindi, M and Moriondo, M (2007). An assessment of weather-related risks in Europe: Maps of flood and drought risks. (Interim report for ADAM FP6 Integrated Project). Joint Research Centre, European Commission, Luxembourg.

Genovese, E (2006). A methodological approach to land use-based flood damage assessment in urban areas: Prague case study.

GFDRR and World Bank (2010). Report on the status of Disaster Risk Reduction in Sub-Saharan Africa. The International Bank for Reconstruction and Development. Washington: The World Bank.

Gilbert, R and Kreimer, A (1999). "Learning from World Bank's Experience of Natural Disasters Related Assistance", World Bank Paper Series No. 2, Disaster Management Facility, World Bank, Washington, D.C.

Gilead, T (2012). Education and the logic of economic progress. Journal of Philosophy of Education, 46(1). 
Gilead, T (2011). The Provenances of Economic Theory's Impact on Education: French Educational Thought at the End of the Ancien Régime, Educational Theory, 61(1): 55-73.

Gill, D.A and Ritchie, L.A (2011). Considering community capitals in disaster recovery and resilience. Public Entity Risk Institute (PERI).

http://www.riskinstitute.org/peri/component/option,com_deeppockets/task,cat ContShow/cat,86/id,1086/Itemid,84/.

Given, L.M (2008). The Sage Encyclopaedia of qualitative research methods. Los Angeles, California: Sage Publications. ISBN 1-4129-4163-6.

Goodwin, C. J (2005). Research in Psychology: Methods and Design. USA: John Wiley \& Sons, Inc.

Gradstien, M; Justman, M and Meier, V (2005). The Political Economy of Education - Implication for Growth and Inequality. Massachusetts: The MIT Press.

Green, G.P and Haines, A (2002). Asset building and community development. Thousand Oaks, CA: Sage.

Grothmann, T and Reusswig, F (2006). "People at risk of flooding: why some residents take precautionary action while others do not". Natural hazards, Vol. 38, Issue 1-2:101-120.

Guest, G; Namey, E and Mitchell. M (2013). Collecting Qualitative Data: A Field Manual for Applied Research. Thousand Oaks, CA: Sage. http://www.sagepub.com/upm-data/48453_ch_1.pdf

Guha-Sapir, D; Vos, F; Below, R and Ponserre, S (2012). Annual Disaster Statistical Review 2011. The numbers and trends. Centre for Research on the Epidemiology of Disasters (CRED); Institute of Health and Society (IRSS), Université catholique de Louvain - Brussels, Belgium.

Hammond, L (2008). 'Strategies of invisibilization: How Ethiopia's resettlement programme hides the poorest of the poor. Journal of Refugee Studies. 21(4): 517-536. 
Hardoy, J.E; Mitlin, D and Satterthwaite, D (1992). Environmental problems in Third World cities. London: Earthscan.

Hartman, C and Squires, G. D (eds.) (2006). There is No Such Thing as a Natural Disaster: Race, Class, and Hurricane Katrina. New York: Routledge.

Hewitt, K (2007). 'Preventable disasters: Addressing social vulnerability, Institutional risk and civil ethics'. Geographische Rundschau, International Edition 3(1): 43-52.

Holling, C.S; Schindler, D.W; Walker, B.W and Roughgarden, J (1995). Biodiversity in the functioning of ecosystems: An ecological synthesis. In C. Perrings, K.G. Maler, C. Folke, C.S. Holling \& B.O. Jansson (eds.) Biodiversity loss: Economic and ecological issues, (pp. 44-83). Cambridge: Cambridge University Press.

Holling, C.S (1973). Resilience and stability of ecological systems. Annual Review of Ecology and Systematics, 4: 2-23.

Holzmann, R and Jorgensen, S (2001). Social risk management: a new conceptual framework for social protection and beyond. International Tax and Public Finance, 8(4): 529-556.

IFRC (2011). Guidelines for livelihoods programming. IFRC and Red Crescent Societies, Geneva. http://foodsecuritycluster.net/

IFRC (2009b). International Federation of Red Cross and Red Crescent Societies 2009: MOZAMBIQUE: Floods and Cyclone. Final Report, www.ifrc.org/docs/appeals/O7/MD RMZ002finaL.pdf. (Accessed on 11 March 2009).

IFRC (2007). Guidelines for cash transfer programming. Geneva : IFRC.

IFRC (2001). World Disasters Report 2001. Geneva: IFRC.

ILO (2014). "What is child labour?" International Labour Organisation. http://www.ilo.org/ipec/facts (Accessed 26 April 2014).

IPCC (2012). Summary for Policymakers. In: Managing the Risks of Extreme Events and Disasters to Advance Climate Change Adaptation [Field, C.B., V. Barros, T.F. Stocker, D. Qin, D.J. Dokken, K.L. Ebi, M.D. Mastrandrea, K.J. Mach, G.-K. Plattner, S.K. Allen, M. Tignor, and P.M. Midgley (eds.). A Special Report of 
Working Groups I and II of the Intergovernmental Panel on Climate Change. Cambridge University Press, Cambridge, UK, and New York, NY, USA, pp. 1-19.

IPCC (2001a). “Climate Change 2001: The Scientific Basis", Contribution of Working Group I to the Third Assessment Report of the Intergovernmental Panel on Climate Change, published for the Intergovernmental Panel on Climate Change. New York: Cambridge University Press, University Press. Available at: http://www.grida.no/climate/ipcc_tar/wg1/index.htm

IPCC (2001b). "Climate Change 2001: Impacts, adaptation and vulnerability", Contribution of Working Group II to the Third Assessment Report of the Intergovernmental Panel on Climate Change (IPCC). Cambridge: Cambridge University Press.

Islam, M.S; Hasan, T; Chowdhury, M.S.I.R; Rahaman, M.H and T. R. Tusher, T.R (2012). Coping Techniques of Local People to Flood and River Erosion in Char Areas of Bangladesh Environ. Sci. \& Natural Resources, 5(2): 251-261. www.banglajol.info/index.php/JESNR/article/download/14827/10563. (Accessed on 25 March 2014).

IUCN (2003). Baroste flood plain in Zambia: local economic dependence on wetland resources. Case Study in Wetland Valuation \#2.

Jacoby, H and Skoufias, E (1997). Risk, financial markets, and human capital in a developing country. Review of Economic Studies, 64(3): 311-335.

Jain, N.K (2000). Floods in a South Asian context: critical reflections on the International Decade and local community participation in flood disaster reduction. In Parker, D.J., Ed), Floods. London: Routledge, 255-59.

Jensen, R (2000). "Agricultural Volatility and Investments in Children." American Economic Review, 90(2): 399-404.

Jongman, B; Ward, P. J and Aerts, J.C.J.H (2012). Global exposure to river and coastal flooding: Long term trends and Changes. Global Environmental Change, 22(4): 823-835. Elsevier Ltd.

Jonkman, S.N; Maaskant, B; Boyd, E and Levitan, M.L (2009). Loss of life caused by the flooding of New Orleans after Hurrican Katrina: Analysis of the relationship between flood characteristics and mortality. Risk Analysis, 29(5): 676698. 
Jonkman, S.N and Vrijling J.K (2008). Loss of life due to floods. Journal of Flood Risk Management, 1(1): 43-56.

Jonkman, S.N (2005). Global perspectives on loss of human life caused by floods. Natural Hazards, 34(2): 151-175.

Jonkman, S.N and Kelman I (2005). An analysis of the causes and circumstances of flood disaster deaths. Disasters, 29(1):75-97.

Jones, P. W (2007). World Bank Financing of Education-Lending, Learning and Development. London: Routledge.

Junk, W.J and Welcomme, R.L (1990). Flood plains. In: Wetlands and Shallow Continental Water Bodies, ed. B.C. Patten et al., pp. 491-524. The Hague, The Netherlands: SPB Academic Publishers.

Kar, N (2009). "Psychological impact of disasters on children: review of assessment and interventions." World Journal of Pediatrics, 5(1): 5-11. In Cutter, S.L; Emrich, C. T; Webb, J.J and Morath, D (2009), Social Vulnerability to Climate Variability Hazards: A Review of the Literature. Hazards and Vulnerability Research Institute, Department of Geography, University of South Carolina, Columbia.

Klein, R.J.T; Nicholls, R. J and Thomalla, F (2003). Resilience to natural hazards: How useful is this concept? Environmental Hazards, 5: 35-45.

Koenig, D (2005). 'Enhancing local development in development-induced displacement and resettlement projects'. In C.D. Wet (ed.) Development-Induced Displacement: Problems, Policies and People. Berghahn Books, Oxford. pp. 105-140.

Konseiga, A (2006). Household Migration Decisions as Survival Strategy: The Case of Burkina Faso. Journal of African Economies, 16(2): 198-233.

Kirsch, T.D; Wadhwani, C; Sauer, L; Doocy, S and Catlett, C (2012). Impact of the 2010 Pakistan Floods on Rural and Urban Populations at Six Months. PLOS Currents Disasters. 2012 Aug 22. Edition 1. doi: 10.1371/4fdfb212d2432.

Laska, S and Morrow, B. H (2006). "Social vulnerabilities and Hurricane Katrina: an unnatural disaster in New Orleans." Marine Technology Society Journal 40(4): 16-26. 
Leichenko, R; McDermott, M; Bezborodko, E and Namendorf, E (2013). Economic Vulnerability and Adaptation to Climate Hazards and Climate Change: Building Resilience in the Barnegat Bay Region. Rutgers, The State University of New Jersey.

Leijnse, H; Uijlenhoet, R and Stricker J. N. M (2007). Rainfall measurement using radio links from cellular communication networks, Water Resour. Res., 43, W03201, doi: 10.1029/2006WR005631.

Li, L; Hong, Y; Wang, J; Adler, R; Policelli, F; Habib, S; Irwin, D; Korme, T and Okello, L (2009). Evaluation of the real-time TRMM-based multisatellite precipitation analysis for an operational flood prediction system in Nzoia Basin, Lake Victoria, Africa. Natural Hazards, 50(1): 109-123, doi: 10.1007/s11069-0089324-5.

Ljungqvist, L (1993). Economic underdevelopment: The case of a missing market for human capital. Journal of Development Economics 40(2): 219-239.

Long, A. P (2007). "Poverty is the new prostitution: race, poverty, and public housing in post in Post-Katrina New Orleans. Journal of American History, 94.

Madamombe, E. K (2004). Zimbabwe: Flood management practices - Selected flood prone areas Zambezi Basin. WMO/GWP Associated Programme on Flood Management. www.apfm.info/pdf/casestudies/cs_zimbabwe.pdf. (Accessed on 15 April 2009).

Main, H and Williams, S.W (1994). Marginal urban environments as havens for low-income housing: Third World regional comparisons. In Main, H. and Williams, S.W., (eds.), Environment and housing in Third World cities. Chichester: Wiley, 151-70.

Maitra, D (2003). Schooling and educational achievement: Evidence from Bangladesh. Education Economics 11(2): 129-153.

Manyunga, J.S (2007). Understanding and Applying the Concept of Community Disaster Resilience: A capital-based approach. Department of Landscape Architecture and Urban Planning, Hazard Reduction \& Recovery Center, Texas AEM University, College Station, TX, 77843-3137, USA.

Manyena, S. B (2006). The concept of resilience revisited. Disasters, 30(4): 433-450. 
Marshall, R (2007). "Labor Standards, Human Capital, and Economic Development". Economic Policy Institute Working Paper No. 271; February 2005; ProQuest.

Marshall, C and Rossman, G.B (1989). Designing qualitative research. Newbury Park, CA: Sage.

Maskrey, A (1999). Reducing global disasters. In Ingleton, J., (ed.), Natural disaster management. Leicester: Tudor Rose, 84-86.

Masozera, M; Bailey, M and Kerchner, C (2007). "Distribution of impacts of natural disasters across income groups: a case study of New Orleans." Ecological Economics 63 (2-3): 299-306.

McDermott, T.K.J (2012). The effects of Natural Disasters on Human Capital Accumulation. Institute for International Integration Studies and School of Business, Trinity College, Dublin, Ireland.

McElroy, A and Townsend, P.K (2009). Medical Anthropology in Ecological Perspective. Boulder, CO: Westview, 375.

McKenzie, D. J (2001). The consumer response to the Mexican peso crisis. Mimeo. Stanford, CA: Stanford University.

Mercer, J (2010). Disaster Risk Reduction or Climate Change Adaptation: Are we reinventing the wheel? Journal of International Development 22: 247-264.

Metzler, J (2008). Impact of natural hazards on school progression: Evidence from Rural Peru. Munich Graduate school of Economics. Germany.

Miller, J.B (1997). FLOODS: People at Risk, Strategies for Prevention. New York and Geneva: United Nations Publication.

Ministry Of Education, Science and Technology, Kenya (2013). Education Cluster Annual Report (2013): An overview of Education in Emergencies in 2013. (http://reliefweb.int/sites/reliefweb.int/files/resources/EiE\%202013\%20Annual\%2 0Report).

Mmom P.C and Aifesehi, P.E (2013). Impact of the 2012 Flood on Water Quality and Rural Livelihood in the Orashi Province of the Niger Delta, Nigeria. Journal of Geography and Geology, 5(3): 216-225. http://www.ccsenet.org/journal/ 
Montz, B.E (2000). The generation of flood hazards and disasters by urban development of flood plains. In Parker D.J. Floods, Volume 1. London and New York: Routledge.

Morduch, J (1999). Between the state and the market: can informal insurance patch the safety net? The World Bank Research Observer, 14(2): 187-207.

Morrow, B. H (2008). Community Resilience: A Social Justice Perspective. The Community and Regional Resilience Initiative Research Report 4. http://www.resilientus.org/library/FINAL_MORROW_9-25-08_1223482348.pdf

Moser, C.O.N (1998). The asset vulnerability framework: reassessing urban poverty reduction strategies. World Development 26(1): 1-19.

Mwangi, E (2004). News and views from Africa.

http.//www.newsfromafrica/indices/index_1707.html. (Accessed on 2 June 2009).

Naude', W; Santos-Paulino, A.U and McGillivray, M (eds), (2009). Vulnerability in developing countries. United Nations University Press.

NFNC (2008) Annual Report on the Food and Nutrition Situation in Zambia. Lusaka, Zambia.

Newman, R; Ashley, R; MacTaggart, F; Gillon, S; Cashman, A; Martin, G and Molyneux-Hodgson, S (2008). Using non-structural responses (NSR) to better manage flood risk in Glasgow Richard. 11th International Conference on Urban Drainage, Edinburgh, Scotland, UK, 2008.

Neumayer, E and Plümper, T (2007). The gendered nature of natural disasters: the impact of catastrophic events on the gender gap in life expectancy, 1981-2002. Annals of the Association of American Geographers, 97(3): 551-566. DOI: 10.1111/j.1467-8306.2007.00563.x.

NOAA (2008). Drought: Public Fact Sheet. National Weather Service. http://www.nws.noaa.gov/om/brochures/climate/DroughtPublic2.pdf (Accessed on 26 April 2014).

Nishat, A; Reazuddin, M; Amin, R and Khan, A. R (eds.) (2000). The 1998 Flood: Impact on Environment of Dhaka City. Dhaka: Department of Environment and IUCN Bangladesh. 
Norris, F; Stevens, S; Pfefferbaum, B; Wyche,K and Pfefferbaum, R (2008). Community resilience as a metaphor, theory, set of capabilities, and strategy for disaster readiness. American Journal of Community Psychology, 41(1-2), 127-150. In Frankenberger, T., Mueller M., Spangler T., and Alexander S. October 2013. Community Resilience: Conceptual Framework and Measurement Feed the Future Learning Agenda. Rockville, MD: Westat.

Nott, J (2006). Extreme Events: A Physical Reconstruction and Risk Assessment. (p. 51). New York: Cambridge University Press. http://dx.doi.org/10.1017/CBO9780511606625.

UNOCHA (2001). Mozambique Floods 2001: Lessons Learned. UNOCHA, Geneva.

O'Connor, J.E and Costa, J.E (2004). The World's Largest Floods, Past and Present: Their Causes and Magnitudes (Circular 1254). Washington, D.C.: U.S. Department of the Interior, U.S. Geological Survey.

Osbahr, H; Twyman, C; Adger, N. W and Thomas, D. S. G (2008). 'Effective livelihood adaptation to climate change disturbance: scale dimensions of practice in Mozambique'. Geoforum, 39(6): 1951-1964.

Oudenhoven, F.J; Mijatovic, D and Eyzaguirre, P. B (2010). Social-ecological indicators of resilience in agrarian and natural landscapes. Management of Environmental Quality, 22(2): 154-173. In Frankenberger, T; Mueller, M; Spangler, $\mathrm{T}$ and Alexander, S (2013). Community Resilience: Conceptual Framework and Measurement Feed the Future Learning Agenda. Rockville, MD: Westat.

Oyekale, A. S and Gedion, K. E (2012). Rural households' vulnerability to climaterelated income shocks and adaption options in central Malawi. Journal of Food Agriculture \& Environment, 10(3-4): 1505-1510.

Paavola, J (2008). Livelihoods, vulnerability and adaptation to climate change in Morogoro, Tanzania. Environmental Science \& Policy, 11(7): 642-654.

Parker, D (1999). Flood. In Ingleton, J., (ed), Natural disaster management. Leicester: Tudor Rose, 38-40.

Pasteur, K (2011). From vulnerability to resilience: A framework for analysis and action to build community resilience. Warwickshire, England: Practical Action Publishing. RAND Corporation. Focus on Community Resilience. Accessed at: 
http://www.rand.org/content/dam/rand/pubs/corporate_pubs/2012/RAND_CP6 40-2012-04.pdf

Peacock, W.G and Girard, C (1997). Ethnic and Racial Inequalities in Disaster Damage and Insurance Settlements. In W.G. Peacock, B.H. Morrow and H. Gladwin (eds.) Hurricane Andrew: Ethnicity, Gender, and the Sociology of Disaster. London: Routledge.

Pendall, R; Foster, K.A and Cowell, M (2007). Resilience and regions: Building understanding of the metaphor. A working paper for building resilience network. Institute of urban regional development, University of California.

Petal, M (2008). Disaster Prevention for Schools Guidance for Education Sector Decision-Makers. UNISDR, Geneva.

Phillips, B. D and Hewett P. L (2005). "Home alone: Disasters, mass emergencies and children in self-care." Journal of Emergency Management, 3(2): 31-35.

Psacharopoulos, G (1987). Economics of education: Research and studies. Book, Edition (ISBN 0080333796). Xvi, 482.

Rashid, S.F (2000). The urban poor in Dhaka city: their struggles and coping strategies during the floods of 1998. Disasters 24(3): 240-53.

Ratha, D (2013). The impact of remittances on economic growth and poverty reduction. Migration Policy Institute. Policy brief. No. 8.

Resnik, J. (2006). International Organizations, the 'Education-Economic Growth' Black Boxand the Development of World Education Culture, Comparative Education Review, 50(2): 173-195.

Riddell, W.C (2004). The Social Benefits of Education: New Evidence on an Old Question. Department of Economics University of British Columbia. Paper prepared for the conference "Taking Public Universities Seriously", University of Toronto, December 3-4, 2004.

Robeyns, I (2006). Three Models of Education Rights, Capabilities and Human Capital, Theory and Research in Education, 4(1): 69-84.

Rozenzweig, M.R and Evenson, R.E (1977). Fertility, schooling, and the economic contribution of children in rural India: An econometric analysis, Econometrica 45(5): 1065-1079. 
Russell, T (2005). The humanitarian relief supply chain: Analysis of the 2004 South East Asia earthquake and Tsunami, unpublished thesis. Massachusetts Institute of Technology. USA.

SADC (2004b). Dar-es-Salaam Declaration on Agriculture and Food Security in the SADC Region. www.sadc.int/ index/browse/page/173. (Accessed on 20 April 2009).

Sadoulet, E; Finan, F; de Janvry, A. and Vakis, R (2004). Can Conditional Cash Transfer Programs Improve Social Risk Management? Lessons for Education and Child Labor Outcomes. Washington DC. World Bank. SP Discussion Paper No. 0420 .

Sanderson, D (2000). Cities, disasters and livelihoods. Environment and Urbanization 12(2): 93-102.

Sapir, D.G (1993). Natural and Man-Made Disasters: The Vulnerability of Women-Headed Households and Children without Families. World Health Statistical Quarterly 46: 227-33.

Shah, G.A (2013). Flood Disasters and its Impacts on Child Education in Sindh: A Case Study of 2010 Flood. International Journal of Advanced Research, 1(3): 329344.

Schultz, T. W (1961). Investment in Human Capital. The American Economic Review, 51(1): 1-17.

Schultz, T.W (1960). Capital formation by education. Journal of Political Economy, 68(6): 571-583.

Schumann, G; Di Baldassarre, G; Alsdorf, D and Bates P. D (2010). Near real-time flood wave approximation on large rivers from space: Application to the River Po, Italy, Water Resources Research., 46(5): 1-8; W05601, doi: 10.1029/2008WR007672.

Seballos, F and Tanner, T (2011). Enabling Child-Centered Agency in Disaster Risk Reduction. Global Assessment Report on Disaster Risk Reduction. IDS, UK.

Sen, A (1981). An Essay on Entitlement and Deprivation (Oxford, Clarendon Press). 
Silbert, M.E (2011). Small island economic vulnerability to natural disasters. Dissertation. University of Florida, Gainesville, Florida, USA. http://warrington. ufl.edu/centers/purc/purcdocs/papers/1001_Silbert_Small_Island_Economic.pdf

Silbert, M. E (2011). Small island economic vulnerability to natural disasters. Dissertation. University of Florida, Gainesville, Florida, USA. In Garbero, A., and R. Muttarak. 2013. Impacts of the 2010 droughts and floods on community welfare in rural Thailand: differential effects of village educational attainment. Ecology and Society 18(4): 27. www.ecologyandsociety.org/vol18/iss4/art27/ES-20135871.pdf

Simwinji, N (1997). Summary of existing relevant Socio-Economic and ecological Information on Zambia's Western Province and Barotseland, IUCN - The World Conservation Union regional Office for Southern Africa, Harare.

Skoufias, E (2007). Poverty alleviation and consumption insurance: evidence from PROGRESA in Mexico. Journal of Socio-Economics, 36:630-649.

http://dx.doi.org/10.1016/j. socec.2006.12.020

Skoufias, E (2003). Economic Crises and Natural Disasters: Coping Strategies and Policy Implications. World Development Vol. 31. Inter-American Development Bank, Washington, DC, USA.

Skoufias, E and Parker, S. W (2002). Labor market shocks and their impacts on work and schooling: evidence from urban Mexico. IFPRI-FCND Discussion Paper no.129, March.

Smith, K (2009). Natural Hazards: The oxford companion to global change. Ed. David Cuff and Andrew Goudie. Oxford University Press.

Smith, R; Simard, C and Sharpe, A (2001). A Proposed Approach to Environment and Sustainable Development Indicators Based on Capital. The National Round Table on the Environment and the Economy's Environment and Sustainable Development Indicators Initiative.

Smith, K (1992). Environmental hazards. London: Routledge.

Stanke, C; Murray, V; Amlôt, R; Nurse, J and Williams, R (2012). The Effects of Flooding on Mental Health: Outcomes and Recommendations from a Review of the Literature. PLOS Currents Disasters. 2012 May 30. Edition 1. doi: 10.1371/4f9f1fa9c3cae. 
http://www.hpa.org.uk/webw/HPAweb\&HPAwebStandard/HPAweb_C/13171 31788841. (Accessed on 22 March 2014).

Stromberg, D (2007). Natural Disasters, Economic Development, and Humanitarian Aid. The Journal of Economic Perspectives, 21(3):199-222.

TANGO International (2006). Conceptual approach and background information for livelihood security assessments. Draft. Prepared for ACDI /VOCA. January.

Thornton, P. K; Boone, R. B; Galvin, K. A; Burnsilver, S. B; Waithaka, M. M; Kuyiah, J; Karanja, S; Gonzalez-Estrada, E and Herrero, M (2007). Coping strategies in livestock-dependent households in east and southern Africa: A synthesis of four case studies. Human Ecology, 35(4):.461-476.

Tierney, K (2006).The importance of social resilience. The USC School of Policy, Planning, and Development, University of South Carolina, SPPD Community Connection, http://www.usc.edu/sppd. (Accessed on 15 January 2007).

Timberlake, L (1997). Biodiversity of the Zambezi Basin Wetlands: A review of available information, Zambezi Society and Biodiversity Foundation for Africa Report to IUCN - The World Conservation Union Regional Office for Southern Africa, Harare.

Timmerman, P (1981). “Vulnerability, Resilience and the collapse of society'. Environmental Monograph 1. Institute of Environmental Society, University of Toronto, Toronto.

Tinh, D.Q (2003). Flood Kindergarten: Community Need to Community Solution. Department of Dyke Management, Flood and Storm Control, Ministry of Agriculture and Rural Development, Hanoi, Vietnam.

Toya, H; Skidmore, M and Robertson, R (2010). 'A Re-evaluation of the Effect of Human Capital Accumulation on Economic Growth Using Natural Disasters as an Instrument', Eastern Economic Journal, Vol. 36: 120-37.

UNDP (2010). Gender and Disasters.

http://www.undp.org/content/dam/undp/library/crisis\%20prevention/disaster/. (Accessed on 22 March 2014).

UNHCR (2006). UNHCR Master Glossary of Terms, June 2006, Rev.1. http://www.refworld.org/docid/42ce7d444.html. (Accessed on 28 April 2014). 
UNEP (2002). Global Environment Outlook 3. London: Earthscan.

UNESCO (2014). http://www4.unescobkk.org/education/efatraining/modulea4/8-learning-materials/ (Accessed on 28 April 2014).

UNESCO (2007). International Standard Classification of Education ISCED 1997. http://www.unesco.org/education/information/nfsunesco/doc/isced_1997.htm. (Accessed on 28 April 2014).

UNESCO (2009). Institute of Statistics. UNESCO Paris.

UNESCO (2005). Education for All 2006: Global monitoring report 2006. Paris: UNESCO.

UNESCO (2000). Educational For All 2000 Assessment, Statistical Document. World Education Forum. UNESCO, Paris.

UNICEF (2013). UNICEF Emergency Field Handbook. New York.

UNISDR (2009). UNISDR Terminology on Disaster Risk Reduction. www.unisdr.org/eng/terminology/terminology-2009-eng.htmI. (Accessed on 5 August 2009).

UNISDR (2008). Climate change and disaster risk reduction. Briefing Note 01. www.preventionweb.net/files/4146_ClimateChangeDRR.pdf. (Accessed on 5 August 2009).

UNISDR (2007). Hyogo framework for 2005-2015: Building the resilience of the nations and communities to disasters. www.unisdr.org/wcdr/intergover/officialdocs/Hyogo- frameworkaction-english.pdf.

UNISDR (2005). Hyogo framework for 2005-2015: Building the resilience of the nations and communities to disasters. www.unisdr.org/wcdr/intergover/officialdocs/Hyogo- frameworkaction-english.pdf. (Accessed on 4 January 2007).

UNOCHA (2003). Mozambique floods February 2003. Save the Children Alliance.

Ureta, M (2005). Hurricane Mitch, Family Budgets and Schooling in Nicaraguall, manuscript, Department of Economics, Texas A\&M University. 
Van Aalst, M. K; Cannon, T and Burton, I (2008). Community level adaptation to climate change: the potential role of participatory community risk assessment. Global Environmental Change, 18(1): 165-179, 2008.

Varley, A (1994). The Exceptional and the Everyday: Vulnerability Analysis in the International Decade for Natural Disaster Reduction. In Varley, A (ed.) Disasters, Development and Environment. New York: Wiley.

Walker, B.H; Anderies, J.M; Kinzig, A.P and Ryan, P (2006). Exploring resilience in social- ecological systems through comparative studies and theory development: Introduction to the special issue. Ecology and Society, 11(1): 12.

Watts, J.H (2008). Integrity in qualitative research. In: Given, L M. (ed). The Sage Encyclopedia of Qualitative Research Methods, Volume 1. Thousand Oaks, California: Sage Publications, pp. 440-441.

World Bank (2000). A Preliminary Assessment of Damage from the Flood and Cyclone Emergency of February-March 2000. The World Bank, Washington, DC.

World Bank (2001b). Social protection sector strategy: from safety net to springboard. Washington, DC: World Bank. In Skoufias, E (2003). Economic Crises and Natural Disasters: Coping Strategies and Policy Implications. World Development Vol. 31.

World Commission on Environment and Development (WCED) (1987). Our Common Future. Oxford: Oxford University Press.

WDR (2014). The World Bank education statistics website (EdStat). http://data.worldbank.org/topic/education

Wertz, F.J (2005). Phenomenological research methods for counselling psychology, Journal of counselling psychology, 52(2): 167-177.

WFP (2013). World Food Programme - Hunger Report, Rome.

WHO (2011). World Health Organization Global Task Force on Cholera Control: February, 2011. Lusaka, Zambia.

Wiles, P; Selvester; K and Fidalgo, L (2005). Learning Lessons from Disaster Recovery: The Case of Mozambique. Disaster Risk Management Working Paper Series. 12. The World Bank, Washington, DC. 
Wilson, G.A (2012). Community resilience and environmental transitions. London, England: Earthscan/Routledge Press.

Wisner, B; Blaikie, P; Cannon, T and Davis, I (2004). At Risk: Natural hazards, people's vulnerability and disasters (2nd ed.), London, Routledge.

Wisner, B (2000). From 'acts of god' to 'water wars'. The urgent analytical and policy role of political ecology in mitigating losses from flood: a view of South Africa from Central America. In Parker, D.J., (ed.), Floods. London: Routledge, 89-99.

Wong, K and Zhao, X (2001). Living with floods: victims' perceptions in Beijiang, Guangdong, China. Area 33(2): 190-201.

World Bank (2009). World Development Indicators. In USAID (2010). USAID

Country Profile, property rights and resource governance, Zambia. Washington DC. http://usaidlandtenure.net/zambia (Accessed on 26 April 2014).

World Bank (2001a). World Development Report 2000/01 attacking poverty. New York: Oxford University Press.

Yin, R.K (2008). Case Study Research: Design and Methods (Applied Social Research Methods).

Yin, R.K (2003). Case Study Research: Design and Methods (3rd ed.). Sage Publications, Beverly Hills.

Yin, $\mathrm{H}$ and Li, C (2001). Human impact on floods and flood disasters on the Yangtze River. Geomorphology, 41, 105-109.

ZDHS (2007). Zambia Demographic and Health Survey Report, 2007. Lusaka, Zambia.

Zhang, Y (2006). Modelling single family housing recovery after hurricane Andrew in Miami-Dade County, Florida. A PhD dissertation, College Station, TX: Texas A\&M University.

Zhang, H; Zhuang, T and Zeng, W. (2012). Impact of Household Endowments on Response Capacity. Int. Journal of Disaster Risk Science, 3(4): 218-226. 
Zoleta-Nantes, D.B (2000). Flood hazard vulnerabilities and coping strategies of residents of urban poor settlements in Metro Manila, The Philippines. In Parker, D.J., (ed.), 2000: Floods. London: Routledge, 69-88.

ZVAC (2009). Zambia Vulnerability Assessment Committee. Disaster Management \& Mitigation Committee, Lusaka, Zambia. 


\section{ANNEXES $^{6}$}

\section{Annex 3: Interview Guides}

\section{Annex 3.1: Key informant interview guide (Community - Households, Local Authorities, Teachers) in areas affected by floods in the last 5 to 10 years}

Name:

Village/School:

Age:

\begin{tabular}{|l|l|l|l|l|}
\hline $\begin{array}{l}15 \text { to } 25 \\
\text { years }\end{array}$ & $\begin{array}{l}25 \text { to } 35 \\
\text { years }\end{array}$ & $\begin{array}{l}35 \text { to } 45 \\
\text { years }\end{array}$ & $\begin{array}{l}45 \text { to } 55 \\
\text { years }\end{array}$ & $\begin{array}{l}\text { Above 55 } \\
\text { years }\end{array}$ \\
\hline & & & & \\
\hline
\end{tabular}

Tick appropriate

Sex:

Religion: (enter

Christian, Muslim, Buda, etc. not congregation)

Tribe:

Educational level: (tick under the appropriate)

\begin{tabular}{|l|l|l|l|l|l|l|l|}
\hline $\begin{array}{l}\text { Incomplete } \\
\text { primary }\end{array}$ & $\begin{array}{l}\text { Complete } \\
\text { primary }\end{array}$ & $\begin{array}{l}\text { Incomplete } \\
\text { secondary }\end{array}$ & $\begin{array}{l}\text { Complete } \\
\text { secondary }\end{array}$ & $\begin{array}{l}\text { Incomplete } \\
\text { vocational }\end{array}$ & $\begin{array}{l}\text { Complete } \\
\text { vocational }\end{array}$ & $\begin{array}{l}\text { Incomplete } \\
\text { tertiary }\end{array}$ & $\begin{array}{l}\text { Complete } \\
\text { tertiary }\end{array}$ \\
\hline & & & & & & & \\
\hline
\end{tabular}

Occupation : ..( main livelihood activity)

Number of children: (these should be those that qualify to be called children - up to 20 years)

\begin{tabular}{|l|l|l|l|l|l|l|l|l|l|l|l|l|l|}
\hline \multirow{2}{*}{ Total } & \multicolumn{2}{|l|}{ school going children } \\
\cline { 2 - 16 } & Grade & 1 & 2 & 3 & 4 & 5 & 6 & 7 & 8 & 9 & 10 & 11 & 12 \\
\hline Male & & & & & & & & & & & & & \\
\hline Female & & & & & & & & & & & & & \\
\hline
\end{tabular}

${ }^{6}$ All information contained in the Annexes (except for Annex 4:12) is the Author's original contribution. The annexes are numbered according to the chapters in which they are cited in. For instance, the first annex is cited in chapter 3 of this thesis, hence numbered, Annex 3.1 
1. How often does it flood in this community and what are the various magnitudes/intensities of the floods? How long do the floods water stay? How do floods affect your community and in what ways? (Develop a calendar of activities year round. For instance from Jan - March what happens etc.).

2. How many primary school going children do you have? Are all of them going to school? If not, why not and what are the non-school going children doing? Those who go to school but do not complete primary school, why is that? What are they doing?

3. What kind of life do you envisage for your children, do you think your children will have that kind of life? What are your strategies to give your children the kind of live you envisage?

4. In your opinion, how do floods affect the education of children? Which sect of children are more affected (boys, girls, youths). Why do you think a particular sect is affected more than the others? What other factors do you believe affect primary education of children apart from floods?

5. What is your general impression about education, especially for children? Of what value is education of your children to you, to the children and the community?

6. What do you think about the quality of education in this plain in terms of qualification of teachers, condition of schools, administration, and children's performance?

7. How long have you or your family lived in this community? What do you like about this place/ what are the advantages of living here/ what are the good things in this place?

8. How do you make a living in this area? What is your net income per month? What kind of livelihood activities are you involved with?

9. How do you manage/cope with (the recurring) floods? 
10. Do you have any community approach to support each other in times of need or during flood period? For instance, social insurance schemes, co-operatives etc? How effective are these schemes or support programmes? What traditional cultural practices exist for support to one another during such floods?

11. What is your general impression about the floods and how is life for you living in the flood plains?

12. Why are you living in this flood plain with all the challenges and dangers of floods? Have you thought of any alternatives to have a better life than being in the flood plains? What are those options and what are you doing about it?

13. Does your community have good basic social services such as clean water supply, clinics, electricity, etc? Who provides these services and at what cost? If there is any cost, can you afford it?

14. Is there any motivation for children to go to school or parents to send their children to school? What are those motivations?

15. What support do you receive from government or NGOs, especially during a flood disaster to sustain your livelihood? Are you getting any specific support in educating your children during and after the floods?

16. What development programmes are on-going in this community? How do you benefit from them, how do you participate in them and how do you contribute to them as an individual or as a community?

17. What do you think the government or NGOs should do to assist your community? Have you approached government for any particular development support? If not, why not? 


\section{Annex 3.2: Key informant interview guide (Stakeholders - Government, NGOs, UN) in areas affected by floods}

Name:

Organization:

Get data on functions of the organization, if NGO.

Position:

Main key result areas of the interviewee:

Age:

\begin{tabular}{|l|l|l|l|l|}
\hline 15 to 25 years & 25 to 35 years & 35 to 45 years & 45 to 55 years & Above 55 years \\
\hline & & & & \\
\hline
\end{tabular}

Tick appropriate

Sex:

Religion: (enter

Christian, Muslim, Buda, etc. not congregation)

Tribe:

Educational level: (tick under the appropriate)

\begin{tabular}{|l|l|l|l|l|l|l|l|}
\hline $\begin{array}{l}\text { Incomplete } \\
\text { primary }\end{array}$ & $\begin{array}{l}\text { Complete } \\
\text { primary }\end{array}$ & $\begin{array}{l}\text { Incomplete } \\
\text { secondary }\end{array}$ & $\begin{array}{l}\text { Complete } \\
\text { secondary }\end{array}$ & $\begin{array}{l}\text { Incomplete } \\
\text { vocational }\end{array}$ & $\begin{array}{l}\text { Complete } \\
\text { vocational }\end{array}$ & $\begin{array}{l}\text { Incomplete } \\
\text { tertiary }\end{array}$ & $\begin{array}{l}\text { Complete } \\
\text { tertiary }\end{array}$ \\
\hline & & & & & & & \\
\hline
\end{tabular}


1. How many years have you been operating within this community? What is your view on the pattern of floods within the community? How do you think floods affect the community? Which members of households are the most affected? (Children, boys, girls, elderly or parents).

2. What do you think is the impact of floods on the education of primary school children (in terms of school attendance, drop out, quality of school, teachers, ability of family to support children during or after floods, etc.)? Who do you think are most affected; boys or girls?

3. How can people cope with the yearly floods in terms of their livelihoods, education for the children and their general wellbeing?

4. How do you make a living in this area? What is your net income per month?

5. What is your opinion about the socio-economic situation of this community? How could their lives be improved? What are the key livelihood support mechanisms of this community? Are there any alternative livelihood support systems that will motivate the community to leave the flood plains? Have there been any actions towards some of these alternatives?

6. What is the role of your department and agency in this community? What support do you provide to the community before, during and after the floods? What interventions do you provide for children? What specific interventions do you provide for education of children? Who are your partners and how do you work with them? What impact do you think your support is making especially on education?

7. What should the government or Non-Governmental Organizations (including the UN) do to support communities minimize the effect/impact of floods and that quality education is guaranteed for the children?

8. Is the flooding a disaster or is it a blessing? How can your organization support communities living in flood areas to improve their capacity to cope and maximize their potential? 
9. What is your opinion on a permanent solution for this community to ensure that education for children is not affected? 


\section{Annex 3.3: Key informant interview guide (Community - Households, Local Authorities, Teachers) in areas not affected by floods in the last 5 to 10 years}

Name:

Village/School:

Age:

\begin{tabular}{|l|l|l|l|l|}
\hline $\begin{array}{l}15 \text { to } 25 \\
\text { years }\end{array}$ & $\begin{array}{l}25 \text { to } 35 \\
\text { years }\end{array}$ & $\begin{array}{l}35 \text { to } 45 \\
\text { years }\end{array}$ & $\begin{array}{l}45 \text { to } 55 \\
\text { years }\end{array}$ & $\begin{array}{l}\text { Above 55 } \\
\text { years }\end{array}$ \\
\hline & & & & \\
\hline
\end{tabular}

Tick appropriate

Sex:

Religion: (enter

Christian, Muslim, Buda, etc. not congregation)

Tribe:

Educational level: (tick under the appropriate)

\begin{tabular}{|l|l|l|l|l|l|l|l|}
\hline $\begin{array}{l}\text { Incomplete } \\
\text { primary }\end{array}$ & $\begin{array}{l}\text { Complete } \\
\text { primary }\end{array}$ & $\begin{array}{l}\text { Incomplete } \\
\text { secondary }\end{array}$ & $\begin{array}{l}\text { Complete } \\
\text { secondary }\end{array}$ & $\begin{array}{l}\text { Incomplete } \\
\text { vocational }\end{array}$ & $\begin{array}{l}\text { Complete } \\
\text { vocational }\end{array}$ & $\begin{array}{l}\text { Incomplete } \\
\text { tertiary }\end{array}$ & $\begin{array}{l}\text { Complete } \\
\text { tertiary }\end{array}$ \\
\hline & & & & & & & \\
\hline
\end{tabular}

Occupation : ..( main livelihood activity)

Number of children: (these should be those that qualify to be called children - up to 20 years) 


\begin{tabular}{|l|l|l|l|l|l|l|l|l|l|l|l|l|l|}
\hline \multirow{2}{*}{ Total } & \multicolumn{10}{|c|}{ School going children } \\
\cline { 2 - 5 } & Grade & 1 & 2 & 3 & 4 & 5 & 6 & 7 & 8 & 9 & 10 & 11 & 12 \\
\hline Male & & & & & & & & & & & & & \\
\hline Female & & & & & & & & & & & & & \\
\hline
\end{tabular}

1. How long have you or your parents lived in this community? When did you last experience floods that affected homes, livelihoods and other basic social services such as primary school education for the children?

2. What is your view/opinion about the situation of those communities who have been affected by floods for the last $5-10$ years? How do you think the floods affect them? Are you providing any support to them during times of crisis or during floods?

3. What is your livelihood support mechanism? Are you getting sufficient basic social services? Who provides them?

4. Are all your children going to school? If yes, how do you support them? If not why not? If all or some of the children do not go to school, what are they doing?

5. How do you cope with sending children to school?

6. Have you considered the possibility of moving to other parts of the country or district where life is much better than where you are now? If not, why not?

7. Do you think education is very important for the children compared to fishing or farming?

8. Are you getting any support from government, NGOs, CSOs for children's education in this community? What kind of support? What other development programmes are on-going? Who is implementing these projects? 
9. What kind of support do you need from government or other stakeholders to improve your life and ensure that children go to school? 


\section{Annex 3.4: Key informant interview guide (Stakeholders - Government, NGOs, UN) in areas not affected by floods}

\section{General information:}

Name:

Organization:

(Get data on functions of the organization, if NGO)

Position:

Main key result areas of the interviewee:

Age:

\begin{tabular}{|l|l|l|l|l|}
\hline $\begin{array}{l}15 \text { to } 25 \\
\text { years }\end{array}$ & $\begin{array}{l}25 \text { to } 35 \\
\text { years }\end{array}$ & $\begin{array}{l}35 \text { to } 45 \\
\text { years }\end{array}$ & $\begin{array}{l}45 \text { to } 55 \\
\text { years }\end{array}$ & $\begin{array}{l}\text { Above 55 } \\
\text { years }\end{array}$ \\
\hline & & & & \\
\hline
\end{tabular}

Tick appropriate

Sex:

Religion: (enter

Christian, Muslim, Buda, etc. not congregation)

Tribe:

Educational level: (tick under the appropriate)

\begin{tabular}{|l|l|l|l|l|l|l|l|}
\hline $\begin{array}{l}\text { Incomplete } \\
\text { primary }\end{array}$ & $\begin{array}{l}\text { Complete } \\
\text { primary }\end{array}$ & $\begin{array}{l}\text { Incomplete } \\
\text { secondary }\end{array}$ & $\begin{array}{l}\text { Complete } \\
\text { secondary }\end{array}$ & $\begin{array}{l}\text { Incomplete } \\
\text { vocational }\end{array}$ & $\begin{array}{l}\text { Complete } \\
\text { vocational }\end{array}$ & $\begin{array}{l}\text { Incomplete } \\
\text { tertiary }\end{array}$ & $\begin{array}{l}\text { Complete } \\
\text { tertiary }\end{array}$ \\
\hline & & & & & & & \\
\hline
\end{tabular}

1. How long have you been working in this area and what kind of support do you give to this community? 
2. Have you done any investigation on the state of education for children in this community and how do you compare the quality to that of children in the flood affected areas and the national average? Do you have any ideas on how education of children could be improved?

3. How do you think this community copes with poverty, livelihoods and sending children to school? Does this community value education? Are you playing any role in changing the mindset and behaviour of parents to send their children to school or do you provide any incentives to encourage parents to send their children to school or the children willing to go to school?

4. Are you providing any education related interventions? Is your support making any impact on this community? If yes, how? (give examples). In your opinion, what development interventions do you think are appropriate for this community? What do you think is needed to get this community out of poverty?

5. Assuming that you are providing support for both the flood affected community and the non-flood affected community; what do you think makes the difference in terms of level of investment, impact, commitment from parents/children, willingness of qualified teachers to teach etc.? 


\section{Annex 3.5: Key informant interview guide (Children - age 10 to 15 affected by floods)}

1. How old are you? Are you born and raised in this community? If not, how long have you lived here? Do you have friends who are not going to school? If so, why are they not going to school?

2. How are things going in school? Do you enjoy it? What are the good things you like about schooling and what challenges do you face? Is it easy for your parents to cater for your education in terms of school fees, books, lunches, transport, clothing, etc.? Do you travel long distances to school? Do you have any recreational facilities? Do you hope to complete primary school in good time? What are your plans after completing primary school? If you do not hope to complete primary school, why not and what do you intend to do afterwards?

3. What do you think about the quality of education in this school in terms of infrastructure, teachers, teaching methods, etc.? Do you meet other school children who go to school in other cities outside the flood plain? How do you compare yourself to them? If you have an alternative to go to school elsewhere, would you like to do that and why? Where would you like to go?

4. What are the things that you like about this place and what things do you dislike?

5. What kind of livelihood activities are your parents involve in? Are you providing any support to your parents? What kind of support do you provide? Do you like to provide that support or you don't have an option? In case you are providing any support to your parents, does that affect your education? In what ways?

6. What is your understanding about floods? Do floods affect your schooling? How? If floods affect your schooling, how do you cope with the situation? How do your parents cope in sending you to school with the challenges faced? 
7. Are you getting any support from government, NGOs or CSOs for your education, especially during times of floods?

8. What do you think the government should do to assist you or the community so that floods do not affect your schooling?

9. What kind of life do you wish to live when you grow up? 


\section{Annex 3.6: Key informant interview guide (Children - age 10 to 15 not affected by floods)}

1. How old are you? Are you born and raised in this community? If not, how long have you lived here? Do you have friends who are not going to school? If so, why are they not going to school?

2. How are things going in school? Do you enjoy it? What are the good things you like about schooling and what challenges do you face? Is it easy for your parents to cater for your education in terms of school fees, books, lunches, transport etc.? Do you travel long distances to school? Do you hope to complete primary school in good time? What are your plans after completing primary school? If you do not complete primary school, why not and what do you intend to do afterwards?

3. What do you think about the quality of education in this school in terms of infrastructure, teachers, teaching methods, etc.? If you have an alternative to go to school elsewhere, would you like to do that and why? Where would you like to go?

4. What are the things that you like about this place and what things do you dislike?

5. What kind of livelihood activities are your parents involve in? Are you providing any support to your parents? What kind of support do you provide? Do you like to provide that support or you don't have an option? In case you are providing any support to your parents, does that affect your education? In what ways?

6. Are you getting any support from government with regards to your education? 
7. How do you compare your situation to that of your colleagues living in the neighbourhood who are seriously affected by floods every year? Do you think your educational attainment is a lot better than your colleagues who have been affected by floods?

8. What do you think the government should do to improve your situation and that of your school colleagues to enable you have good quality education?

9. What kind of life do you wish to live when you grow up? 


\section{Annex 3.7: Focus group interview guide (Communities affected by floods in the last 5 to 10 years)}

1. How long have you lived in this community and how long did your parents live in this community?

2. How often do floods affect you and in which ways? What are your strategies to mitigate the effect of floods? What steps have you taken as a community to stop this yearly situation? How do you cope with livelihoods and ensuring children go to school during the floods period? Do you have any other options or alternative livelihoods? Or have you ever considered any other alternatives than staying in this place?

3. Are you getting any support from government, NGOs, local authorities? What kind of support do you get? Is it sufficient enough to cater for your livelihoods, sending children to school and take care of other necessities?

4. Has the government made suggestions to you or made any offers to improve your situation to avoid been affected every year by floods? Have you considered any of those offers and what is your thought about them?

5. What is the relationship of this community with the government? (one could look at government structures in the community, how does that community work with these structures, e.g. Area Development Committee, Satellite Disaster Management Committees, Health Area Committees, Social committees etc.) Do you think the government is doing enough or do you expect more from the government?

6. How do you compare your situation with those communities in this same area that have not been affected by floods for the last 5 years? Do you think their situation is better or the same? What makes the difference? How do you compare your situation with other communities in other parts of the country not affected by floods? What do you think is the difference in terms of education for children between your community and the other communities I have mentioned? 


\section{Annex 3.8: Focus group interview guide (Communities not affected by floods in the last 5 to 10 years)}

1. You are living in this area and the situation in terms of development seems to be the same with those other communities affected by floods; what do you think is the difference? Do you think your life is better than those communities affected by floods; how? Are all your children going to school? Are you able to pay their school fees?

2. What are your livelihood support mechanisms? In case your area happens to be flooded, how would you cope, especially with sending children to school?

3. How many of you have been to school or still going to school? What level of education did you attain? Do you think/believe that education is important for you and/or your children?

4. What key challenges are you facing in supporting your children in school? Are you getting any support from government, NGOs or local authorities in this regard?

5. What expectations do you have from government in terms of your personal and community development? How do you think your situation could be improved to a better life?

6. What is your vision of a good education or school system? 


\section{Annex 4: Analysis of Primary School Data in Flood and Non-Flood Affected Communities in the Study Area}

Annex 4.1: Total school enrolment in flood and non-flood affected primary schools in Zambia

\begin{tabular}{|c|c|c|c|c|c|c|c|c|c|c|}
\hline \multirow[b]{2}{*}{ Grade } & \multicolumn{2}{|c|}{2008} & \multicolumn{2}{|c|}{2009} & \multicolumn{2}{|c|}{2010} & \multicolumn{2}{|c|}{2011} & \multicolumn{2}{|c|}{2012} \\
\hline & FAS & $\begin{array}{c}\text { N- } \\
\text { FAS }\end{array}$ & FAS & $\begin{array}{c}\text { N- } \\
\text { FAS }\end{array}$ & FAS & $\begin{array}{c}\text { N- } \\
\text { FAS }\end{array}$ & FAS & $\begin{array}{c}\text { N- } \\
\text { FAS }\end{array}$ & FAS & $\begin{array}{c}\text { N- } \\
\text { FAS }\end{array}$ \\
\hline Class 1 & 434 & 1367 & 357 & 1380 & 340 & 1290 & 399 & 1470 & 453 & 1616 \\
\hline Class 2 & 381 & 1348 & 314 & 1361 & 299 & 1360 & 296 & 1369 & 350 & 1474 \\
\hline Class 3 & 336 & 1360 & 284 & 1479 & 290 & 1307 & 288 & 1424 & 299 & 1539 \\
\hline Class 4 & 276 & 1401 & 244 & 1505 & 242 & 1223 & 275 & 1388 & 288 & 1568 \\
\hline Class 5 & 276 & 1268 & 233 & 1346 & 223 & 1374 & 241 & 1263 & 256 & 1517 \\
\hline Class 6 & 244 & 1305 & 215 & 1279 & 215 & 1284 & 214 & 1413 & 248 & 1413 \\
\hline Class 7 & 181 & 1295 & 225 & 1151 & 186 & 1699 & 189 & 1213 & 164 & 1363 \\
\hline Total & 2128 & 9344 & 1872 & 9501 & 1795 & 9537 & 1902 & 9540 & 2058 & 10490 \\
\hline
\end{tabular}

Where: FAS - Flood Affected Schools; N-FAS - Non-Flood Affected Schools 
Annex 4.2: Proportion (\%) of enrolment according to grade level and gender in flood affected and nonflood affected primary schools in Zambia between 2008 and 2012

\begin{tabular}{|c|c|c|c|c|c|c|}
\hline \multirow{2}{*}{$\begin{array}{c}\text { Grade } \\
\text { Levels }\end{array}$} & \multicolumn{3}{|c|}{ Flood Affected Schools } & \multicolumn{3}{|c|}{ Non-Flood Affected Schools } \\
\hline & Male & Female & Total & Male & Female & Total \\
\hline Grade 1 & 10.40 & 9.88 & 20.28 & 7.14 & 7.56 & 14.70 \\
\hline Grade 2 & 8.47 & 8.31 & 16.78 & 7.13 & 7.15 & 14.28 \\
\hline Grade 3 & 7.54 & 7.82 & 15.36 & 7.12 & 7.56 & 14.68 \\
\hline Grade 4 & 6.46 & 7.13 & 13.59 & 7.20 & 7.43 & 14.63 \\
\hline Grade 5 & 6.38 & 6.21 & 12.59 & 7.02 & 6.95 & 13.97 \\
\hline Grade 6 & 6.04 & 5.61 & 11.65 & 6.80 & 7.04 & 13.83 \\
\hline Grade 7 & 5.12 & 4.64 & 9.76 & 7.33 & 6.57 & 13.90 \\
\hline
\end{tabular}

Note: Proportions / Rates are based on the total school enrolment per area 


\section{Length of stay in primary school in the study area}

Annex 4.3: Proportion (\%) of primary school pupils aged above 7 years at first enrolment in flood affected and non-flood affected areas in Zambia

\begin{tabular}{|c|c|c|c|c|c|c|}
\hline \multicolumn{7}{|c|}{ Aged above 7 Years at Grade 1} \\
\hline \multirow[b]{2}{*}{ Year } & \multicolumn{3}{|c|}{ Flood Affected Schools } & \multicolumn{3}{|c|}{ Non-Flood Affected Schools } \\
\hline & Male & Female & Total & Male & Female & Total \\
\hline 2008 & 27.88 & 31.49 & 59.37 & 15.51 & 12.73 & 28.24 \\
\hline 2009 & 26.33 & 29.41 & 55.74 & 17.9 & 10.94 & 28.84 \\
\hline 2010 & 35.76 & 28 & 63.76 & 9.22 & 14.11 & 23.33 \\
\hline 2011 & 21.8 & 18.8 & 40.6 & 9.12 & 10 & 19.12 \\
\hline 2012 & 17.34 & 11.03 & 28.37 & 6.75 & 5.82 & 12.56 \\
\hline Proportion (\%) & 25.82 & 23.75 & 49.57 & 11.70 & 10.72 & 22.42 \\
\hline
\end{tabular}

Annex 4.4: Proportion (\%) of pupils aged above 14 years at completion of primary school in flood affected and non-flood affected areas in Zambia

\begin{tabular}{|c|c|c|c|c|c|c|}
\hline \multirow{3}{*}{ Year } & \multicolumn{5}{|c|}{ Proportion (\%) aged above 14 at Grade 7} & \\
\hline & \multicolumn{3}{|c|}{ Flood Affected Schools } & \multicolumn{3}{|c|}{ Non-Flood Affected Schools } \\
\hline & Male & Female & Total & Male & Female & Total \\
\hline 2008 & 25.41 & 27.36 & 52.78 & 18.53 & 11.2 & 29.73 \\
\hline 2009 & 26.11 & 26.11 & 52.22 & 7.47 & 6.69 & 14.16 \\
\hline 2010 & 23.98 & 25.98 & 49.96 & 6.06 & 4.65 & 10.71 \\
\hline 2011 & 23.81 & 16.93 & 40.74 & 8.57 & 7.75 & 16.32 \\
\hline 2012 & 10.98 & 20.12 & 31.1 & 4.84 & 5.72 & 10.56 \\
\hline $\begin{array}{r}\text { Average Annual } \\
\text { Proportion (\%) }\end{array}$ & 22.06 & 23.30 & 45.36 & 9.09 & 7.20 & 16.30 \\
\hline
\end{tabular}




\section{Rate of Repeating}

Annex 4.5: Comparison of the rate of repeating grades among primary school pupils in the study area

\begin{tabular}{|c|c|c|c|c|c|c|c|c|}
\hline & Grade 1 & Grade 2 & Grade 3 & Grade 4 & Grade 5 & Grade 6 & Grade 7 & $\begin{array}{l}\text { Average } \\
\text { Total }\end{array}$ \\
\hline FAS & 3.2 & 1.43 & 0.74 & 0.86 & 0.56 & 0.51 & 1.56 & 8.86 \\
\hline N-FAS & 0.37 & 0.37 & 0.45 & 0.57 & 0.46 & 0.40 & 0.55 & 3.17 \\
\hline
\end{tabular}

Calculated as total repeaters per grade divided by the total school enrolment

Where: FAS - Flood Affected Schools

N-FAS - Non-Flood Affected Schools

Annex 4.6: Average annual rate of repeating among primary school pupils in the study area

\begin{tabular}{|c|c|c|c|c|c|c|}
\hline \multirow{2}{*}{ Year } & \multicolumn{3}{|c|}{ Flood Affected Schools } & \multicolumn{2}{c|}{ Non-Flood Affected Schools } \\
\cline { 2 - 7 } & Male & Female & Total Rate & Male & Female & Total Rate \\
\hline $\mathbf{2 0 0 8}$ & 3.62 & 4.28 & $\mathbf{7 . 8 9}$ & 2.44 & 1.97 & 4.41 \\
\hline $\mathbf{2 0 0 9}$ & 6.14 & 5.13 & $\mathbf{1 1 . 2 7}$ & 1.91 & 1.20 & 3.15 \\
\hline $\mathbf{2 0 1 0}$ & 5.63 & 5.07 & $\mathbf{1 0 . 7 0}$ & 2.26 & 1.49 & 3.75 \\
\hline $\mathbf{2 0 1 1}$ & 5.15 & 3.31 & 8.46 & 1.51 & 0.88 & 2.39 \\
\hline $\mathbf{2 0 1 2}$ & 3.30 & 2.67 & $\mathbf{5 . 9 8}$ & 1.20 & 0.92 & $\mathbf{2}$ \\
\hline $\begin{array}{c}\text { Average Annual } \\
\text { Rate (\%) }\end{array}$ & 4.77 & 4.09 & 8.86 & 1.86 & 1.29 & 3.17 \\
\hline
\end{tabular}




\section{Dropout Rate}

Annex 4.7: Comparison of dropout rate by grade level among primary school pupils in the study area

\begin{tabular}{|c|c|c|c|c|c|c|c|c|}
\hline & Grade 1 & Grade 2 & Grade 3 & Grade 4 & Grade 5 & Grade 6 & Grade 7 & $\begin{array}{c}\text { Average } \\
\text { Total }\end{array}$ \\
\hline FAS & 0.4 & 0.21 & 0.35 & 0.21 & 0.35 & 0.16 & 1.78 & 3.46 \\
\hline N-FAS & 0.03 & 0.03 & 0.02 & 0.03 & 0.11 & 0.14 & 0.1 & $\mathbf{0 . 4 6}$ \\
\hline
\end{tabular}

Calculated as total repeaters per grade divided by the total school enrolment

Where: FAS - Flood Affected Schools;

N-FAS - Non-Flood Affected Schools

Annex 4.8: Annual dropout rate among primary school pupils in the study area

\begin{tabular}{|c|c|c|c|c|c|c|}
\hline \multirow[b]{3}{*}{ Year } & \multicolumn{5}{|c|}{ Annual Dropout Rate } & \\
\hline & \multicolumn{3}{|c|}{ Flood Affected Schools } & \multicolumn{3}{|c|}{ Non-Flood Affected Schools } \\
\hline & Male & Female & Total & Male & Female & Total \\
\hline 2008 & 1.46 & 1.69 & 3.15 & 0.16 & 0.43 & 0.59 \\
\hline 2009 & 3.21 & 3.79 & 7.00 & 0.14 & 0.39 & 0.53 \\
\hline 2010 & 1.73 & 2.01 & 3.73 & 0.26 & 0.34 & 0.60 \\
\hline 2011 & 1.42 & 1.31 & 2.73 & 0.21 & 0.23 & 0.44 \\
\hline 2012 & 0.24 & 0.44 & 0.68 & 0.11 & 0.04 & 0.15 \\
\hline $\begin{array}{l}\text { Average Annual } \\
\text { Rate }\end{array}$ & 1.61 & 1.85 & 3.46 & 0.18 & 0.28 & 0.46 \\
\hline
\end{tabular}

Calculated as total dropout divided by the total school enrolment 
Annex 4.9: Reasons for primary school dropout in the study areas

\begin{tabular}{|c|c|c|c|c|c|c|c|c|}
\hline \multicolumn{9}{|c|}{ FLOOD AFFECTED SCHOOLS } \\
\hline Year & Illness & Economic & Marriage & Expulsion & Pregnancy & Orphaned & Death & Other \\
\hline 2008 & 4.48 & 19.40 & 2.99 & 8.96 & 33.40 & 11.25 & 2.49 & 11.07 \\
\hline 2009 & 3.07 & 50.19 & 10.24 & 1.86 & 62.44 & 13.20 & 7.14 & 3.05 \\
\hline 2010 & 13.13 & 23.88 & 7.14 & 0.84 & 45.91 & 16.16 & 4.85 & 1.74 \\
\hline 2011 & 9.41 & 30.07 & 3.82 & 1.92 & 27.31 & 4.38 & 1.77 & 2.37 \\
\hline 2012 & 0.00 & 7.14 & 4.33 & 0.00 & 15.27 & 0.00 & 1.53 & 6.27 \\
\hline $\begin{array}{l}\text { Average } \\
\text { Annual } \\
\text { Rate (\%) }\end{array}$ & 6.02 & 26.14 & 5.70 & 2.72 & 42.27 & 9.00 & 4.06 & 4.90 \\
\hline \multicolumn{9}{|c|}{ NON-FLOOD AFFECTED SCHOOLS } \\
\hline 2008 & 26.86 & 10.91 & 0.00 & 0.00 & 20.00 & 25.82 & 3.64 & 29.06 \\
\hline 2009 & 17.06 & 10.00 & 0.00 & 2.00 & 12.00 & 34.84 & 6.05 & 27.46 \\
\hline 2010 & 13.93 & 51.40 & 1.55 & 0.50 & 12.26 & 11.02 & 3.75 & 8.26 \\
\hline 2011 & 6.96 & 32.10 & 0.00 & 0.00 & 11.90 & 19.62 & 11.90 & 16.17 \\
\hline 2012 & 9.74 & 21.11 & 0.63 & 0.00 & 14.10 & 13.10 & 8.73 & 5.60 \\
\hline $\begin{array}{l}\text { Average } \\
\text { Annual } \\
\text { Rate (\%) }\end{array}$ & 14.91 & 25.10 & 0.44 & 0.50 & 14.05 & 20.88 & 6.82 & 17.31 \\
\hline
\end{tabular}


Annex 4.9: Pupil - Teacher Ratio in the sampled primary schools for 5 years

\begin{tabular}{|l|c|c|c|c|c|c|c|c|c|c|c|c|}
\hline & \multicolumn{2}{|c|}{2008} & \multicolumn{2}{c|}{2009} & \multicolumn{2}{c|}{2010} & \multicolumn{2}{c|}{2011} & \multicolumn{2}{c|}{2012} & $\begin{array}{c}\text { Annual } \\
\text { Averages }\end{array}$ \\
\cline { 2 - 13 } & FAS & $\begin{array}{c}\text { N- } \\
\text { FAS }\end{array}$ & FAS & $\begin{array}{c}\text { N- } \\
\text { FAS }\end{array}$ & FAS & $\begin{array}{c}\text { N- } \\
\text { FAS }\end{array}$ & FAS & $\begin{array}{c}\text { N- } \\
\text { FAS }\end{array}$ & FAS & $\begin{array}{c}\text { N- } \\
\text { FAS }\end{array}$ & $\begin{array}{c}\text { FAS } \\
\text { N- } \\
\text { FAS }\end{array}$ \\
\hline $\begin{array}{l}\text { Total Pupil } \\
\text { Enrolment }\end{array}$ & 2128 & 9344 & 1872 & 9501 & 1795 & 9537 & 1902 & 9540 & 2058 & 10490 & 1951 & 9682 \\
\hline $\begin{array}{l}\text { Total } \\
\text { Number of }\end{array}$ & 40 & 311 & 36 & 329 & 42 & 302 & 44 & 357 & 53 & 370 & 43 & 334 \\
\hline $\begin{array}{l}\text { Pupil } \\
\text { /Teacher }\end{array}$ & 53.2 & 30.05 & 52 & 28.88 & 42.74 & 31.58 & 43.23 & 26.72 & 38.83 & 28.35 & 45.37 & 28.99 \\
\hline $\begin{array}{l}\text { Pupil - } \\
\text { Teacher } \\
\text { Ratio }\end{array}$ & $53: 1$ & $\mathbf{3 0 : 1}$ & $\mathbf{5 2 : 1}$ & $\mathbf{2 9 : 1}$ & $\mathbf{4 3 : 1}$ & $\mathbf{3 2 : 1}$ & $\mathbf{4 3 : 1}$ & $\mathbf{2 7 : 1}$ & $\mathbf{3 9 : 1}$ & $\mathbf{2 8 : 1}$ & $\mathbf{4 5 : 1}$ & $\mathbf{2 9 : 1}$ \\
\hline
\end{tabular}

Where: FAS - Flood Affected Schools;

$$
\text { N-FAS - Non-Flood Affected Schools }
$$


Annex 4.10: Performance of pupils from sampled schools in national primary school examinations

\begin{tabular}{|c|c|c|c|c|c|c|c|c|}
\hline \multirow[b]{2}{*}{$\begin{array}{l}\text { Yea } \\
\mathbf{r}\end{array}$} & \multicolumn{4}{|c|}{$\begin{array}{l}\text { Performance in Flood Affected Schools } \\
(\%)\end{array}$} & \multicolumn{4}{|c|}{$\begin{array}{l}\text { Performance in Non-Flood Affected Schools } \\
(\%)\end{array}$} \\
\hline & $\begin{array}{l}\text { Division } \\
1\end{array}$ & $\begin{array}{l}\text { Division } \\
2\end{array}$ & $\begin{array}{l}\text { Division } \\
3\end{array}$ & $\begin{array}{l}\text { Division } \\
4\end{array}$ & $\begin{array}{l}\text { Division } \\
1\end{array}$ & $\begin{array}{l}\text { Division } \\
2\end{array}$ & $\begin{array}{l}\text { Division } \\
3\end{array}$ & $\begin{array}{l}\text { Division } \\
4\end{array}$ \\
\hline 2008 & 4.15 & 15.20 & 33.63 & 47.50 & 12.54 & 33.00 & 23.00 & 32.00 \\
\hline 2009 & 1.25 & 11.36 & 17.91 & 69.52 & 14.88 & 24.12 & 16.77 & 44.31 \\
\hline 2010 & 4.04 & 8.10 & 27.30 & 60.61 & 10.87 & 25.00 & 20.00 & 44.32 \\
\hline 2011 & 6.45 & 16.13 & 26.90 & 50.54 & 13.47 & 23.51 & 22.22 & 41.27 \\
\hline 2012 & 5.36 & 36.61 & 22.32 & 35.71 & 10.98 & 35.60 & 23.73 & 30.00 \\
\hline Ave & 4.25 & 17.48 & 25.61 & 52.78 & 12.55 & 28.25 & 21.14 & 38.38 \\
\hline
\end{tabular}


Annex 4.12: Flood intensity data comparing water levels in the flood plains of Zambia over time

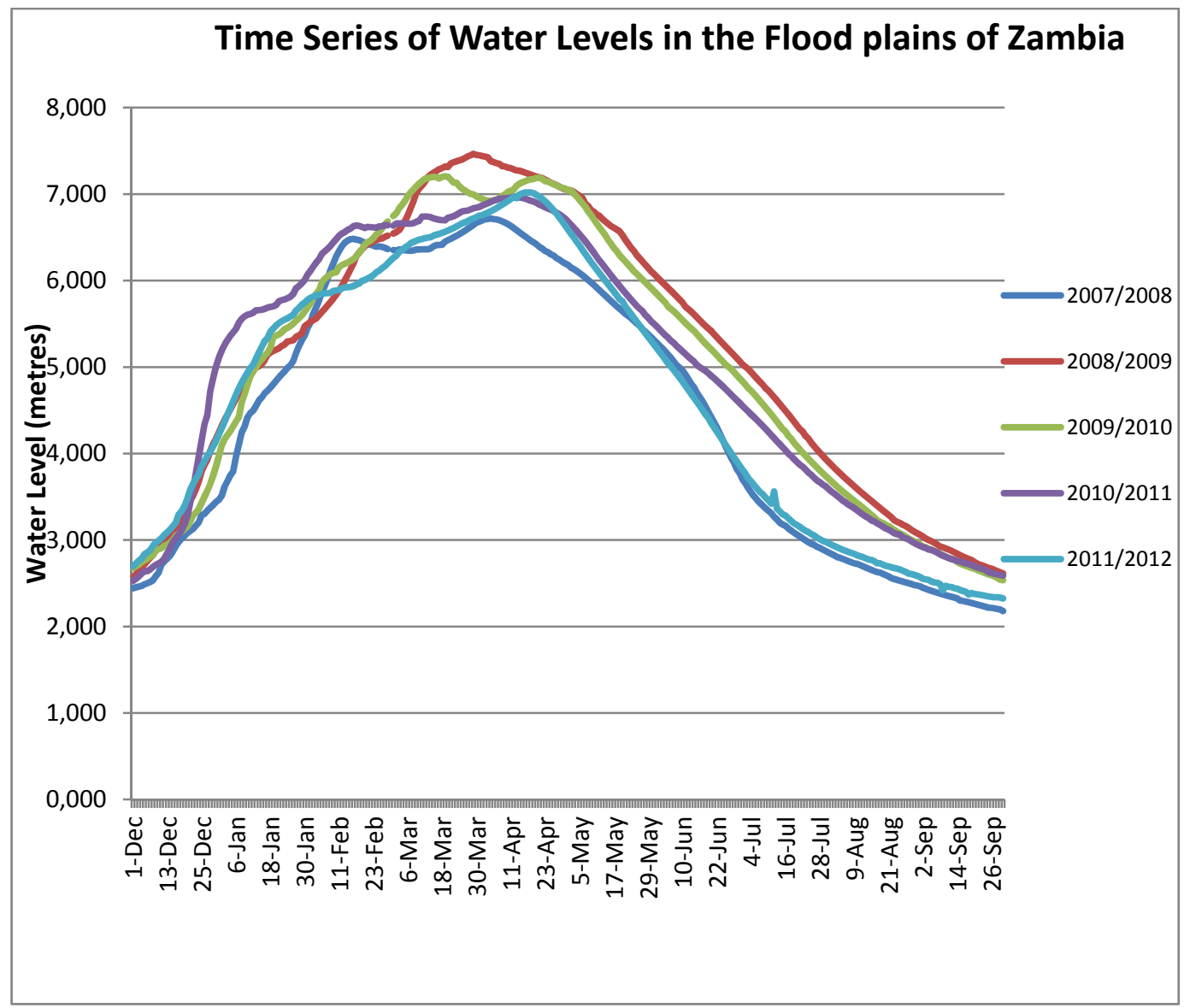

Source: Adapted by Author from Zambia Meteorological Department 


\section{SAMENVATTING}

In de afgelopen jaren is er een toenemende zorg ontstaan dat een steeds groter gedeelte van de wereldbevolking kwetsbaar wordt voor de negatieve uitwerking van natuurrampen. Natuurrampen ontstaan wanneer de institutionele beschermingsmechanismen, met inbegrip van sociaal en fysiek kapitaal, ontoereikend zijn, of eenvoudigweg verpletterd worden. Deze rampen vernietigen de middelen van bestaan, ontwortelen gemeenschappen en kunnen ook de ontwikkelingsopbrengsten in gevaar brengen door hun uitwerking op de menselijke ontwikkeling, met name door de mogelijke effecten op de schoolprestaties van kinderen. Overstromingen vormen één van de meest voorkomende natuurrampen in Sub Sahara Afrika.

In het stroomgebied van de Zambezi komen overstromingen jaarlijks voor en Zambia waar de Zambezi doorheen stroomt, lijdt voortdurend disproportioneel onder deze overstromingen. De overstromingen verstoren het onderwijs van de kinderen en verminderen daarmee hun leerprestaties. Er wonen ongeveer drie miljoen mensen in de riviervlaktes in Zambia waarvan bij benadering 30\% schoolgaande kinderen zijn. Deze studie is gedaan om beter te begrijpen waarom en hoe overstromingen het basisonderwijs in Zambia aantasten, waarom mensen kwetsbaar zijn voor de effecten van overstromingen, hoe zij omgaan met de situatie en hoe de veerkracht van huishoudens en gemeenschappen in de getroffen gebieden kan worden versterkt.

De bevindingen kunnen hopelijk de lokale en nationale overheids- en gemeenschapsstructuren in Zambia van dienst zijn, en ook ontwikkelingsorganisaties, zoals UNICEF en anderen, helpen de huishoudens te ondersteunen geschikte beschermingsmechanismen op te zetten en te onderhouden om de onderwijsbehoeften van kinderen die in de overstromingsgebieden van het land wonen, te beschermen en te verbeteren. Voor de gegevensverzameling zijn kwalitatieve fenomenologische, en kwantitatieve comparatieve methoden gebruikt, waarbij twee groepen gemeenschappen met identieke sociaal-economische eigenschapen zijn vergeleken: één groep die getroffen was door overstromingen de afgelopen vijf jaar (2008-2012) en één groep die dat niet was. 
De resultaten tonen aan dat het aantal aanmeldingen voor school in de overstromingsgebieden veel lager ligt in vergelijking met de regio's die niet door overstromingen zijn getroffen. Ook blijven de leerlingen in de getroffen scholen vaker zitten en gaan ze vaker vroegtijdig van school af. De prestaties van kinderen in de door overstromingen getroffen scholen bij het landelijke examen liggen ook veel lager. Verder hebben de leraren in deze gebieden gemiddeld minder ervaring en zijn er verhoudingsgewijs ook minder leraren. De leerling:leraar ratio in de overstromingsgebieden is 45:1 vergeleken met 28:1 in de gebieden die niet aan overstromingen blootstaan.

De studie heeft onderzocht waarom huishoudens en gemeenschappen in de getroffen gebieden zo kwetsbaar blijven voor de overstromingen. De resultaten tonen aan dat de huishoudens niet bereid zijn te verhuizen vanwege hun rechten op grond, hun traditionele wijze van bestaan en de specifieke cultuur die samenhangt met het leven in de overstromingsgebieden. Bovendien zijn de gemeenschappen arm en kunnen zich de levensstandaard in de hoger gelegen gebieden niet permitteren, en ook hun kinderen daar niet naar school sturen vanwege de hoge kosten. Er kwam ook naar voren dat de moeilijkheden die de huishoudens ondervinden om de uitdagingen aan te gaan, te wijten zijn aan de verwaarlozing van de publieke infrastructuur door de overheid en de zwakke politieke structuren waarbinnen de getroffen huishoudens weinig politieke zeggenschap hebben, ook vanwege hun lage opleidingsniveau. Verder zijn de basis sociale voorzieningen niet gemakkelijk toegankelijk en functioneren de vroegtijdige waarschuwingssystemen niet.

Ondanks deze beperkingen, hebben de huishoudens en gemeenschappen in de overstromingsgebieden manieren gevonden om aan de uitwerking van de overstromingen het hoofd te bieden. Sommige gemeenschappen bouwen hun huizen op terpen, om zo buiten het bereik van het water te blijven. Ze hebben ook geleerd effectief gebruik te maken van hun boten gedurende de overstromingen. Sommige gemeenschapsinwoners hebben geïmproviseerde tweede huizen op het hoger gelegen land gemaakt waar ze voor kortere perioden kunnen verblijven als er overstromingen zijn. Sociale netwerken binnen de getroffen gemeenschappen spelen een belangrijke rol in het verschaffen van morele en financiële steun (gemeenschapsmicro-krediet schema's zijn hiervan een voorbeeld). Gedurende de overstromingen geven ook de regering en humanitaire organisaties noodhulp om de uitwerking van de overstromingen op te vangen, maar deze steun is gewoonlijk niet toereikend. 
Om de veerkracht van de huishoudens en het onderwijs aan de kinderen te verbeteren en de tekortkomingen in de hulp van buitenaf in dit opzicht in kaart te brengen, heeft deze studie zich verstaan met de gemeenschappen en de betrokkenen om uit te vinden hoe volgens hen het basisonderwijs in de gebieden die vatbaar zijn voor overstromingen, veerkrachtig kan worden gemaakt. De uitkomst van deze discussies en de onderzochte literatuur geven aan dat een combinatie van zowel structurele als niet-structurele maatregelen met bijdragen van de gemeenschap, de ontwikkelingsorganisaties en de overheid de veerkracht tegenover de uitwerking van overstromingen op het onderwijs van kinderen, kan bevorderen. 


\section{VALORISATION ADDENDUM}

Zambia has a population of about 12 million people, with a quarter living in flood prone areas. When floods occur, the education of primary school children is affected due to damage to school infrastructure, restricted mobility, forced displacements of households, and the absence of teachers who are already limited in number and in capacity. As a result the education of primary school children is disrupted. Although households themselves engages in ex ante and ex post coping, this coping may still have adverse consequences as far as children's schooling is concerned. Furthermore, due to the covariate nature of the risks of flooding, measures to build resilience have to take into consideration that the entire community is similarly affected. This requires a coordinate approach from the various stakeholders including government, schools and development agencies to ensure that floods do not have adverse impact on the educational achievement of children in Zambia's flood plains.

Based on the above premise, the study has been designed to investigate how floods affect primary education in the flood plains in Zambia, the environmental and socioeconomic characteristics that exposes households and communities to the effects of flooding and how households cope with children's education under this circumstance. The interventions from government and other stakeholders to respond to the problems posed by floods and the subsequent impact of those interventions on children's education have also been discussed.

The study focused on the Western Province of Zambia where the Zambezi River crosses. The river creates a large span of area in Western Province of Zambia called the Baroste Flood Plains. In total, the Barostse Plain covers an area of about 550,000 hectares and has an estimated population of 1.2 million. The people residing in this flood plain are from the Lozi ethnic group usually referred to as the "plains or water people". Basic social services, such as roads, sanitation, electricity and potable water services are limited in the plains. Also, education is limited: only primary educational facilities exist. These facilities tend also not to be robust: most primary schools are makeshift structures and are repeatedly damaged during floods. 
The livelihood of the community is mainly in subsistence farming, consisting of animal rearing and fishing. During the dry season (between April and October), there are several economic activities in the plain. When the rainy season start in November, the plains often become flooded and economic activities are reduced. Flooding also damages homes, schools and destroys books and other learning materials. When flooding becomes a disaster, it leads to mass displacements of households, deaths by drowning, and associated calamities including snake bites and disease associated with floods.

The methodology that was used to understand how the above perennial flooding in the Baroste Plain affects primary education and how it can be prevented from disrupting primary education included both qualitative phenomenological and quantitative comparative methods.

Two communities in the same area (those affected by floods and those not affected by floods) during a 5 years period (2008 to 2012) were drawn for the study. The rationale for the qualitative approach was to conduct an in-depth investigation and capture the perceptions - based on 'lived experiences'- of the local communities in flood prone areas and the perceptions of stakeholders from government and non-governmental organizations (NGOs) on floods impact on primary education, household vulnerability factors, communities' coping mechanisms and the effects of stakeholder interventions on primary education. The quantitative inquiry was done using a comparative analysis of school records from 20 selected primary schools in the 2 communities and from the MoE to understand the relationship between the incidence of floods and the state of primary education.

It was found that children in the flood plains compared to those in the upper land have low net school enrolment, the rate of repeating classes is high, dropout rate is high and performance in national examination is low. Schooling for children is not an utmost priority for the communities in the flood plains, as reflected in the coping strategies of households. For instance households tend to prioritize coping mechanisms that result in quick income and more secured livelihoods. Education is often not prioritized as most parents have not acquired higher level education themselves (secondary and/or tertiary), therefore the value attached to education is minimal. Moreover, the motivation of parents to send their children to school is limited due to the cost involved. Many parents cannot afford the cost, especially after primary school. 
The general environment in which children attend primary school in the Barotse Plain is not conducive for learning. Most schools are makeshift structure. When floods occur, the structures are damaged, school materials lost. Despite being makeshift, repairs take an unexpectedly long time. Hygienic sanitary facilities are missing. Other basic services such as hospitals, safe drinking water, electricity and good roads are also not available. This situation diminishes the motivation and the learning outcomes of children.

Another major problem for primary education in the flood plains, especially for younger children in lower grades (who are normally younger than 10 years) is the difficulty encountered in accessing schools even during low-intensity floods. Often they are excluded from education for a period of 4 to 5 months. The water levels are simply too high for the children to walk to school and they are not strong enough to paddle to school on locally crafted boats. Even for those who can paddle with boats, it is very risky and therefore most parents do not allow the children to travel to school during the floods period. Due to increased flooding in recent years (a possible result of climate change), the period of flooding has increased from 4 months to 6 months, meaning that pupils are absent from school for a significant part of the school year.

The ratio of teacher to pupil is much lower at schools in the flood plains than in schools in the upper lands. Most teachers in the flood plains are not experienced: they tend to be teachers who have just completed high school (sometimes without achieving their teaching certificate) and need a career start. They take up teaching jobs in the plains as a last resort, when all other options have failed. It was also found that teachers in the flood plains are often not motivated due to the challenges associated with floods in the plains.

A major contribution of the present study was to identify the vulnerabilities of households and communities to the impact of floods, and how these, and their coping, negatively affected primary school education. The continuous habitation of people in the plains due to their livelihood strategies, culture and traditional attachment put them at a risk. The government's attempts to relocate people permanently from the flood plains have failed because better alternatives have not been provided. The existing early warning systems that are supposed to inform households of the onset and intensity of floods are not effective. Most households do not have financial capacity to have alternative homes in the upper land. The local administration (government) in 
the Barotse Plain is weak, making it difficult for local authorities to limit or respond to the covariate risks facing the flood plain communities.

The vulnerabilities of communities and their children's education to flooding are often due to poor coping mechanisms. This study established that many of these coping mechanisms have a negative impact on children's education. In fact little resources are invested in education. Some households cope by constructing houses on top of mounds to protect their houses from the damage of flood waters. Others construct alternative homes in the upper land, so that they relocate on a temporary basis during the flood period.

Boats have been known to be of great importance for transporting people during the flooding period. Diversification of livelihoods with some families cultivating crops, fishing and rearing animals at the same time ensured that not all is lost during difficult times, but children are required to provide part of the labor. There are situations where households move to bigger towns to look for jobs on a temporary basis during the flood periods in order to earn a living and return back to the plains when water recedes. In most cases, when households move to the upper lands to cope, children are subjected to work to assist in the upkeep of the homes instead of going to school.

The government and other stakeholders provide support to communities mainly during and after floods - this support is important given the covariate nature of the risk of flooding. This thesis found that some of these interventions do indeed have a positive effect on children's education, but can be more effective. For instance, when households are displaced and placed in camps, the government and humanitarian organizations provide some relief aid with food, medical supplies and non-food items. The government makes arrangements through the MoE to enroll children in upper land schools close to the camps and children with special needs are also catered for. Some families receive support from relations abroad (remittances) which helps the home upkeep and in some cases part of the money is used for children schooling in the upper lands. As the water recedes and households return to the flood plain, government and humanitarian agencies support the repatriation process. Support is also provided to rehabilitate public services after the floods, though that support is not on a large scale and also not immediate. 


\section{MGSoG Dissertation Series}

\section{Richard Bluhm}

Growth Dynamics and Development

Essays in Applied Econometrics and Political Economy

MGSoG Dissertation Series, nr 54 (2015)

Nevena P. Zhelyazkova

Work-Family Reconciliation and Use of Parental Leave in Luxembourg

Empirical Analysis of Administrative Records

MGSoG Dissertation Series, nr 53 (2015)

Sachin Kumar Badkas

Metachoice and Metadata

Innovating with Environmental Policy Analysis in Europe

MGSoG Dissertation Series, nr 52 (2014)

Irina S. Burlacu

An Evaluation of Tax-Benefit Systems Impact on the Welfare of Frontier Workers

The Case of Luxembourg and Belgium

MGSoG Dissertation Series, nr 51 (2014)

Özge Bilgili

Simultaneity in Transnational Migration Research:

Links Between Migrants' Host and Home Country Orientation

MGSoG Dissertation Series, nr 50 (2014)

Yulia Privalova Krieger

Reshaping the Big Agenda: Transnational Politics and Domestic Resistance

Financial crisis and social protection reform in Bosnia and Herzegovina

MGSoG Dissertation Series, nr 49 (2014)

Marieke van Houte

Moving Back or Moving Forward?

Return migration after conflict

MGSoG Dissertation Series, nr 48 (2014) 
Oxana Slobozhan

Global Governance in the Management of Natural Resources

The Case of the Extractive Industries Transparency Initiative (EITI)

MGSoG Dissertation Series, nr 47 (2014)

Luis Bernardo Mejia Guinand

The Changing Role of the Central Planning Offices in Latin America:

A Comparative Historical Analysis Perspective (1950-2013)

MGSoG Dissertation Series, nr 46 (2014)

Cheng Boon Ong

Ethnic Segregation in Housing, Schools and Neighbourhoods in the Netherlands

MGSoG Dissertation Series, nr 45 (2014)

Luciana V. Cingolani

Bureaucracies for Development: Oxymoron or Reality?

Studies on State Capacity in Challenging Governance Contexts

MGSoG Dissertation Series, nr 44 (2014)

Carlos Cadena Gaitán

Green Politics in Latin American Cities - Sustainable Transport Agendas

MGSoG Dissertation Series, nr 43 (2014)

Katie Kuschminder

Female Return Migration and Reintegration Strategies in Ethiopia

MGSoG Dissertation Series, nr 42 (2014)

Metka Hercog

Highly-Skilled Migration and New Destination Countries

MGSoG Dissertation Series, nr 41 (2014)

Margaret Agaba Rugadya

Can Remittances Influence the Tenure and Quality of Housing in Uganda?

MGSoG Dissertation Series, nr 40 (2014)

Ilire Agimi

New Governance Under Limited Statehood

The Case of Local Government Reform in Kosovo

MGSoG Dissertation Series, nr 39 (2014) 
Kristine Farla

Empirical Studies on Institutions, Policies and Economic Development

MGSoG Dissertation Series, nr 38 (2013)

Marina Petrovic

Social Assistance and Activation in the Pursuit of Happiness:

Shedding New Light on Old Policy Solutions to Social Exclusion

MGSoG Dissertation Series, nr 37 (2013)

Laura Torvinen

Assessing Governance Assessments; The Case of Mozambique

Governance Assessments in the Context of Aid Effectiveness Discourse

MGSoG Dissertation Series, nr 36 (2013)

Biniam Egu Bedasso

Institutional Change in the Long Shadow of Elites

Essays on Institutions, Human Capital and Ethnicity in Developing Countries

MGSoG Dissertation Series, nr 35 (2013)

Sepideh Yousefzadeh Faal Deghati

Childhoods Embargoed

Constructing and Reconstructing Multidimensional Child Poverty in Iran 1984-2009

MGSoG Dissertation Series, nr 34 (2013)

Robert Bauchmüller

Investing in Early Childhood Care and Education:

The Impact of Quality on Inequality

MGSoG Dissertation Series, nr 33 (2013)

Martin Rehm

Unified Yet Separated

Empirical Study on the Impact of Hierarchical Positions within Communities of Learning

MGSoG Dissertation Series, nr 32 (2013)

Dorcas Mbuvi

Utility Reforms and Performance of the Urban Water Sector in Africa

MGSoG Dissertation Series, nr 31 (2012)

Lina Salanauskaite

Distributional Impacts of Public Policies:

Essays in Ex-Ante and Ex-Post Evaluation

MGSoG Dissertation Series, nr 30 (2012) 


\section{Esther Schüring}

To Condition or not - is that the Question?

An Analysis of the Effectiveness of Ex-Ante and Ex-Post Conditionality in Social Cash

Transfer Programs

MGSoG Dissertation Series, nr 29 (2012)

Joe Abah

Strong Organisations in Weak States

Atypical Public Sector Performance in Dysfunctional Environments

MGSoG Dissertation Series, nr 28 (2012)

Zina Samih Nimeh

Social Citizenship Rights: Inequality and Exclusion

MGSoG Dissertation Series, nr 27 (2012)

Lenka Eisenhamerová

Legitimacy of 'Humanitarian Military Intervention'

MGSoG Dissertation Series, nr 26 (2011)

Sonila Tomini

Informal Payments for Health Care Services in Albania

MGSoG Dissertation Series, nr 25 (2011)

Jinjing Li

Dynamic Microsimulation in Public Policy Evaluation

MGSoG Dissertation Series, nr 24 (2011)

Aziz Atamanov

Rural Nonfarm Employment and International Migration as Alternatives to Agricultural

Employment:

The Case of Kyrgyzstan

MGSoG Dissertation Series, nr 23 (2011)

Frieda Vandeninden

Poverty Alleviation: Aid and Social Pensions

MGSoG Dissertation Series, nr 22 (2011)

Juliana Nyasha Tirivayi

The Welfare Effects of Integrating AIDS Treatment with Food Transfers:

Evidence from Zambia

MGSoG Dissertation Series, nr 21 (2011) 
Agnieska Ewa Sowa

Who's Left Behind? Social Dimensions of Health Transition and Utilization of Medical Care in Poland

MGSoG Dissertation Series, nr 20 (2011)

Emmanaouil Sfakianakis

The Role of Private Actors in the Provision of Public Goods with Applications to Infrastructure and Financial Stability

MGSoG Dissertation Series, nr 19 (2011)

\section{Siu Hing Lo}

White Collars Green Sleeves

An Interonganizational Comparison of Determinants of Energy-Related Behaviors among Office Workers

MGSoG Dissertation Series, nr 18 (2011)

Treena $\mathrm{Wu}$

Constraints to Human Capital Investment in Developing Countries:

Using the Asian Financial Crisis in Indonesia as a Natural Experiment

MGSoG Dissertation Series, nr 17 (2011)

Henry Espinoza Peña

Impact Evaluation of a Job-Training Programme for Disadvantaged Youths:

The Case of Projoven

MGSoG Dissertation Series, nr 16 (2011)

Florian Tomini

Between Family and Friends

Understanding the Interdependency of Private Transfers

MGSoG Dissertation Series, nr 15 (2010)

Michał Polalowski

The Institutional Transformation of Social Policy in East Central Europe:

Poland and Hungary in comparative and historical perspective

MGSoG Dissertation Series, nr 14 (2010)

Maha Ahmed

Defining, Measuring and Addressing Vulnerability:

The Case of Post Conflict Environments

MGSoG Dissertation Series, nr 13 (2010) 
Pascal Beckers

Local Space and Economic Success

The role of spatial segregation of migrants in the Netherlands

MGSoG Dissertation Series, nr 12 (2010)

Victor Cebotari

Conplicting Demands in Ethnically Diverse Societies

Ethnopolitical Contention and Identity Values in Europe

MGSoG Dissertation Series, nr 11 (2010)

Dennis Gyllensporre

Competing and Complementary Perspectives on the EU as a Crisis Management Actor:

An Examination of the Common Security and Defence Policy through the Lenses of Idealism and Realism

MGSoG Dissertation Series, nr 10 (2010)

Judit Vall Castello

Business Cycle and Policy Effects on Labour Market Transitions of Older and Disabled

Workers in Spain

MGSoG Dissertation Series, nr. 9 (2010)

Keetie Roelen

False Positives or Hidden Dimensions: the definition and measurement of child poverty

MGSoG Dissertation Series, nr. 8 (2010)

Denisa Maria Sologon

Earning Dynamics in Europe

MGSoG Dissertation Series, nr. 7 (2010)

Melissa Siegel

Money and Mobility: Migration and Remittances

MGSoG Dissertation Series, nr. 6 (2010)

Jessica S. Hagen-Zanker

Modest Expectations: Causes and effects of migration on migrant households in source countries

MGSoG Dissertation Series, nr. 5 (2010)

Mirtha R. Muniz Castillo

Human Development and Autonomy in Project Aid: Experiences from four

bilateral projects in Nicaragua and El Salvador

MGSoG Dissertation Series, nr. 4 (2009) 
Christiane Arndt

Governance Indicators

MGSoG Dissertation Series, nr. 3 (2009)

Britta Augsburg

Microfinance - Greater Good or Lesser Evil?

MGSoG Dissertation Series, nr. 2 (2009)

Geranda Notten

Measuring and Managing Poverty Risks

MGSoG Dissertation Series, nr. 1 (2008) 